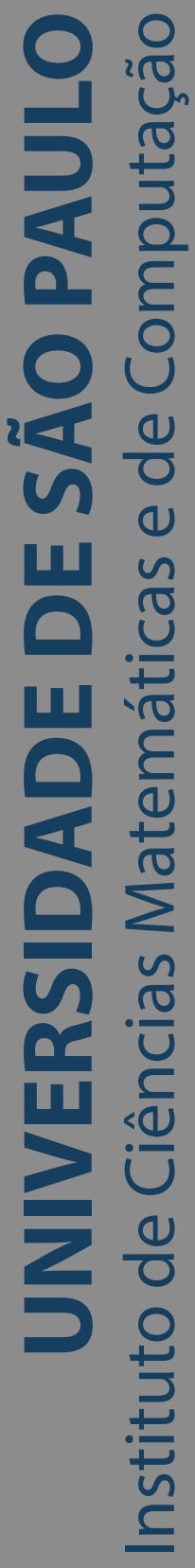

\title{
Modelo de infraestrutura para publicação de dados abertos
} governamentais conectados de qualidade

\section{Bruno Elias Penteado}

Tese de Doutorado do Programa de Pós-Graduação em Ciências de Computação e Matemática Computacional (PPG-CCMC) 

Data de Depósito:

Assinatura:

\title{
Bruno Elias Penteado
}

\section{Modelo de infraestrutura para publicação de dados abertos governamentais conectados de qualidade}

\author{
Tese apresentada ao Instituto de Ciências \\ Matemáticas e de Computação - ICMC-USP, \\ como parte dos requisitos para obtenção do título \\ de Doutor em Ciências - Ciências de Computação e \\ Matemática Computacional. VERSÃO REVISADA \\ Área de Concentração: Ciências de Computação e \\ Matemática Computacional \\ Orientador: Prof. Dr. Seiji Isotani \\ Coorientador: Prof. Dr. José Carlos Maldonado
}


Ficha catalográfica elaborada pela Biblioteca Prof. Achille Bassi e Seção Técnica de Informática, ICMC/USP, com os dados inseridos pelo(a) autor(a)

Penteado, Bruno Elias

P419m Modelo de infraestrutura para publicação de dados abertos governamentais conectados de qualidade / Bruno Elias Penteado; orientador Seiji Isotani; coorientador José Carlos Maldonado. -- São Carlos, 2020 .

$296 \mathrm{p}$.

Tese (Doutorado - Programa de Pós-Graduação em Ciências de Computação e Matemática Computacional) -Instituto de Ciências Matemáticas e de Computação, Universidade de São Paulo, 2020.

1. Dados conectados. 2. Dados abertos governamentais. 3. Web semântica. 4. Qualidade de dados. 5. Publicação de dados. I. Isotani, Seiji, orient. II. Maldonado, José Carlos, coorient. III. Título. 


\section{Bruno Elias Penteado}

\section{Infrastructure model for publishing quality open government linked data}

Doctoral dissertation submitted to the Institute of Mathematics and Computer Sciences - ICMC-USP, in partial fulfillment of the requirements for the degree of the Doctorate Program in Computer Science and Computational Mathematics. FINAL VERSION

Concentration Area: Computer Science and Computational Mathematics

Advisor: Prof. Dr. Seiji Isotani

Co-advisor: Prof. Dr. José Carlos Maldonado 

Este trabalho é dedicado a todos que deram um pouco de si para que ele fosse possível de ser realizado,

em especial aos meus pais, Waldemar e Maria, e à minha companheira de vida, Julia.

Dedico também aos que estão por vir, em especial para meu primeiro filho, Raul, que nasceu simultaneamente a esta tese. 

Minha trajetória de doutorado até aqui não foi nada linear. Depois de passados anos de minha defesa de mestrado, sentia a vontade de continuar pesquisando. Mesmo trabalhando em uma empresa privada, em Bauru, tive a curiosidade e a iniciativa de propor pequenos estudos sempre que possível (o que nem sempre era bem visto). Mas por vários motivos, não foi possível ter entrado antes. Por 3 anos fiz meu doutorado com dedicação parcial, em paralelo às minhas atividades profissionais, que sempre envolveram tecnologia e educação. Durante o primeiro ano, passava metade da semana em São Paulo, onde optei por cursar uma disciplina na Escola Politécnica da USP. Ao longo do doutorado, tive uma reviravolta no tópico a ser pesquisado, convergindo para a área de dados e Web, dois assuntos que sempre me fascinaram. Já no começo veio um prêmio de melhor artigo no SBIE 2017. Mas, durante os estudos, veio uma crise econômica que derrubou empregos, o número de bolsas e oportunidades de intercâmbio. Ainda assim, fui agraciado com a oportunidade de visitar o laboratório LIS, da Universidade AixMarseille (França), durante um ano. Foi uma experiência fantástica, onde pude mergulhar em outra cultura (ah, os pains au chocolat!), morar em uma cidade de grande história e diversidade, além de aprender outro idioma in loco, e para o qual tive de pedir uma extensão em meu prazo de doutoramento. Na reta final, já sem bolsa, voltei à minha cidade natal (Leme) onde ficamos até o momento da defesa desta tese. Agora, é trabalhar para se manter no mundo acadêmico!

Por tudo isso...

Agradeço à minha amada esposa, Julia, pelo apoio, carinho e compreensão em todos esses anos e por ter me ajudado até o último momento na entrega desta tese. Agora nosso próximo plano é preparar nosso futuro cientista!

Agradeço aos meus pais, responsáveis por me trazerem até aqui e instigarem minha curiosidade científica desde cedo, mesmo tendo poucos anos de estudo formal, e por todo o suporte e carinho fornecidos até hoje. Esse trabalho também é de vocês!

Agradeço ao prof. Seiji Isotani por ter me acolhido em seu grupo de estudo e pelos insights e dicas dadas durante o processo de doutoramento. E também aos colegas de CAEd, com quem pude contar sempre que necessário, em especial aos colegas Armando Toda e Rachel Reis, com quem compartilhei mais minhas incertezas. Agradeço também ao prof. Maldonado, pela minha aceitação no programa e pelos conselhos dados no início desta formação. Agradeço à instituição da Universidade de São Paulo, pelo fornecimento dessa grande infraestrutura disponível para empreender pesquisas de ponta, a par das melhores universidades do mundo. 
Agradeço às pessoas envolvidas em meu estágio sanduíche em Marselha, na França. Primeiramente, à profa. Patricia Jacques, pela oportunidade de ter feito parte desse projeto envolvendo pesquisadores do Brasil, França e Argentina. Em especial aos professores Magalie Ochs e Philippe Blache pela recepção e cuidados dados a nós durante a estadia na França. Do mesmo modo, agradeço à Universidade Aix-Marseille por ter me acolhido. E também aos colegas de laboratório LIS, Gael e Aref, pelos cafés e pelo esforço para arranhar algumas palavras em português.

Agradeço aos participantes do experimento pela disponibilidade e disposição de ir até o final do estudo. E também à profa. Rita Berardi (UTFPR) pela troca de ideias sobre o assunto e me auxiliar com os experimentos.

Agradeço também aos meus sogros, Lucidi e Hilda, por nos receberem de volta em sua casa depois do estágio sanduíche na França e que sempre se demonstraram solícitos e felizes com meu sucesso.

O presente trabalho foi realizado com apoio da Coordenação de Aperfeiçoamento de Pessoal de Nível Superior - Brasil (CAPES) - Código de Financiamento 001. Além disso, aos recursos financeiros em forma de bolsa durante 10 meses no Brasil e 1 ano na França. Agradeço também à empresa Mstech, de Bauru-SP, onde trabalhei por mais de 13 anos e que me incentivava a perseguir a excelência profissional.

A todos os outros que contribuíram com dicas, conselhos, discussões e devaneios e que me fizeram entender que o doutorado se trata mais do processo do que de um título. Em especial aos membros da banca, professores Ivan Rizzo Guilherme, Sean Wolfgand Matsui Siqueira e Ana Carolina Simionato Arakaki, pelas revisões e sugestões.

Sou agradecido por ter tido todos esses privilégios e de ter conseguido chegar ao final com saúde.

A todos, meu muito obrigado! 
"We're entering a new world in which data may be more important than software."

(Tim O'Reilly) 



\section{RESUMO}

PENTEADO, B. E. Modelo de infraestrutura para publicação de dados abertos governamentais conectados de qualidade. 2020. 293 p. Tese (Doutorado em Ciências - Ciências de Computação e Matemática Computacional) - Instituto de Ciências Matemáticas e de Computação, Universidade de São Paulo, São Carlos - SP, 2020.

Contexto: A produção de dados abertos governamentais (DAG) tem aumentado desde a última década, sendo considerada como um dos pilares da democracia moderna. A disponibilidade desses dados carrega promessas como: o desenvolvimento econômico, por meio de produtos e serviços baseados nesses dados; o controle social, ao transparecer para a sociedade as ações e resultados dos governos; o embasamento de políticas públicas, ao gerar indicadores de efetividade ao longo do tempo, servindo para pesquisas ou acompanhamentos do próprio governo; o combate à corrupção, por meio da prestação de contas na execução orçamentária de políticas públicas. Diferentes órgãos governamentais divulgam informações dentro de seu escopo, tornando possível que consumidores de dados combinem diferentes fontes para responder questões que antes não eram possíveis. Problema: Embora tenha havido progressos variados em torno desses eixos, vários fatores impedem que esses benefícios sejam realizados em maior escala. Da perspectiva tecnológica, a disponibilização dos dados para que possam ser combinados, a formatação padronizada e sua interoperabilidade são talvez os fatores que mais impactam sobre sua produção. As tecnologias semânticas têm sido desenvolvidas para tratar este problema de interoperabilidade ao representar informações de modo que possam ser interpretadas inequivocamente por humanos e máquinas, por meio dos chamados dados conectados. O encontro dessas áreas traz a possibilidade de fazer com que as informações governamentais sejam mais facilmente processadas, inclusive sendo inferidas informações implícitas. As metodologias existentes apresentam limitações como a percepção de serem muito genéricas e de não tratarem corretamente questões de qualidade dos dados, fazendo com que publicadores adotem métodos ad-hoc de publicação. Objetivo: Assim, o objetivo desta tese é desenvolver uma infraestrutura de publicação de dados abertos governamentais conectados (DAGC) de qualidade para o ecossistema de dados da Web, que utilize os padrões da Web para garantir a interoperabilidade em diferentes aspectos. Métodos: Foi conduzido um mapeamento sistemático para identificar as metodologias existentes, o que trazem de comum e quais suas limitações em torno dos problemas encontrados em sua prática. A partir desses pontos, foi adotada a metodologia Design Science Research Methodology (DSR-M), sob a epistemologia da Design Science, de caráter pragmático, que objetiva o desenvolvimento de artefatos para resolver problemas. Ela guiou a seleção de teorias kernel para atender aos requisitos levantados e descreve a busca de uma solução viável de design para os artefatos da infraestrutura. Foram conduzidos estudos empíricos (cenário ilustrativo e quasi-experimento), utilizando fontes de dados reais, para avaliar a eficácia e a facilidade de uso destes artefatos, por meio do atendimento 
aos requisitos e mediante um arcabouço de qualidade de dados conectados. Resultados: A infraestrutura proposta é composta por três artefatos: i) um modelo de ciclo de vida de publicação de DAGC, descrevendo quais são as atividades, papéis, ferramentas, verificações e saídas de cada fase de produção; ii) uma arquitetura conceitual, que atende às práticas de compartilhamento de dados, possibilita o acesso aos dados por parte de humanos e máquinas, e considera pontos de controle de verificação dos dados sendo gerados ao longo do processo; iii) modelo de metadados que compila práticas para descrever dados e metadados conectados, objetivando facilitar sua descoberta e processamento. O produto resultante, gerado pelos participantes do estudo empírico, demonstrou nível de qualidade semelhante ou superior aos datasets estado da arte - dentro das métricas de qualidade de dados conectados selecionadas para a avaliação. Conclusão: Esta tese trouxe importantes contribuições teóricas e práticas para a área de publicação de dados abertos governamentais conectados. Ela demonstra como concretizar o atendimento aos requisitos de governo e de abertura de dados por meio de uma infraestrutura com diferentes componentes que permitem que humanos e máquinas possam buscar, acessar e processar dados de qualidade, detalhando diferentes possibilidades de instanciar a infraestrutura.

Palavras-chave: Dados conectados, Dados abertos governamentais, Web semântica, Qualidade de dados, Publicação de dados. 


\section{ABSTRACT}

PENTEADO, B. E. Infrastructure model for publishing quality open government linked data. 2020. 293 p. Tese (Doutorado em Ciências - Ciências de Computação e Matemática Computacional) - Instituto de Ciências Matemáticas e de Computação, Universidade de São Paulo, São Carlos - SP, 2020.

Context: The production os open government data (OGD) has increased since the last decade, being considered as one of the fundamental pillars of modern democracy. The availability of these data carries the promises of economic development, through products and services based on these data; social control, by making it transparent to the society the actions and outcomes from the government; the basis for public policies, by generating indicators of effectiveness throughout time, serving for researches or as a follow-up for the government itself; corruption deterrence, by the accountability of budget execution of public policies. Different public bodies release information of their own scope, making it possible that data consumers combine different data sources to answer questions that were not previously possible. Problem: Although there was some progress in different levels around these axes, multiple factors hamper these benefits from being realized on a larger scale. From the technological perspective, the availability of data for combination, the standardized preparation, and their interoperability are arguably the most impacting factors for their production. Semantic technologies have been developed to address this problem of interoperability by representing information so that they can be interpreted unequivocally by humans and machines alike, the so-called linked data. The overlap of these areas carries the possibility of making government information easier to process, including inferring implicit information. Current methodologies present limitations such as their perception of being too generic and not addressing quality systematically, making data publishers prefer to adopt ad-hoc publication practices. Objective: Thus, this thesis aims to develop a high quality linked open government data (LOGD) publication infrastructure for the Web ecosystem, that uses Web standards to ensure interoperability in many aspects. Methods: A systematic mapping was carried out to identify existing methodologies, their commonalities and their limitations regarding the problems found in their practice. With this knowledge, the Design Science Research Methodology (DSR-M) was adopted, under the design science epistemiology, having a pragmatic character and which aims the development of artifacts to solve practical problems. It guided the selection of kernel theories to meet the requirements and to describe the search for a feasible design solution for the infrastructure artifacts. Empirical studies were carried out (both illustrative scenario and quasi-experiment) using real data sources, to evaluate the efficacy and ease of use of these artifacts, by meeting elicited requirements and by assessing through a quality assessment framework. Results: The proposed infrastructure is made by three artifacts: i) a publishing lifecycle model for LOGD, describing the activities, roles, tools verifications and outputs to each of the production phases; ii) a conceptual architecture, meeting 
data sharing practices and enabling data access for both humans and machines, considering verification checkpoints along the process; iii) a metadata model, compiling practices to describe linked open government data, aiming to make discovery and processing easier. The resulting product, created by the participants in the empirical study, showed a similar or superior level of quality to state-of-the-art datasets - concerning the linked data quality metrics selected for the evaluation.

Conclusion: This thesis has made both theoretical and practical contributions to the field of linked open government data. In short, it materializes meeting the requirements of open government and data employing an infrastructure with multiple components that enables both humans and machines to search, access and process quality data, detailing different alternatives to instantiate the infrastructure.

Keywords: Linked data, Open government data, Semantic Web, Data quality, Data publishing. 


\section{LISTA DE ILUSTRAÇÕES}

Figura 1 - Procedimentos metodológicos da DSR Methodology. . . . . . . . . . . . 35

Figura 2 - Arquitetura básica da Web de documentos. . . . . . . . . . . . . . 40

Figura 3 - Arcabouço de conceitos relacionados ao governo aberto. . . . . . . . . . . . 44

Figura 4 - Relacionamentos entre os conceitos básicos de dados abertos governamentais conectados. . . . . . . . . . . . . . . . . . 47

Figura 5 - Procedimento para selecionar os trabalhos primários de produção de DAGC. 57

Figura 6 - Linha do tempo de eventos relevantes que influenciaram a iniciativa de DAG no Brasil. . . . . . . . . . . . . . . . . . . . . . . 67

Figura 7 - Modelo de governança para o planejamento, execução e monitoramento dos

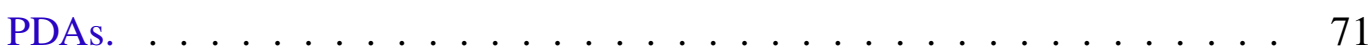

Figura 8 - Grau de atendimento das práticas da DWBP, agrupado por dimensão. . . . . 75

Figura 9 - Esquema que ilustra o grau crescente de abertura do formato dos dados, desde os mais fechados (à esquerda) ao mais aberto (direita, ao alto). . . . . . . . 90

Figura 10 - Modelo dos principais conceitos e seus relacionamentos dentro da DWBP. . 92

Figura 11 - Implementação dos requisitos derivados da conjuntura teórica. . . . . . . . 102

Figura 12 - Componentes do modelo de ciclo de vida proposto. . . . . . . . . . . . . . 103

Figura 13 - Visão geral do modelo de ciclo de vida proposto nesta tese. . . . . . . . . . 105

Figura 14 - Matriz de responsabilidades atribuídas às atividades do processo. . . . . . . 108

Figura 15 - Atividades da fase de Especificação. . . . . . . . . . . . . . . . . 110

Figura 16 - Atividades da fase de Modelagem. . . . . . . . . . . . . . . . . 115

Figura 17 - Atividades da fase de Conversão. . . . . . . . . . . . . . . . . . . . . . . . 119

Figura 18 - Atividades da fase de Publicação . . . . . . . . . . . . . . . . . . . . 123

Figura 19 - Atividades da fase de Exploração. . . . . . . . . . . . . . . . . . . . 126

Figura 20 - Atividades da fase de Manutenção. . . . . . . . . . . . . . . . . . . . 128

Figura 21 - Arquitetura geral dos componentes propostos. . . . . . . . . . . . . 133

Figura 22 - Diagrama de sequência das ações do publicador de dados no ciclo de vida. . 134

Figura 23 - Diagrama de sequência de possíveis ações do consumidor dos dados. . . . . 135

Figura 24 - Pontos de controle de qualidade da infraestrutura proposta. . . . . . . . . 136

Figura 25 - Estruturação dos níveis dos metadados. . . . . . . . . . . . . . . . . 138

Figura 26 - Instanciação da arquitetura de suporte proposta. . . . . . . . . . . . . . . 144

Figura 27 - Grafo da movimentação de docentes nas escolas municipais de São Paulo, no período 2016-2017. . . . . . . . . . . . . . . . . . 153

Figura 28 - Aproximação da visualização do grafo, dando destaque às escolas. . . . . . 154 
Figura 29 - Mapeamento de grandes movimentações entre pares de escolas. . . . . . . . 155

Figura 30 - Experiência dos participantes com DAG e DAC . . . . . . . . . . . . . . 159

Figura 31 - Ilustração do cenário proposto no roteiro do estudo de caso. . . . . . . . . . 160

Figura 32 - Trecho do arquivo de modelo de metadados, contendo os marcadores a serem substituídos ao longo do roteiro. . . . . . . . . . . . . . 162

Figura 33 - Distribuição relativa média de tempo entre as fases. . . . . . . . . . . . 168

Figura 34 - Percepção da facilidade de uso dos artefatos propostos. . . . . . . . . . . 169

Figura 35 - Fluxo linear sugerido e o fluxo iterativo ocorrido. . . . . . . . . . . . 170

Figura 36 - Comparação das métricas de qualidade dos dados conectados gerados pelos participantes. . . . . . . . . . . . . . . 173

Figura 37 - Comparação das métricas de qualidade dos dados conectados gerados pelos participantes. . . . . . . . . . . . . . . . 175

Figura 38 - Relacionamento dos conceitos trabalhados nesta tese. . . . . . . . . . . . 184 
Quadro 1 - Questões de pesquisa desta tese. . . . . . . . . . . . . . . . 31

Quadro 2 - Fases de pesquisa desta tese . . . . . . . . . . . . . 37

Quadro 3 - Lista de requisitos levantados e compilados da literatura de DAGC. . . . . 48

Quadro 4 - Lista de requisitos para um processo de publicação de DAGC. . . . . . . . 49

Quadro 5 - Requisitos mínimos para um processo de publicação de DAGC. . . . . . 52

Quadro 6 - Termos usados para a busca. . . . . . . . . . . . . 55

Quadro 7 - Conjunto final de trabalhos primários extraídos do mapeamento da literatura. 58

Quadro 8 - Mapeamento dos passos e estudos das metodologias selecionadas. . . . . 59

Quadro 9 - Métodos de avaliação aplicados nos estudos selecionados. . . . . . . . . 61

Quadro 10 - Ferramentas usadas ou sugeridas nos estudos primários. . . . . . . . . . 63

Quadro 11 - Papéis e composição para governança de dados abertos no Brasil. . . . . . 72

Quadro 12 - Conjuntos de dados selecionadoas para a análise. . . . . . . . . . 73

Quadro 13 - Mapeamento dos requisitos dos construtos de DAGC aos elementos estruturantes selecionados. . . . . . . . . . . . . . . . 80

Quadro 14 - Práticas do arcabouço DWBP sobre as dimensões selecionados. . . . . . . 93

Quadro 15 - Atividades da fase de Especificação. . . . . . . . . . . . . . . . . . 111

Quadro 16 - Atividades da fase de Modelagem. . . . . . . . . . . . . . . . 116

Quadro 17 - Atividades da fase de Conversão. . . . . . . . . . . . . . . . . . . 120

Quadro 18 - Atividades da fase de Publicação. . . . . . . . . . . . . . . . . . . 124

Quadro 19 - Atividades da fase de Exploração. . . . . . . . . . . . . . . . . . 127

Quadro 20 - Atividades da fase de Manutenção. . . . . . . . . . . . . . . . . . . 129

Quadro 21 - Critérios para a definição de ferramentas a serem usadas durante o ciclo de vida proposto. . . . . . . . . . . . . . . . 130

Quadro 22 - Atendimento dos requisitos em função do conjunto de artefatos propostos. . 139

Quadro 23 - Implementação das melhores práticas da DWBP no arquitetura do cenário. 147

Quadro 24 - Implementação dos mecanismos de controle de qualidade ao longo do processo. . . . . . . . . . . . . . . . . . 152

Quadro 25 - Questões avaliadas no estudo empírico. . . . . . . . . . . . . . 157

Quadro 26 - Instrumentos de coleta dos dados. . . . . . . . . . . . . . . 163

Quadro 27 - Arcabouço de métricas aplicadas (DEBATTISTA; LANGE; AUER, 2018). 164

Quadro 28 - Atendimento aos requisitos da DWBP pelos participantes. . . . . . . . 171 

Tabela 1 - Erros e metadados faltantes no template dos participantes. . . . . . . . . 171

Tabela 2 - Tabela detalhada dos valores aferidos das métricas contínuas de qualidade. . 174

Tabela 3 - Tabela detalhada dos valores aferidos das métricas discretas de qualidade. . 175

Tabela 4 - Comparação das métricas de qualidade dos dados conectados gerados pelos participantes com iniciativas oficiais. . . . . . . . . . . . . 176 



\section{LISTA DE ABREVIATURAS E SIGLAS}

API Application Programming Interface

BP Best practice

CGU Comitê Gestor da União

CIGA Comitê Interministerial de Governo Aberto

CKAN Comprehensive Knowledge Archive Network

CSV Comma-Separated Values

D2RQ Data To Resource Query

DAC Dados Abertos Conectados

DAG Dados Abertos Governamentais

DAGC Dados Abertos Governamentais Conectados

DOI Digital Object Identifier

DSR Design Science Research

DWBP Data on the Web Best Practices

e-PING Padrões de Interoperabilidade de Governo Eletrônico

e-VoG Vocabulários e Ontologias do Governo Eletrônico

FOAF Friend Of A Friend

GA Governo Aberto

HTML Hypertext Markup Language

HTTP Hypertext Transfer Protocol

IDEB Índice de Desenvolvimento da Educação Básica

INDA Infraestrutura Nacional de Dados Abertos

INEP Instituto Nacional de Estudos e Pesquisas Educacionais Anísio Teixeira

IRI Internationalized Resource Identifier

ISO International Organization for Standardization

JSON-LD JavaScript Object Notation - Linked Data

LOD Linked Open Data

LOV Linked Open Vocabularies

N3 N-Triples

OGP Open Government Partnership

OWL Web Ontology Language

PDA Planos de Dados Abertos 


$\begin{array}{ll}\text { PDF } & \text { Portable Document Format } \\ \text { PURL } & \text { Permanent URL } \\ \text { RACI } & \text { Responsible-Accountable-Consulted-Informed } \\ \text { RDF } & \text { Resource Description Framework } \\ \text { RDFS } & \text { RDF Schema } \\ \text { SHACL } & \text { Shapes Constraint Language } \\ \text { SKOS } & \text { Simple Knowledge Organization System } \\ \text { SPARQL } & \text { SPARQL Protocol and RDF Query Language } \\ \text { URI } & \text { Uniform Resource Identifier } \\ \text { URL } & \text { Uniforme Resource Locator } \\ \text { V\&V } & \text { Verificação e validação } \\ \text { W3C } & \text { World Wide Web Consortium } \\ \text { XML } & \text { eXtensible Markup Language }\end{array}$


INTRODUÇÃO . . . . . . . . . . . . . . . . . 27

1.1 Contexto, motivação e desafios . . . . . . . . . . . 27

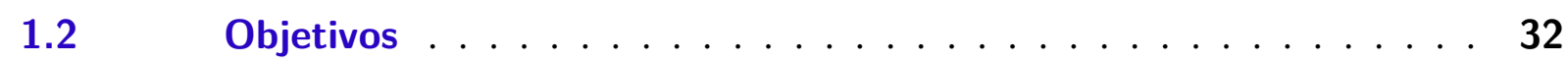

$1.3 \quad$ Metodologia da pesquisa . . . . . . . . . . . 32

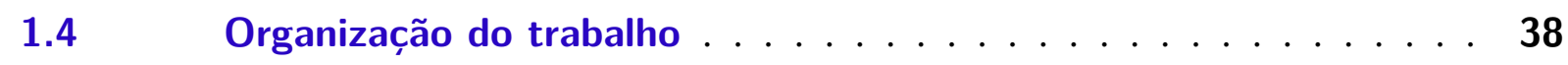

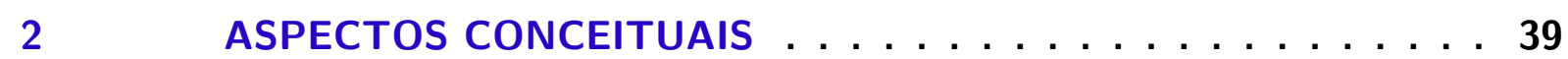

$2.1 \quad$ A Web e suas tecnologias . . . . . . . . . . . . . 39

2.2 Web Semântica e os dados conectados . . . . . . . . . . . . 40

2.3 Dados: abertos, governamentais e conectados . . . . . . . . . . 43

2.3.1 Definição de requisitos dos dados . . . . . . . . . . . . . . . . 47

2.3.2 Definição de requisitos do processo . . . . . . . . . . . . . 49

3 ESTAdO DA ARTE E DA PRÁTICA . . . . . . . . . . . . . 53

3.1 Mapeamento sistemático de metodologias de produção de DAGC . 54

3.1.1 Objetivos e questões de pesquisa . . . . . . . . . . . . . . 54

3.1.2 Bases de dados e estratégias de busca . . . . . . . . . . . . . 55

3.1.3 Seleção dos estudos . . . . . . . . . . . . . . . . 56

3.1.4 Análise dos dados e resultados . . . . . . . . . . . . . . 57

3.1.5 Sumário dos resultados . . . . . . . . . . . . . . . 65

3.2 Dados abertos no governo federal brasileiro . . . . . . . . . 66

3.2.1 Linha do tempo dos dados abertos no Brasil . . . . . . . . . . . 66

3.2.2 Stakeholders-chave .................. 71

$3.3 \quad$ Adoção de boas práticas de ecossistema de dados . . . . . . . . 73

3.4 Dados abertos governamentais conectados no Brasil . . . . . . . . 76

$3.5 \quad$ Considerações finais . . . . . . . . . . . . . . 76

4 PROJETO DA INFRAESTRUTURA . . . . . . . . . 79

$4.1 \quad$ Projeto do artefato . . . . . . . . . . . 79

$4.2 \quad$ Ecossistema de dados . . . . . . . . . . . . 82

4.3 Qualidade de dados conectados . . . . . . . . . . . . 84

$4.4 \quad$ Metadados . . . . . . . . . . . . . . . 88

$4.5 \quad$ Modelo de dados 5 estrelas $\ldots \ldots \ldots \ldots$

$4.6 \quad$ Implementação dos requisitos . . . . . . . . . . . . 91 
4.6.1 Compartilhamento de dados na Web . . . . . . . . . . . . . 91

4.6.2 Garantia e controle da qualidade . . . . . . . . . . . . . . . 95

4.6.3 Metadados para dados conectados . . . . . . . . . . . . . 97

$4.7 \quad$ Considerações finais . . . . . . . . . . . . . . . . . 98

5 INFRAESTRUTURA PARA DADOS ABERTOS GOVERNAMEN-

TAIS CONECTADOS . . . . . . . . . . . . . . . 101

$5.1 \quad$ Visão geral . . . . . . . . . . . . . . . 102

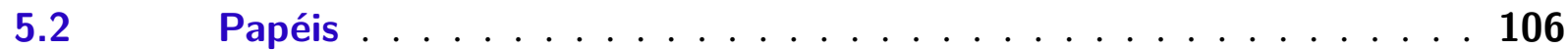

$5.3 \quad$ Processo $\ldots \ldots \ldots \ldots \ldots \ldots$

5.3.1 Especificação - planejar para a publicação . . . . . . . . . . . 109

5.3.2 Modelagem - como representar os dados semanticamente . . . . . . 115

5.3.3 Conversão - transformar e conectar . . . . . . . . . . . . . . . 119

5.3.4 Publicação - expor e divulgar os dados . . . . . . . . . . . . . . . . 122

5.3.5 Exploração - o que é possível de se fazer com os dados? . . . . . . 126

5.3.6 Manutenção - como mantê-los por décadas sem causar problemas no consumo? . . . . . . . . . . . . . . . . . . . . . . . . . . . 128

$5.4 \quad$ Ferramentas de suporte . . . . . . . . . . . . . 130

$5.5 \quad$ Arquitetura da infraestrutura .................. 132

$5.6 \quad$ Metadados . . . . . . . . . . . . . . . . . 137

$5.7 \quad$ Considerações finais . . . . . . . . . . . . . . . . . 139

6 AVALIAÇÃO . . . . . . . . . . . . . . 141

$6.1 \quad$ Análise da arquitetura .................... 141

$6.1 .1 \quad$ Cenário ............................ 142

6.1.2 Instanciação da arquitetura . . . . . . . . . . . . . . . . 143

6.1.3 Resultados . . . . . . . . . . . . . . . 147

6.1 .4 Desafios e lições aprendidas . . . . . . . . . . . . . . . 154

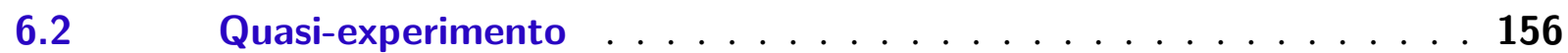

6.2.1 Questões de pesquisa . . . . . . . . . . . . . . . . 156

6.2.2 Estratégia de pesquisa . . . . . . . . . . . . . . 157

6.2.3 Participantes . . . . . . . . . . . . . . . 158

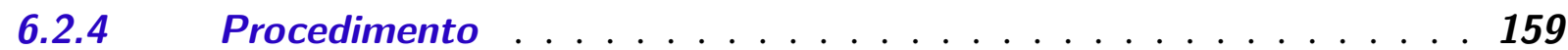

6.2.5 Coleta dos dados . . . . . . . . . . . . . . . . . . . 162

6.2.6 Análise dos dados . . . . . . . . . . . . . . . 163

6.2.7 Resultados . . . . . . . . . . . . . . . 168

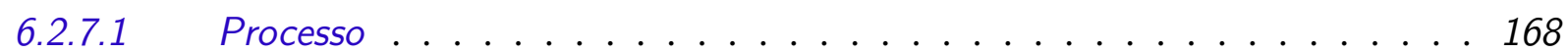

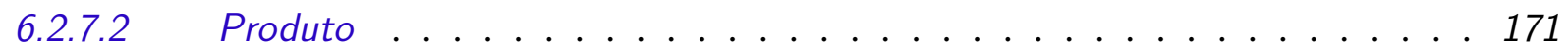

$6.2 .8 \quad$ Limitações . . . . . . . . . . . . . . . . . . 177

6.3 Considerações finais . . . . . . . . . . . . 178 
CONSIDERAÇÕES FINAIS . . . . . . . . . . . . . . 179

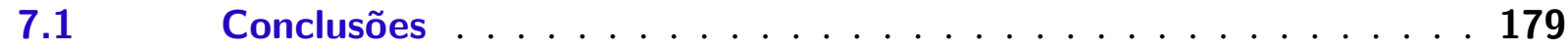

7.2 Contribuições desta pesquisa $\ldots \ldots \ldots \ldots 18 \ldots \ldots$

7.2.1 Objetivos específicos . . . . . . . . . . . . . . . 183

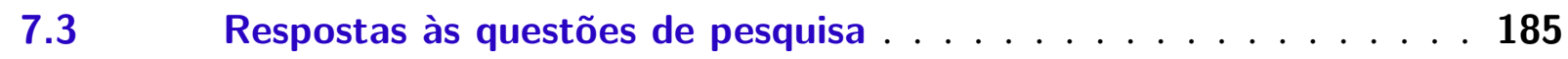

7.4 Desafios na área de publicação de DAGC . . . . . . . . . . . 187

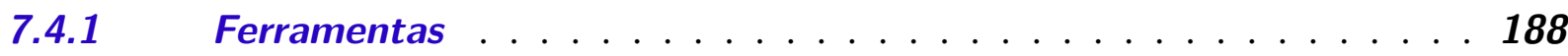

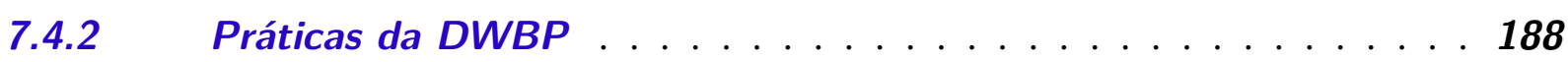

7.4.3 Dados conectados no governo . . . . . . . . . . . . 189

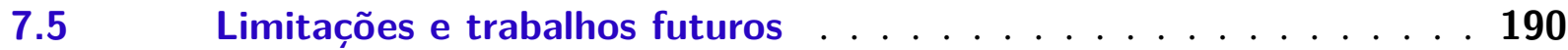

7.6 Principais publicações e trabalhos correlatos . . . . . . . . 192

7.6.1 Periódicos . . . . . . . . . . . . . . . . . . . . . . 192

7.6.2 Conferências . . . . . . . . . . . . . . . . . . 193

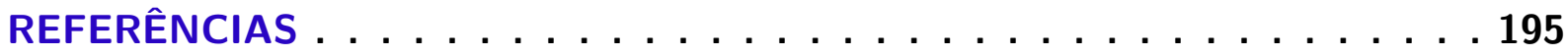

APÊNDICE A DETALHAMENTO DO PROCESSO . . . . . 213

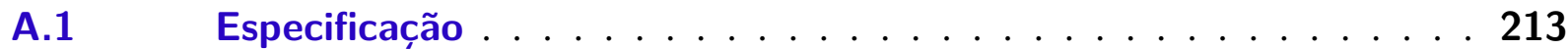

A.1.1 Identificar necessidades de dados . . . . . . . . . . . . . . . . . . 213

A.1.2 Selecionar/identificar dados a serem abertos . . . . . . . . . . 214

A.1.3 Especificar conexões externas entre fontes de dados . . . . . . . . 215

A.1.4 Especificar diretrizes . . . . . . . . . . . . . . 216

A.1.5 Especificar metadados . . . . . . . . . . . . . . . 216

A.1.6 Especificar, aplicar e validar licenças . . . . . . . . . . . . 217

A.1.7 Projetar padrão de URIs . . . . . . . . . . . . . . 218

A.1.8 Criar e manter portal de dados (conectados) . . . . . . . . . . 219

A.2 Modelagem . . . . . . . . . . . . . . . . . . 220

A.2.1 Pré-processar dados . . . . . . . . . . . . . . . . . . . 220

A.2.2 Normalizar dados . . . . . . . . . . . . . . . . . . 221

A.2.3 Criar dados . . . . . . . . . . . . . . . . . . . 222

A.2.4 Pesquisar e reutilizar vocabulários . . . . . . . . . . . . . 222

A.2.5 Criar vocabulários . . . . . . . . . . . . . . . . . . 223

A.2.6 Mapear semanticamente os dados . . . . . . . . . . . . . . 224

A.2.7 Anotar metadados dos datasets . . . . . . . . . . . . . . 225

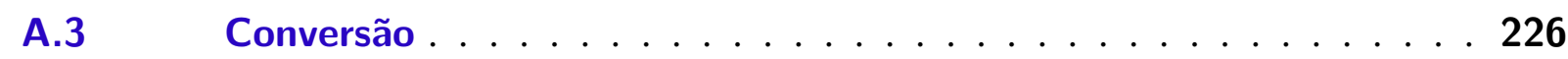

A.3.1 Conectar dados a outras fontes . . . . . . . . . . . . . . . . 226

A.3.2 Enriquecer a base de dados original . . . . . . . . . . . . 227

A.3.3 Transformar dados e metadados para RDF . . . . . . . . . 228

A.3.4 Verificar e limpar RDF . . . . . . . . . . . . . . 229 


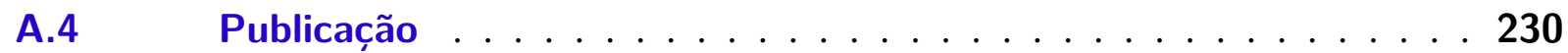

A.4.1 Versionar dados . . . . . . . . . . . . . . . . 230

A.4.2 Publicar dados e metadados no portal . . . . . . . . . . . . 231

A.4.3 Divulgar os dados publicados . . . . . . . . . . . . . 232

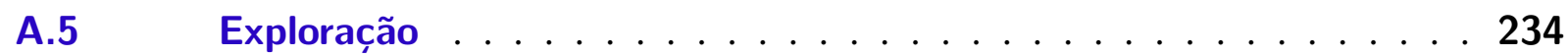

A.5.1 Implantar interface de dados conectados . . . . . . . . . . . . 234

A.5.2 Construir exemplos de uso sobre os dados . . . . . . . . . . 235

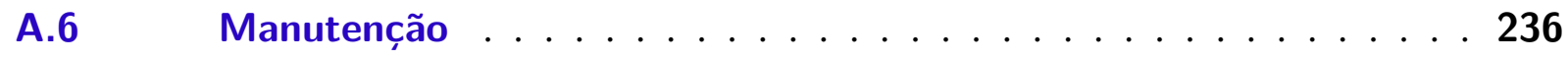

A.6.1 Definir e implementar requisitos não funcionais . . . . . . . . . 236

A.6.2 Definir e implementar tarefas de preservação dos dados . . . . . . 237

A.6.3 Engajar com a comunidade de dados . . . . . . . . . . . 238

APÊNDICE B MODELO DE METADADOS . . . . . . 241

APÊNDICE C TERMO DE CONSENTIMENTO . . . . . . 253

C.1 Termo de consentimento livre e esclarecido . . . . . . . . 253

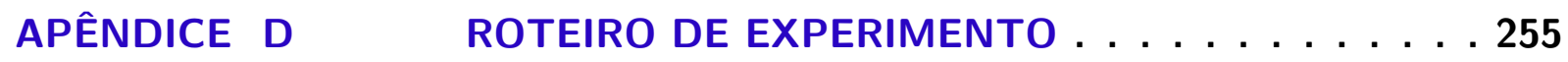

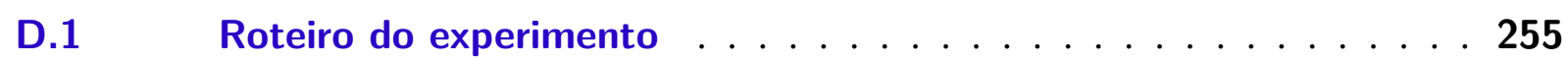

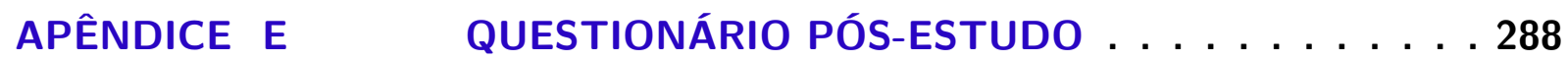

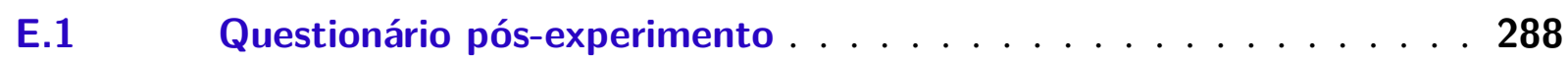




\section{1}

INTRODUÇÃO

\subsection{Contexto, motivação e desafios}

A abertura de Dados Abertos Governamentais (DAG) tem recebido grande atenção da comunidade acadêmica, de órgãos públicos e de empresas em todo o mundo, em particular na última década, como um mecanismo para prover mais transparência e prestação de contas aos cidadãos, por meio do acesso gratuito e livre a informações governamentais. A transparência e o acesso à informação são considerados pilares fundamentais em muitas frentes nas instituições públicas. A participação democrática, a confiança no governo, a dissuasão da corrupção e a tomada de decisão são exemplos de situações baseadas em dados, na acurácia das informações e no fornecimento de informações básicas para diferentes agentes de informação (ISOTANI; BITTENCOURT, 2015; CUILLIER; PIOTROWSKI, 2009; FLORINI, 2007).

Entidades públicas são os maiores criadores e coletores de dados em diferentes domínios, tais como educação, saúde, justiça e meteorologia, dentre outros (JANSSEN, 2011). Supostamente, o acesso aberto a dados financiados pela sociedade pode impulsionar um maior retorno sobre o investimento público, permitindo a geração de riqueza e insights por meio da análise desses dados e a comercialização de seus produtos e serviços, ao mesmo tempo que fornecem subsídios aos criadores de políticas públicas para apoiar o tratamento de problemas complexos (KROTOSKI, 2011; ARZBERGER et al., 2004). Os dados abertos, disponíveis livremente, compartilhados on-line e sem cobranças reduzem drasticamente o tempo e os recursos financeiros necessários para examinar as ações do governo e responsabilizá-lo por essas ações (YU; ROBINSON, 2012). Além disso, os dados abertos governamentais permitem a geração de novos conjuntos de dados, novas informações e conhecimentos quando dados de várias fontes são combinados (UHLIR; SCHRÖDER, 2007).

Um número crescente de iniciativas de dados governamentais abertos tem sido implementado em todo o mundo, com um número também crescente de governos nacionais publicando 
dados em catálogos de dados (OGP, 2019b). Além disso, cidadãos, pesquisadores, empreendedores e profissionais de comunicação estão usando dados governamentais na maioria dos países, mesmo naqueles que não possuem iniciativas oficiais de seus governos para dados completamente abertos (WWWF, 2019, p. 7). Conforme os dados abertos têm crescido em escopo e em popularidade, diferentes esforços têm sido feitos para avaliar diferentes aspectos, desde legislações, licenças de uso até padrões tecnológicos. No entanto, o mais recente relatório Open Barometer de 2017 da World Wide Web Foundation (WWWF, 2019), que analisou 1725 conjuntos de dados de 115 países em 15 diferentes setores:

- Somente 7\% dos conjuntos de dados publicados podem ser considerados como completamente abertos, somente metade deles são legíveis por máquinas e somente um em cada quatro apresentam uma licença de uso aberta;

- Dados governamentais são geralmente incompletos, desatualizados, de baixa qualidade e fragmentados, como consequência de abordagens informais da gestão de dados. Procedimentos, prazos e responsabilidades não são frequentemente claros o suficiente, tornando a gestão dos dados abertos e sua publicação ineficientes e propensa a erros;

- Dados são difíceis de se reutilizar pois não existem metadados ou guias de uso disponíveis - menos de um terço dos conjuntos de dados publicados apresentam algum tipo básico de metadados ou documentação;

- Muitos governos tratam a publicação de dados abertos como atividades paralelas, sem garantir recursos necessários para sua devida execução.

Assim, do ponto de vista do estado da prática, governos de todo o mundo têm descumprido seus compromissos de abertura de dados - mesmo em países mais ricos, que dispõem de mais recursos para desenvolverem dados abertos governamentais de maior qualidade.

Embora a publicação de dados tenha evoluído, ainda ocorre o problema dos silos informacionais - quando um sistema de dados é incompatível ou não integrado a outros sistemas de dados relacionados logicamente, o que dificulta o cruzamento e o reaproveitamento de informações. Uma forma de tratar este problema seria conectar essas diferentes fontes de dados por meio de padrões de comunicação comuns (como o formato dos dados, a representação das informações contidas e os significados compartilhados), resultando nos chamados dados conectados.

Ao considerarmos Dados Abertos Governamentais Conectados (DAGC), o cenário é ainda mais desafiador. Poucos países publicaram dados neste formato e o fizeram em pequena quantidade. No trabalho de Matheus, Ribeiro e Vaz (2015) investigou-se dados abertos em nível municipal, estadual e federal e não foram encontrados arquivos com dados abertos conectados, sendo apenas um com dados em formato de arquivo RDF . Uma situação similar foi encontrada em outros países como Colômbia (ROJAS; BERMÚDEZ; LOVELLE, 2014), Itália (BOSELLI et al., 2014) e Grécia (ALEXOPOULOS; SPILIOTOPOULOU; CHARALABIDIS, 2013) com, 
respectivamente, $5 \%, 5 \%$ e $2 \%$ de seus conjuntos de dados sendo conectados ou, ao menos, em formato RDF. Nos EUA, em uma busca pelo portal data.gov, encontramos, no início de 2020, por volta de $2,5 \%$ de conjuntos de dados em formato RDF, não explicitando quantos desses em formato conectado. Este fato pode ser devido ao fato que iniciativas governamentais são avaliadas de acordo com o grau de cumprimento às leis e não em relação ao grau de utilidade da informação fornecida (ATTARD et al., 2015).

Na literatura científica, algumas metodologias para publicação de dados abertos governamentais conectados foram propostas, mas os adotantes afirmam que elas são muito genéricas para seus propósitos, com poucos estudos detalhando o processo como um todo, sem diretrizes para ferramentas de software, modelos de documentos, técnicas ou outros artefatos que possam ajudá-los na adoção desta tecnologia (LAESSIG; JACOB; ABOUZAHR, 2019; JOVANOVIK; TRAJANOV, 2017; BOSELLI et al., 2014; SANTOS, 2014). Como consequência, muitos produtores não possuem conhecimento suficiente dessas recomendações e propõem métodos ad-hoc para produzir dados abertos conectados (SANTOS et al., 2018), geralmente baseados somente nos princípios básicos dos dados conectados (BERNERS-LEE, 2006). Embora esses princípios estabeleçam critérios mínimos para dados conectados, não contemplam muitos aspectos úteis para sua reutilização, como definição de metadados e aferição da qualidade, dentre outros. Varytimou, Loutas e Peristeras (2015) indicam, baseados em interações com praticantes, que a literatura de publicação de DAGC lida com conjuntos de dados menos complexos e não operacionais e necessitam de um ponto de vista de engenharia, com a identificação de desafios práticos, considerando as limitações organizacionais. Boselli et al. (2014) também discorrem sobre problemas similares, como a qualidade de ligação com conjuntos de dados externos, a falta de ontologias específicas de domínio e seus alinhamentos (quando existem) e o conhecimento em consultas SPARQL ao consumir dados conectados.

Kucera et al. (2015) e Janssen, Charalabidis e Zuiderwijk (2012) compilam os principais impedimentos e barreiras para a publicação de DAG, em termos sociais, econômicos, organizacionais, legais e tecnológicos. Em relação aos impedimentos e barreiras tecnológicos, escopo desta pesquisa, são destacados: diferenças de esquema de dados entre diferentes versões de um mesmo conjunto de dados, registro de usuários para acessar os dados, disponibilização de dados não-primários, qualidade dos dados disponibilizados, dificuldade em encontrar os dados, falta de metadados explicativos e estruturais dos dados, sistemas legados e falta de ferramental adequado para a publicação.

Além disso, diversos problemas têm sido reportados em relação à qualidade dos dados publicados na Web. Behkamal et al. (2014) argumentam que o uso bem-sucedido de dados abertos depende fortemente de sua qualidade. A qualidade dos dados desempenha papel importante no uso de portais governamentais (DETLOR et al., 2013) e um certo nível de qualidade de dados é essencial para o uso dos dados abertos governamentais (O'HARA, 2012). Para conseguir avaliar a qualidade dos conjuntos de dados em geral, os usuários precisam de informações sobre a 
natureza dos dados (DAWES, 2010).

Como exemplos de problemas de qualidade em dados conectados, Hogan, Hitzler e Janowicz (2016) identificaram 3 problemas recorrentes ao mapear artigos sobre dados abertos conectados (DAC) no periódico de artigos científicos Semantic Web Journal, um dos principais veículos de divulgação da área: a inexistência de ligações externas válidas nos conjuntos de dados publicados, problemas de qualidade com os datasets (nomeação de entidades, desreferenciamento de URIs, hospedagem de servidor SPARQL, etc.) e o impacto dos conjunto de DAC (muito restritos, pequenos ou de baixa qualidade), além de não ficarem disponíveis na Web por muito tempo. Zaveri et al. (2013) levantaram 7 dimensões de erros comuns encontrados na DBpedia, em nível de triplas (acurácia, objetos incorretos, problemas com tipos de dados, relacionamentos implícitos entre atributos, relevância, consistência representacional e interligação), indicando sua dificuldade de detecção e correção. Kontokostas et al. (2014) coletaram, de diversas fontes, as causas de erros mais comuns, em termos sintáticos e semânticos, e criaram um biblioteca de 17 tipos de padrões de erros mais comuns e que podem ser testados sobre uma base de conhecimento.

Outros trabalhos recentes também têm explorado o tópico de qualidade em DAC. Tais estudos trazem avaliações e problemas de qualidade em torno de conjuntos de dados de diferentes domínios, não necessariamente governamentais, talvez pela falta de dados suficientes e benchmarks disponíveis para aferições. Mas pode-se ter uma estimativa de qualidade similar aos apresentados nos artigos mencionados. Diversos estudos têm proposto arcabouços de métricas para aferição da qualidade de dados conectados, em específico Ibáñez et al. (2019), Debattista, Lange e Auer (2018), Rani, R. e Mishra (2018), Färber et al. (2018), Zaveri et al. (2016), Behkamal et al. (2014), enquanto outros abordam apenas alguns aspectos de dados conectados dentro do escopo de dados abertos (VETRÒ et al., 2016) ou dados abertos governamentais (YI, 2019; JANEV; MIJOVIć; VRANEs, 2018; MARTÍN; ROSARIO; PÉREZ, 2016).

Em suma, os dados conectados conectam os silos informacionais que existem entre diferentes fontes de dados, facilitando a extensão dos modelos de dados e permitindo atualizações facilitadas. Como resultado, a integração de dados e a navegação através de dados complexos se torna mais fácil e mais eficiente. Além disso, com a adoção de bases de dados baseadas em grafos, a ligação de diferentes fontes e formatos permite a inferência de novos conhecimentos a partir de fatos existentes. Fica, com isso, possibilitada a reutilização desses dados não apenas por humanos, mas também por agentes de software que podem cruzar dados de diferentes fontes, apoiar análises e visualizações, aumentando assim a capacidade dos usuários (WOOD; ZAIDMAN; RUTH, 2014; BERNERS-LEE; HENDLER; LASSILA, 2001).

A tese trabalhada neste trabalho é de que a infraestrutura de publicação de DAGC aqui proposta pode ser usada como um meio eficaz de publicar DAGC de qualidade.

A partir destas motivações, desafios e lacunas existentes, apresentamos o seguinte problema e seus desdobramentos em questões de pesquisa: 
Problema de pesquisa: a produção de DAGC ainda é baixa em governos de todo o mundo e pesquisas recentes parecem indicar que essas iniciativas não seguem um processo sistemático de produção e de controle de qualidade, o que impacta o desenvolvimento de seus benefícios esperados. Levando em conta os desafios identificados, o objetivo desta pesquisa é definido como: desenvolver uma infraestrutura de publicação de dados abertos governamentais conectados (DAGC) de qualidade para o ecossistema de dados da Web.

Para atingir este objetivo, as seguintes questões de pesquisa foram definidas conforme o Quadro 1. Este estudo busca desenvolver um conjunto de artefatos e, para isso, foi usada uma abordagem de pesquisa de ciência do design - Design Science Research, DSR (HEVNER et al., 2004; MARCH; SMITH, 1995) - para a formulação das questões de pesquisa.

Quadro 1 - Questões de pesquisa desta tese.

Objetivo: desenvolver uma infraestrutura de publicação de dados abertos governamentais conectados (DAGC) de qualidade para o ecossistema de dados da Web

\begin{tabular}{|c|c|c|c|c|c|}
\hline $\begin{array}{l}\text { QP1: Quais } \\
\text { são os } \\
\text { problemas } \\
\text { encontrados } \\
\text { com DAGC? }\end{array}$ & $\begin{array}{l}\text { QP2: Quais } \\
\text { são os requi- } \\
\text { sitos para } \\
\text { uma infraes- } \\
\text { trutura que } \\
\text { gere DAGC } \\
\text { de qualidade } \\
\text { para o ecos- } \\
\text { sistema de } \\
\text { dados na } \\
\text { Web? }\end{array}$ & $\begin{array}{l}\text { QP3: Que } \\
\text { elementos } \\
\text { caracterizam } \\
\text { uma infraes- } \\
\text { trutura que } \\
\text { gere DAGC } \\
\text { de qualidade } \\
\text { para o ecos- } \\
\text { sistema de } \\
\text { dados na } \\
\text { Web? }\end{array}$ & $\begin{array}{l}\text { QP4: Quais } \\
\text { são as me- } \\
\text { todologias } \\
\text { de produção } \\
\text { de DAGC } \\
\text { atuais? }\end{array}$ & $\begin{array}{l}\text { QP5: Como } \\
\text { é a infra- } \\
\text { estrutura } \\
\text { desenvolvida } \\
\text { que gera } \\
\text { DAGC de } \\
\text { qualidade } \\
\text { para o ecos- } \\
\text { sistema de } \\
\text { dados na } \\
\text { Web? }\end{array}$ & $\begin{array}{l}\text { QP6: Qual a } \\
\text { eficácia da in- } \\
\text { fraestrutura } \\
\text { desenvolvida } \\
\text { em relação } \\
\text { à qualidade } \\
\text { e ao ecos- } \\
\text { sistema de } \\
\text { dados na } \\
\text { Web? }\end{array}$ \\
\hline
\end{tabular}

Fonte: Elaborada pelo autor.

Contribuições potenciais: nesta pesquisa temos o interesse em propor um modelo de ciclo de vida sistemático e artefatos de suporte que possam impactar a produção de dados de qualidade no âmbito governamental, dadas suas especificidades. Acreditamos que para que os dados sejam consistentemente produzidos com qualidade, é necessária a adoção de um processo sistemático que contemple diferentes perspectivas sobre a qualidade. Ao analisar de forma mais abrangente o cenário de produção dos DAGC, podemos detectar pontos de melhoria, seja em formas de práticas, validações ou ferramentas disponíveis. Esta tese se delimita ao fornecer um modelo de processo sistemático e uma arquitetura de suporte que definem os passos necessários para especificar, modelar, publicar e explorar dados conectados, apontando quais são os recursos existentes que podem ser usados para este fim. No entanto, não propõe resolver profundamente cada um deles, já que cada problema em aberto seria um novo tópico de pesquisa. Além disso, fornece um material concreto que pode ser adotado por diferentes órgãos públicos para que esses possam adequar a seus planos de publicação de dados. 


\subsection{Objetivos}

O objetivo geral deste trabalho é o de propor e validar um modelo de ciclo de vida e seus artefatos de suporte para auxiliar na criação de dados conectados de qualidade em escopo governamental, aumentando seu potencial de reutilização por consumidores de dados. O modelo de ciclo de vida proposto visa preencher as lacunas, identificadas neste trabalho, da inclusão de práticas que consideram o ecossistema de dados da Web e da incorporação de atividades de controle de qualidade (verificação e validação) durante a execução de suas atividades, buscando detalhar quais passos, papéis, componentes, ferramentas e verificações são necessários para concluir cada etapa.

Como objetivos específicos desta pesquisa, citamos:

- Descrever como as iniciativas de dados abertos governamentais evoluíram no governo federal brasileiro, como exemplo ilustrativo da complexidade organizacional em que um processo deste tipo está inserido;

- Identificar como os processos do estado da arte operacionalizam a publicação dos DAGC;

- Propor uma arquitetura para a publicação e o compartilhamento de dados na Web que contenha práticas que atendam às necessidades dos DAGC, em termos de requisitos de compartilhamento e controle de qualidade;

- Especificar detalhadamente como cada atividade pode ser atendida, em termos de tarefas, ferramentas, verificações e papéis envolvidos;

- Desenvolver e validar o modelo de ciclo de vida e a arquitetura propostos a partir de dados reais. O uso da metodologia nesta demonstração deve ser útil também como referência e guia prático.

É importante também ressaltar aspectos que estão fora do escopo desta pesquisa. Como ela aborda o processo técnico de produção de dados conectados, outros fatores sociais, econômicos, organizacionais ou legais, embora essenciais, ficam de fora do escopo - tais como recursos financeiros, capacitação de funcionários, aquisição de licenças ou máquinas, dentre outros que são externos ao processo de produção - $c f$. Janssen, Charalabidis e Zuiderwijk (2012).

\subsection{Metodologia da pesquisa}

Uma categorização básica para a classificação epistemológica da ciência é a divisão entre as ciências naturais e a ciência do artificial (SIMON, 1996). As primeiras dizem respeito à compreensão de fenômenos que ocorrem naturalmente, seja na natureza ou na sociedade, e a segunda, ao projeto (design) de objetos artificiais (artefatos projetados para atender a certos objetivos) e seus fenômenos consequentes. 
O problema desta pesquisa tem sua essência na segunda vertente - a do estudo, projeto e desenvolvimento de artefatos para atingir o objetivo da produção de dados abertos governamentais conectados, já que se trata de produção inerentemente humana, e não um fenômeno do mundo natural per se. Um artefato, por ser uma invenção humana, em princípio não é objeto de investigação das ciências tradicionais (PIMENTEL; FILIPPO; SANTORO, 2019). Conforme exposto na seção anterior, esta tese pretende estender o conhecimento humano ao propor uma nova forma de publicar dados conectados, resultantes, por sua vez, de artefatos criados anteriormente e que puderam estender as funcionalidades dos dados digitais. Deste modo, é necessária uma abordagem de estudo de criação e aperfeiçoamento de artefatos para esta finalidade.

Esta tese está baseada numa concepção filosófica de pesquisa pragmática nos termos definidos por Easterbrook (2007) e Creswell (2010). De acordo com esses autores, essa concepção é caracterizada pela preocupação com a solução de problemas, buscando a aplicação "do que funciona" para a solução do problema.

A metodologia de pesquisa adotada nesta tese foi a DSR-M (Design Science Research Methodology), baseada na epistemologia de Design Science Research ${ }^{1}$ (DSR ou Pesquisa em Ciência de Projeto, em tradução livre). Nesta abordagem, os pesquisadores criam artefatos ${ }^{2}$ que acreditam ser úteis para um grupo de pessoas, avaliando seu mérito de várias maneiras (WEBER, 2018). É um contraponto à disciplina mais tradicional dentro das ciências da computação e de sistemas de informação, em que o objetivo principal é o de desenvolver e testar teorias, princípios e leis que explicam ou predizem fenômenos humanos ou organizacionais em torno da análise, projeto, implementação, gerenciamento e uso de sistemas de informações (HEVNER et al., 2004). No entanto, os artefatos alvo da DSR não estão isentos das leis naturais ou comportamentais; ao contrário, sua criação se apoia em teorias existentes que são aplicadas, testadas, modificadas e estendidas por meio da experiência (HEVNER et al., 2004). De acordo com Denyer, Tranfield e Aken (2008), a pesquisa na base do paradigma da DSR é caracterizada por:

- Questões de pesquisa direcionadas por um interesse em problemas de campo;

- Uma ênfase na produção de conhecimento prescritivo, conectando a intervenções e sistemas para produzir saídas, fornecendo a chave para resolver os problemas de campo;

- Uma justificativa de produtos de pesquisa baseada amplamente na validade pragmática (as ações baseadas nesse conhecimento produzem os resultados esperados?).

Além disso, o objetivo desta abordagem é relacionar o desenvolvimento de um artefato com a produção do conhecimento científico-teórico, sendo próxima da concepção da pesquisaação (LEWIN, 1947) e da metodologia de sistemas flexíveis (CHECKLAND, 2013), no sentido

O termo em inglês é amplamente usado, mesmo em trabalhos em língua portuguesa.

2 Aqui adotamos a conceituação do termo artefato como "objetos criados por humanos", em consonância com o trabalho de Hevner et al. (2004) 
de criar soluções para um problema dentro de um determinado contexto; porém, a DSR se diferencia destas ao ter como foco o artefato em si, ao passo que a pesquisa-ação e a metodologia de sistemas flexíveis se focam no problema (ZUIDERWIJK, 2015). O uso da DSR pode propiciar a obtenção do conhecimento a partir da criação do artefato, bem como da aplicação dele, por meio de seu uso.

Vaishnavi e Kuechler (2015) definem 8 tipos de artefatos (também chamados de produto da pesquisa) que podem ser criados ao final da aplicação da DSR:

- Construto: objeto conceitual que serve como meio de descrever e representar algum tipo de fenômeno do mundo;

- Modelo: objeto conceitual que aborda diferentes construtos e seus relacionamentos como uma maneira de descrever e representar algum fenômeno do mundo real;

- Método: conjunto de ações, geralmente ordenadas, usadas para atingir algum resultado (produto ou serviço);

- Arquitetura: sistema de estruturas em alto nível;

- Arcabouço: guia, conceitual ou real, que serve como suporte para uma atividade;

- Princípio de projeto: princípios-chave e conceitos para guiar o projeto;

- Instanciação: sistema de software ou hardware que os pesquisadores criam usando algum método para implementar um construto ou modelo;

- Teorias de projeto: conjunto prescritivo sobre como fazer algo, que inclui outros artefatos.

No entanto, a epistemologia DSR é relativamente nova e encontra-se em processo de evolução, contendo certos passos que ainda não são consenso na comunidade (WEBER, 2018), existindo também variações quantos aos procedimentos metodológicos. Hevner et al. (2004) propõem sete diretrizes que devem ser aplicadas e adaptadas aos requisitos de um projeto de DSR em particular. Peffers et al. (2007) propõem uma metodologia iterativa para a produção de pesquisas em DSR, argumentando que é necessário que a área de sistemas de informação possua modelos mentais e templates para que pesquisadores, revisores e leitores possam reconhecer e avaliar os resultados da pesquisa.

Conforme apontado em Weber (2018), existem diversas outras variações de metodologias DSR, com suas respectivas vantagens e desvantagens e a escolha, por parte do pesquisador, depende de avaliar a que melhor se encaixa ao problema de pesquisa em questão. A $D S R$ Methodology (PEFFERS et al., 2007) contém seis passos sequenciais e iterativos, conforme ilustrado na Figura 1, e foi a metodologia adotada nesta tese, tendo como ponto de entrada a iniciação centrada no problema.

Os passos definidos pelos autores e seguidos nesta tese são os seguintes: 
Figura 1 - Procedimentos metodológicos da DSR Methodology.

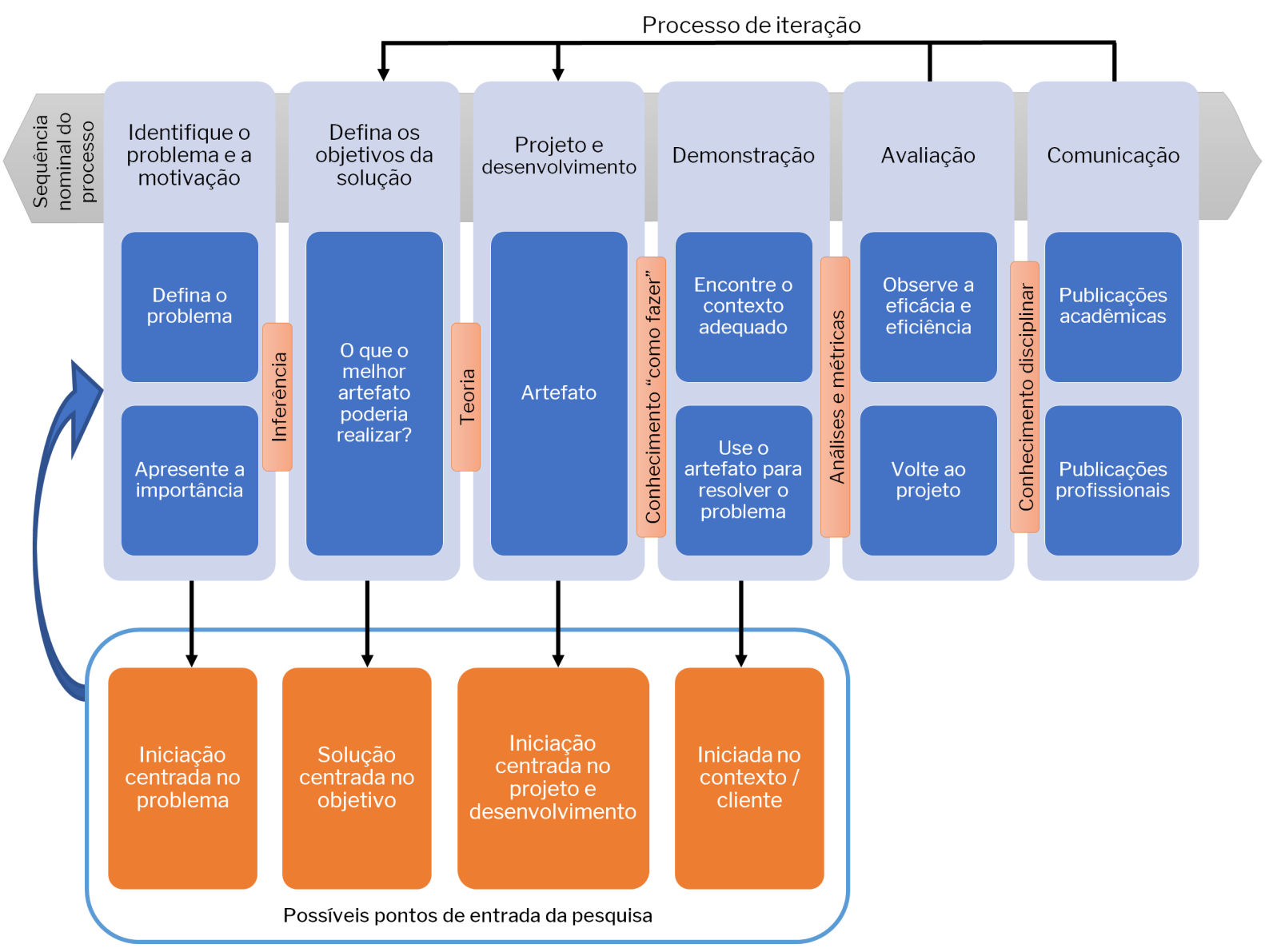

Fonte: Adaptada de Peffers et al. (2007).

- Identificar, definir e motivar o problema: define o problema de pesquisa específico e justifica o valor de uma solução para ele. Este passo é implementado neste primeiro capítulo, com a determinação da motivação e dos objetivos da pesquisa;

- Definir objetivos que uma solução (possivelmente parcial) para o problema deve atender: inferir os objetivos de uma solução a partir da especificação do problema e conhecimento do que é possível e viável, seja de modo quantitativo (o quanto esta solução é melhor que outras, segundo arcabouço de métricas) ou qualitativo (descrição de como espera-se que o novo artefato auxilie na solução dos problemas levantados), levando em conta o estado atual do problema e como ele é atualmente solucionado. Este passo é adotado no Capítulo 3, que demonstra as premissas adotadas para gerar os requisitos para o artefato;

- Projetar e desenvolver o artefato: criar o artefato (construto, modelo, método, instanciação), no qual uma contribuição de pesquisa está embutida em seu design. Inclui determinar as funcionalidades desejadas do artefato, sua arquitetura e sua criação de fato. São aportados arcabouços teóricos para delimitar a solução. Este passo é implementado no Capítulo 4, que demonstra o racional para a construção do artefato; 
- Demonstrar que o artefato pode ser usado para resolver o problema: demonstra o artefato para resolver uma ou mais instâncias do problema, ilustrado no Capítulo 5. Inclui o conhecimento efetivo de como usar o artefato para resolver o problema e pode envolver experimentação, simulação, estudo de caso, prova ou outra atividade empírica;

- Avaliar a eficiência do artefato na resolução do problema: observar e medir quão bem o artefato suporta uma solução para o problema. Na DSR não é pressuposto o uso de um método de pesquisa específico para as avaliações, cabendo ao pesquisador selecionar o método mais adequado ao seu contexto. Este passo é realizado no Capítulo 6, com a aplicação e a avaliação empírica com dados reais;

- Comunicar os resultados da pesquisa: comunicar os elementos da condução da DSR (o problema e sua relevância, o artefato, sua utilidade e novidade, o rigor de seu desenho, sua efetividade em relação ao problema) a outros pesquisadores e audiências relevantes. É viabilizada por meio desta tese e de seus artigos derivados.

O procedimento foi também usado para determinar as fases da pesquisa, conforme mostrado no Quadro 2.

O projeto e a criação de artefatos pode ser auxiliado pelas chamadas teorias kernel (HEVNER et al., 2004; PRIES-HEJE; BASKERVILLE, 2008). Existem diferentes visões do que compreende uma teoria. Esta tese assume uma visão mais ampla de uma teoria kernel, como em Zuiderwijk (2015), uma vez que queremos fazer uso da pesquisa relativamente limitada em produção de DAGC. Gregor (2006) identifica cinco tipos inter-relacionados de teorias relevantes para o domínio de sistema de informações: i) teoria para análise; ii) teoria para explicação; iii) teoria para predição; iv) teoria para explicação e predição e v) teoria para projeto e ação. O último tipo não é sempre reconhecido como teoria, sendo considerado mais como prática (HOOKER, 2004), adotando-se como teoria apenas as relacionadas às ciências naturais ou sociais. Ainda nas ciências sociais, um grande número de pesquisadores adota uma visão ampla do termo "teoria", referindo-se também ao que outros pesquisadores chamam de modelos, arcabouços ou corpos de conhecimento (GREGOR; JONES, 2007), métodos ou implementações (MARCH; SMITH, 1995).

Esta pesquisa contribui para uma teoria do design ao fornecer conhecimentos de design apropriados para a construção de um modelo de ciclo de vida para publicação de DAGC de qualidade no ecossistema da Web, discutindo se ele pode ser útil e auxiliar na identificação das relações entre os elementos de design propostos. Essa escolha apresenta a vantagem de não limitar a base de conhecimento que pode ser usada para o projeto somente para o que chamam de teorias, e também de utilizar teorias incipientes, ainda em formação, podendo fazer uso de uma gama maior de estudos e conhecimentos para fornecer direcionamentos para o design do modelo de ciclo de vida. Esta pesquisa trabalha com a hipótese de que uma infraestrutura de DAGC 
Quadro 2 - Fases de pesquisa desta tese.

\section{Objetivo de pesquisa:}

Desenvolver um processo que gere DAGC de qualidade para o ecossistema de dados na Web

\begin{tabular}{|l|l|l|}
\hline Fases da pesquisa & Questões de pesquisa & Instrumentos de pesquisa \\
\hline $\begin{array}{l}\text { Fase 1. Identificação do pro- } \\
\text { blema e fatores relacionados }\end{array}$ & $\begin{array}{l}\text { QP1: Quais são os problemas } \\
\text { encontrados com DAGC? }\end{array}$ & $\begin{array}{l}\text { Capítulo 1: revisão de litera- } \\
\text { tura }\end{array}$ \\
\hline $\begin{array}{l}\text { Fase 2. Definições dos objeti- } \\
\text { vos de uma solução }\end{array}$ & $\begin{array}{l}\text { QP2: Quais são os requisitos } \\
\text { para uma infraestrutura que } \\
\text { gere DAGC de qualidade para } \\
\text { o ecossistema de dados na } \\
\text { Web? }\end{array}$ & $\begin{array}{l}\text { Capítulo 2: análise de requisi- } \\
\text { tos e revisão de literatura }\end{array}$ \\
\hline Fase 3. Projeto do artefato & $\begin{array}{l}\text { QP3: Que elementos caracte- } \\
\text { rizam uma infraestrutura que } \\
\text { gere DAGC de qualidade para } \\
\text { o ecossistema de dados na } \\
\text { Web? }\end{array}$ & $\begin{array}{l}\text { Capítulo 2: análise de requisi- } \\
\text { tos, revisões de literatura; }\end{array}$ \\
\hline $\begin{array}{l}\text { Fase 4. Identificação do es- } \\
\text { tado da arte }\end{array}$ & $\begin{array}{l}\text { QP4: Quais são as metodolo- } \\
\text { gias de produção de DAGC } \\
\text { atuais? }\end{array}$ & $\begin{array}{l}\text { Capítulo 3: mapeamento sis- } \\
\text { temático da literatura }\end{array}$ \\
\hline $\begin{array}{l}\text { Fase 5. Desenvolvimento da } \\
\text { infraestrutura }\end{array}$ & $\begin{array}{l}\text { QP5: Como é a infraestrutura } \\
\text { desenvolvida que gera DAGC } \\
\text { de qualidade para o ecossis- } \\
\text { tema de dados na Web? }\end{array}$ & $\begin{array}{l}\text { Capítulo 4: prototipação do } \\
\text { artefato }\end{array}$ \\
\hline $\begin{array}{l}\text { QP6: Qual a eficácia da infra- } \\
\text { estrutura desenvolvida em re- } \\
\text { sistema de dados na Web? }\end{array}$ & Capítulo 5: estudo empírico \\
\hline Fanfraesade e ao ecos-
\end{tabular}

Fonte: Elaborada pelo autor.

(composta por um modelo de ciclo de vida, modelo de metadados e arquitetura de suporte) pode ser usado como um meio eficaz para publicar dados abertos governamentais de qualidade.

Para a fase de avaliação, foi adotado o planejamento de quasi-experimento com grupo único, em que os participantes adotaram o modelo de processo, artefatos e ferramentas propostos e os resultados de métricas de qualidade dos dados gerados foram comparados ao estado da arte, bem como o grau de atendimento das melhores práticas em publicação de dados na Web. 


\subsection{Organização do trabalho}

Neste primeiro capítulo, foram apresentados o contexto e os desafios da área de pesquisa, suas motivações, bem como as questões, os objetivos e a metodologia de desenvolvimento desta tese.

No Capítulo 2, "Aspectos conceituais", são introduzidos os conceitos relacionados às áreas de dados abertos governamentais conectados e o referencial teórico usado para fundamentar o trabalho. A partir do referencial teórico adotado são derivados os requisitos para o processo e para seu produto resultante. São também selecionadas as teorias que podem fornecer elementos para o design do artefato e que atendem aos requisitos levantados.

No Capítulo 3, "Estado da arte e da prática", é mostrada como se deu a evolução dos dados abertos governamentais no Brasil até o momento, contextualizando sua organização política, legal e tecnológica. Em relação ao ecossistema de dados, é analisado um recorte de conjuntos de dados em relação a boas práticas no compartilhamento de dados na Web. Por fim, é demonstrado o mapeamento sistemático realizado para levantar quais metodologias foram desenvolvidas para a finalidade de DAGC.

No Capítulo 5, "Infraestrutura para dados abertos governamentais conectados", detalhamos como nossa proposta de ciclo de vida contempla os diferentes requisitos conceituais levantados no Capítulo 2 e como se relaciona ao estado da arte, levantado no Capítulo 3. São detalhados os componentes dessa proposta: o processo, a arquitetura, a seleção de ferramentas e o conjunto de metadados.

O Capítulo 6, "Avaliação", exemplifica com um cenário ilustrativo a aplicação do metamodelo proposto para um ciclo de vida completo de publicação de dados. Foi escolhido um problema do domínio educacional para o qual a exploração de dados conectados pode ajudar. A arquitetura proposta é analisada quanto ao atendimento dos elementos selecionados no Capítulo 2. Em seguida, o modelo do processo é avaliado em estudos de caso na tarefa de publicação de dados abertos governamentais, tanto em relação ao processo quanto ao produto resultante.

O Capítulo 7, "Considerações finais", inclui as conclusões desta tese, as contribuições ao corpo de conhecimento da área, suas limitações e trabalhos futuros, bem como as principais publicações do autor da tese.

No apêndice A detalhamos cada uma das atividades do ciclo de vida, com sugestões de papéis, tarefas, entradas, saídas, ferramentas e possíveis verificações. O apêndice B traz o modelo básico de metadados proposto para dar suporte, contendo diferentes vocabulários e propriedades relevantes para este cenário. $\mathrm{O}$ apêndice $\mathrm{C}$ exibe o termo enviado para os participantes do estudo. O apêndice D exibe o roteiro usado pelos participantes no estudo empírico de validação dos artefatos propostos. Por fim, o apêndice E mostra o questionário aplicado aos participantes do estudo empírico, em torno de suas percepções ao uso dos artefatos propostos. 


\section{ASPECTOS CONCEITUAIS}

Este capítulo apresenta os referenciais teórico e tecnológico necessários à compreensão do que é a publicação de dados abertos governamentais conectados. As próximas seções do capítulo estão assim organizadas:

A Seção 2.1 descreve a evolução, os conceitos gerais e as principais tecnologias relacionadas à Web, fundamentais para a compreensão técnica de uma abordagem de compartilhamento na Web de dados, apresentada na Seção 2.2.

A Seção 2.3 apresenta os conceitos sobre governo aberto (GA), dados abertos (DA), dados abertos governamentais (DAG), dados abertos conectados (DAC) e dados abertos governamentais conectados (DAGC) e como eles se relacionam entre si. Os princípios da cada conceitos são sumarizados e transformados em requisitos.

\subsection{A Web e suas tecnologias}

Em 1945, o matemático Vannevar Bush escreveu o artigo "As we may think” (Como podemos pensar, em tradução livre), onde identificou o problema que temos em gerenciar grandes coleções de documentos e em como manter os vínculos que estabelecemos entre esses documentos, tratando-o como um problema científico (BUSH, 1945). Como solução, propôs um dispositivo chamado Memex, usado para estender a capacidade da memória humana, que nos auxiliaria a realizar o gerenciamento externo desses vínculos e a nos lembrar dos conteúdos desses documentos. Já em meados da década de 60, o sociólogo Theodore Nelson desenvolve essa ideia e propõe o uso de computadores para implementá-la, por meio da estrutura de hipertextos e hiperlinks (termos cunhados pelo autor) para ligar documentos e suas partes (NELSON, 1965). Em meados da década de 80, Berners-Lee elaborou ainda mais este conceito, estendendo-o para fundir com a embrionária Internet. Com isso, foram criadas as ligações entre documentos em rede, para além da limitação de os documentos estarem num mesmo computador, criando, assim, 
a Web (BERNERS-LEE, 1989).

$\mathrm{Na}$ arquitetura básica da Web, dois componentes importantes se comunicam: o cliente e o servidor. O cliente, geralmente por meio de software navegadores, faz requisições de documentos e dados que são retornados pelo servidor de modo estático ou dinâmico, isto é, retornando o arquivo como ele foi criado ou mediante algum tipo de processamento requisitado pelo cliente. Além disso, existem 3 componentes básicos na arquitetura da Web que configuram os aspectos fundamentais para a publicação de documentos e dados: i) endereços que nos permitem identificar e localizar documentos (URL); ii) protocolos de comunicação que permitem ao cliente se comunicar com o servidor, por meio de requisições e respostas (HTTP); iii) linguagens de representação que permitem descrever o conteúdo das páginas (HTML). A Figura 2 ilustra esse processo de modo simplificado.

Figura 2 - Arquitetura básica da Web de documentos.

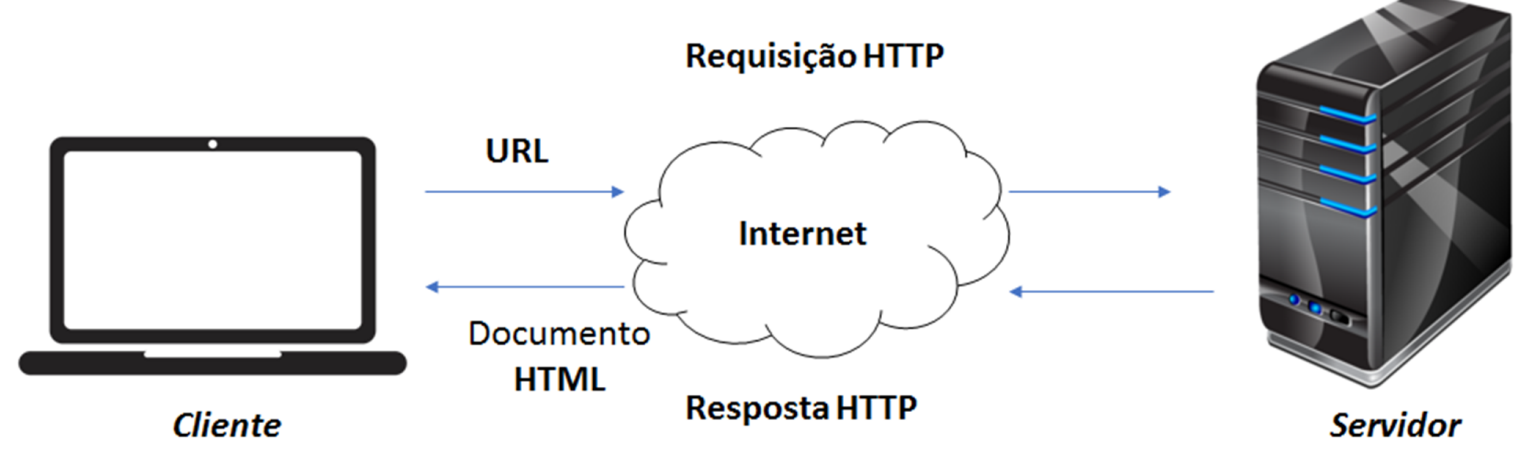

Fonte: Elaborada pelo autor.

Assim evoluiu a Internet com a Web, conhecida como Web de documentos. No entanto, dados relacionados entre si, mas de diferentes fontes não são possíveis de serem conectados automaticamente, pois os dados são controlados pelas aplicações que os gerenciam e que os mantêm para si, gerando silos informacionais (W3C, 2011).

\subsection{Web Semântica e os dados conectados}

Vislumbra-se que o próximo passo para a Web seja utilizar esta mesma arquitetura básica para conectar dados - a chamada Web de dados ou Web Semântica, que tem como finalidade atribuir significado aos conteúdos publicados na Internet, de modo que sejam compreensíveis tanto por humanos quanto por máquinas. Os dados na Web Semântica não devem apenas ser criados em formatos processáveis por máquinas, mas também equipados com definições semânticas formais que especificam claramente quais conclusões devem ser tiradas das informações coletadas (COMISSÃO EUROPEIA, 2019). Entretanto, como apontado em Berners-Lee, Hendler e Lassila (2001), a Web Semântica não trata apenas de colocar dados na Web, mas sim de criar conexões, de modo que uma pessoa ou máquina possa explorar esses dados por meio dos 
princípios de dados conectados, já que sua utilidade aumenta quando eles são interligados com outros conjuntos de dados.

A ideia básica dos dados conectados é que se trata de um conjunto de boas práticas para publicar e conectar dados estruturados na Web, visando criar a Web de dados (BIZER; HEATH; BERNERS-LEE, 2009). A Web de dados tem como objetivo fazer um contraponto à Web de documentos (ISOTANI; BITTENCOURT, 2015). Na Web de documentos, recursos como páginas Web, figuras e vídeos estão conectados por meio de URIs. Essa conexão é fundamental para fazer associações entre diferentes recursos disponíveis na Web e para o consumo da informação destes recursos por pessoas (agentes humanos). Podemos dizer que na Web de documentos são os recursos, e não as informações neles contidas, que estão conectados. Porém, para que um programa de computador possa utilizar as informações contidas na Web, é necessário que estejam disponíveis informações adicionais que caracterizem os recursos, expliquem como eles se relacionam e informem quais dados estão contidos neles.

Berners-Lee (2006) definiu quatro princípios para a publicação de dados conectados, que podem garantir um certo nível de uniformidade refletindo diretamente em seu potencial de reuso (cada princípio é detalhado logo a seguir):

- Usar URI para identificar coisas;

- Usar URI HTTP para estarem disponíveis na Web;

- Quando se buscar por uma URI, fornecer informações úteis, usando padrões da Web (RDF, SPARQL);

- Incluir links para outras URI, de modo a permitir a descoberta de mais informações.

Inicialmente, na década de 90, os endereços foram utilizados para identificar recursos de qualquer tipo (páginas, imagens, arquivos, vídeos, etc.) que estavam disponíveis na Web - a chamada URL (Uniform Resource Locator). Em seguida, surgiu o conceito de URI (Uniform Resource Identifier), que estende o conceito da URL, servindo para identificar na Web qualquer coisa que exista, dentro ou fora dela. Se com as URL podemos localizar e identificar coisas na Web, com as URI ${ }^{1}$ podemos identificar objetos de fora dela representados na Web. Por exemplo, uma pessoa pode ser identificada por uma URI contendo seus detalhes e esse identificador pode ser utilizado em diferentes aplicações na Web; no entanto, a pessoa em si não está na Web, como está, por exemplo, um arquivo. Uma extensão às URI foram as IRI (Internationalized Resource Identifier), em que o recurso pode ser identificado em qualquer língua - ou até mesmo uma mistura entre diferentes línguas.

1 Nesta tese, usaremos recorrentemente o conceito de URI, uma vez que trataremos de recursos que podem ou não estar na Web, mas que necessitam de um identificador na Web. 
As URI podem ser implementadas em qualquer esquema hierárquico de nomenclaturas, dentre os quais pode ser usado o protocolo HTTP - tornando-se, de fato, o conceito de URL. O segundo princípio diz que a pesquisa de nomes HTTP sob a autoridade do DNS (Domain Name System) deve ser usada como protocolo de pesquisa entre o identificador (URI) e a representação do recurso. Outros esquemas podem ser usados para a representação de informações, como o URN (Uniform Resource Name) ou o DOI (Digital Object Identifier), todavia estes padrões alternativos não lidam com pesquisa centralizada, entre outras características favoráveis às URIs HTTP (BERNERS-LEE, 2006).

Certos padrões não proprietários devem ser seguidos de modo a fornecer mais informações sobre o recurso de dados pesquisado por meio da URI HTTP, tanto em termos de representação da informação quanto de protocolo de acesso a esses dados. Para a representação dos dados, deve ser utilizado o padrão RDF (Resource Description Framework), um formato de representação baseado em grafo. No modelo RDF, a informação é representada em declarações, chamadas de triplas RDF, pois são compostas por um sujeito, um predicado e um objeto, como em uma sentença simples, como por ex.: Bruno Penteado (sujeito) conhece (predicado) Seiji Isotani (objeto).

Para modelagens mais complexas de relacionamentos lógicos entre os dados e conceitos representados, são usados os padrões RDFS (RDF Schema, extensão do RDF com vocabulário para modelagem de dados) ou OWL (Web Ontology Language, linguagem expressiva projetada para representar conhecimentos complexos sobre conceitos e seus relacionamentos, para serem processados por máquinas). Diversos formatos de serialização de RDF podem ser adotados, como o RDF/XML, N3, JSON-LD ou o Turtle.

Considerando o acesso aos dados, é recomendável a implementação do protocolo SPARQL (Sparql Protocol And Rdf Query Language), recomendado pela W3C (W3C, 2008b), que define tanto uma linguagem para consulta desses dados semânticos quanto o protocolo remoto para realizar consultas SPARQL e receber os resultados. Outras abordagens recentes, como o GraphQ-LD (TAELMAN; SANDE; VERBORGH, 2018), foram desenvolvidas para reaproveitar o conhecimento e a estrutura de acesso a frameworks de desenvolvimento Web; no entanto, eles servem como middleware para o protocolo SPARQL.

Por fim, o grande potencial da Web Semântica vem da criação de conexões com dados externos presentes na Web. Porém, para que um programa de computador possa utilizar as informações contidas na Web, é necessário que estejam disponíveis para ele conhecimentos adicionais que caracterizem os recursos, como eles se relacionam e quais dados estão contidos neles. Neste contexto, emerge a Web de dados, na qual os recursos estão conectados também por URIs, porém informações adicionais são disponibilizadas para permitir que as máquinas possam compreender melhor os dados contidos nestes recursos e o "significado" de determinada relação entre dois ou mais recursos (ISOTANI; BITTENCOURT, 2015). Para isso, o modo mais simples para conectar dados é usar, em um arquivo, uma URI que 
aponta para uma outra URI. Para o exemplo anterior, podemos ter: <ex:Bruno_Penteado $>$ $<$ foaf:knows $><$ ex:Seiji_Isotani>. Pela arquitetura da Web, temos um identificador global hipotético "http://example.org/persons\#Bruno_Penteado" atribuído à pessoa Bruno Penteado (usando o prefixo ex: como alias para http://example.org/persons\#). Com isso, qualquer pessoa ou aplicação pode usar este identificador para se referir a esta pessoa e obter mais informações.

\subsection{Dados: abertos, governamentais e conectados}

Dados abertos podem ser definidos como proposto pela OpenDefinition.org, que declara que "o conhecimento é aberto se qualquer pessoa está livre para acessá-lo, utilizá-lo, modificá-lo, e compartilhá-lo - restrito, no máximo, a medidas que preservam a proveniência e abertura" 2 . Janssen, Charalabidis e Zuiderwijk (2012) definem dados abertos governamentais como dados que não são restritos por privacidade ou confidencialidade, que são produzidos com dinheiro público e disponibilizados sem quaisquer restrições sobre seu uso ou distribuição. Idealmente, dados governamentais devem ser disponibilizados ao público com um mínimo de custo possível, preferencialmente como download gratuito a partir da Internet ${ }^{3}$.

Um outro conceito importante é o de governo aberto. Parycek e Sachs (2010) o descrevem como um método de governança que fornece espaço para a abertura, transparência e diálogo entre governo e seus cidadãos, possibilitado pela penetração da tecnologia na vida das pessoas, e se coloca como uma evolução do governo eletrônico. Abu-Shanab (2013) considera como uma especialização do conceito de governo eletrônico, considerando não só a ideia geral da oferta de serviços aos cidadãos, mas focando no status da informação governamental. O governo aberto pode ser identificado como uma iniciativa característica de uma sociedade democrática (DAVIES; BAWA, 2012; BERTOT et al., 2010), geralmente associada aos conceitos de transparência e responsabilização (accountability) governamentais. Contudo, alguns princípios de governo aberto devem ser considerados, como participação efetiva, transparência, responsabilização, dados abertos, abertura e reuso de informações públicas, acesso e simplicidade, colaboração e cocriação, inclusão e diversidade (BURLE; BELLIX; MACHADO, 2016).

Talvez a primeira menção institucional de governo aberto foi na administração de Barack Obama, nos EUA, em janeiro de 2009, em que o conceito foi instituído no país e definido em torno de 3 dimensões: transparência, participação e colaboração (OBAMA, 2009). Tal conceituação apresenta problemas de definição, incluindo redundância de significado entre esses componentes, como a presença do pilar de colaboração dentro da participação (YU; ROBINSON, 2012). Assim, adotamos parte do modelo teórico de Abu-Shanab (2015), que considera 4 componentes do governo aberto: transparência, prestação de contas das informações, colaboração e empoderamento, ilustrados na Figura 3.

$<$ http://opendefinition.org/>

$<$ https://okfn.org/opendata/> 
Figura 3 - Arcabouço de conceitos relacionados ao governo aberto.

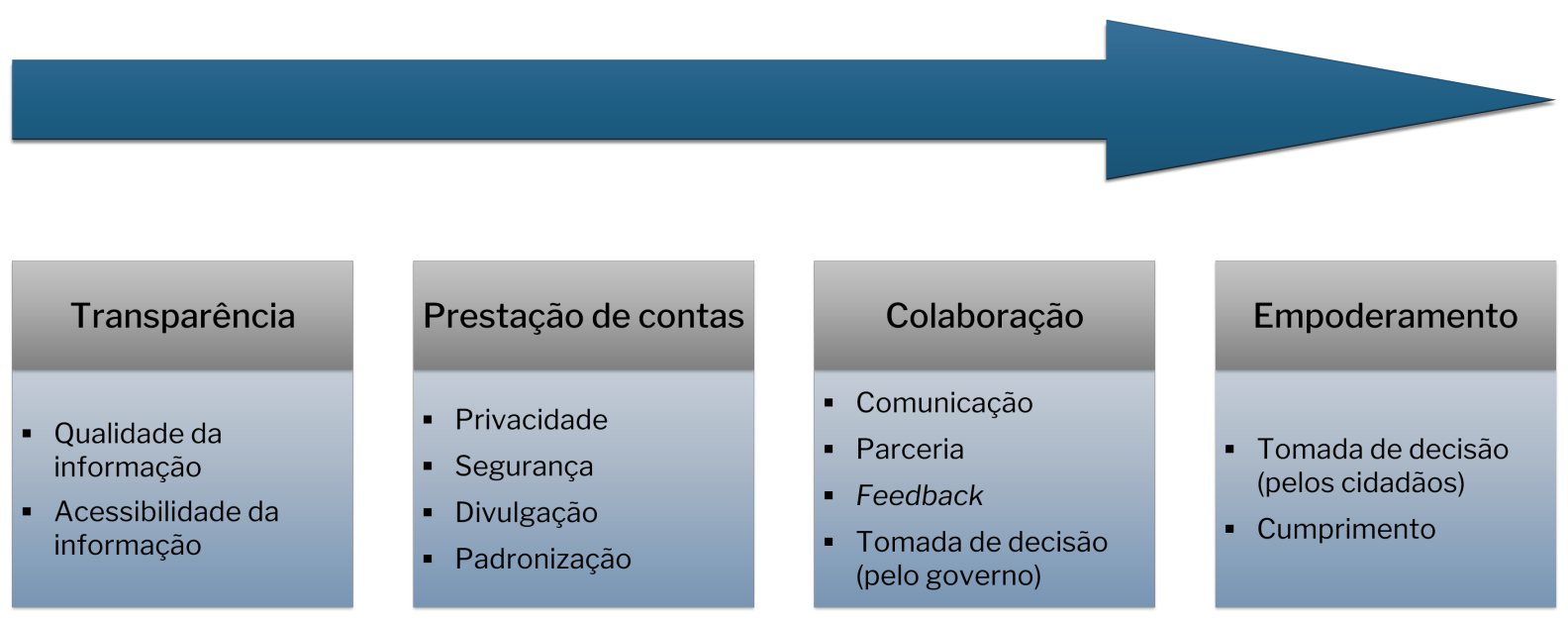

Fonte: Adaptada de Abu-Shanab (2015).

Neste arcabouço, a transparência inclui duas vertentes fundamentais: a qualidade da informação (em termos de acurácia, compreensibilidade, relevância, validade e atualização) e sua acessibilidade. A prestação de contas (accountability) sobre as informações é definida pelo senso de se saber que informações são privadas, asseguradas e padronizadas entre diferentes canais do governo. A colaboração diz respeito a diferentes formas de relacionamentos (por exemplo: governo-para-consumidor, governo-para-negócios, governo-para-governo) para a participação no processo democrático. $\mathrm{O}$ empoderamento diz respeito ao estado em que os cidadãos podem tomar decisões por si próprios. Neste modelo, existe uma direção na implementação, partindo desde a disponibilização de dados de qualidade até o empoderamento dos stakeholders envolvidos em seu consumo. Além disso, o estabelecimento dos três primeiros pilares permite a obtenção do empoderamento dos cidadãos - que é o objetivo do governo aberto, de acordo com este arcabouço.

O’Reilly (2011) também traz uma abordagem teórica sobre os condicionantes para a viabilização do governo aberto. Para o autor, o primeiro passo é haver a ampla publicação de dados governamentais na Web; em seguida deve haver a melhoria sistemática da qualidade dos dados publicados. A partir desses dados amplos e de qualidade, é necessário instituir uma cultura de governo aberto, em que os stakeholders envolvidos sejam capacitados e encorajados a adotar estas práticas. Por fim, a criação de políticas para a promoção e o desenvolvimento do governo aberto.

Dados abertos e governo aberto são conceitos relacionados, mas diferentes entre si. Os dados abertos são um dos principais componentes do governo aberto. Ao permitir a publicação e reuso de forma gratuita e em formato legível por máquinas, os dados abertos dão suporte à efetividade da participação, colaboração e transparência - alguns dos fatores que definem o conceito de governo aberto. Tornar informações governamentais públicas passou a ser considerado um direito humano e civil, de acordo com o compromisso definido pelos Objetivos de 
Desenvolvimento do Milênio (NAÇÕES UNIDAS, 2000b, p.7). A intersecção de ambos - os dados abertos governamentais - pode ser considerada tanto uma filosofia quanto um conjunto crescente de políticas para promover a transparência, a responsabilização e a criação de valor ao tornar dados governamentais disponíveis para o público (OECD, 2017).

Esse conceito também aborda a publicação de dados de setores públicos em formatos interoperáveis e padronizados, de modo a facilitar o acesso aos dados para os cidadãos, de preferência utilizando padrões e arquiteturas abertas (THOMPSON; FISHENDEN, 2013) e alterando o relacionamento dos cidadãos para com o governo, almejando os princípios democráticos que implicam o direito do cidadão de participar coletivamente ou individualmente na governança de seu território (JANICES; AGUERRE, 2013). O reuso desses dados carrega a promessa do desenvolvimento de produtos e serviços com benefícios econômicos e sociais (VICKERY, 2011). Eaves (2009) propôs 3 leis básicas sobre dados abertos governamentais:

- Se o dado não pode ser encontrado e indexado na Web, ele não existe;

- Se não estiver aberto e disponível em formato compreensível por máquina, ele não pode ser reaproveitado;

- Se algum dispositivo legal não permitir sua replicação, ele não é útil.

Os dados abertos governamentais apresentam 8 princípios básicos, estabelecidos mediante consenso de especialistas (OGD, 2012):

- Completos: todos os dados públicos são disponibilizados, exceto os que apresentem limitações reguladas de privacidade, segurança e controle de acesso;

- Primários: os dados devem ser publicados na forma coletada na fonte, com a granularidade mais fina possível, de forma não agregada ou transformada;

- Atualizados: os dados devem ser disponibilizados com a rapidez necessária para preservar o seu valor;

- Acessíveis: os dados são disponibilizados para um público o mais amplo possível e para propósitos os mais variados possíveis;

- Processáveis por máquina: os dados são razoavelmente estruturados para possibilitar o seu processamento automatizado;

- Não discriminatórios: dados disponíveis a todos os cidadãos, sem que seja necessária identificação ou registro para acessá-los;

- Não proprietários: os dados devem estar em formatos sobre os quais nenhum ente tenha controle exclusivo; 
- Licenças não restritivas: os dados não estão sujeitos a regulações de propriedade intelectual (patentes, marcas, direito autoral), mas somente a restrições razoáveis de privacidade, segurança e controle de acesso.

Esses 8 princípios originais foram estendidos para conter outros 7 ((OGD, 2012)): i) on-line e gratuitos: os dados devem estar na Web sem custo, ou ao menos com um pequeno custo marginal para sua reprodução; ii) permanentes: devem estar disponíveis em locais estáveis na Web por tempo indefinido; iii) confiáveis: conteúdos publicados devem estar assinados digitalmente, de modo a garantir que não foram alterados desde que foram publicados; iv) presunção de abertura: informações públicas devem ser disponibilizadas proativamente e ao alcance do público (on-line), sem barreiras para seu consumo; v) documentados: informações sobre o formato e o significado dos dados devem estar presentes; vi) seguros: deve se fazer uso de formato de dados que não inclua conteúdos executáveis; vii) projetado com feedback público: dados devem ser apurados conforme aplicações que o público faz dos dados.

Os dados abertos, com o suporte da tecnologia, podem ser fornecidos em grande quantidade e em formatos que podem ser processados por computadores pessoais comuns, de modo que possam ser analisados, comparados e combinados a partir de múltiplas fontes de dados. Isso aumenta a capacidade de tomadores de decisão, cientistas, empreendedores, imprensa e cidadãos de encontrarem soluções para problemas complexos.

Governos de todo o mundo, principalmente na última década, têm concentrado esforços na disponibilização de dados para a sociedade seguindo a filosofia dos dados abertos - ou seja, acessíveis para qualquer cidadão, sem restrições de uso. Esse movimento tem por motivação benefícios como: aumento da transparência e da responsabilização democrática; apoio ao crescimento econômico, ao estimular a criação de novos serviços e produtos baseados em dados; e aprimoramento de como os serviços públicos são disponibilizados (JANSSEN; CHARALABIDIS; ZUIDERWIJK, 2012). No entanto, diversos fatores contribuem para que essa visão ainda não tenha sido alcançada. Do ponto de vista tecnológico, podemos citar os diferentes formatos de dados, a ausência de dados legíveis por máquinas, a ausência de metadados, dentre outros (JANSSEN; CHARALABIDIS; ZUIDERWIJK, 2012; NEUMAIER; UMBRICH; POLLERES, 2016).

A abordagem de dados conectados (linked data) permite tratar problemas desse tipo. No contexto de administração pública, a intenção é termos esses dados também no formato aberto (com licença de uso de dados disponível), tendo assim os dados abertos conectados (do inglês linked open data, LOD) (ISOTANI; BITTENCOURT, 2015). Trata-se de boas práticas para publicar e conectar conjuntos de dados estruturados na Web, formando assim uma "Web de dados", reaproveitando a infraestrutura da Web e também tecnologias semânticas já consolidadas (BIZER; HEATH; BERNERS-LEE, 2009). A partir dessas tecnologias é possível tornar mais simples a conexão entre diferentes bases de dados concebidas de forma isolada, proporcionando uma contextualização maior dos dados e análises mais ricas. A Figura 4 ilustra como os conceitos 
descritos nesta seção estão relacionados entre si, enfatizando o foco desta tese - os dados abertos governamentais conectados.

Figura 4 - Relacionamentos entre os conceitos básicos de dados abertos governamentais conectados.

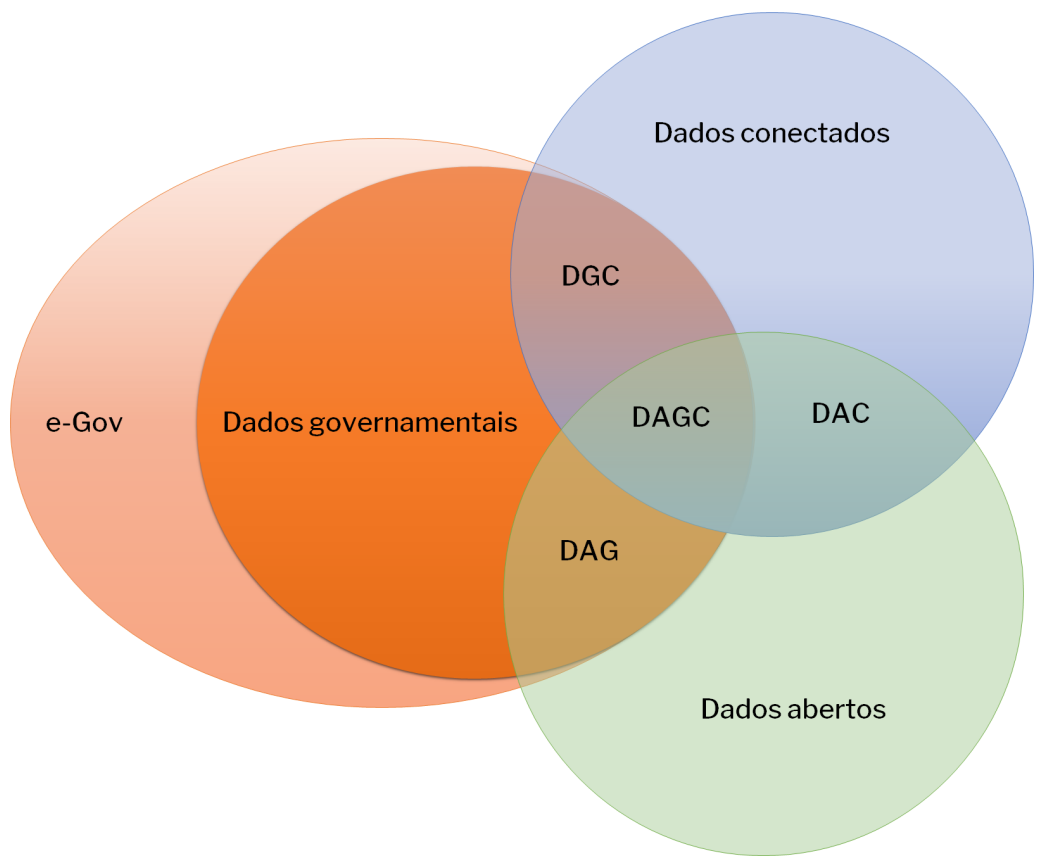

Fonte: Adaptada de Attard et al. (2015).

\subsubsection{Definição de requisitos dos dados}

A partir dos principais conceitos envolvidos com a publicação de DAGC, foram levantados requisitos funcionais e não-funcionais que precisam ser atendidos pelo processo para os atingir os dados resultantes. Assim, de forma indireta, o modelo de processo proposto também deve implementá-los e validá-los de forma sistemática para garantir sua manutenção ao final. Esta seção formaliza os principais requisitos encontrados para que dados abertos governamentais conectados sejam plenamente atendidos. Nesta tese, o escopo dos requisitos diz respeito aos aspectos que o produto deve ter e, por consequência, como o processo de publicação deve ser modelado para que permita que os dados tenham essas características.

O Quadro 3 lista os requisitos funcionais e não-funcionais encontrados dentre os aspectos conceituais analisados. Aqui, requisitos funcionais são tratados como os requisitos que definem a funcionalidade específica e que mostram como um artefato pode ser usado, ao passo que requisitos não-funcionais especificam critérios que podem ser usados para julgar a operação do sistema, em vez de comportamentos específicos (STELLMAN; GREENE, 2005). É apresentada uma compilação de requisitos que são, de alguma forma, concretizáveis por meio de tecnologia ou cuja atividade esteja sob o controle do processo de publicação. Por exemplo, o princípio número 2 dos DAG diz que os "dados devem ser primários, no maior nível de granularidade”, no 
entanto isso depende de que a alta gestão libere os dados neste formato e não de uma decisão de design ou do processo em si.

Quadro 3 - Lista de requisitos levantados e compilados da literatura de DAGC.

\begin{tabular}{|c|c|}
\hline $\begin{array}{l}\text { Conceito } \\
\text { Dados abertos }\end{array}$ & $\begin{array}{l}\text { Requisitos } \\
\text { - Acesso livre } \\
\text { - Preservar proveniência dos dados } \\
\text { - Permissão sobre o (re)uso dos dados }\end{array}$ \\
\hline Governo aberto & $\begin{array}{l}\text { - Garantia da qualidade da informação (transparência) } \\
\text { - Acessibilidade à informação (transparência) } \\
\text { - Privacidade (prestação de contas) } \\
\text { - Segurança no acesso aos dados (prestação de contas) } \\
\text { - Padronização dos dados (prestação de contas) } \\
\text { - Comunicação com sociedade (colaboração) } \\
\text { - Feedback (colaboração) } \\
\text { - Tomada de decisão pelo governo (colaboração) } \\
\text { - Tomada de decisão pelo cidadão (empoderamento) } \\
\text { - Uso de arquiteturas abertas }\end{array}$ \\
\hline $\begin{array}{l}\text { Dados abertos gover- } \\
\text { namentais }\end{array}$ & $\begin{array}{l}\text { - Dados devem estar disponíveis em volume } \\
\text { - Dados disponíveis na Web } \\
\text { - Dados publicados com protocolos e formatos padrão } \\
\text { - Dados acessíveis diretamente, sem passar por formulários de } \\
\text { registro ou outras restrições tecnológicas } \\
\text { - Dados devem estar disponíveis em formatos não proprietários } \\
\text { - Dados devem estar em formatos processáveis por máquinas } \\
\text { - Dados devem ser facilmente encontrados } \\
\text { - Dados devem ser permanentes pelo máximo de tempo possível } \\
\text { - Dados devem estar assinados eletronicamente } \\
\text { - Dados devem estar indexados na Web } \\
\text { - Dados em formatos legíveis por máquinas } \\
\text { - Dados devem ter licença de uso explícitas } \\
\text { - Dados devem estar on-line } \\
\text { - Dados devem ser confiáveis } \\
\text { - Dados devem estar documentados } \\
\text { - Dados devem ser seguros para abrir } \\
\text { - Dados devem ser projetados com feedback público }\end{array}$ \\
\hline
\end{tabular}




\begin{tabular}{|l|l|}
\hline Conceito & Requisitos \\
\hline Dados conectados & - Usar identificadores globais \\
& - Disponibilizar recursos na Web \\
& - Usar padrões da Web ao acessar recursos \\
& - Incluir links para outros dados \\
& - Dados com licença de uso \\
& - Dados estruturados \\
& - Dados em formato não proprietário \\
& - Dados em formato semântico, anotados com vocabulários ou \\
& ontologias \\
\hline
\end{tabular}

Fonte: Elaborada pelo autor.

Essa listagem ajuda a responder à QP2, que trata dos requisitos que devem ser atendidos para o projeto de um processo de publicação de DAGC, ao concretizar os princípios dos construtos envolvidos na concepção dos DAGC. Outros construtos sobre o escopo de processos de publicação de DAGC podem ser incorporados, bem como outras definições sobre os construtos adotados; no entanto, acreditamos que o acréscimo de requisitos desta lista resultará em redundâncias. A reprodutibilidade por outros pesquisadores é esperada ao se adotar os mesmos construtos. No entanto, isto depende de como eles descrevem e concretizam os princípios em requisitos, podendo levar a um conjunto diferente de requisitos.

\subsubsection{Definição de requisitos do processo}

Tão importante quanto definir como deve ser o produto gerado pela metodologia é definir quais são os aspectos que a própria metodologia deve conter. Kucera (2014) apresenta uma lista com 22 requisitos, listados na Quadro 4, levantados a partir da especificação de barreiras e impedimentos para a publicação de DAG. Estes foram usados para o design do modelo de ciclo de vida de publicação de DAGC.

Quadro 4 - Lista de requisitos para um processo de publicação de DAGC.

\begin{tabular}{|l|l|l|}
\hline ID & Requisito & Descrição \\
\hline RQ1 & Definição de papéis & $\begin{array}{l}\text { A metodologia deve especificar papéis e suas responsabili- } \\
\text { dades nas atividades e tarefas relacionadas à publicação, de } \\
\text { modo a assegurar que esteja especificado claramente quem é } \\
\text { responsável pelo quê durante o processo. }\end{array}$ \\
\hline RQ2 & $\begin{array}{l}\text { Avaliação da de- } \\
\text { manda por DAG }\end{array}$ & $\begin{array}{l}\text { A metodologia deve fornecer diretrizes de como avaliar a } \\
\text { demanda por DAG, de modo a focar conjuntos de dados de } \\
\text { maior demanda pelos usuários potenciais. }\end{array}$ \\
\hline
\end{tabular}




\begin{tabular}{|c|c|c|}
\hline ID & 0 & \\
\hline RQ3 & $\begin{array}{l}\text { Seleção e priorização } \\
\text { de conjuntos de da- } \\
\text { dos }\end{array}$ & $\begin{array}{l}\text { Setores públicos possuem muitos conjuntos de dados. A } \\
\text { metodologia deve fornecer diretrizes para identificar e se- } \\
\text { lecionar conjuntos de dados para abertura. Pode não ser } \\
\text { possível publicar todos os conjuntos, então recomendações } \\
\text { sobre priorização também devem ser fornecidas. }\end{array}$ \\
\hline RQ4 & $\begin{array}{l}\text { Avaliação dos benefí- } \\
\text { cios dos DAG }\end{array}$ & $\begin{array}{l}\text { A metodologia deve fornecer explicação dos benefícios típi- } \\
\text { cos dos DAG e recomendações para sua avaliação. }\end{array}$ \\
\hline RQ5 & $\begin{array}{l}\text { timativa de esfor- } \\
\text { s e custos }\end{array}$ & $\begin{array}{l}\text { Recomendações sobre esforços e custos devem ser forneci- } \\
\text { das pela metodologia, de modo a apoiar a gestão de recursos } \\
\text { e suporte financeiro. }\end{array}$ \\
\hline RQ6 & $\begin{array}{l}\text { Recomendações so- } \\
\text { bre taxas }\end{array}$ & $\begin{array}{l}\text { A metodologia deve discutir as questões de coleta de taxas } \\
\text { para os dados em oposição a fornecê-los gratuitamente, de } \\
\text { modo a alinhar a publicação de DAG com princípios aplicá- } \\
\text { veis de cobrança. }\end{array}$ \\
\hline RQ7 & $\begin{array}{l}\text { aderên- } \\
\text { ão }\end{array}$ & $\begin{array}{l}\text { A metodologia deve fornecer diretrizes sobre a análise de } \\
\text { legislação aplicável e as possíveis limitações à publicação } \\
\text { de conjuntos de dados particulares, de modo a garantir a } \\
\text { aderência a legislações. }\end{array}$ \\
\hline RQ8 & & $\begin{array}{l}\text { lologia deve discutir a gestão de riscos e f } \\
\text { ações de como lidar com suas possíveis oc }\end{array}$ \\
\hline RQ9 & & $\begin{array}{l}\text { A metodologia deve fornecer recomendações sobre como } \\
\text { licenciar os dados abertos e como informar os usuários sobre } \\
\text { os termos das licenças, garantindo a abertura legal dos dados. }\end{array}$ \\
\hline RQ10 & $\begin{array}{l}\text { Reuso de conjuntos } \\
\text { de dados já publica- } \\
\text { dos }\end{array}$ & $\begin{array}{l}\text { A metodologia deve fornecer recomendações sobre como } \\
\text { publicadores de DAG podem reusar dados já publicados, } \\
\text { bem como informar sobre a existência dos portais de dados, } \\
\text { de modo a evitar publicações duplicadas. }\end{array}$ \\
\hline RQ11 & $\begin{array}{l}\text { Formatos de dados } \\
\text { recomendados }\end{array}$ & $\begin{array}{l}\text { A metodologia deve recomendar formatos de dados e dire- } \\
\text { trizes para sua aplicação para garantir que os dados sejam } \\
\text { tecnicamente abertos. }\end{array}$ \\
\hline RQ12 & $\begin{array}{l}\text { Interligação de con- } \\
\text { juntos de dados rela- } \\
\text { cionados }\end{array}$ & $\begin{array}{l}\text { Para aumentar o valor de conjuntos de dados relacionados, a } \\
\text { metodologia deve fornecer recomendações para a publicação } \\
\text { de dados conectados e como conectá-los. }\end{array}$ \\
\hline RQ13 & $\begin{array}{l}\text { Avaliação de im- } \\
\text { pacto das TIC }\end{array}$ & $\begin{array}{l}\text { A publicação dos DAG pode exigir mudanças na infraestru- } \\
\text { tura de TIC e sistemas. Assim, a avaliação de impacto deve } \\
\text { ser levada em conta. }\end{array}$ \\
\hline
\end{tabular}




\begin{tabular}{|c|c|c|}
\hline ID & Requisito & Descrição \\
\hline RQ14 & $\begin{array}{l}\text { Processo de publica- } \\
\text { ção de DAG }\end{array}$ & $\begin{array}{l}\text { O processo de publicação e recomendações para sua execu- } \\
\text { ção devem ser incluídos na metodologia, de modo a garantir } \\
\text { que cada ator envolvido saiba quais passos devem ser execu- } \\
\text { tados. }\end{array}$ \\
\hline RQ15 & $\begin{array}{l}\text { Catalogação de da- } \\
\text { dos }\end{array}$ & $\begin{array}{l}\text { Devem ser fornecidas diretrizes de catalogação de dados } \\
\text { junto com esquemas de metadados recomendados, para ga- } \\
\text { rantir que os dados publicados sejam facilmente encontrados, } \\
\text { e que as informações sejam compreendidas com seus esque- } \\
\text { mas e sua semântica. }\end{array}$ \\
\hline RQ16 & $\begin{array}{l}\text { Garantia da quali- } \\
\text { dade de dados }\end{array}$ & $\begin{array}{l}\text { A metodologia deve fornecer diretrizes de modo a atender } \\
\text { os requisitos de qualidade de dados. }\end{array}$ \\
\hline RQ17 & $\begin{array}{l}\text { Garantia de acesso } \\
\text { simplificado aos con- } \\
\text { juntos de dados }\end{array}$ & $\begin{array}{l}\text { A metodologia deve discutir as barreiras comuns para o } \\
\text { acesso aos conjuntos de dados, incluindo a aplicação da } \\
\text { exigência do registro de usuários nos portais de dados. }\end{array}$ \\
\hline RQ18 & $\begin{array}{l}\text { Manutenção dos con- } \\
\text { juntos de dados }\end{array}$ & $\begin{array}{l}\text { A manutenção dos dados deve ser tratada pela metodologia } \\
\text { para assegurar que os conjuntos de dados sejam atualizados } \\
\text { regularmente. }\end{array}$ \\
\hline RQ19 & $\begin{array}{l}\text { Estratégia de comu- } \\
\text { nicação }\end{array}$ & $\begin{array}{l}\text { Recomendação de como desenvolver uma estratégia de co- } \\
\text { municação. Essa estratégia deve definir como o feedback dos } \\
\text { usuários serão processados, como os DAG serão promovidos } \\
\text { e como as atividades de DAG serão alinhadas com outras } \\
\text { atividades do órgão. }\end{array}$ \\
\hline RQ20 & $\begin{array}{l}\text { Independência do } \\
\text { portal de dados } \\
\text { central }\end{array}$ & $\begin{array}{l}\text { As recomendações e práticas descritas na metodologia de- } \\
\text { vem ser independentes do portal de dados nacional central. }\end{array}$ \\
\hline RQ21 & $\begin{array}{l}\text { Softwares recomen- } \\
\text { dados }\end{array}$ & $\begin{array}{l}\text { De modo a facilitar a seleção de ferramentas de software } \\
\text { apropriadas para a publicação de DAG, a metodologia deve } \\
\text { fornecer uma lista de ferramentas recomendadas. }\end{array}$ \\
\hline RQ22 & $\begin{array}{l}\text { Órgãos públicos de } \\
\text { diferentes tamanhos } \\
\text { devem ser levados } \\
\text { em conta }\end{array}$ & $\begin{array}{l}\text { O setor público consiste de diferentes órgãos. Os peque- } \\
\text { nos podem ter recursos muito limitados para a publicação } \\
\text { de DAG. Assim, o tamanho desses setores deve ser levado } \\
\text { em conta ao se formular recomendações de metodologia de } \\
\text { publicação de DAG. }\end{array}$ \\
\hline
\end{tabular}

Fonte: adaptado de Kučera (2014).

Dentre os requisitos citados na Quadro 4, nem todos se encaixam no escopo desta tese. Alguns requisitos são voltados para a gestão de DAG, como RQ4 (avaliação de benefícios), 
RQ5 (estimativa de esforços e custos), RQ6 (recomendações sobre taxas), RQ8 (análise de riscos), RQ13 (avaliação de impacto nas TICs) e RQ20 (independência de portal central). Outros competem às políticas definidas nacionalmente para a seleção dos conjuntos de dados (RQ2 avaliação da demanda e RQ3 - seleção de conjuntos de dados). Outros, ainda, são naturalmente adotados pelo escopo de dados conectados (RQ10 - reuso de dados, RQ11 - formatos de dados, RQ12 - interligação de conjuntos de dados relacionados). Deste modo, foram considerados os requisitos apresentados no Quadro 5 para a modelagem do ciclo de vida proposto nesta tese.

Quadro 5 - Requisitos mínimos para um processo de publicação de DAGC.

\begin{tabular}{|l|l|}
\hline Unidade & Requisitos \\
\hline Processo & - Definir papéis (RQ1) \\
& - Garantir conformidade com legislação (RQ7) \\
& - Licenciamento dos dados (RQ9) \\
& - Especificar processo de publicação (RQ14) \\
- Catalogar os dados (RQ15) \\
- Garantir a qualidade dos dados (RQ16) \\
- Garantir acesso simplificado aos dados (RQ17) \\
- Garantir a manutenção dos dados (RQ18) \\
- Fornecer estratégias de comunicação (RQ19) \\
- Recomendar softwares (RQ21) \\
- Considerar diferentes tamanhos de publicadores de da- \\
dos (RQ22) \\
\hline
\end{tabular}

Fonte: Elaborada pelo autor.

No próximo capítulo é apresentado o estado da arte reportado na literatura em metodologias de produção de dados abertos governamentais conectados, de modo a identificar as lacunas existentes entre as metodologias desenvolvidas e documentadas na literatura e como algumas delas são abordadas nesta tese. 


\section{ESTADO DA ARTE E DA PRÁTICA}

Com a adoção de políticas públicas de disponibilização de dados se tornando parte da agenda de governos em todo o mundo, novas metodologias e processos têm sido propostos para a produção de dados abertos governamentais conectados; porém a quantidade de DAGC ainda é relativamente baixa. Neste capítulo, buscamos contextualizar e explorar como os DAG(C) se desenvolveram e quais metodologias foram propostas para sua produção. Além disso, o capítulo cobre o estado da arte sobre metodologias de produção de DAGC de modo a se obter uma visão geral do processo de produção dos dados e para melhor compreender como os dados têm sido produzidos, de acordo com a literatura. São apresentados o estado da arte em metodologias de publicação de DAGC, obtido por meio de mapeamento sistemático, assim como o estado da prática, com o mapeamento de ações e estruturação da publicação de DAG no âmbito federal brasileiro.

Na Seção 3.1 descrevemos o planejamento e a condução de um mapeamento sistemático da literatura para investigar metodologias que foram propostas e usadas para apoiar a produção de DAGC. O objetivo é caracterizar as abordagens aplicadas na produção de DAGC propostos na literatura, identificando seus pontos em comum e limitações.

Na Seção 3.2 adotamos uma perspectiva histórica e organizacional da adoção dos dados abertos governamentais no Brasil e ilustramos como ela se amadureceu ao longo das últimas décadas. O objetivo é de caracterizar o desenvolvimento dos DAG no contexto brasileiro, identificando quais são seus arranjos organizacionais e como ele se desenvolveu junto a outros países, até a produção de DAGC.

$\mathrm{Na}$ Seção 3.3 focamos em um recorte dos dados para diagnosticar como esses dados em nível federal adotam algumas das práticas mais recentes de compartilhamento de dados nas Web.

Na Seção 3.4 reportamos quais foram as iniciativas brasileiras para publicação de dados em formato conectado. 


\subsection{Mapeamento sistemático de metodologias de produ- ção de DAGC}

Alinhado ao objetivo desta tese, de propor um modelo de processo de produção de DAGC, foi levantado o estado da arte em metodologias, processos e ciclos de vida relacionados a esse domínio. Esta seção fornece uma visão geral sobre metodologias de produção de DAGC presentes na literatura. $\mathrm{O}$ objetivo é de identificar quais práticas têm sido adotadas e utilizadas pelas diferentes propostas, que ferramental foi proposto, como elas foram avaliadas e quais mecanismos de controle de qualidade foram propostos.

O mapeamento conduzido nesta tese seguiu um paradigma baseado em evidências, mais especificamente um mapeamento sistemático. Esta abordagem foi escolhida pois mostra-se mais adequado quando o objetivo é o de se obter uma visão geral de uma área de pesquisa, identificando as pesquisas realizadas e os resultados disponíveis nesta área (PETERSEN et al., 2008). Esse paradigma tem sido aplicado a diferentes áreas de conhecimento e, mais recentemente, à área de engenharia de software, para fornecer sínteses sobre questões de "quando", "como" e "em que contexto" certas tecnologias, métodos, processos e ferramentas são mais adequados dentro das práticas da comunidade (KITCHENHAM; CHARTERS, 2007).

Um mapeamento sistemático fornece "um procedimento sistemático e objetivo para identificar a natureza e a extensão dos dados de estudos empíricos que estão disponíveis para responder uma questão de pesquisa em particular" (BUDGEN et al., 2008). Neste caso, a questão de pesquisa é mais ampla do que específica - como é o caso de uma revisão sistemática. $\mathrm{O}$ objetivo é mapear os estudos dentro de uma área de pesquisa em vez de fornecer informações detalhadas sobre uma questão de pesquisa ou fenômeno de interesse (PETERSEN et al., 2008). Para isso, o mapeamento sistemático é formalmente planejado, apresentando fases bem definidas de modo a evitar vieses e produzir pesquisa com significância científica. Pelo outro lado, ao se adotar estratégias mais rigorosas, ela exige maior esforço e tempo para ser conduzida.

\subsubsection{Objetivos e questões de pesquisa}

O objetivo geral deste mapeamento foi identificar formas de publicação de DAC no contexto governamental, tanto para as atividades envolvidas quanto para as ferramentas desenvolvidas para apoiá-las. Trata-se de uma contribuição importante para a comunidade científica e de praticantes desta área, ao descrever o que foi feito e as lacunas a serem investigadas para melhores práticas na produção de DAGC. Em particular, foi de interesse investigar quais os passos que têm sido adotados especialmente em relação ao controle da qualidade, visto que este é um ponto ainda a ser desenvolvido na área de publicação de DAGC. Outro ponto importante investigado foi o de levantar qual foi o rigor dos métodos de avaliação aplicados em estudos deste tipo.

Para isso foram definidas as seguintes questões de pesquisa: 
- QP1: Quais são os passos em comum entre as diferentes metodologias propostas?

- QP2: Como essas metodologias foram avaliadas empiricamente?

- QP3: Que ferramentas e vocabulários foram usados ou recomendados para apoiar esses passos?

- QP4: Que tipos de validação foram empregadas para garantir práticas de qualidade de dados?

A resposta a estas questões fornecem uma visão geral da literatura relevante, com os passos importantes para sugerir um arcabouço metodológico claro para a publicação de DAGC.

\subsubsection{Bases de dados e estratégias de busca}

As seguintes fontes de dados foram selecionadas neste mapeamento sistemático, uma vez que são talvez os repositórios mais significativos em assuntos que envolvem a Ciência da Computação: ACM Digital Library ${ }^{1}$, IEEE Explore ${ }^{2}$, Science Direct ${ }^{3}$, Springer Link ${ }^{4}$, ISI Web of Knowledge ${ }^{5}$ e Scopus $^{6}$.

Os termos-chave identificados foram metodologia, publicação e dados abertos governamentais conectados. O Quadro 6 apresenta uma string de busca genérica gerada a partir da combinação dos termos e seus sinônimos, definidos para este estudo, usando operadores booleanos e no idioma inglês. As strings foram adaptadas para cada mecanismo de busca das fontes de dados.

Quadro 6 - Termos usados para a busca.

(methodology OR process OR pipeline OR guideline OR "best practices"OR framework )

( publishing OR publication OR production OR opening )

( "linked government data"OR "linked open government data"OR "government linked data"OR "government open linked data"OR ( "open government"AND( "linked data"OR "linked open data") ) )

Fonte: Elaborada pelo autor.

\footnotetext{
$<\mathrm{https} / / / \mathrm{dl} . \mathrm{acm} . \mathrm{org} />$

$<$ https://ieeexplore.ieee.org/Xplore/home.jsp $>$

$<\mathrm{https}: / / \mathrm{www}$. sciencedirect.com/search/advanced $>$

$<$ https://link.springer.com/>

$<$ https://www.webofknowledge.com>

$<$ https://www.scopus.com/search/form.uri?display=basic $>$
} 


\subsubsection{Seleção dos estudos}

A seleção dos estudos deve refletir os trabalhos primários com o propósito de identificar diferentes tipos de métodos usados para publicar DAGC. Para isso, elaboramos os seguintes critérios de inclusão:

- O estudo apresenta um método para publicar dados conectados no âmbito governamental como sua principal contribuição;

- O estudo está presente em um veículo revisado por pares;

- A linguagem do estudo é o inglês;

- O texto do trabalho está disponível, mesmo que mediante contato direto com os autores.

Os critérios de exclusão adotados foram os seguintes:

- O estudo não apresenta um método para publicação de DAGC;

- O estudo é uma versão prévia de um outro estudo retornado;

- O estudo foca na aplicação de DAC em um domínio específico;

- O estudo investiga somente um passo do processo como um todo;

- O estudo não investiga dados conectados, mas dados abertos mais genericamente.

Mapeamentos sistemáticos podem trazer diferentes ameaças à validade (ZHOU et al., 2016). A string de busca foi composta por 3 termos-chave e o uso de sinônimos foi baseado em análise textual de textos completos de artigos relacionados. Alguns desses termos foram de difícil especificação, pois a ordem de alguns termos era diferente ou alguns termos omitidos. Para garantir a qualidade dos resultados, usamos os estudos descritos na recomendação da W3C Linked Data Best Practices (W3C, 2014a) como controle para refinar a string de busca, ao garantir que eles eram retornados. Alguns trabalhos não estavam disponíveis nas bases de dados, e para esses casos, buscamos na Web por uma cópia e, na sua ausência, os autores foram contatados para tentar obter uma cópia; no entanto, algumas vezes não foi possível.

A seleção dos estudos primários foi conduzida em maio de 2019. Nos casos em que múltiplos artigos sobre um mesmo projeto em diferentes estados de maturidade foram retornados, foram selecionados apenas os mais recentes - que, obviamente, estivessem relacionados ao assunto. A Figura 5 mostra o procedimento adotado e as quantidades processadas. Inicialmente, foram aplicadas as string concretas, adaptada a cada fonte de dados. A seguir, os artigos duplicados foram removidos. Em seguida, foram aplicados os critérios de inclusão e exclusão para cada estudo, considerando o título, resumo e, quando ainda em dúvida, o texto completo. Finalmente, em posse do conjunto final, foram extraídos os dados para responder às questões de pesquisa. 
Figura 5 - Procedimento para selecionar os trabalhos primários de produção de DAGC.

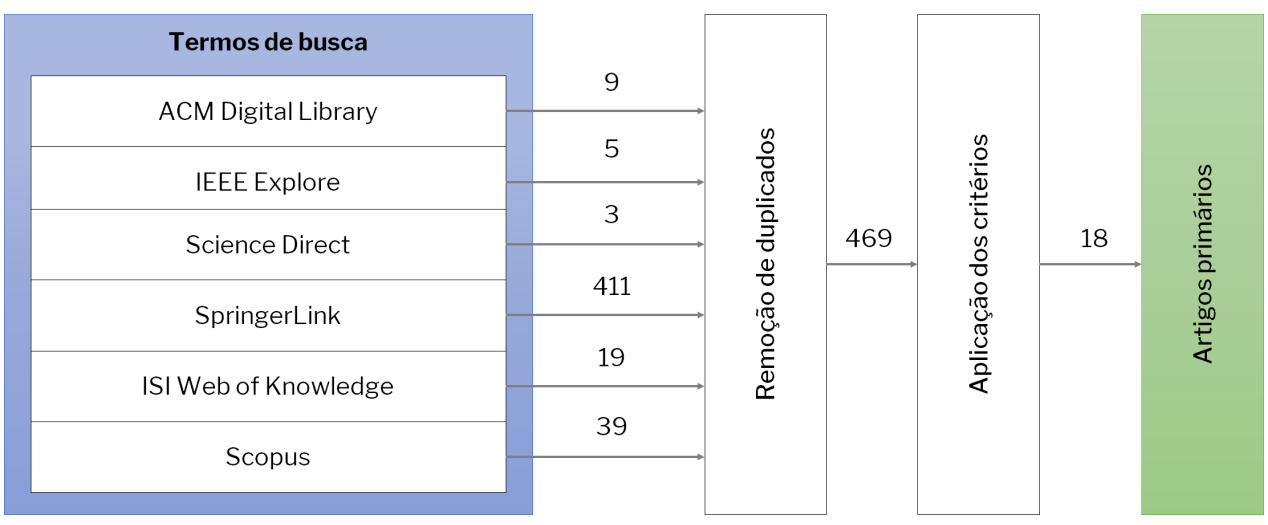

Fonte: Elaborada pelo autor.

\subsubsection{Análise dos dados e resultados}

A seleção final resultou em 18 trabalhos primários, com datas de publicação entre 2011 e 2019, que foram utilizados para extrair informações em relação às questões de pesquisa. O Quadro 7 apresenta os trabalhos selecionados. Em seguida, as questões de pesquisa são respondidas com base nos dados extraídos dos artigos.

A seguir, mostramos a síntese dos trabalhos em torno das questões de pesquisa colocadas.

QP1: Quais são os passos em comum entre as diferentes metodologias propostas?

Esta questão de pesquisa teve por objetivo mapear quais são os pontos em comum e diferenças entre as diferentes metodologias que foram propostas. Um desafio foi o de encontrar a granularidade adequada para isso. A maioria dos estudos dividiu suas tarefas em fases e, por sua vez, em passos mais atômicos, com saídas mais concretas. Para analisar esses dados, foram mapeadas todas as atividades que foram explicitamente descritas como um passo importante nos trabalhos, criando uma matriz de passos e estudos, conforme ilustrado na Quadro 8. Cada atividade é marcada com um "X"caso o estudo (nas colunas) tenha mencionado-a explicitamente no artigo. 
Quadro 7 - Conjunto final de trabalhos primários extraídos do mapeamento da literatura.

\begin{tabular}{|c|c|c|}
\hline ID & Título & Referência \\
\hline W1 & Opening data for global health & $\begin{array}{l}\text { (LAESSIG; JACOB; ABOU- } \\
\text { ZAHR, 2019) }\end{array}$ \\
\hline W2 & $\begin{array}{l}\text { UnBGOLD: UnB government open linked data: } \\
\text { semantic enrichment of open data tool }\end{array}$ & (MARTINS et al., 2018) \\
\hline W3 & Linking of Open Government Data & (FLEINER, 2018) \\
\hline W4 & $\begin{array}{l}\text { RDF Dataset Management Framework for } \\
\text { Data.go.th }\end{array}$ & $\begin{array}{l}\text { (KRATAITHONG; BURANA- } \\
\text { RACH; SUPNITHI, 2018) }\end{array}$ \\
\hline W5 & $\begin{array}{l}\text { Open Government Data: Problem Assessment of } \\
\text { Machine Processability }\end{array}$ & $\begin{array}{l}\text { (ELMEKKI; } \\
\text { LAMHLILA; } \\
\end{array}$ \\
\hline W6 & $\begin{array}{l}\text { A Scalable Framework for Creating Open Govern- } \\
\text { ment Data Services from Open Government Data } \\
\text { Catalog }\end{array}$ & (BURANARACH et al., 2017) \\
\hline W7 & Towards a Linked Data Publishing Methodology & $\begin{array}{l}\text { (KLEIN; GSCHWEND; NEU- } \\
\text { RONI, 2016) }\end{array}$ \\
\hline W8 & $\begin{array}{l}\text { Introduction to linked data and its lifecycle on the } \\
\text { web }\end{array}$ & (NGOMO et al., 2014) \\
\hline W9 & $\begin{array}{l}\text { Semantic Annotation and Publication of Linked } \\
\text { Open Data }\end{array}$ & (SORRENTINO et al., 2013) \\
\hline W10 & $\begin{array}{l}\text { Fusepool R5 linked data framework: concepts, } \\
\text { methodologies, and tools for linked data }\end{array}$ & (KASCHESKY; SELMI, 2013) \\
\hline W11 & $\begin{array}{l}\text { A Lightweight Approach to Semantify Saudi Open } \\
\text { Government Data }\end{array}$ & (AL-KHALIFA, 2013) \\
\hline W12 & Integrating Serbian public data into the LOD cloud & (JANEV et al., 2012) \\
\hline W13 & $\begin{array}{l}\text { Publishing Pipeline for Linked Government Data, } \\
\text { in: The Semantic Web: Research and Applications }\end{array}$ & $\begin{array}{l}\text { (MAALI; CYGANIAK; PE- } \\
\text { RISTERAS, 2012) }\end{array}$ \\
\hline W14 & $\begin{array}{l}\text { The Joy of Data - A Cookbook for Publishing Lin- } \\
\text { ked Government Data on the Web }\end{array}$ & (HYLAND; WOOD, 2011) \\
\hline W15 & $\begin{array}{l}\text { Methodological Guidelines for Publishing Govern- } \\
\text { ment Linked Data }\end{array}$ & $\begin{array}{l}\text { (VILLAZON-TERRAZAS et } \\
\text { al., 2011) }\end{array}$ \\
\hline W16 & $\begin{array}{l}\text { Towards an architecture and adoption process for } \\
\text { linked data technologies in open government con- } \\
\text { texts: a case study for the Library of Congress of } \\
\text { Chile }\end{array}$ & $\begin{array}{l}\text { (CIFUENTES-SILVA; SIFA- } \\
\text { QUI; LABRA-GAYO, 2011) }\end{array}$ \\
\hline W17 & $\begin{array}{l}\text { StdTrip: Promoting the Reuse of Standard Vocabu- } \\
\text { laries in Open Government Data }\end{array}$ & (SALAS et al., 2011) \\
\hline W18 & $\begin{array}{l}\text { Producing and Using Linked Open Government } \\
\text { Data in the TWC LOGD Portal }\end{array}$ & (LEBO et al., 2011) \\
\hline
\end{tabular}




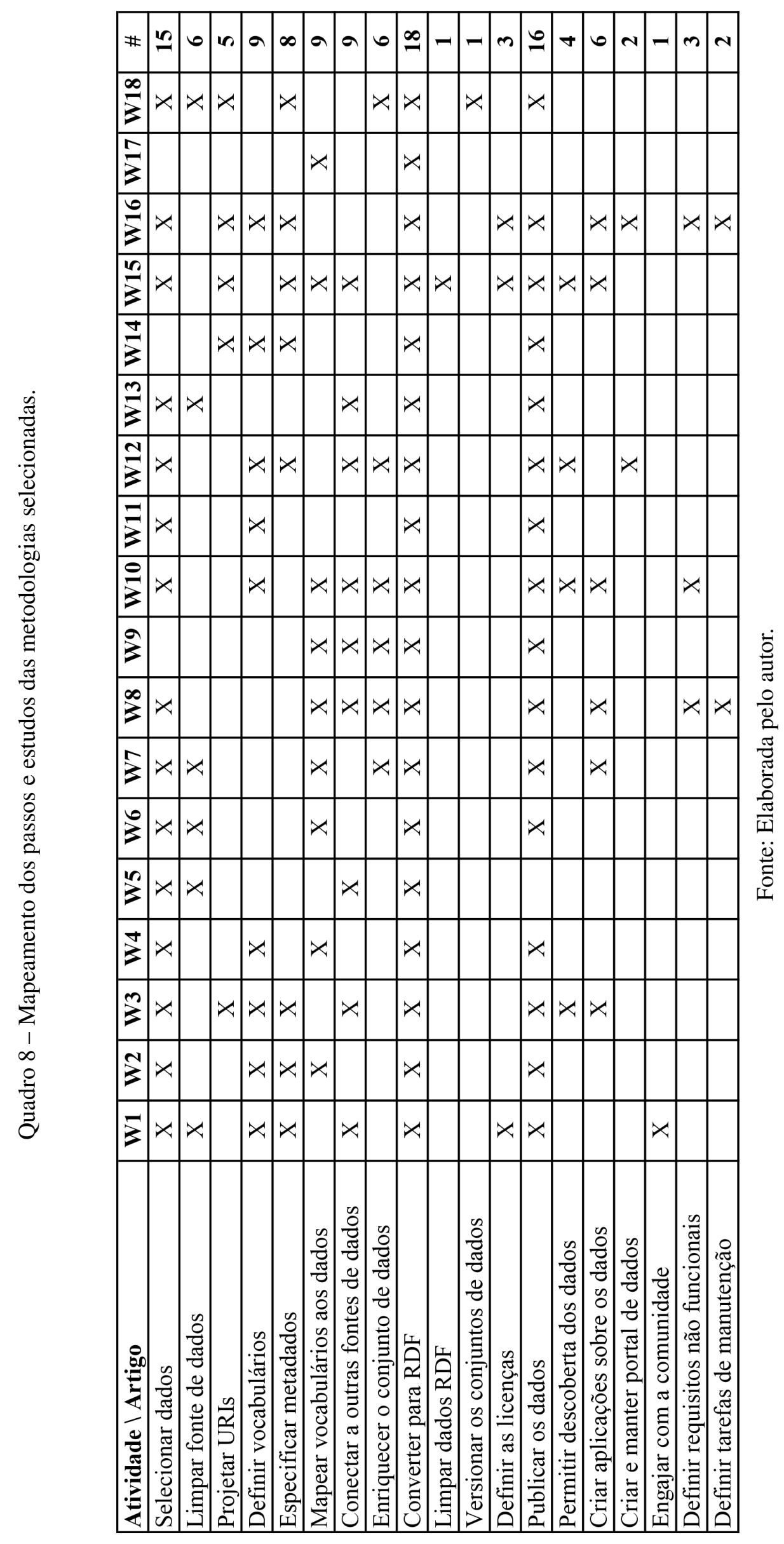


A Quadro 8 lista todas as tarefas explícitas identificadas e o mais próximo possível da ordenação apresentada nos artigos.

O primeiro passo, por vezes implícito, diz respeito à seleção de conjuntos de dados a serem conectados e considera reaproveitar conjuntos de dados existentes ou disponibilizar novos. Em seguida, alguns estudos consideram a limpeza dos dados, de modo a remover inconsistências, erros de digitação ou problemas com a estrutura dos dados. Como um dos pilares é a desreferenciação dos recursos por meio de URIs HTTP, a modelagem cuidadosa de URIs também foi considerada. Um outro passo é a definição de vocabulários, novamente analisando quando se reutilizar vocabulários existentes ou construir novos, dependendo do contexto dos dados. A especificação de metadados - tanto em nível de conjunto de dados quanto para os dados em si - é também considerada como um passo para descrever o que está sendo publicado para consumidores potenciais.

Posteriormente, é realizado o mapeamento cuidadoso dos vocabulários aos dados. Além disso, devem ser indicadas as fontes externas com os quais se quer conectar os dados, tal como a DBpedia ou GeoNames, e o passo de criar essas conexões deve ser executado. Alguns estudos usam essa conexão para realizar o enriquecimento do conjunto de dados original, importando dados de diversas fontes externas. Com todo este material, é executado o passo de transformar dados brutos em RDF.

A conversão de formatos depende do mapeamento manual ou de estruturas inferidas a partir dos dados e podem necessitar de tarefas de limpeza também. Uma vez que os conjuntos de dados e suas distribuições sofrem alterações ao longo do tempo, são necessários mecanismos para manter o rastreamento dessas versões.

Com todos os dados conectados, é necessário disponibilizá-los na Web, para serem reutilizados em portais de dados ou endpoints SPARQL. Este passo pode ser impulsionado ao anunciá-lo em diferentes índices de busca de dados abertos ou mesmo engajar com a comunidade de usuários e consumidores. Alguns estudos apontam para a importância de criar aplicações com os dados, para auxiliar a comunidade a aumentar sua compreensão sobre os dados.

Uma vez publicados, é importante existir um plano para manter tudo funcionando ao longo do tempo. Para isso, os estudos especificam tarefas para manter o portal de dados e definir requisitos não funcionais (como níveis de desempenho ao servir os dados, tempo de atividade, perfis de segurança para acessar os dados etc.) e tarefas de manutenção (por ex.: checagens de disponibilidade dos dados).

Ao observar a última coluna, é possível notar que alguns passos estão muito mais presentes que outros. Em particular, os passos mais básicos são: selecionar os dados, converter para RDF e publicar os dados. Em seguida, definir e mapear os vocabulários. De fato, alguns estudos estão restritos basicamente a esses passos fundamentais (por ex,: W6, W11 e W13), obtendo o quarto nível do esquema de 5 estrelas (BERNERS-LEE, 2006), detalhado no Capítulo 4. 
Em seguida, a interconexão de diferentes fontes de dados, configurando o quinto nível. Um número similar de presença para a especificação dos metadados. Existem atividades mais esparsas, considerando o processo de publicação em um contexto mais amplo, como o versionamento e o licenciamento dos dados, feedback da comunidade e tarefas de manutenção.

\section{QP2: Como essas metodologias foram avaliadas empiricamente?}

Neste trabalho, consideramos as metodologias para publicação de DAGC como artefatos projetados para resolver problemas de um domínio em particular, atingindo conhecimento e compreensão sobre ele, como conceituado pela Design Science Research (HEVNER et al., 2004). Deste modo, usamos a categorização de Peffers et al. (2012), derivada de trabalhos em DSR, para classificar os diferentes métodos de avaliação aplicados nos estudos selecionados.

Como ilustrado no Quadro 9, 39\% dos estudos (7 de 18) não forneceram avaliação empírica, se restringindo a fazer uma lista de passos e recomendações, justificados pelos princípios básicos dos dados conectados e o modelo de 5 estrelas. Metade dos trabalhos ( 9 de 18) foram avaliados em cenários ilustrativos da aplicação da metodologia. Os cenários foram variados, indo desde a visualização de estatísticas meteorológicas (W4) até a catalogação da biblioteca nacional (W16), bem como porções de dados administrativos (ex.: W6, W18). De acordo com este arcabouço, os cenários ilustrativos se diferem dos estudos de caso, pois esse último envolve analisar o impacto da intervenção no ambiente natural. Em nenhum dos artigos foi encontrado o método de estudo de caso como forma de avaliação, ficando restritos a somente provar um conceito. Além disso, dois dos artigos (W2 e W17) focaram-se em mostrar como uma ferramenta pode apoiar o processo de produção dos DAGC, detalhando suas funcionalidades. Deve-se enfatizar que neste trabalho nos focamos na validação explicitada no artigo. Alguns trabalhos foram baseados em experiências prévias dos autores em projetos de DAG ou talvez em validações executadas em outros estágios das pesquisas e que não constam no corpo do texto.

Quadro 9 - Métodos de avaliação aplicados nos estudos selecionados.

\begin{tabular}{|l|l|l|}
\hline Método de avaliação & Descrição & Estudos \\
\hline Cenário ilustrativo & $\begin{array}{l}\text { Aplicação do método em dados reais, } \\
\text { com o objetivo de ilustrar a utilidade do } \\
\text { artefato. }\end{array}$ & $\begin{array}{l}\text { W4, W6, W7, W9, W12, } \\
\text { W13, W16, W18 }\end{array}$ \\
\hline Protótipo & $\begin{array}{l}\text { Implementação de um artefato com o ob- } \\
\text { jetivo de demonstrar a utilidade ou ade- } \\
\text { quação do artefato }\end{array}$ & W2, W17 \\
\hline Argumento lógico & $\begin{array}{l}\text { Um argumento com validade de face, ou } \\
\text { seja, que argumenta subjetivamente o con- } \\
\text { ceito trabalhado, sem validação empírica }\end{array}$ & W1, W3, W5, W8, W10, \\
\hline
\end{tabular}

Fonte: Elaborada pelo autor. 
QP3: Que ferramentas e vocabulários foram usados ou recomendados para apoiar esses passos?

Embora a prescrição de ferramentas não seja obrigatória em uma metodologia, certamente ela oferece um bom ponto de partida para os praticantes, na tomada de decisões como comprar ou construir (buy or build), dentre outros. Como discutido em Konstantinou e Spanos (2015) e Heath e Bizer (2011), trabalhar com conjuntos de dados pequenos e estáticos é uma tarefa que pode ser feita manualmente. Entretanto, em projetos de DAC, especialmente no escopo governamental com conjuntos de dados grandes e diversificados, o uso de ferramentas é necessário para facilitar o esforço de uma maneira automática ou semiautomática. Assim, consideramos que esta é uma fonte importante de informação. Para isso, usamos os mesmos passos identificados na QP1 e mapeamos como cada um dos estudos tratou esses passos. A Quadro 10 mostra o mapeamento de ferramentas e vocabulários usados nos estudos selecionados ${ }^{7}$.

A maior diversidade em ferramentas foi encontrada no passo de conversão dos dados, com muitas ferramentas propostas, usadas ou sugeridas. Neste caso, a escolha de uma ferramenta em particular depende da natureza dos dados. Por exemplo, quando os dados são extraídos diretamente a partir de uma base de dados relacional, a plataforma D2RQ (<http://d2rq.org/>) foi a mais usada. Em outros casos, em que outros formatos de dados são usados, tais como CSV, XML ou JSON, a ferramenta OpenRefine (<http://openrefine.org/>) foi a mais frequentemente utilizada. A maioria dessas ferramentas também fornecem uma funcionalidade que suporta $o$ mapeamento de vocabulários durante a tarefa de converter dados brutos em RDF - por isso a sobreposição de ferramentas em ambas os passos. Para a seleção dos dados, algumas ferramentas foram personalizadas, objetivando extrair dados a partir de um repositório e usá-los como entrada para os próximos passos - assumindo que os conjuntos de dados já foram previamente especificados e estão disponíveis (seja em uma base de dados relacional ou em um catálogo de dados abertos). Para a definição de vocabulários, duas abordagens distintas foram identificadas: ferramentas para buscar vocabulários (como LOV (<https://lov.linkeddata.es/>) e Swoogle (<http: //swoogle.umbc.edu/>)) e ferramentas para criar novos vocabulários, como o Protégé ( $<$ https: //protege.stanford.edu/>), OntoWiki (<http://ontowiki.net/>) e TopBraid Composer (<https: //www.topquadrant.com/products/topbraid-composer/>). Para a limpeza dos dados, o OpenRefine foi usado em dois estudos, junto com outras ferramentas personalizadas. Para o projeto de URIs, nenhuma ferramenta foi usada, mas sim diretrizes, como a diretriz Cool URI ${ }^{8}$, que recomenda práticas de como modelar instâncias de dados usando URIs HTTP. Outras diretrizes foram listadas: Designing URI for the UK Public Sector ${ }^{9}$ e Style Guidelines for Naming and Labeling Ontologies $^{10}$.

\footnotetext{
7 A lista com todas as referências está disponível em: <http://purl.org/caed/tools>

$8<$ <ttps://www.w3.org/TR/2008/NOTE-cooluris-20081203/>

$9<$ https://www.gov.uk/government/publications/designing-uri-sets-for-the-uk-public-sector>

$10<\mathrm{http} / / / \mathrm{dcp} a p e r s . d u b l i n c o r e . o r g / p u b s /$ article/view/3626>
} 
Quadro 10 - Ferramentas usadas ou sugeridas nos estudos primários.

\begin{tabular}{|c|c|}
\hline Atividade & Ferramenta / Diretriz \\
\hline Selecionar dados & $\begin{array}{c}\text { Open Data Kit }[W 1], \text { KoBo Toolki }[W 1] \text {, UnBGOLD }[W 2] \text {, deat browser } \\
{[W 13] \text {, custom tools }[W 5, W 6]}\end{array}$ \\
\hline Limpar fonte de dados & Open Refine $[W 7, W 13]$, custom tools $[W 5, W 6]$ \\
\hline Projetar URIs & $\begin{array}{c}\text { LOV }[W 3, W 15] \text {, Protégé }[W 3, W 15] \text {, Semantic Media Wiki }[W 8] \text {, OntoWiki } \\
{[W 8], \text { Swoogle }[W 15, W 16], \text { SchemaWeb }[W 15] \text {, SchemaCache }[W 15] \text {, }} \\
\text { Neologism }[W 15], \text { NeOn Toolkit }[W 15] \text {, TopBraid Composer }[W 15] \text {, Altova } \\
{[W 15]}\end{array}$ \\
\hline Definir vocabulários & $\begin{array}{c}\text { Cool URIs }[W 3, W 14, W 15, W 16] \text {, Designing URIs for the UK Public Sector, } \\
\text { Style Guidelines for Ontologies }\end{array}$ \\
\hline Especificar metadados & $\begin{array}{c}\text { UnBGOLD }[W 2], \text { VoID }[W 3, W 15, W 18], \text { Open Provenance Model }[W 15, \\
W 18], \text { Dublin Core }[W 3] \text {, Provenir }[W 18]\end{array}$ \\
\hline $\begin{array}{l}\text { Mapear vocabulários } \\
\text { aos dados }\end{array}$ & $\begin{array}{c}\text { OpenRefine }[W 7, W 10, W 13, W 15] \text {, D2RQ }[W 4, W 6, W 9, W 15] \text {, UnBGOLD } \\
{[W 2], \text { Semantic Media Wiki }[W 8], \text { OntoWiki }[W 8], \text { WebDAV }[W 10],} \\
\text { Sponger }[W 10], \text { StdTrip }[W 17], \text { XLWrap }[W 15], \text { RDF123 }[W 15], \text { NOR20 } \\
{[W 15], \text { UltraWrap }[W 15], \text { GRDDL }[W 15], \text { TopBraid Composer }[W 15] \text {, }} \\
\text { ReDeFer }[W 15], \text { any23 }[W 15], \text { Stats2RDF }[W 15]\end{array}$ \\
\hline $\begin{array}{l}\text { Conectar a outras fontes } \\
\text { de dados }\end{array}$ & $\begin{array}{c}\text { SILK }[W 3, W 8, W 9, W 10, W 15], \text { LIMES }[W 3, W 8, W 15], \text { OpenRefine }[W 10, \\
W 13], \text { RKBExplorer }[W 8], \text { GNAT }[W 8], \text { RDF-AI }[W 8], \text { Pundit }[W 10]\end{array}$ \\
\hline $\begin{array}{l}\text { Enriquecer o conjunto } \\
\text { de dados }\end{array}$ & $\begin{array}{l}\text { OpenRefine }[W 10], \text { MOMIS }[W 9], \text { Fusepool P3 }[W 7], \text { csv2rdf4lod }[W 18], \\
\text { DL-Learner }[W 8], \text { Protégé reasoners }[W 8], \text { OntoWiki plugins }[W 8]\end{array}$ \\
\hline Converter para RDF & $\begin{array}{c}\text { OpenRefine }[W 7, W 10, W 13, W 15], \text { D2RQ }[W 6, W 8, W 9, W 15], \text { Jena }[W 2, \\
W 4], \text { Kettle }[W 16], \text { StdTrip }[W 17], \mathbf{c s v 2 r d f 4 l o d}[W 18], \text { OpenCalais }[W 8] \text {, } \\
\text { Alchemy }[W 8], \text { FOX }[W 8], \text { Sparqlify }[W 8], \text { Virtuoso RDF Views }[W 8], \\
\text { WebDAV }[W 10], \text { Sponger }[W 10], \text { XLWrap }[W 15], \text { RDF123 }[W 15], \text { NOR20 } \\
{[W 15], \text { UltraWrap }[W 15], \text { GRDDL }[W 15], \text { TopBraid Composer }[W 15],} \\
\text { ReDeFer }[W 15], \text { any23 }[W 15], \text { Stats2RDF }[W 15], \text { custom tools }[W 5, W 11, \\
W 12]\end{array}$ \\
\hline Limpar dados RDF & RDF Alerts [W15], sameAs Link Validator [W15] \\
\hline $\begin{array}{l}\text { Versionar os conjuntos } \\
\text { de dados }\end{array}$ & - \\
\hline Definir as licenças & Creative Commons Choose $[W 1]$ \\
\hline Publicar os dados & $\begin{array}{c}\text { CKAN }[W 1, W 2, W 12, W 13, W 14], \text { Virtuoso }[W 6, W 10, W 15, W 16], \text { Socrata } \\
{[W 1] \text {, OpenDataSoft }[W 1], \text { Jackan }[W 2], \text { OAM Framework }[W 4], \text { LMF }} \\
{[W 9] \text {, Clerezza }[W 10], \text { Jena TDB }[W 10, W 15], \text { Fuseki }[W 13], \text { Sesame }[W 15 \text {, }} \\
W 16], \text { 4Store }[W 15, W 16], \text { OWLIM }[W 15, W 16], \text { YARS }[W 15], \text { Redland } \\
{[W 16] \text {, Bigdata }[W 16]}\end{array}$ \\
\hline $\begin{array}{l}\text { Permitir descoberta dos } \\
\text { dados }\end{array}$ & Sitemap protocol $[W 3, W 15, W 16]$, Datahub $[W 3]$, CKAN.net $[W 13, W 15]$ \\
\hline $\begin{array}{l}\text { Criar aplicações sobre } \\
\text { os dados }\end{array}$ & $\begin{array}{c}\text { Pubby }[W 15, W 16], \text { LodLive.it }[W 10], \text { Relfinder }[W 10], \text { D3JS }[W 10], \text { Elda } \\
{[W 16], \text { D2R Server }[W 16], \text { djubby }[W 16], \text { WESO DESH }[W 16]}\end{array}$ \\
\hline $\begin{array}{l}\text { Criar e manter portal de } \\
\text { dados }\end{array}$ & CKAN [WI2] \\
\hline $\begin{array}{l}\text { Engajar com a } \\
\text { comunidade }\end{array}$ & - \\
\hline $\begin{array}{l}\text { Definir requisitos não } \\
\text { funcionais }\end{array}$ & - \\
\hline $\begin{array}{l}\text { Definir tarefas de } \\
\text { manutenção }\end{array}$ & $\begin{array}{l}\text { Trelis }[W 8], \text { ProLOD }[W 8], \text { LinkQA }[W 8], \text { WIQA }[W 8], \text { Sieve }[W 8] \text {, } \\
\text { tSPARQL }[W 8], \text { CTIC Vapour }[W 16], \text { RDF/XML Validator }[W 16]\end{array}$ \\
\hline
\end{tabular}

Fonte: Elaborada pelo autor.

Em relação ao armazenamento de dados conectados, duas ferramentas foram as mais 
usadas: CKAN (<https://ckan.org/>) e OpenLink Virtuoso (<https://virtuoso.openlinksw.com/>). O CKAN é atualmente o catálogo de dados mais usado em iniciativas de DAG, hospedando arquivos e servindo-os pela Web bem como seus metadados por interfaces de API. Pelo outro lado, o Virtuoso é uma ferramenta de código aberto usada para hospedar grafos RDF e disponibilizálos por meio de uma interface SPARQL. Embora ele ofereça maior flexibilidade, ele também traz problemas de usabilidade para usuários finais - que devem ter conhecimento em consultas SPARQL, além de problemas de desempenho por motivo da dinamicidade dos resultados das consultas.

QP4: Que tipos de validação foram empregadas para garantir práticas de qualidade de dados?

Como detalhado no Capítulo 2, atividades de verificação e validação são os processos de checar se um produto atende às especificações e que ele atende seu propósito. Publicar DAG na Web é um grande passo, mas seu valor é determinado pela sua qualidade. Por se tratar de um processo complexo, as tarefas de verificação e validação podem ser usadas para garantir a qualidade dos dados produzidos. Embora a qualidade dos dados de DAC seja um conceito essencial, a autonomia dos fornecedores de dados torna a Web vulnerável a dados faltantes, incompletos, imprecisos, inconsistentes ou desatualizados (NGOMO et al., 2014). E, como argumentado previamente, mesmo com todos os esforços, o resultado final pode não atingir alta qualidade. Assim, foi buscado investigar que tarefas de controle de qualidade foram empregadas durante o processo. Como resultado, poucos estudos propuseram uma atividade explícita de V\&V por todo o ciclo de vida da produção de DAGC. O trabalho W8 traz as tarefas mais detalhadas, com uma fase dedicada à qualidade dos dados conectados e suas respectivas validações. Os autores consideram o trabalho de (ZAVERI et al., 2016) e listam 18 dimensões de qualidade com 68 métricas. Entretanto, o estudo não o aplicou em um estudo de caso real, somente em um exemplo ilustrativo. O trabalho W15 empregou dois passos em sua metodologia: uma na fase de limpeza dos dados, para checagem da validade sintática das triplas RDF e ao final da fase de interconexão, no qual experts do domínio devem revisar as conexões automáticas criadas com ferramentas como SILK ou LIMES. O trabalho W10 fornece uma fase de V\&V, entre a fase de conexão e a publicação dos dados. Nesta fase, os autores argumentam que os dados devem ser checados em função de acurácia, completude, visibilidade, catalogação de metadados, promoção, adequação e privacidade. O estudo não detalha esta fase nem a aplica em um estudo de caso. Em W6 é apresentado um passo para a validação de dados tabulares, após a coleção automática de um catálogo digital e antes de convertê-los para RDF. Os autores apresentam seu algoritmo e o aplicam em conjuntos de dados do portal de dados da Tailândia, avaliando as métricas de precisão e a revocação do algoritmo para a identificação de problemas estruturais nos dados. Outros estudos mencionam a importância de $V \& V$ durante o processo. No entanto, eles oferecem sugestões e não contemplam tarefas dedicadas. Em W16, os autores aplicaram em seu cenário a validação da conversão das triplas RDF em função da corretude sintática. Em W7, os autores também realizaram checagens de qualidade após a transformação dos dados, e somente o fizeram 
nas aplicações, sem fornecer mais detalhes. Em W5, discute-se o problema da incompletude dos dados, mas não detalha como sua metodologia e componentes arquiteturais tratam esse problema. Em W4, os autores declaram que, em sua abordagem, somente conjuntos de dados bem formados podem ser processados, mas não mostram como podem ser checados em sua metodologia. No trabalho W3 é apontada a importância da validação de conexões a conjuntos de dados externos, que devem ser feitos por especialistas no domínio. Em W1 é enfatizada a importância que potenciais usuários necessitam para compreender e validar os dados durante a fase de coleta; entretanto, os autores não detalham como isso pode ser executado sistematicamente.

\subsubsection{Sumário dos resultados}

Embora o movimento de DAG ainda esteja produzindo grandes quantidades de dados em todo o mundo, os dados conectados ainda representam uma pequena porção. Pelo ano de publicação, nota-se que grande parte dos estudos foram realizados no início deste década e ganharam força novamente nos últimos anos. A razão para a criação destas metodologias no período de 2011 a 2013 é talvez por conta da criação de portais de DAG, tal como nos EUA (em 2009) e no Reino Unido (em 2010) que publicaram centenas de conjuntos de dados em seus primeiros anos, vislumbrando uma oportunidade para uma Web de dados.

Muitos dos estudos recentes são relacionados à aplicação de um método para criar dados conectados para um propósito particular, às vezes baseado em algum dos estudos listados nesta seção ou, na maioria das vezes, criando uma abordagem ad-hoc para seu problema. A justificativa é que as metodologias existentes são muito genéricas e não consideram as particularidades de seus domínios. Alguns domínios foram mais prevalentes nas aplicações de DAGC: dados geográficos, licitações, agricultura e meio ambiente, cidades inteligentes e dados legislativos. Além disso, um subconjunto significativo de estudos retornados investigou apenas um ou poucos passos do processo como um todo.

A partir do mapeamento sistemático, pudemos identificar diferentes abordagens aplicadas ao processo de produção de DAGC. Algumas metodologias se focam apenas nos passos básicos de conversão dos dados para RDF e os princípios básicos dos dados conectados. Como apontado em (JOVANOVIK; TRAJANOV, 2017), as metodologias existentes para publicação de DAGC apresentam um número variável de passos, mas cobrem essencialmente as mesmas atividades. A principal diferença é o agrupamento das ações dentro de cada passo e dos diferentes níveis de granularidade. Outros, apresentam uma concepção mais genérica e incluem passos complementares que aumentam o potencial de reuso desses dados.

O não atendimento de um passo não desqualifica a metodologia, mas sim o torna mais específico a um determinado contexto. Como visto no Capítulo 2, a natureza dos DAG na Web apresenta a complexidade de não se ter uma aplicação específica a ser modelada, mas sim torná-la a mais ampla possível, para diferentes cenários sobre os mesmos dados. 
Quanto à avaliação, foi percebido que grande parte das metodologias propostas não traz forma alguma de avaliação empírica, e são geralmente descritas como um tutorial ou guia de boas práticas em vez de uma investigação formal - razão talvez pela qual tais metodologias são consideradas genéricas e pouco adotadas em trabalhos posteriores. Do mesmo modo, dada a natureza complexa e interdependente da produção de DAGC, o uso de metodologias mais formais, como experimentos controlados, parece inadequado. Isso foi refletido nos resultados, trazendo os cenários ilustrativos como principal forma de avaliação.

Como a maior parte dessas metodologias foi concebidas para serem genéricas e para diferentes domínios, poucas ferramentas são sugeridas como parte do processo - outro ponto que sugere a percepção da comunidade de que elas são muito genéricas. A maioria das ferramentas levantadas estão alinhadas com os passos mais essenciais do processo (mapeamento, conversão, ligação e armazenamento dos dados), com poucas recomendações para as outras tarefas.

Poucos estudos especificaram práticas sistemáticas para controle da qualidade - boa parte deles se limitaram a reconhecer a importância de existir atividades de V\&V ou de incluir poucos passos em pontos-chave. Os artigos trabalham essa questão de análise da qualidade em pontos bem definidos do processo, geralmente após a triplificação dos dados. Dada a natureza distribuída da Web e a natureza intrínseca dos dados conectados, mesmo se um conjunto de dados tenha sido disponibilizado corretamente, sua qualidade também depende de suas dependências a dados externos, o que torna a manutenção de DAC um grande desafio.

Deste modo, esta tese estende a literatura ao desenvolver um modelo de ciclo de vida que integra essas atividades e que aborda o controle da qualidade durante o processo. Além disso, a incorporação de práticas contemporâneas de compartilhamento de dados na Web faz com que sejam atendidos os requisitos essenciais apontados no Capítulo 2.

\subsection{Dados abertos no governo federal brasileiro}

O Brasil é um dos países pioneiros a adotar práticas de disponibilização de dados abertos governamentais. A seguir, demonstramos fatos relevantes relacionados a regulamentações, parcerias e práticas relacionadas a DAG. Para isso, foi realizado um levantamento bibliográfico com a análise documental de normas, regulamentos e leis federais; documentos oficiais de grupos de trabalho voltados para esta finalidade; documentos de planejamento, padrões e vocabulários da estratégia digital brasileira sobre dados abertos. Acreditamos que a abordagem histórica de um fenômeno é essencial para compreender como se deu a situação atual.

\subsubsection{Linha do tempo dos dados abertos no Brasil}

Na Figura 6 é apresentada uma linha do tempo que descreve a contextualização histórica de iniciativas de DAG no Brasil, baseado em marcos relevantes levantados na documentação pesquisada. 


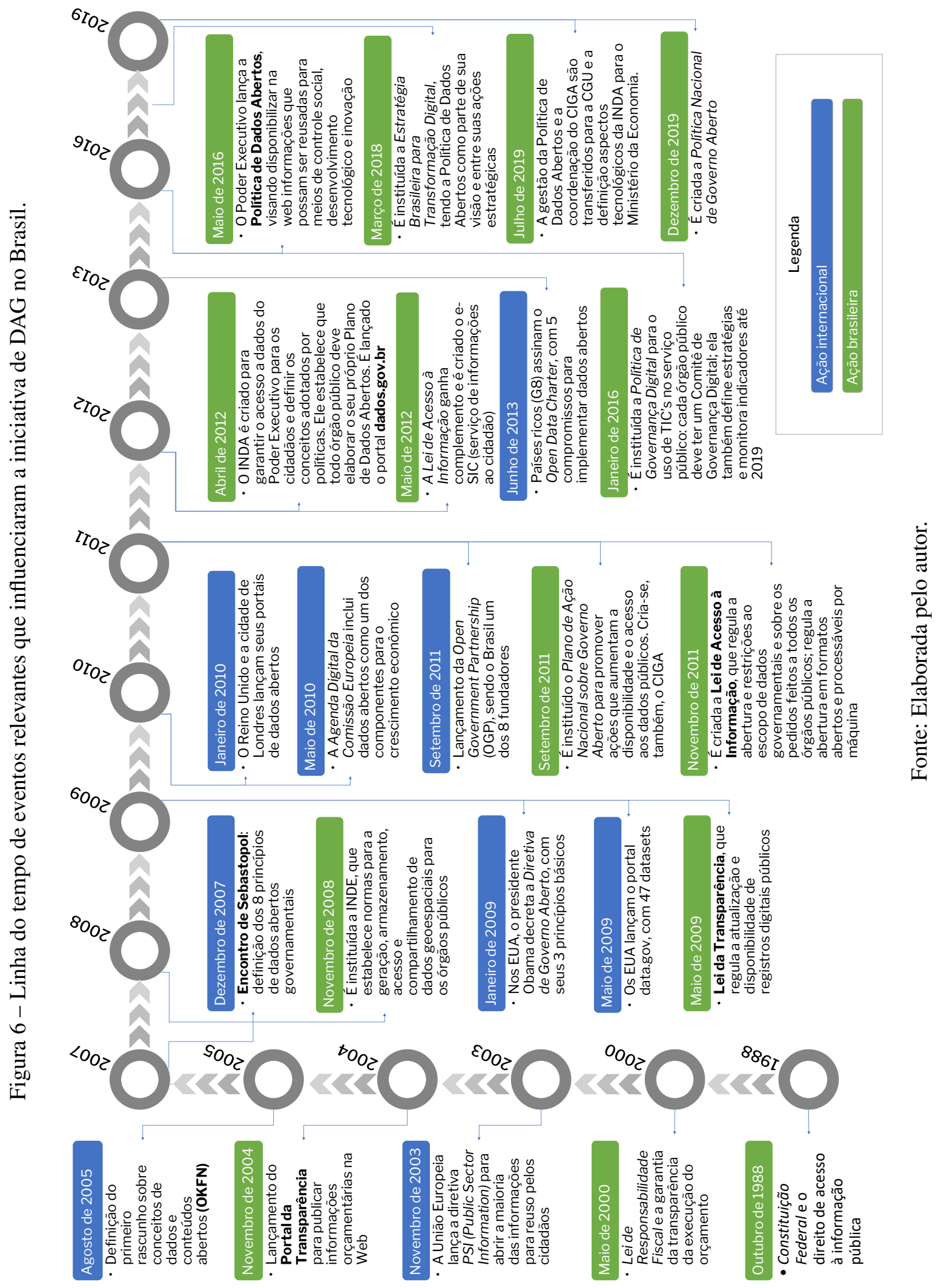


A primeira iniciativa encontrada remete ao ano de 1988, quando o direito ao acesso a informações públicas foi garantido na Constituição Federal (BRASIL, 1988, art. V), mas sem detalhar ações efetivas para sua implementação. Em maio de 2000, por meio da Lei Suplementar 101, conhecida como Lei de Responsabilidade Fiscal (BRASIL, 2000), que regula a transparência da gestão fiscal, garantindo a transparência por meio de informações detalhadas sobre execuções financeiras e orçamentárias para o acesso ao público.

Como um passo seguinte, em novembro de 2004, o Portal da Transparência ${ }^{11}$, a primeira ação concreta do governo brasileiro em relação à publicação de dados na Internet, foi lançado pela Controladoria Geral da União para publicar as execuções financeiras e orçamentárias do poder executivo federal. Mesmo sem usar o termo "dados abertos", esta iniciativa ofereceu informações sobre gastos públicos, visando combater a corrupção e o mau uso de dinheiro público.

Os significados em torno dos dados abertos foram estabelecidos pela primeira vez pela Open Knowledge Foundation em agosto de 2005, em um processo evolutivo junto à comunidade. Este trabalho resultou na conceitualização compartilhada sobre o significado de dados abertos, influenciando ações posteriores na área. No encontro de Sebastopol, em dezembro de 2007, cerca de 30 pessoas de diferentes formações (direito, gestão pública, tecnologia, dentre outras) se reuniram e discutiram para se obter um consenso sobre uma agenda para publicação de informações em formato digital. Ao final do encontro, foram definidos os 8 princípios básicos dos DAG: completos, primários, atuais, acessíveis, processáveis por máquina, não discriminatórios, não proprietários e sem licenças restritivas. Embora muitas organizações já tinham o hábito de publicar dados antes disso, o resultado deste encontro (isto é, os princípios dos DAG) influenciou muitas decisões de criação de políticas ao redor do mundo.

Em 2009, em seu primeiro dia como presidente dos Estados Unidos, Barack Obama enviou o memorando sobre transparência e governo aberto (OBAMA, 2009). Este documento instruiu os membros de sua administração a planejar estratégias de implementação construídas sobre 3 princípios de governo aberto: transparência, participação e colaboração. Logo depois, em maio de 2009, o portal data.gov foi lançado, como um catálogo centralizado de conjuntos de dados publicados pelas agências federais daquele país. Esta ação objetivou melhorar o acesso público a conjuntos de dados de alto valor para a sociedade e em formatos processáveis por máquinas, o que estimulou muitos países e cidades a seguir esta iniciativa. Inicialmente, dispunha de 47 conjuntos de dados disponíveis - atualmente, existem mais de 260 mil. Logo após, em janeiro de 2010, emerge a segunda grande iniciativa de portais de dados nacionais, no Reino Unido. No Brasil, também em maio de 2009, a Lei de Responsabilidade Fiscal (BRASIL, 2000) foi estendida pela Lei Suplementar 131, conhecida como Lei de Transparência (BRASIL, 2009), que regula a disponibilização e atualização de registros digitais para o acesso público.

Em maio de 2010, a Comissão Europeia apresentou um plano de ação para promover o

$11<$ <ww.portaldatransparencia.gov.br> 
desenvolvimento sustentável econômico e social baseado em produtos e serviços para a internet e sua aplicação interoperável até 2020, na chamada Agenda Digital (COMISSÃO EUROPEIA, 2010). Neste documento, os governos poderiam estimular os mercados ao tornar informações de setores públicos disponíveis de maneira transparente e não discriminatória, estendendo a Diretiva PSI de 2003, que dispunha sobre o escopo de documentos a serem abertos, licenciamentos, procedimentos, metadados e cronogramas para requisições a dados feitas por cidadãos.

Em setembro de 2011, oito países estabeleceram um acordo multilateral para garantir compromissos concretos dos governos para promover a transparência, colaborar com seus cidadãos, frear a corrupção e desenvolver nova tecnologias para melhorar a governança - a chamada Parceria para Governo Aberto (OGP, do inglês Open Government Partnership). Esses países endossaram suas declarações de governo aberto e anunciaram seus planos de ação nacionais. Essa declaração consistia de 4 diretrizes em alto nível, implementadas nos países por meio dos respectivos planos de ação (OGP, 2019a): i) aumentar a disponibilidade de informações sobre atividades governamentais; ii) apoiar a participação cívica; iii) implementar os mais altos padrões de integridade profissional por todas as administrações e iv) aumentar o acesso a novas tecnologias para abertura e responsabilização.

Ainda em setembro de 2011, por meio de um decreto presidencial (sem número) é instituído o Plano de Ação Brasileiro para Governo Aberto, abarcando as diretrizes e compromissos feitos pela declaração da OGP. Como parte deste compromisso com a OGP, três planos de ação bienais foram lançados (2011-2013, 2014-2016, 2016-2018) e, em todos eles, foram contemplados itens relacionados a dados abertos. Também foi criado o Comitê Interministerial para Governo Aberto (CIGA), responsável por gerenciar o plano de adequação aos compromissos da OGP.

Em novembro de 2011, foi aprovada a Lei de Acesso à Informação, n. 12.527 (BRASIL, 2011) que operacionalizou a obrigação federal para fornecer livremente informações públicas aos cidadãos, conforme descrito na Constituição Federal, ao atribuir ao governo o fornecimento de informações quando requisitadas e delimitando procedimentos e cronogramas para essa finalidade. A lei também estabeleceu critérios e regras para informações pessoais e de segurança pública. A lei abrange os três poderes institucionais (executivo, legislativo e judiciário), estabelecendo punições por más condutas que possam prejudicar esse acesso. A lei também estabelece o uso de formatos abertos e processáveis por máquina para os arquivos de dados.

Em abril de 2012, por meio da Instrução Normativa $n^{0} 4$, foi criada a INDA (Infraestrutura Nacional para Dados Abertos), que medeia as políticas de dados abertos do governo federal brasileiro, consistindo de um conjunto de padrões, tecnologias, procedimentos e mecanismos de controle para apoiar o compartilhamento de dados. Em paralelo à criação da INDA, foi também lançado oficialmente o Portal Brasileiro de dados Abertos (dados.gov.br) que, como em outros países, centraliza o acesso aos conjuntos de dados, em formatos abertos e equipado com ferramentas de buscas. Ele buscou ser um ponto de convergência para a catalogação dos dados 
públicos coletados e produzidos por todos os órgãos públicos.

Com isso, o desafio da promoção de políticas de dados abertos deixou de ser tecnológico e ferramental e passou a ser a efetiva publicação dos dados pelas organizações. O decreto 7.724, de maio de 2012, complementou a Lei de Acesso à Informação, consistindo em procedimentos como: a publicação dos dados, o processo para questionar e apelar às decisões tomadas, os prazos limite para o fornecimento dos dados, estabeleceu o sistema e-SIC (Sistema Eletrônico do Serviço de Informações ao Cidadão) como o principal canal de comunicação dos cidadãos com o governo.

Em junho de 2013, os países do G8 assinaram o Open Data Charter, consistindo de cinco princípios estratégicos a serem implementados por seus membros. Esses compromissos estabeleciam que os dados devem ser publicados em formato aberto, por padrão, bem como aumentar a quantidade, a qualidade e fomentar seu reuso. Além disso, quatorze áreas foram selecionadas como prioritárias para a abertura desses dados.

Em janeiro de 2016, por meio do decreto $n^{\circ}$ 8.638, foi estipulado a Política de Governança Digital para os órgãos públicos do governo federal. Ela determina diretrizes como o autoatendimento como prioridade nos serviços públicos digitais - ou seja, sem suporte direto dos órgãos públicos oferecendo o serviço. Além disso, ela determina que os dados devem ser publicados em formatos abertos, acessíveis tanto por máquinas quanto por humanos, garantindo os direitos à segurança e privacidade. Este decreto também institui a Estratégia de Governança Digital, que determina o uso de tecnologias da informação por órgãos públicos para melhorar a disponibilidade de informações, responsabilização, transparência e encorajar o participação da sociedade na tomada de decisão.

Em maio de 2016 foi instituído o decreto 8.777, que estabelece a Política de Dados Abertos do poder executivo federal. Este decreto promove a publicação de dados abertos para todos os órgãos públicos sob administração direta do poder executivo, assegurando o uso livre de bases de dados e consolidando um modelo de governança. Ele também objetivou melhorar a cultura pública de transparência, o controle social, a pesquisa científica empírica e a oferta de serviços públicos federais. Foi expandida pela resolução de outubro de 2017, que estabelece normas sobre a elaboração e a publicação dos Planos de Dados Abertos.

Em março de 2018, é instituída, via decreto n. 9.319, a Estratégia Brasileira de Transformação Digital (e-Digital), que considera os dados abertos e a transparência do governo como um dos fundamentos para a cidadania digital. São propostos dois eixos temáticos, dentre os quais a "Transformação digital", tendo como visão a economia baseada em dados e ações estratégicas de fortalecimento da Política Nacional de Dados Abertos de Governo.

Em julho de 2019 foi assinado o decreto 9.903, que transfere a gestão da Política de Dados Abertos, do Ministério do Planejamento para a Controladoria Geral da União e transfere para o Ministério da Economia a definição de padrões e demais aspectos tecnológicos da INDA. 
Em dezembro de 2019, por meio do decreto 10.160, revoga o decreto de setembro de 2011 sobre o Plano de Ação Nacional sobre Governo Aberto, dando lugar à Política Nacional de Governo Aberto que estimula o uso dos dados abertos do governo federal em direção aos benefícios esperados de seu uso e redefine as responsabilidades e composição do CIGA, sob coordenação da CGU.

\subsubsection{Stakeholders-chave}

Como definido na Política de Dados Abertos do poder executivo federal (decreto 8.777/2016), a implementação da política deve ocorrer por meio dos respectivos Planos de Dados Abertos (PDA) de cada órgão federal. Estes planos definem os critérios para publicar os conjuntos de dados, as informações selecionadas, a estratégia e o cronograma de publicação, além do processo de catalogação dos conjuntos de dados no portal dados.gov.br. O modelo de governança é composto tanto por departamentos internos de cada órgão quanto por atores externos, assegurando a aderência dos dados abertos e das políticas de governo aberto.

A Figura 7 descreve, em linhas gerais, a organização interna de cada órgão que publica dados (à esquerda) e quais são os órgãos externos de controle que atuam sobre eles (à direita).

Figura 7 - Modelo de governança para o planejamento, execução e monitoramento dos PDAs.
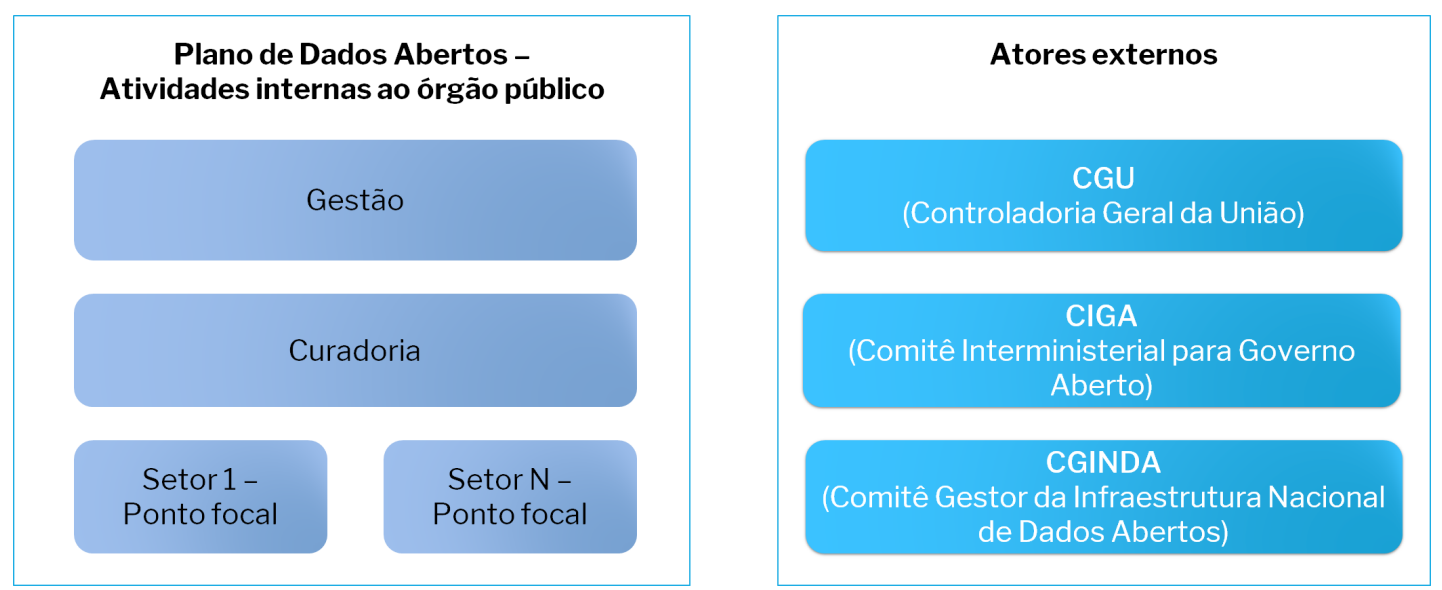

Fonte: Elaborada pelo autor.

Internamente, cada órgão desenvolve três atividades principais: i) a produção dos dados; ii) a curadoria dos dados e iii) a gestão dos planos. A produção dos dados é de responsabilidade de setores específicos que coletam os dados de acordo com regras de negócio. A curadoria trata da avaliação da qualidade e persistência dos dados publicados, assumida por diferentes áreas nos órgãos, verificando a adequação aos padrões definidos pela INDA e a nomenclatura das bases, conforme dispostas no PDA, além de monitorar disponibilidade e atualização das bases já catalogadas, além de propor melhorias de qualidade dos dados disponibilizados. A gestão dos planos individuais objetivam aprovar e monitorar a execução dos PDAs em nível estratégico, geralmente assumido pelo comitê executivo do órgão ou um comitê de tecnologia da informação. 
Quadro 11 - Papéis e composição para governança de dados abertos no Brasil.

\begin{tabular}{|c|c|c|}
\hline Papel & Função & Composição \\
\hline $\begin{array}{l}\text { CGU } \\
\text { (Controladoria- } \\
\text { Geral da União) }\end{array}$ & $\begin{array}{l}\text { Publicar cronograma e monitorar } \\
\text { sua execução, aplicação e adoção de } \\
\text { procedimentos da cada PDA. }\end{array}$ & $\begin{array}{l}\text { Membros do conselho de Transpa- } \\
\text { rência e controle social }\end{array}$ \\
\hline $\begin{array}{l}\text { CIGA (Comitê In- } \\
\text { terministerial para } \\
\text { Governo Aberto) }\end{array}$ & $\begin{array}{l}\text { Propor medidas para o desenvolvi- } \\
\text { mento e implementação da estra- } \\
\text { tégia de governo aberto no poder } \\
\text { executivo federal. Conduzir a ela- } \\
\text { boração, implementação, monitora- } \\
\text { mento e avaliação do planos de ação } \\
\text { nacionais sobre governo aberto, em } \\
\text { conformidade aos compromissos da } \\
\text { OGP }\end{array}$ & $\begin{array}{l}\text { Composto por } 13 \text { ministérios } \\
\text { (CGU; Casa Civil; Justiça; Rela- } \\
\text { ções exteriores; Economia; Educa- } \\
\text { ção; Cidadania, Saúde; Meio Am- } \\
\text { biente; Desenvolvimento regional; } \\
\text { Ciência, tecnologia, inovação e co- } \\
\text { municação; Mulher, família e di- } \\
\text { reitos humanos; secretaria-geral } \\
\text { da presidência) e coordenado pela } \\
\text { CGU }\end{array}$ \\
\hline $\begin{array}{l}\text { CG/INDA (Co- } \\
\text { mitê Gestor para } \\
\text { Infraestrutura } \\
\text { Nacional de } \\
\text { Dados Abertos) }\end{array}$ & $\begin{array}{l}\text { Definir modelos de licença de da- } \\
\text { dos abertos; desenvolver diretrizes } \\
\text { para desenvolvimento, implantação, } \\
\text { manutenção e gestão do portal da- } \\
\text { dos.gov.br, monitorar a evolução de } \\
\text { compromissos específicos dos res- } \\
\text { pectivos PDAs. }\end{array}$ & $\begin{array}{l}\text { Representantes de diferentes mi- } \\
\text { nistérios e institutos (Ministério } \\
\text { da Economia; Casa civil; CGU; } \\
\text { Ciência, tecnologia, inovação e } \\
\text { comunicação; Cidadania; Educa- } \\
\text { ção; Saúde;Secretaria de Governo; } \\
\text { IBGE), além de um representante } \\
\text { da sociedade civil, um membro da } \\
\text { academia e coordenado pelo Mi- } \\
\text { nistério da Economia }\end{array}$ \\
\hline $\begin{array}{l}\text { Gestão do PDA } \\
\text { individual }\end{array}$ & $\begin{array}{l}\text { Monitora a execução do PDA, guia } \\
\text { e assegura a adequação com as nor- } \\
\text { mas relacionadas. }\end{array}$ & Varia de acordo com cada órgão \\
\hline Curadoria & $\begin{array}{l}\text { Apoia o processo de publicação; } \\
\text { avalia a qualidade e a persistência } \\
\text { dos dados publicados. }\end{array}$ & Varia de acordo com cada órgão \\
\hline $\begin{array}{l}\text { Ponto focal seto- } \\
\text { rial }\end{array}$ & $\begin{array}{l}\text { Coleta e cataloga dados de seu setor } \\
\text { e propõe modificações ao PDA }\end{array}$ & Varia de acordo com cada órgão \\
\hline
\end{tabular}

Fonte: Elaborada pelo autor.

Externamente, o CIGA (Comitê Interministerial para Governo Aberto) garante a aderência aos princípios de governo aberto de acordo com o Plano de Ação Nacional, alinhado aos compromissos definidos junto à OGP. O CGINDA (Comitê Gestor da Infraestrutura Nacional de Dados Abertos) monitora a avaliação dos critérios de qualidade para os dados abertos, estabelecidos pela INDA (por exemplo: formatos de arquivos, aderência ao e-PING, metadados, disponibilidade de URL, dentre outros). Além disso, a Controladoria Geral da União (CGU) - um braço do poder executivo que auxilia a auditoria de contas e bens públicos - monitora a 
aplicação e o atendimentos dos cronogramas e procedimentos dos planos de dados individuais. Para isso, foi criado um portal público para o monitoramento de publicação de dados e dos PDAs bienais de cada órgão. A composição deste modelo é detalhado na Figura 7 e na Quadro 11.

\subsection{Adoção de boas práticas de ecossistema de dados}

Como forma de avaliar o estado atual da adoção de boas práticas de compartilhamento de dados na Web, realizamos uma pesquisa exploratória para verificar o grau de atendimento dos DAG em relação aos princípios do ecossistema de dados. Para isso, analisamos um recorte de bases de dados educacionais (Ministério da Educação e INEP - Instituto Nacional de Estudos e Pesquisas Educacionais Anísio Teixeira), utilizando um estudo caso múltiplo, com técnica de casos diversos, explorando diferentes bases de dados conforme a natureza de seus dados: censitário, acadêmico, desempenho escolar e orçamentário (SANTOS, 2014). Deste modo, foram selecionados um conjunto de dado por cada categoria e verificados a conformidade de cada prática recomendada, com os critérios de atendimento: Sim, Não, Parcialmente e Não se Aplica. Para cada conjunto de dados, foi selecionada sua distribuição mais recente. O referencial técnico adotado foi a recomendação DWBP (W3C, 2017), que sugere boas práticas de compartilhamento de dados, não necessariamente conectados. O domínio educacional foi escolhido por ser um dos pioneiros dentro do governo brasileiro e no mundo. Por exemplo, o censo escolar da educação básica é publicado desde 1995 e é um dos poucos conjuntos de dados nacionais a apresentar alto grau de qualidade, de acordo com o Open Data Barometer. O Quadro 12 traz quais foram as bases de dados selecionadas e detalhes das distribuições utilizadas na análise.

Quadro 12 - Conjuntos de dados selecionadoas para a análise.

\begin{tabular}{|c|c|c|c|c|}
\hline & \multicolumn{4}{|c|}{ Conjuntos de dados selecionados } \\
\hline Categoria & Censitário & Acadêmico & Desempenho & Orçamentário \\
\hline $\begin{array}{c}\text { Nome do dataset no } \\
\text { portal dados.gov.br }\end{array}$ & $\begin{array}{c}\text { microdados- } \\
\text { do-censo- } \\
\text { escolar }\end{array}$ & $\begin{array}{c}\text { microdados- } \\
\text { do-exame- } \\
\text { nacional-do- } \\
\text { ensino-medio- } \\
\text { enem }\end{array}$ & $\begin{array}{c}\text { ensino-basico- } \\
\text { ideb-por- } \\
\text { municipios }\end{array}$ & $\begin{array}{c}\text { ensino-basico- } \\
\text { pnae- } \\
\text { programa- } \\
\text { nacional-de- } \\
\text { alimentacao- } \\
\text { escolar }\end{array}$ \\
\hline $\begin{array}{c}\text { Formato do arquivo } \\
\text { de dados }\end{array}$ & zip+CSV & zip+CSV & XML+JSON & XML+JSON \\
\hline
\end{tabular}

Fonte: Adaptada de Penteado, Bittencourt e Isotani (2019a).

A Figura 8 ilustra o resultado da análise, por meio de uma compilação do nível de atendimento das 35 práticas preconizadas pela DWBP, agrupadas em suas 12 dimensões. São 
indicados, para cada dimensão, quantas práticas são plenamente atendidas (S), parcialmente atendidas (P), não são atendidas (N) ou que não foi possível avaliar (?). Os resultados completos podem ser consultados no artigo de Penteado, Bittencourt e Isotani (2019a).

Como resultado, notamos poucas práticas plenamente atendidas atualmente e muitas práticas atendidas parcialmente. Isso ocorre, pois as informações disponibilizadas são de fácil acesso para o consumo humano, mas não para o processamento automático por agentes de software, inviabilizando a análise automática e contínua dos dados disponibilizados.

Em relação ao atendimento às práticas, a dimensão de formato de dados da DWBP foi a mais atendida, em parte devido ao decreto 8.777/2016 e pelas especificações da INDA sobre os padrões a serem utilizados. Outras quatro dimensões não tiveram nenhum critério plenamente atendido: enriquecimento de dados, vocabulários, republicação e qualidade dos dados, muito em função da não disponibilização de informações em nível semântico no portal.

Embora a DWBP (W3C, 2017) não seja voltada para dados conectados (mas contém algumas práticas relacionadas), ela usa os conceitos do ecossistema de dados para derivar suas boas práticas. Argumentamos aqui que essas práticas são também essenciais para a publicação de DAGC, de modo a extrair os benefícios da Web de dados apropriadamente, uma vez que ela considera ações de como disponibilizar dados que facilitem seu reuso e seu aprimoramento por meio de feedback da comunidade e, do ponto de vista técnico, reaproveite os componentes da arquitetura básica da Web - podendo incluir os princípios dos dados conectados. 

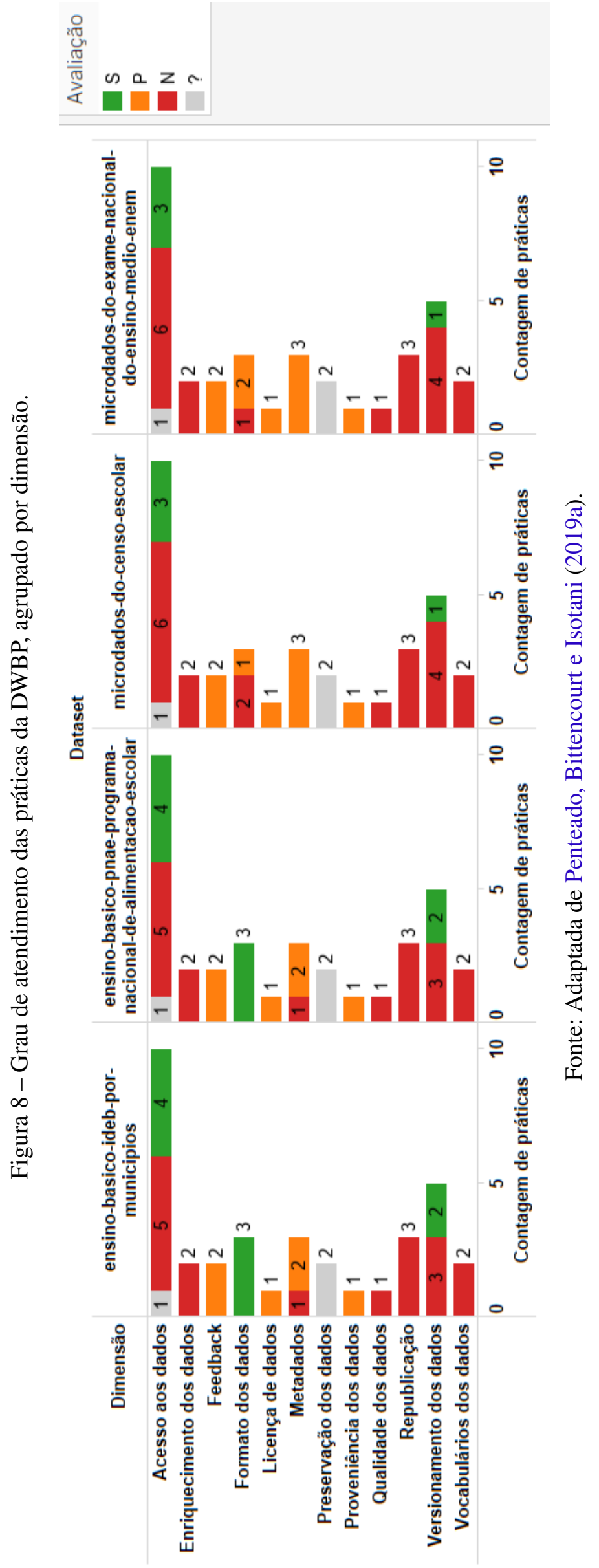


\subsection{Dados abertos governamentais conectados no Brasil}

Em relação a dados conectados, foram encontradas poucas iniciativas, considerando o universo de mais de 7 mil conjuntos de dados publicados no portal dados.gov.br. A mais antiga foi realizada pelo Ministério do Planejamento (agora parte do Ministério da Economia), com dados do Orçamento Fiscal e da Seguridade Social, publicados a partir do ano 2000 até o ano de 2014, que contém dados sobre a execução do orçamento federal e são disponibilizados como arquivos RDF compactados e por meio de um endpoint SPARQL ${ }^{12}$, tendo sua ontologia publicada na $\mathrm{Web}^{13}$. Outros 23 conjuntos de dados relacionados à Previdência Social, com temas diversos como acidentes de trabalho, serviço social, exames com parecer, etc.; estão disponíveis como dumps RDF acessados via portal. No entanto, o conteúdo desses conjuntos de dados foram verificados e somente foram encontrados arquivos em nível 4 do esquema de 5 estrelas, ou seja, eles estão em formato RDF, com a ontologia publicada na Web, mas não estão conectados a fontes de dados externas.

A terceira, lançada em 2019 pelo Senado federal (Martim, 2019), cobre os metadados das bases de leis nacionais no portal LeXML, disponibilizadas como código JSON-LD em cada página da lei e reutilizando unicamente os termos do vocabulário Schema.org ${ }^{14}$ no domínio de legislação; no entanto sem disponibilizar um repositório central dos dados semânticos. Trata-se de um caso pioneiro no mundo para dados de todas as normas jurídicas de hierarquia superior, contendo mais de 220 mil normas. Seu objetivo foi de tornar as leis indexáveis para mecanismos de buscas, como o Google Dataset Search, ao embutir os metadados em formato JSON-LD como parte do HTML das páginas das leis.

\subsection{Considerações finais}

Pesquisas empíricas mostram que a maior parte dos dados abertos governamentais publicados estão em níveis baixos de abertura, conforme o esquema de 5-estrelas. Por exemplo, Yi (2019) aponta que mais de 50\% dos dados disponíveis nos EUA e no Reino Unido estão no nível 1 (em sua maioria, em formatos HTML ou PDF), ou seja, seus conteúdos não são diretamente legíveis por máquina e $52 \%$ dos conjuntos de dados na Coréia do Sul estão em nível 3 apresentando altos índices de incompletude dos dados. Neste capítulo buscamos levantar metodologias de produção de DAGC disponíveis na literatura. Foram focados os pontos em comum entre elas, como elas podem ser concretizadas na prática (por meio da sugestão ou recomendação de ferramentas), como foram avaliadas e como a qualidade foi sistematicamente especificada por meio delas.

Considerando as variabilidade e pontos em comum das diferentes metodologias, con-

\footnotetext{
$12<$ http://www1.siop.planejamento.gov.br/sparql/>

$13<$ http://vocab.e.gov.br/2013/09/loa.owl>

$14<$ https://schema.org/>
} 
sideramos ser necessária a criação de um modelo de ciclo de vida para a produção de DAGC. Uma vez que existem atividades centrais, que são comuns aos diferentes contextos (QP1), o modelo deve fornecer um guia, contendo um ferramental associado, para que pesquisadores e profissionais da área possam compreender o processo como um todo e tomar decisões informadas sobre quais passos devem ser usados ou descartados e seus impactos no produto final.

Uma lacuna detectada na literatura diz respeito à incorporação sistemática de atividades de controle de qualidade durante todo o processo de produção dos DAGC. Enquanto que a qualidade dos dados é um requisitos importante para o crescimento orgânico dos dados abertos conectados, poucas iniciativas de pesquisa se focaram na qualidade dos dados para a Web Semântica e especialmente para os dados abertos conectados (BEHKAMAL et al., 2014). Experiências práticas na publicação de dados conectados apontam que muitos dos datasets publicados sofrem de problemas de qualidade como erros de sintaxe, instâncias redundantes e valores de atributos incorretos ou incompletos (BEHKAMAL et al., 2014). Uma das estratégias mais eficientes para evitar tais problemas é avaliar a qualidade do dataset antes que ele seja publicado na nuvem DAC - o que pode ajudar publicadores e consumidores desses dados quando avaliarem se devem fazer, respectivamente, interligações ou aplicações, sobre esses dados, permitindo que eles possam tomar melhores decisões e mais bem informadas ao reutilizar esses datasets.

Relegar o tratamento da qualidade dos dados para os consumidores representa um grande desperdício de recursos, já que a administração pública pode tornar esse procedimento mais barato no geral, ao evitar o custo social representado por DAG de baixa qualidade. Além disso, os governos são, em tese, os maiores interessados no aproveitamento desses dados: aumentar a qualidade desses DAG pode impulsionar seu reuso e focar os recursos de seus consumidores na geração de serviços de valor agregado. Para isso, planejar, avaliar e garantir a qualidade dos DAG é um dos primeiros passos para motivar administrações públicas a investir para melhorar a qualidade de seus dados. Portanto, julgamos, nesta tese, ser necessário incorporar atividades de garantia de qualidade de dados integrado ao processo de produção desses dados conectados, de modo a ter um produto de dados de alta qualidade e de forma eficiente.

Além disso, muitas ferramentas foram propostas, mas as ferramentas por si só não garantem o atendimento da qualidade - apenas atuam como um apontador, sem identificar quais as causas ou fornecem soluções concretas para melhorar a qualidade dos dados. E muitas dessas ferramentas foram desenvolvidas para apontar problemas de qualidade depois que os dados já foram transformados, limitando o alcance da detecção de possíveis problemas durante o processo de produção.

No próximo capítulo, discutimos nossa proposta para minimizar essa lacuna, ao fornecer um modelo de ciclo de vida que contemple as diferentes atividades, com suas ferramentas de apoio e passos de $\mathrm{V} \& \mathrm{~V}$, atendendo aos requisitos do ecossistema de dados e aos dos pilares do governo aberto, detalhados no capítulo anterior. 

CAPÍTULO

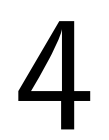

\section{PROJETO DA INFRAESTRUTURA}

Neste capítulo demonstramos as teorias kernel selecionadas (ecossistema de dados, qualidade de dados conectados, metadados e modelo 5 estrelas) e como elas atendem aos requisitos levantados.

$\mathrm{Na}$ Seção 4.1 mapeamos como as teorias selecionadas atendem aos requisitos levantados e discutimos possíveis elementos concretos das teorias que serão usados para operacionalizar seus princípios no design dos artefatos. Em seguida, cada uma das teorias selecionadas é detalhada, exemplificando como elas atendem aos requisitos desta tese.

Por fim, na Seção 4.6 especificamos como elas são operacionalizadas dentro da proposta de design da infraestrutura.

\subsection{Projeto do artefato}

Considerando os requisitos identificados previamente, procuramos estendê-los para o design dos artefatos. Para isso, após sua análise, buscamos na literatura por possíveis elementos de design (ZUIDERWIJK, 2015) que pudessem atender a esses requisitos. Foi selecionado um número limitado de elementos que cobrissem o máximo de requisitos funcionais. A partir da literatura, quatro elementos são propostos para atender aos requisitos e auxiliar no entendimento dos conceitos: o esquema 5 estrelas de dados conectados, o ecossistema de dados, os metadados e a garantia da qualidade.

Para todos esses elementos, mostramos como eles atendem aos requisitos e desenvolvemos as proposições. Aqui, consideramos os elementos como teorias kernel em seu sentido mais amplo, como em Zuiderwijk (2015). Teorias kernel são "o conhecimento ou teoria subjacente das ciências naturais, sociais ou de design que dão a base e a explicação para o design". A Quadro 13 mostra como foi feito esse mapeamento. Nele, os requisitos redundantes foram removidos ou refraseados para agregar requisitos semelhantes. 
Quadro 13 - Mapeamento dos requisitos dos construtos de DAGC aos elementos estruturantes selecionados.

\begin{tabular}{|c|c|c|c|c|c|}
\hline Construtos & Requisitos & $\begin{array}{c}\text { Ecossistema } \\
\text { de dados }\end{array}$ & $\begin{array}{l}\text { Qualidade } \\
\text { de DAC }\end{array}$ & Metadados & $\begin{array}{l}\text { Esquema } \\
5 \text { estrelas }\end{array}$ \\
\hline \multirow[t]{3}{*}{$\begin{array}{l}\text { Dados } \\
\text { abertos }\end{array}$} & $\begin{array}{l}\text { Acesso livre na Web, } \\
\text { sem passar por for- } \\
\text { mulários de registro } \\
\text { ou outras restrições } \\
\text { tecnológicas }\end{array}$ & $\mathrm{X}$ & $\mathrm{X}$ & & $\mathrm{X}$ \\
\hline & $\begin{array}{l}\text { Preservar proveniên- } \\
\text { cia dos dados }\end{array}$ & $X$ & $X$ & $X$ & \\
\hline & $\begin{array}{l}\text { Licença explícita so- } \\
\text { bre o (re)uso dos da- } \\
\text { dos }\end{array}$ & $\mathrm{X}$ & $\mathrm{X}$ & $\mathrm{X}$ & $\mathrm{X}$ \\
\hline \multirow{5}{*}{$\begin{array}{l}\text { Governo } \\
\text { aberto }\end{array}$} & $\begin{array}{l}\text { Garantia da quali- } \\
\text { dade da informação } \\
\text { (transparência) }\end{array}$ & & $\mathrm{X}$ & & \\
\hline & $\begin{array}{l}\text { Garantia de privaci- } \\
\text { dade (prestação de } \\
\text { contas) }\end{array}$ & & & & \\
\hline & $\begin{array}{l}\text { Segurança no acesso } \\
\text { aos dados (prestação } \\
\text { de contas) }\end{array}$ & & $X$ & & \\
\hline & $\begin{array}{l}\text { Comunicação com } \\
\text { sociedade (colabora- } \\
\text { ção) }\end{array}$ & $\mathrm{X}$ & & & \\
\hline & $\begin{array}{l}\text { Permitir feedback } \\
\text { público (colabora- } \\
\text { ção) }\end{array}$ & $X$ & & & \\
\hline \multirow{2}{*}{$\begin{array}{l}\text { Dados } \\
\text { abertos } \\
\text { governamentais }\end{array}$} & $\begin{array}{l}\text { Dados devem estar } \\
\text { disponíveis em vo- } \\
\text { lume e/ou por API }\end{array}$ & $X$ & & $X$ & \\
\hline & $\begin{array}{l}\text { Dados publicados } \\
\text { com arquitetura, pro- } \\
\text { tocolos e formatos } \\
\text { não proprietários }\end{array}$ & $X$ & & $X$ & $X$ \\
\hline
\end{tabular}




\begin{tabular}{|c|c|c|c|c|c|}
\hline Construtos & Requisitos & $\begin{array}{c}\text { Ecossistema } \\
\text { de dados }\end{array}$ & $\begin{array}{c}\text { Qualidade } \\
\text { de DAC }\end{array}$ & Metadados & $\begin{array}{l}\text { Esquema } \\
5 \text { estrelas }\end{array}$ \\
\hline & $\begin{array}{l}\text { Dados devem estar } \\
\text { em formatos proces- } \\
\text { sáveis por máquinas }\end{array}$ & $X$ & $X$ & $X$ & $X$ \\
\hline & $\begin{array}{l}\text { Dados devem ser } \\
\text { facilmente encontra- } \\
\text { dos e indexados na } \\
\text { Web }\end{array}$ & $\mathrm{X}$ & $X$ & $X$ & \\
\hline & $\begin{array}{l}\text { Dados devem ser } \\
\text { permanentes }\end{array}$ & $X$ & & & \\
\hline & $\begin{array}{lr}\text { Dados } & \text { devem } \\
\text { ser } & \text { confiáveis } \\
\text { (assinados } & \text { eletroni- } \\
\text { camente) } & \\
\end{array}$ & & & & \\
\hline & $\begin{array}{l}\text { Dados devem estar } \\
\text { documentados }\end{array}$ & $\mathrm{X}$ & $\mathrm{X}$ & $X$ & \\
\hline \multirow{3}{*}{$\begin{array}{l}\text { Dados } \\
\text { conectados }\end{array}$} & $\begin{array}{l}\text { Usar identificadores } \\
\text { globais }\end{array}$ & $X$ & $X$ & & $X$ \\
\hline & $\begin{array}{l}\text { Incluir links para ou- } \\
\text { tros dados }\end{array}$ & $\mathrm{X}$ & $X$ & & $X$ \\
\hline & $\begin{array}{l}\text { Dados em formato } \\
\text { semântico }\end{array}$ & & $X$ & $X$ & $X$ \\
\hline
\end{tabular}

Fonte: elaborada pelo autor.

Alguns dos requisitos não são contemplados pelos elementos de design. Um deles diz respeito à privacidade de dados de indivíduos. Nenhuma das teorias kernel selecionadas cobre este requisito. No entanto, trata-se de uma atividade válida para o processo, que deve ser verificada por mecanismos de garantia de qualidade. $\mathrm{O}$ outro requisito não atendido diz respeito à confiança nos dados (princípio n. 11 dos DAG; OGD, 2012). Trata-se de um tópico que parece não ter sido muito explorado na comunidade de DAG. Alguns autores afirmam que o reuso e a transformação dos dados originais em novas formas, como para o caso dos infomediários ${ }^{1}$, são os objetivos dos DAG e, até o momento, não existem métodos para que uma assinatura digital seja preservada quando os dados são modificados (TAUBERER, 2014). Entretanto, existe atualmente um grupo de trabalho na $\mathrm{W}_{3} \mathrm{C}^{2}$ em processo de criação de uma especificação de mecanismos para garantir a autenticidade e integridade de documentos de dados conectados usando assinaturas digitais. A

1 Infomediários são as organizações que intermedeiam o tratamento de informação entre os fornecedores dos dados e seus consumidores, tais como agências de notícias, ONGs, etc.

$2<$ https://w3c-dvcg.github.io/ld-signatures/> 
seguir, são abordadas as quatro teorias kernel envolvidas no projeto do artefato.

\subsection{Ecossistema de dados}

O ecossistema de dados aborda redes complexas sociotécnicas nas quais os atores interagem e colaboram entre si para encontrar, arquivar, consumir e reutilizar dados (OLIVEIRA; LIMA; LÓSCIO, 2019; LEE, 2014; ZUIDERWIJK; JANSSEN; DAVIS, 2014; UBALDI, 2013; POLLOCK, 2011). Trata-se de uma metáfora frequentemente usada para transmitir um senso de sistemas sociais interdependentes de indivíduos, organizações, infraestruturas materiais e de recursos, que podem ser criados em sistemas intensivos de informação (MERCADO-LARA; GILGARCIA, 2014; ZUIDERWIJK; JANSSEN; DAVIS, 2014). Conforme apontado por Oliveira, Lima e Lóscio (2019), a teoria de ecossistema de dados é ainda incipiente, carecendo de uma definição consistente entre os trabalhos desenvolvidos nessa área, que se focaram mais na investigação de determinados componentes ou tecnologias que refletem somente uma pequena porção de todo o campo de pesquisa.

Dentro do ecossistema, um mesmo ator pode desempenhar diferentes papéis e é necessária a integração de diversas ferramentas para o uso e a publicação dos dados abertos. Mercado-Lara e Gil-Garcia (2014), Ding et al. (2011) e Ubaldi (2013) identificam 3 tipos básicos de stakeholders que interagem dentro de um ecossistema de dados: os produtores de dados (práticas e políticas governamentais), os usuários dos dados (sociedade civil e negócios) e os infomediários (consumidores intermediários, que organizam os dados, criam aplicações e analisam os dados). Mercado-Lara e Gil-Garcia (2014) e Immonen, Palviainen e Ovaska (2014) enfatizam as dependências entre os atores e elementos do ecossistema, de tal modo que quando um elemento é modificado, os efeitos podem ser sentidos por todo o sistema; assim os atores afetam e são afetados pela criação e entrega de recursos produzidos pelos outros atores - por exemplo, os consumidores dos dados são fortemente influenciados pela decisão de um fornecedor de dados de não mais publicar ou atualizar um conjunto de dados, mudar o formato da publicação, comprometer a qualidade dos dados ou mudar a licença de como eles podem ser usados (ZELETI; OJO, 2016).

Um ecossistema não se desenvolve somente por meio de governança top-down, mas pela interação proveitosa entre atores que competem e colaboram entre si (HEIMSTÄDT; SAUNDERSON; HEATH, 2014). Pollock (2011) enfatiza a natureza dinâmica do ecossistema, apontando ciclos de refinamento dos dados a partir de feedbacks, o compartilhamento de dados de volta aos publicadores e entre os infomediários, sugerindo o uso de ferramentas de integração automatizadas. Dawes, Vidiasova e Parkhimovich (2016) também argumentam que a compreensão do ecossistema de dados deve enfatizar um sistema auto-organizado e evolutivo de feedback e ajustes entre diferentes atores e processos.

Zuiderwijk, Janssen e Davis (2014) também apontam que o ecossistema de dados deve 
contemplar os seguintes requisitos essenciais: i) publicar dados na Internet; ii) possibilitar a busca, avaliação e visualização das respectivas licenças de dados; iii) possibilitar limpar, analisar, enriquecer, combinar, conectar e visualizar os dados; iv) possibilitar a interpretação e discussão dos dados e fornecer feedback ao publicador de dados e outros stakeholders; v) ilustrar possíveis cenários de como os dados podem ser usados; vi) garantir a gestão da qualidade que permita avaliar a qualidade dos dados; vii) apresentar diferentes tipos de metadados para garantir interoperabilidade e conectar apropriadamente diferentes elementos.

Schalkwyk, Willmers e McNaughton (2016) listam 3 fatores contextuais que promovem ou inibem o funcionamento dos elementos do ecossistema de dados: i) o contexto regulatório: que inclui leis, políticas, padrões e acordos, responsáveis por guiar como especificar como os elementos devem ser estruturados e relacionados; ii) contexto institucional, no qual os atores operam, contendo valores, regras e normas que regulam o comportamento dos atores no ecossistema; iii) contexto tecnológico, abordando os recursos de TI, seus operadores e as tecnologias para conectar os diferentes elementos. No Capítulo 3 ilustramos como são esses fatores no contexto brasileiro.

Zeleti e Ojo (2016) argumentam sobre os pré-requisitos necessários para que o ecossistema de dados possa se desenvolver. Os atores devem desenvolver um conjunto de competências e habilidades, como conhecimento geral sobre recursos do ecossistema de dados (sistemas e tecnologias), habilidades técnicas exigidas para gerenciar e processar os dados (ex.: integração e mineração dos dados) e conhecimento operacional para incorporar recursos relacionados aos dados em processos institucionais e de negócios (LEE, 2014). Além disso, os autores apontam também a garantia da disponibilidade de recursos (serviços, ferramentas, capital financeiro, capital humano, equipamentos, materiais e tecnologias proprietárias) para impulsionar o fornecimento e o consumo dos dados. Zuiderwijk et al. (2015) listam 3 categorias de recursos: i) recursos humanos, se referindo a indivíduos que usam suas habilidades para explorar os dados; ii) recursos de dados, se referindo aos ativos de dados, como bases de dados, bases de conhecimento ou arquivos de dados; iii) recursos de TI: se referindo ao hardware (infraestrutura, redes e computadores), plataformas e aplicações (software). Shin e Choi (2015) acrescentam outros elementos ao ecossistema: i) infraestrutura; ii) software e tecnologias; iii) serviços e aplicações; iv) padrões; v) usuários; vi) fatores sociais e culturais; vii) governo e viii) indústria. Zuiderwijk et al. (2015) enfatizam que, frequentemente, tais recursos devem ser combinados de modo a atender às expectativas de um ou mais atores.

Conforme apontado em mapeamento sistemático de Oliveira, Lima e Lóscio (2019), esta área de pesquisa carece da especificação de processos detalhados e sistemáticos, dada sua recente criação. Logo, esta pesquisa objetiva criar um modelo de processo que integre algumas dessas perspectivas do ecossistema de dados abertos, oferecendo dados conectados de qualidade, ao mesmo tempo que atende aos padrões e diretrizes estabelecidas pelos órgãos de regulação e da comunidade, buscando considerar os componentes de um sistema sociotécnico (KÖSTER; 
SUÁREZ, 2016; SHIN; CHOI, 2015; LEE, 2014). Como consequência, implementamos os requisitos listados por Zuiderwijk, Janssen e Davis (2014) sobre os ecossistemas de dado (citados acima) e abordamos as 3 categorias de recursos sugeridos por Zuiderwijk et al. (2015) (recursos humanos, de dados e de TI). Embora existam muitos desafios contextuais (políticas de dados abertos, financiamento, organização, dentre outros) esta pesquisa foca-se nas questões tecnológicas, apontando possíveis influências desse contexto dentro do processo de publicação dos dados.

\subsection{Qualidade de dados conectados}

Existem muitas discrepâncias na definição de conceitos de qualidade de dados devido à natureza contextual da qualidade (BATINI; SCANNAPIECO, 2006). Nesta seção, definimos a terminologia, as especificidades dos dados conectados, métodos de avaliação da qualidade de DAG e DAC e as dimensões e métricas de qualidade em dados conectados.

A qualidade de dados é comumente concebida como aptidão para o uso (JURAN; GRYNA, 1988), e depende de vários fatores, mais ou menos importantes de acordo com o domínio da aplicação, tais como acurácia, atualização, completude, relevância, objetividade, credibilidade, compreensibilidade, consistência, concisão, disponibilidade e verificabilidade (WANG; STRONG, 1996). O padrão ISO 25012 define qualidade de dados como "a capacidade dos dados de satisfazer necessidades implícitas e explícitas quando usadas em condições especificadas" (ISO, 2008). Ou seja, a habilidade de uma coleção de dados de atender aos requisitos dos usuários. Assim, a aptidão para o uso enfatiza a importância de levar em consideração o ponto de vista de qualidade do consumidor, o que faz com que sua avaliação seja composta por indicadores subjetivos, complexos de serem medidos automaticamente.

Kim (2002) argumenta ser necessário considerar que a oferta de dados de baixa qualidade aumenta os custos, em um sentido amplo - de acessar, limpar e interpretar os dados. Esses custos adicionais dependem de muitos fatores, como a natureza dos dados ou do tipo de uso e usuários. Tais custos para a qualidade são reportados na literatura, particularmente para empresas, afirmando que dados de qualidade são fundamentais para o sucesso de uma organização (HAUG; PEDERSEN; ARLBJØRN, 2009; EVEN; SHANKARANARAYANAN, 2009). O mesmo foi reportado para dados governamentais (ZUIDERWIJK; JANSSEN, 2015). Compreender conjuntos de dados mal documentados e realizar atividades de limpeza representam uma proporção significativa do esforço necessário para reutilizar dados abertos (VETRÒ et al., 2016). Deste modo, fica claro que quando dados de baixa qualidade são publicados como dados abertos, o reuso acaba desencorajado e os usuários desses dados investirão esforços para checar e aumentar essa qualidade - de maneira descentralizada e descoordenada.

A tradicional disciplina de qualidade de dados é uma área de pesquisa já bem desenvolvida com vários benchmarks e arcabouços para compreender suas dimensões (WANG; STRONG, 
1996; STVILIA et al., 2007; KAHN; STRONG; WANG, 2002). Muitos trabalhos foram desenvolvidos na área, mas enquanto tais abordagens servem como conhecimento subjacente para a medição da qualidade de dados conectados, eles não devem ser aplicados diretamente neste domínio. Isto porque, em essência, a qualidade de dados conectados é relacionada a novos aspectos como: a qualidade da representação dos dados ou à consistência em relação à informação apresentada em outros datasets publicados, qualidade da representação semântica, qualidade de dados como os metadados semânticos e a qualidade das ligações feitas (RULA; MAURINO; BATINI, 2016; NGOMO et al., 2014; BEHKAMAL et al., 2014). Além disso, mecanismos de inferência de conhecimento em dados abertos conectados geralmente seguem a premissa de mundo aberto, diferente das disciplinas de qualidade de dados baseadas em bases de dados relacionais, que utilizam a premissa de mundo fechado ${ }^{3}$.

Documentos Web são, por natureza, não estruturados e interligados, o que exige diferentes métricas de qualidade e técnicas de avaliação de dados em comparação com os tradicionais bancos de dados relacionais com dados estruturados - como por exemplo a métrica de importância e de qualidade de documentos Web, que são calculados por meio de algoritmos como o PageRank (PAGE et al., 1999). A garantia da qualidade em dados abertos conectados é um processo complexo, pois consiste de informações estruturadas apoiadas por modelos, ontologias e vocabulários, contendo repositórios de consultas livres (endpoints ou pontos de extremidade) e diversidade de interligações - o que a torna um grande desafio científico, com diversos tópicos sendo pesquisados atualmente.

Rula, Maurino e Batini (2016) listam cinco desafios únicos relacionados aos DAC: i) se referem a bases de conhecimento de dados publicados e interconectados a partir de múltiplos fornecedores autônomos de informação; ii) a difusão crescente do paradigma de DAC permite que consumidores explorem grande quantidade de dados e, conforme o tamanho cresce, fica mais difícil avaliar a qualidade desses dados; iii) conjuntos de dados conectados podem ser frequentemente usados por aplicações de terceiros de maneiras não esperadas pelos criadores do conjunto de dados; iv) a qualidade dos dados integrados é relacionada à qualidade das fontes de dados originais, o que não é simples de ser modelado; v) dados conectados relevantes podem mudar rapidamente e não serem assumidos estáticos, refletindo mudanças no mundo real, havendo o risco de se tornarem desatualizadas em tempo de seu uso.

A avaliação da qualidade de dados é o processo de analisar se os dados atendem às necessidades de seu consumidor em um caso de uso específico (BIZER; CYGANIAK, 2009). Por exemplo, bases de conhecimento como a DBpedia e YAGO contém dados extraídos a partir de fontes estruturadas e semi-estruturadas. Elas são usadas em diversas aplicações, como sistemas de anotações, buscas exploratórias e máquinas de recomendações. No entanto, seus dados não são integrados a sistemas críticos, como aplicações médicas ou de aviação, já que a

3 A suposição de mundo fechado assume que o que não é declarado na base de dados deve ser considerado como falso; já a suposição de mundo aberto assume que o que não é declarado na base de dados é considerado como desconhecido. 
qualidade de seus dados é insuficiente (ASSAF; SENART; TRONCY, 2016). A avaliação da qualidade é dependente de qual qualidade para quem, onde e quando. Assim, um arcabouço de avaliação de qualidade deve incluir diversas perspectivas e ser baseada em uma abordagem multidimensional. Por exemplo, em dados governamentais, ao selecionar indicadores para um benchmark ou mensuração, também deve ser levado em conta os ideais gerais (nacionais) como transparência, privacidade, regras das leis, objetivos e prioridades políticas, tais como eficiência, efetividade e participação social (JANSEN; ØLNES, 2016). A mensuração da qualidade pode ser descrita em termos objetivos ou subjetivos (SHEWHART, 1980), mais comumente por meio do uso de indicadores - estatística que sintetiza diferentes variáveis sobre uma determinada atividade. Um indicador objetivo denota o grau de conformidade a um processo ou sua saída com um conjunto pré-determinado de critérios que são assumidos como essenciais em relação ao valor que o dado fornece. Um indicador subjetivo afere o nível de valor percebido reportado pelas pessoas que se beneficiam de um processo ou seus produtos.

No contexto de dados abertos governamentais (DAG), existem diversos benchmarks internacionais, como o Open Data Barometer ${ }^{4}$ (com medições em torno de 3 categorias: prontidão dos dados por parte do governo e seus consumidores, implementação e disponibilidade dos dados, e impacto positivo políticos, econômicos e sociais), o Open data index ${ }^{5}$ (com 6 métricas sobre 15 datasets previamente selecionados definidos como de alta relevância), realizadas por órgãos independentes e que influenciam como diferentes governos nacionais disponibilizam seus dados. As métricas usadas nesses benchmarks são geralmente um subconjunto dos 8 princípios dos dados abertos governamentais. No entanto, nenhum deles avalia características relacionadas aos dados conectados.

Além disso, existe variação em relação à unidade de análise considerada, como na avaliação de portais de dados (ex.: Ubaldi, 2013), conjuntos de dados (ex.: Rula, Maurino e Batini, 2016), unidades atômicas dos dados (como as células de um arquivo estruturado) ou mesmo uma combinação entre eles (por ex.: Vetròet al., 2016 ); também e em níveis de granularidade, indo desde a porcentagem de células completas (VETRÒ et al., 2016) até medidas de alto nível como o impacto do uso dos dados abertos governamentais no país (UBALDI, 2013). Assaf, Senart e Troncy (2016) apresentam 4 diferentes níveis de granularidade, usando esta informação para definir o nível similar de categorias de Wang e Strong (1996): i) as entidades, abordando indicadores que se focam nos dados em nível de instâncias ou registros, ii) os conjuntos de dados: indicadores em nível de conjuntos de dados e distribuições; iii) modelo semântico: focam nos modelos semânticos, vocabulários e ontologias; iv) o processo de interligação: avalia as ligações que referenciam ou são referenciadas dentro dos dados.

A natureza de dados governamentais dificulta a avaliação da qualidade de seus conjuntos de dados, quando se leva em conta a perspectiva dos contextos específicos para avaliação. Isso se

\footnotetext{
$4<$ https://opendatabarometer.org/>

$5<$ https://index.okfn.org/place/>
} 
dá pois, geralmente, esses dados não são disponibilizados para uma aplicação específica, mas sim para serem os mais genéricos possíveis, atendendo a diferentes demandas da sociedade. Assim, é preciso encontrar um equilíbrio entre generalização e o compromisso com atributos mensuráveis de qualidade.

Um dos aspectos mais fundamentais sobre a qualidade dos dados diz respeito ao formato dos arquivos de dados disponibilizados. De acordo com os princípios propostos por Berners-Lee (2006), os conjuntos de dados devem ser disponibilizados em formatos cujos conteúdos sejam processáveis por máquinas. Por exemplo, uma mesma informação pode estar em um arquivo PDF ou CSV. Enquanto os valores podem ser processados a partir do arquivo CSV, esses mesmos valores não são processados diretamente a partir do PDF, pois estão confinados devido ao seu formato. Os mesmos valores podem estar em formato de planilha Excel, que necessitaria de aquisição de licença para processá-los. Deste modo, assume-se que dados abertos em formatos de dados interoperáveis aceleram o reuso dos dados (YI, 2019). Um exemplo de modelo de avaliação simples, que busca esse compromisso, é o esquema de 5-estrelas, mencionado anteriormente.

Em relação à estrutura dos construtos avaliados, parece existir certa convergência, em que conceitos mais amplos são definidos e são desmembrados em conceitos menores, até se chegar em métricas que podem ser medidas em relação aos dados ou à sua percepção pelas pessoas envolvidas em seu uso. Por exemplo, o modelo de qualidade apresentado pela ISO 25012 (ISO, 2008) define 15 características, consideradas a partir de dois pontos de vista: inerente aos dados (acurácia, completude, consistência, credibilidade e atualidade) e dependente do sistema (disponibilidade, portabilidade, recuperabilidade). As características complementares são consideradas tanto sob uma perspectiva quanto outra: acessibilidade, conformidade, eficiência, precisão, compreensibilidade e rastreabilidade. Sua extensão, o padrão ISO 25024 (ISO, 2015), complementa o modelo, ao definir métricas alinhadas às características definidas no padrão ISO 25012.

Wang e Strong (1996) desenvolveram um arcabouço para avaliar a qualidade de dados, no contexto de banco de dados relacionais, e sua estrutura foi replicada ou serviu de base para diversos arcabouços de avaliação de dados conectados (ZAVERI et al., 2016; RADULOVIC et al., 2018; FÄRBER et al., 2018; DEBATTISTA; LANGE; AUER, 2018). O arcabouço é composto por 3 níveis (do mais granular ao mais genérico):

- As métricas (ou atributos, critérios) de qualidade: é uma característica particular dos dados, tanto objetiva (por ex.: acurácia do dado) quanto subjetiva (por ex.: reputação da fonte de dados).

- As dimensões de qualidade: aspecto principal pelo qual a qualidade pode ser observada, comportando diversos critérios de qualidade para caracterizá-lo.

- As categorias de qualidade: agrupamentos mais amplos de dimensões e critérios. 
Assim, um passo fundamental para a avaliação da qualidade dos dados é a identificação de métricas-chave para medir a qualidade dos dados, essencial para fornecer uma melhor e mais sólida base para análises comparativas.

Não foram encontrados na literatura trabalhos que exploram a avaliação de DAC na interseção dessas duas abordagens, ou seja, considerando os dados abertos conectados e governamentais (DACG). Abordagens somente baseadas em DAG deixam de explorar características únicas dos dados conectados e, por sua vez, arcabouços de qualidade de DAC deixam de fora características importantes de dados governamentais. No escopo desta tese, utilizamos os pressupostos da qualidade para: definir um planejamento de garantia da qualidade no processo, criar mecanismos de verificação e validação dos artefatos intermediários e selecionar um conjunto de métricas pela qual o produto do processo pode ser avaliado.

\subsection{Metadados}

De modo a potencializar o reuso e benefícios dos DAG, os órgãos públicos devem tornar seus dados mais fáceis de buscar e reutilizar. Para isso, esses órgãos devem fornecer descritores precisos sobre seus conjuntos de dados para ajudar em sua identificação, localização e recuperação de recursos on-line pelos usuários de dados. Esses descritores são comumente conhecidos como metadados. Os metadados são geralmente concebidos como os "dados sobre os dados" (WOOLCOTT, 2017; DEMPSEY; HEERY, 1998). São informações estruturadas que descrevem, explicam e tornam as fontes de dados mais fáceis de serem localizadas, recuperadas e gerenciadas (WOOLCOTT, 2017). Para DAG disponíveis na Web, os metadados fornecem informações adicionais que auxiliam os consumidores desses dados a entender melhor o significado dos dados, sua estrutura, termos de licença de uso, a procedência dos dados, sua qualidade, métodos de acesso e frequência de atualização (W3C, 2017).

Este é um corpo de conhecimento que influencia diretamente o consumo de dados abertos (ZUIDERWIJK, 2015), pois para reutilizar um conjunto de dados publicado é necessário que seu usuário conheça o que está representado, seu possiveis valores, suas relações, seu escopo temporal, seus criadores, dentre outras características, para decidir se e como usá-los. Os metadados facilitam a integração de dados e informações de fontes de dados heterogêneas (JEFFERY, 2000) e auxiliam na descoberta de dados relevantes (JEFFERY et al., 2014).

Metadados estão presentes em diferentes formatos de arquivos, como em PDF, JPEG, WAV, arquivos do Microsoft Office, dentre outros, contendo principalmente aspectos descritivos dos arquivos. Por vezes, os metadados são confundidos com os próprios dados - em especial quando ambos são armazenados juntos, como é o caso de dados triplificados. No domínio dos dados conectados, eles desempenham papel importante, uma vez que o objetivo é conectar informações de diferentes fontes, sendo necessário explorar os metadados para que essa tarefa seja realizada com sucesso e facilitando que aplicações de software possam processar os dados 
em diferentes fontes. A Web é um espaço aberto de informações, em que a ausência de um contexto específico significa que o fornecimento de metadados é um requisito fundamental (W3C, 2017).

Embora apresente diversos benefícios, o fornecimento de metadados em iniciativas de DAG é muitas vezes inadequado (JURISCH et al., 2015; MARTIN; FOULONNEAU; TURKI, 2013; DAWES, 2010; DAWES; HELBIG, 2010), acarretando inconsistência de metadados e reduzindo o reuso de dados (MARTIN; FOULONNEAU; TURKI, 2013).

Deste modo, selecionamos este corpo de conhecimento como uma das teorias kernel a serem utilizados no projeto do artefato, dada sua importância no contexto dos dados conectados, em que se supõe que agentes de software possam aferir as características dos conjuntos de dados automaticamente. $\mathrm{O}$ modelo proposto deve incluir atividades e componentes para auxiliar a criação, catalogação e distribuição desses metadados.

\subsection{Modelo de dados 5 estrelas}

Berners-Lee (2006) propôs um esquema com 5 níveis, para denotar o grau de abertura dos dados conectados (Figura 9), em que cada nível acumula as características do nível anterior e o estende:

- 1 estrela: dados de qualquer formato, com licença de uso definida (ex.: PDF, imagens, HTML);

- 2 estrelas: dados estruturados legíveis por máquina (ex.: planilhas Excel);

- 3 estrelas: como o anterior, mas em formato não-proprietário (ex.: XML, CSV...);

- 4 estrelas: como o anterior, mas usando padrões da Web para representá-los (ex.: URIs, RDF, SPARQL);

- 5 estrelas: como o anterior, mas que esteja ligado a fontes externas, fornecendo maior contexto aos dados (DAC).

No primeiro nível, os dados estão na Web, sob uma licença aberta, todavia os dados estão contidos em um documento do qual não é possível se extrair de modo automático e facilitado, suas informações (por ex.: imagens, PDF, HTML). No entanto, é a forma mais simples de publicar e ainda é comumente utilizada por muitos governos como uma maneira rápida de atender a pedidos de acesso à informação.

No segundo nível, os dados estão disponíveis na Web, com a licença de uso especificada e em forma estruturada (linhas e colunas), mas para acessar os dados é necessário obter software proprietário (ex: documentos da suíte Microsoft Office). Ainda se trata de uma maneira simples de 
Figura 9 - Esquema que ilustra o grau crescente de abertura do formato dos dados, desde os mais fechados (à esquerda) ao mais aberto (direita, ao alto).

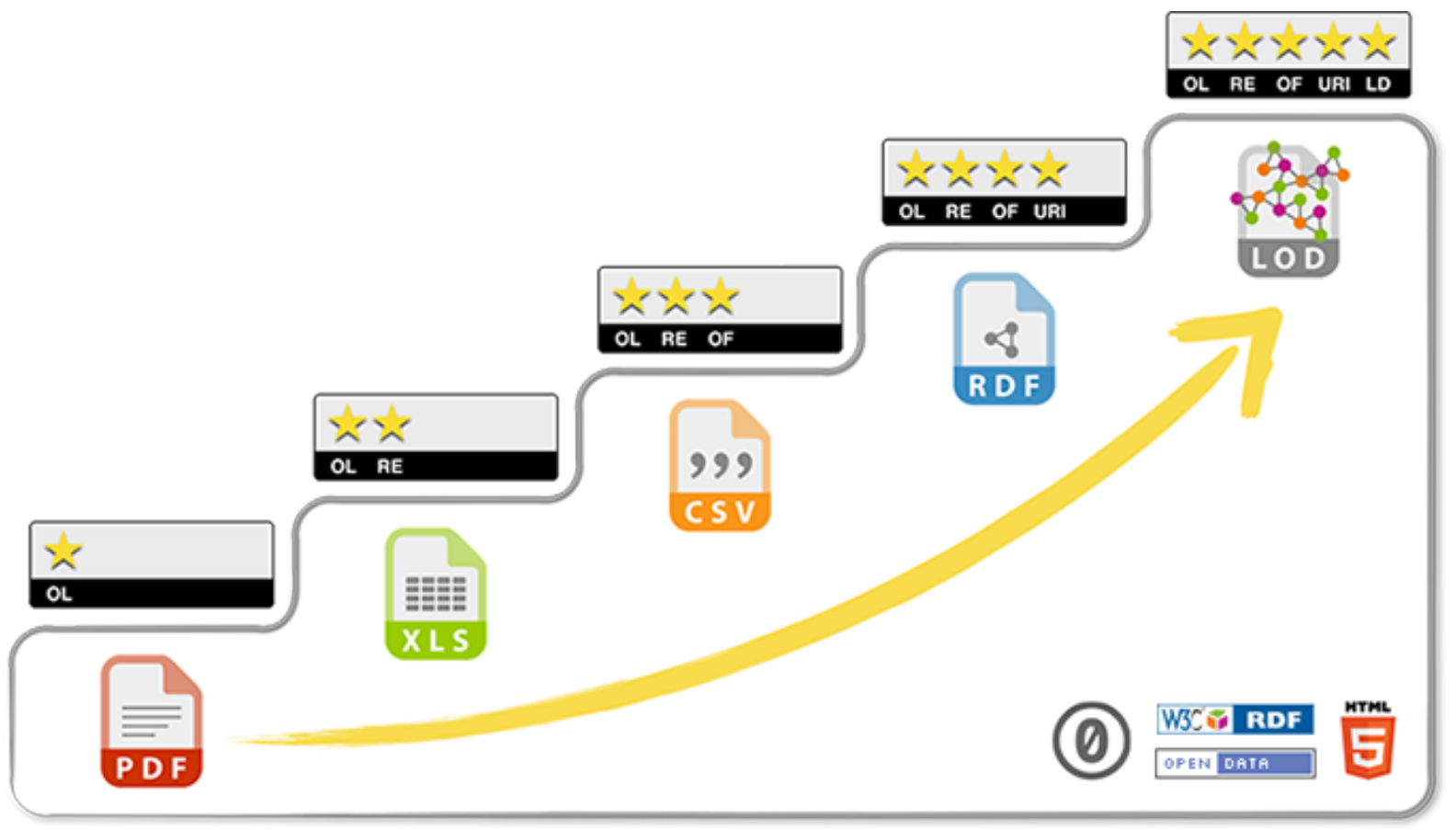

Fonte: Berners-Lee (2010).

publicar os dados, pois eles frequentemente são compilados nessas ferramentas e são colocados à disposição dessa mesma maneira, esperando que os consumidores tenham software compatível para acessá-los.

No terceiro nível, os dados estão disponíveis em formatos estruturados e não proprietários, como os CSV, XML, JSON, sem ser necessária a aquisição de licenças de software para processálos. Eles podem ser reprocessados mais facilmente, mas ainda assim se tratam de documentos na Web e seu conteúdo não é diretamente acessível. A grande maioria dos DAG publicados se encerra neste nível.

No quarto nível, os dados estruturados são representados por meio do modelo de dados RDF. Os itens de dados são identificados por URIs e podem ser compartilhados na Web, podendo ser referenciados ou reutilizados em partes e não mais considerando o arquivo como um todo. Os dados são anotados semanticamente, por meio de vocabulários disponíveis na Web que permitem que máquinas e humanos possam acessá-los e interpretá-los. É necessário um processamento considerável por parte dos publicadores. Aqui são atendidos 3 dos 4 princípios básicos dos dados conectados (usar URI para identificar coisas; usar URIs HTTP para serem acessados na Web e o fornecimento de informações usando padrões da Web).

Por fim, no quinto nível os dados em RDF são conectados a outras fontes de dados, podendo enriquecê-los ou prover dados suplementares de contexto. Nele, é atendido o último princípio dos dados conectados (incluir conexões para URIs de outras organizações) e com isso, 
obtém-se um efeito em rede, ao se reaproveitar as conexões feitas com as fontes conectadas. Como a Web é um grande sistema descentralizado, podem ocorrer problemas de conexões quebradas ou incorretas.

Desta maneira, para o objetivo desta tese, deve-se implementar o esquema de 5 estrelas em seu nível mais alto de abertura, com dados em formato RDF e conectados a outros conjuntos de dados disponíveis na Web e que, por sua vez, já satisfaz os princípios básicos dos dados conectados (BERNERS-LEE, 2006).

\subsection{Implementação dos requisitos}

A partir da conjectura teórica proposta, foram selecionadas práticas para o atendimento dos requisitos levantados anteriormente. A seguir, são especificadas as práticas que implementam o arcabouço teórico adotado e como elas atendem aos requisitos levantados, atendendo à QP3 (Que elementos caracterizam uma infraestrutura que gere DAGC de qualidade para o ecossistema de dados na Web?).

\subsubsection{Compartilhamento de dados na Web}

Vislumbrando o nascimento dos modelos de ecossistema de dados, Lóscio, Burle e Calegari (2017) propuseram um documento de boas práticas, o Data on the Web Best Practices (DWBP, ou Melhores Práticas para os Dados na Web, em tradução livre). A DWBP foi aceita como recomendação pela $\mathrm{W} 3 \mathrm{C}$ e traz um conjunto de práticas relacionadas à publicação e uso de dados na Web, projetada para apoiar um ecossistema autossustentável, facilitando a comunicação entre publicadores e consumidores (W3C, 2017). Seu objetivo principal é fazer com que os dados sejam encontrados e compreendidos tanto por humanos quanto por computadores, facilitando a interação entre produtores e consumidores dos dados, oportunizando dados precisos, regularmente atualizados e disponíveis o tempo todo. Além disso, visa fomentar a expansão continuada da Web como meio para a troca de dados e, com isso, tirar proveito máximo das suas capacidades, como promover o reuso dos dados, a habilidade de ligar um fato a outro, descobrir recursos relacionados e criar visualizações interativas (W3C, 2017).

Enquanto que classificações como o esquema de 5 estrelas (BERNERS-LEE, 2006) buscam apresentar um grau de abertura quanto ao formato dos arquivos, a recomendação DWBP traz práticas mais amplas, ancoradas nas capacidades técnicas da arquitetura da Web, e que envolve como os dados são entregues, codificados, mantidos e do relacionamento entre os produtores e consumidores desses dados, estendendo os princípios dos dados abertos governamentais. Esta recomendação tem como prática geral o reaproveitamento de padrões já estabelecidos na Web para a recuperação das informações, conforme também recomendado por Berners-Lee para a publicação de dados conectados. A Figura 10 demonstra uma visão geral dos principais conceitos relacionados à DWBP. 
Neste trabalho adotamos a nomenclatura usada na recomendação: datasets (conjuntos de dados) e distribuições. O dataset é uma coleção de dados, publicada ou mantida por um único agente, não sendo necessariamente na forma de um arquivo em torno de um assunto específico. A distribuição representa uma forma física específica do dataset, podendo ser arquivos, APIs ou feeds RSS. É também chamada de recurso em algumas plataformas.

Figura 10 - Modelo dos principais conceitos e seus relacionamentos dentro da DWBP.

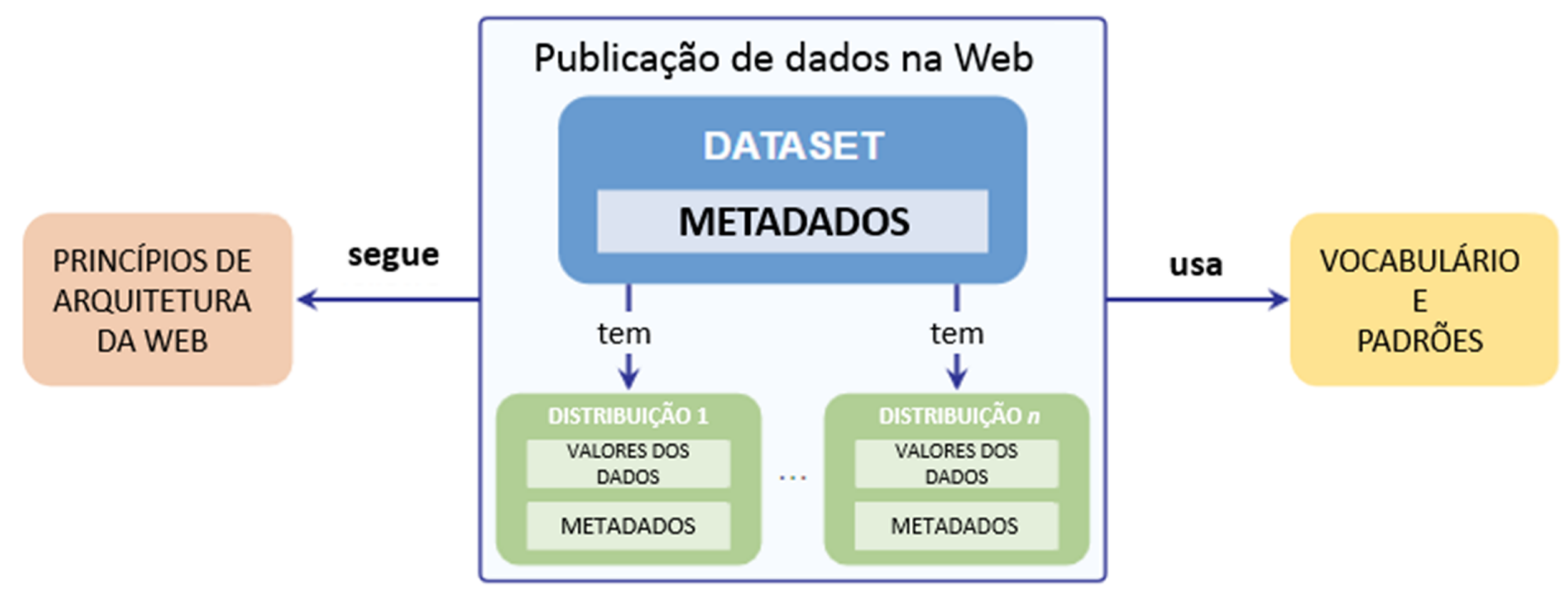

Fonte: W3C (2017).

A recomendação DWBP é composta por 35 práticas distribuídas em 12 dimensões:

1. Metadados (como fornecer metadados para humanos e computadores?): fornecer metadados (BP1); fornecer metadados descritivos (BP2); fornecer metadados estruturais (BP3);

2. Licença dos dados (como permitir/restringir o acesso?): fornecer informações sobre as licenças para os dados (BP4);

3. Proveniência e qualidade (como adicionar qualidade?): fornecer informações sobre a proveniência dos dados (BP5); fornecer informação sobre a qualidade dos dados (BP6);

4. Versionamento dos dados (como localizar diferentes versões e seus históricos?): fornecer indicador de versões (BP7); fornecer histórico de versões (BP8);

5. Identificação dos dados (como identificar datasets e distribuições?): usar URIs persistentes como identificadores de datasets (BP9) e dentro dos datasets (BP10); atribuir URIs para versões de datasets e séries (BP11);

6. Formato dos dados (que formatos de dados usar?): usar formatos padronizados, processáveis por computador (BP12); usar representações neutras de localidade (BP13); fornecer os dados em múltiplos formatos (BP14); 
7. Vocabulário para os dados (como melhorar a interoperabilidade dos dados?): reusar vocabulários, preferencialmente os padronizados (BP12); escolher o nível correto de formalização (BP14);

8. Acesso aos dados (como fornecer acesso aos dados?): fornecer download em massa (BP15); fornecer subconjuntos do datasets como um todo (BP16); usar negociação de conteúdo para acessá-los sob diferentes formatos (BP17); fornecer acesso em tempo real (BP17); fornecer dados atualizados (BP18); fornecer explicação para dados que não estejam mais disponíveis (BP19); tornar os dados disponíveis por meio de API (BP20); usar padrões da Web como fundamento para a API (BP21); fornecer documentação completa para a API (BP22); evitar mudanças que causem quebras na API (BP23);

9. Preservação dos dados (como os dados podem ser arquivados?): preservar os identificadores (BP27); avaliar a cobertura do dataset (BP28);

10. Feedback (como engajar os usuários?): coletar feedback dos consumidores dos dados (BP29); tornar o feedback disponível (BP30);

11. Enriquecimento dos dados (como adicionar valor aos dados?): enriquecer dados ao gerar mais dados (BP31); fornecer apresentações complementares dos dados (BP32);

12. Republicação dos dados (como reusar responsavelmente os dados?): fornecer feedback para o publicador original (BP33); seguir os termos das licenças (BP34); citar a publicação original (BP35);

A Quadro 14 detalha as 35 práticas que fazem parte da DWBP.

Quadro 14 - Práticas do arcabouço DWBP sobre as dimensões selecionados.

\begin{tabular}{|l|l|}
\hline \multirow{2}{*}{ Dimensão } & Prática \\
\hline \multirow{4}{*}{ Letadados } & BP1 - Fornecer metadados \\
\cline { 2 - 2 } & BP2 - Fornecer metadados descritivos \\
\cline { 2 - 2 } & BP3 - Fornecer metadados estruturais \\
\hline Procedência dos dados & BP4 - Fornecer informação de licença de dados \\
\hline Versionamento dos dados & BP6 - Fornecer informação sobre procedência dos dados \\
\hline \multirow{3}{*}{ Formato dos dados } & BP7 - Fornecer indicador de vebre qualidade dos dados \\
\cline { 2 - 3 } & BP8 - Fornecer histórico de versão \\
\cline { 2 - 3 } & $\begin{array}{l}\text { BP9 - Usar URIs persistentes como identificadores dos data- } \\
\text { sets }\end{array}$ \\
\hline
\end{tabular}




\begin{tabular}{|c|c|}
\hline Dimensão & Prática \\
\hline & $\begin{array}{l}\text { BP10 - Usar URIs persistentes como identificadores dentro } \\
\text { dos datasets }\end{array}$ \\
\hline & BP11 - Atribuir URIs para versões e séries dos datasets \\
\hline \multirow{3}{*}{ Vocabulário dos dados } & BP12 - Usar formatos de dados processáveis por computador \\
\hline & $\begin{array}{l}\text { BP13 - Usar representações de dados com neutralidade de } \\
\text { localidade (datas, moedas, números) }\end{array}$ \\
\hline & BP14 - Fornecer dados em formatos múltiplos \\
\hline \multirow{2}{*}{ Acesso aos dados } & BP15 - Reusar vocabulários, de preferência padronizados \\
\hline & BP16 - Escolher o nível correto de formalização \\
\hline \multirow{10}{*}{ Preservação dos dados } & BP17 - Fornecer download em massa \\
\hline & BP18 - Fornecer subconjuntos para datasets grandes \\
\hline & $\begin{array}{l}\text { BP19 - Usar negociação de conteúdo para servir os dados em } \\
\text { múltiplos formatos }\end{array}$ \\
\hline & BP20 - Fornecer acesso em tempo real \\
\hline & BP21 - Fornecer dados atualizados \\
\hline & $\begin{array}{l}\text { BP22 - Fornecer explicação para os dados que não estiverem } \\
\text { disponíveis }\end{array}$ \\
\hline & BP23 - Tornar os dados disponíveis por meio de uma API \\
\hline & BP24 - Usar padrões Web como fundamentos da API \\
\hline & BP25 - Fornecer documentação completa para a API \\
\hline & BP26 - Evitar quebras na API \\
\hline \multirow{2}{*}{ Preservação dos dados } & BP27 - Preservar os identificadores \\
\hline & BP28 - Avaliar a cobertura do conjunto de dados \\
\hline \multirow{2}{*}{ Feedback } & BP29 - Coletar feedback dos consumidores dos dados \\
\hline & BP30 - Tornar o feedback disponível \\
\hline \multirow{2}{*}{$\begin{array}{l}\text { Enriquecimento dos } \\
\text { dados }\end{array}$} & BP31 - Enriquecer os dados ao gerar novos dados \\
\hline & BP32 - Fornecer apresentações complementares dos dados \\
\hline \multirow{3}{*}{ Republicação } & BP33 - Fornecer feedback ao publicador original \\
\hline & BP34 - Seguir os termos de licença \\
\hline & BP35 - Citar a publicação original \\
\hline
\end{tabular}

Fonte: elaborada pelo autor.

Lóscio, Burle e Calegari (2019) analisaram dois casos, um no Brasil e outro na Costa Rica, sobre o atendimento das práticas do DWBP em dois órgãos que publicam DAG, apontando as práticas mais facilmente cobertas e as que apresentaram maiores desafios para serem implementadas. Em ambos os casos, um subconjunto de práticas (BP10, BP20, BP23-26, BP31, BP33-35) não puderam ser adotadas, exigindo conhecimento técnico avançado. Penteado, Bitten- 
court e Isotani (2019a) realizaram um estudo exploratório em bases educacionais brasileiras para investigar o grau de adesão a essas práticas. Neste caso, foram encontradas poucas evidências de conformidade à DWBP, mesmo se tratando de dados maduros. Os autores apontam que muitas dessas práticas não são dependentes dos dados em si, mas de toda sua infraestrutura de suporte à publicação. No primeiro estudo, houve alinhamento prévio com os publicadores dos dados, o que não ocorreu no segundo caso - explicando, assim, a discrepância nos resultados de conformidade à DWBP. Martino, Rosim e Quarati (2019) também exploraram o atendimento de um subconjunto de práticas da DWBP e da FAIR ${ }^{6}$ em conjuntos de DAG hidrográficos em 19 países, oferecendo recomendações para futuras publicações de dados na área. Veeckman et al. (2017) oferecem recomendações e práticas para a publicação de dados de transporte e mostra seu alinhamento com as práticas da DWBP, em termos de reuso, processamento e descoberta dos dados.

As práticas sugeridas pela DWBP estão alinhadas às características do ecossistema de dados, como os requisitos descritos em Zuiderwijk, Janssen e Davis (2014). Desse modo, a infraestrutura e o modelo de ciclo de vida propostos devem contemplar a adoção dessas práticas para atender aos requisitos do ecossistema de dados, com atividades que regulam as interações da publicação de dados com o que é necessário para seu compartilhamento, processamento e reuso.

\subsubsection{Garantia e controle da qualidade}

A garantia da qualidade, no domínio da engenharia de software, é um conjunto de ações sistemáticas e planejadas necessárias para fornecer confiança adequada que o processo de produção ou de manutenção está em conformidade com requisitos técnicos estabelecidos (GALIN, 2004; IEEE, 1991). Esta prática tem por objetivo aprimorar o processo de produção, identificando pontos de melhoria no processo e propondo atividades que possam mitigar a ocorrência de novos problemas, tendo caráter mais preventivo. Essas atividades almejam prevenir a causa dos erros, detectá-los e corrigi-los o mais cedo possível durante o processo de desenvolvimento e reduzir a proporção de produtos do processo que não se qualificam para o uso. A garantia da qualidade não se restringe ao processo de produção em si, mas todos os passos relacionados ao processo.

Outro conceito relacionado importante é o de controle da qualidade, definido como um conjunto de atividades projetadas para avaliar a qualidade de um produto desenvolvido (IEEE, 1991), ou seja, atividades cujo objetivo principal seja inspecionar se o produto desenvolvido atende aos requisitos técnicos especificados para ele, durante seu ciclo de vida. Assim, pode-se considerar que o controle da qualidade é um subconjunto da garantia da qualidade. Uma nomenclatura alternativa usada para o controle de qualidade são chamadas atividades de verificação $e$ validação (V\&V). De acordo com o padrão IEEE 1012 (IEEE, 2016) os processos de verificação

$6<$ https://www.go-fair.org/fair-principles $>$. Arcabouço para gestão e curadoria de dados científicos, que fornece recomendações em publicação de dados, acessibilidade, interoperabilidade e usabilidade. 
e validação são processos técnicos de controle de qualidade, aplicado na engenharia de sistemas, software ou hardware, para demonstrar se os requisitos estão corretos, completos, precisos, consistentes e testáveis. Os processos de V\&V determinam se o desenvolvimento de produtos em uma dada atividade estão em conformidade aos requisitos daquela atividade e se o produto satisfaz sua intenção de uso e as necessidades de seu usuário. Uma concepção simplificada desses construtos é a de que na verificação questiona-se se o produto está sendo construído corretamente, considerando a aderência aos requisitos levantados, e na validação questiona-se se o produto correto está sendo construído, no sentido de o produto realmente servir para o uso em situações reais para o qual ele foi concebido.

Uma instanciação de um ciclo de vida pode não necessitar de execução de todos seus passos. Do mesmo modo, se um projeto de publicação usa somente determinadas atividades de produção, então a conformidade de qualidade é obtida se o mínimo de tarefas de V\&V são implementadas para todas atividades do ciclo de vida selecionadas para o projeto, sendo opcionais para as atividades de produção não atendidas pelo projeto de publicação.

O padrão IEEE 1012 traz proposições de especificação e gerenciamento para controle de qualidade em hardware, software e sistemas mistos. Até o momento, não existe na literatura algo parecido, integrado ao processo de publicação de dados. Na literatura, foram desenvolvidas duas vertentes em relação à qualidade de produção de DAGC: i) a concepção de fase específica para aferição da qualidade dos dados já produzidos segundo algum arcabouço de métricas de qualidade e ii) métodos de controle de qualidade pontuais, geralmente por meio de ferramentas que aferem a qualidade dos dados - em ambos os casos não se trata de algo sistematicamente integrado ao longo de um processo de ciclo de vida.

Para o primeiro caso, Ngomo et al. (2014) propõem um ciclo de vida para publicação de dados conectados que contém uma fase específica chamada de análise da qualidade, usada para determinar a qualidade de conjuntos de dados e torná-la disponível explicitamente. Behkamal et al. (2014) também apresentam uma fase distinta de controle da qualidade durante o processo, conduzida logo após a conversão de dados para o formato RDF, em torno de 5 características de qualidade baseadas no framework ISO/IEC 25012.

Como exemplo do segundo caso, Kontokostas et al. (2014) desenvolveram uma metodologia baseada no desenvolvimento dirigido a testes, que realiza testes em bases de conhecimento para avaliar seu grau de qualidade. Por meio deste método, são gerados automaticamente casos de teste no padrão SPARQL e em padrões previamente definidos, e que são aplicados na base, para verificar inconsistências baseadas em erros comuns de modelagem semântica e também em verificações personalizadas para o domínio da base de dados. Neste caso, os testes são feitos sobre os dados (triplas que armazenam os esquemas e os dados em si) e não sobre software como em outras metodologias de qualidade baseadas em engenharia de software e é realizado ao final do processo de publicação dos dados, quando já estão publicados em um servidor que responde a consultas no padrão SPARQL. Outros trabalhos também exploraram os testes para avaliação 
da qualidade em bases de dados conectados, como em Guéret et al. (2012), Flemming (2010), Mendes, Mühleisen e Bizer (2012) com a ferramenta Sieve, e Bizer e Cyganiak (2009) com a ferramenta WIQA.

Na proposta desta tese, são adotadas práticas de ambos os conceitos. A garantia da qualidade é aplicada para determinar o planejamento das atividades a cada passo do ciclo de vida, envolvendo diferentes técnicas. Já o controle da qualidade é utilizado em determinados passos, com o objetivo de 'testar' se o produto daquela fase está em conformidade com os requisitos técnicos estabelecidos para a etapa em questão. A validação é um problema no caso de dados abertos, uma vez que eles são abertos para atender pedidos mais genéricos, normalmente via abertura passiva ou ativa. Para aliviar este problema, o processo proposto contempla a interação com a comunidade interessada nos dados, de modo a se levantar requisitos mínimos e que podem ser validados e verificados ao longo do processo.

\subsubsection{Metadados para dados conectados}

Como apontado anteriormente, os metadados são essenciais para potencializar o reuso de DAG, uma vez que esses dados têm a intenção de servir ao público geral, em sua diversidade de cenários, e não a uma aplicação específica. No escopo dos DAGC, os metadados são ainda mais importantes pois fornecem os requisitos para que fontes de dados heterogêneas possam ser alinhadas, conectadas e reaproveitadas, usando processamento automático.

Tradicionalmente, o vocabulário Dublin Core, criado e desenvolvido para descrever objetos digitais na Web, tem sido talvez o mais usado em iniciativas de DAG. No caso do governo federal brasileiro, em que os metadados obrigatórios e opcionais são especificados pela cartilha técnica da INDA $^{7}$, todos os metadados podem ser mapeados para termos deste vocabulário.

Esta área tem avançado recentemente, com a publicação de diversas recomendações ou padrões, tanto de domínios genéricos como específicos. Esta tese pretende trazer um modelo genérico de metadados para dados conectados, que podem ser reproduzidos em qualquer cenário, independente de seu domínio. Para isso, os seguintes vocabulários de metadados para dados conectados foram levantados:

- Data Catalog Vocabulary (DCAT): criado em 2012 e atualizado em 2020, é um vocabulário RDF projetado para facilitar a interoperabilidade entre catálogos de dados publicados na Web;

- Vocabulary of Interlinked Datasets (VoID): criado em 2011, é um vocabulário RDF para expressar metadados sobre conjuntos de dados em RDF, trazendo termos para descrever metadados de acesso (diferentes protocolos), estruturais (schema dos conjuntos de dados

7 <http://www.dados.gov.br/pagina/cartilha-publicacao-dados-abertos> 
para serem usadas em tarefas de integração) e de conexões entre conjuntos de dados (como diferentes conjuntos de dados são relacionados e podem ser combinados);

- Service Description (SD): criado em 2013, é um vocabulário RDF para descrever serviços SPARQL, fornecendo mecanismos pelo qual um usuário pode descobrir informações sobre o serviço SPARQL tais como funções suportadas e detalhes sobre os conjuntos de dados disponíveis;

- Provenance Ontology (PROV): criado em 2011, é um vocabulário RDF usado para representar e trocar informações de proveniência de dados gerados em diferentes sistemas e diferentes contextos.

- Data Quality Vocabulary (DQV): criado em 2015, é um vocabulário RDF que descreve a qualidade de um conjunto de dados. A qualidade não é apresentada de modo formal, mas sim por meios pelos quais as informações podem ser fornecidas de tal modo que os usuários possam julgar a aptidão para o uso do conjunto de dados.

Outros metadados podem ser utilizados, porém os vocabulários citados cobrem os requisitos necessários para a disponibilização dos DAGC. Neste trabalho, esses vocabulários serão empregados para a criação de um modelo básico de metadados para apoiar o modelo de ciclo de vida proposto, contribuindo para potencializar o compartilhamento dos conjuntos de dados na Web e para aferir e descrever a qualidade dos dados conectados produzidos ao final do processo.

\subsection{Considerações finais}

Neste capítulo, apresentamos o referencial teórico adotado para embasar os artefatos proposto nesta tese, ao descrever seus requisitos e as práticas relacionadas que são usadas para concretizar esses requisitos do design da infraestrutura proposta.

Com base na fundamentação teórica apresentada, são levantadas as seguintes funções a serem atendidas no design da infraestrutura:

- Dados conectados: promover o atendimento ao nível mais alto de abertura de dados de acordo com o esquema de 5 estrelas, ou seja, produzir dados semânticos com conexões a diferentes fontes de dados;

- Governo aberto/dados abertos governamentais: atender aos requisitos de qualidade e acessibilidade da informação, bem como fornecer meios de comunicação com a comunidade; a qualidade aqui é considerada em função das características específicas de dados conectados; 
- Ecossistema de dados: incluir atividades que intermedeiam a publicação dos dados conectados com a comunidade e que permitam uma melhor descrição dos dados, facilitando buscar, arquivar, explorar, reutilizar e combinar os dados publicados;

- Metadados: descrever informações importantes sobre os conjuntos de dados produzidos, em particular para metadados relevantes para o cenário de dados conectados, de qualidade e do ecossistema da Web.

A recomendação DWBP aborda, dentre suas diversas práticas, tópicos de qualidade e de metadados. No entanto, entendemos que essas são áreas importantes por si só e que não foram devidamente contempladas com a profundidade necessária nas práticas prescritas. Assim, procuramos estender essas práticas com outras práticas específicas dessas áreas, cientes de que podem existir sobreposições das práticas dessas áreas de conhecimento com o que é previsto na DWBP 

CAPÍTULO

\section{5}

\section{INFRAESTRUTURA PARA DADOS ABERTOS GOVERNAMENTAIS CONECTADOS}

Neste capítulo, detalhamos o desenvolvimento da infraestrutura proposta. Nele, é mostrado como os requisitos apresentados no Capítulo 2 e atendidos pelo referenciais teórico e tecnológico do Capítulo 4 são implementados e integrados no modelo, especificando suas fases. Para o modelo de ciclo de vida, cada fase é decomposta em atividades menores e, para cada atividade, são descritos: ações para execução; suas saídas; os controles necessários; as possíveis ferramentas e os papéis envolvidos.

No Capítulo 3, de estado da arte, foram apresentadas metodologias, processos e ciclos de vida para a publicação de DAGC. Entretanto, nenhuma dessas propostas supera todos os desafios postos no Capítulo 1 e que são questões de pesquisa desta tese. Assim, o modelo de ciclo de vida apresentado neste capítulo visa integrar as áreas relacionadas de maneira a abranger as questões de pesquisa apresentadas, por meio da sistematização e padronização de processos, artefatos e ferramentas.

Neste capítulo, descrevemos uma infraestrutura para a publicação de DAGC, ao considerar: i) uma arquitetura conceitual, no qual são mapeados os componentes que podem ser usados para atender aos requisitos levantados; ii) um modelo de processo ${ }^{1}$ de publicação, contendo a dinâmica de atividades a serem conduzidas; iii) um racional de escolha de ferramentas, para auxiliar no processo de escolha de ferramentas em determinado contexto; iv) um modelo genérico de metadados a ser utilizado em diferentes implementações de DAGC; v) os papéis recomendados para o processo, com seus conhecimentos específicos contribuindo para o objetivo geral.

1 Aqui, adotamos o termo processo para indicar as atividades. Consideramos o processo como um subconjunto do ciclo de vida, ao considerar este como a repetição iterativa do processo, até o término do uso dos dados. 
Deste modo, é especificada uma infraestrutura que integra mecanismos de controle de qualidade, metadados e práticas de compartilhamento no ecossistema de dados às práticas estabelecidas de publicação de dados conectados.

A hipótese trabalhada nesta tese é de que a infraestrutura de publicação de DAGC aqui proposta pode ser usada como um meio eficaz de publicar DAGC de qualidade. Por essa razão, adotamos a metodologia DSR para projetar e avaliar o artefato - entendido aqui como em Hevner et al. (2004) no sentido de "algo que pode ser transformado em um material (por ex: modelo) ou processo (método)". Este método é um meio particularmente efetivo de desenvolver e avaliar novos artefatos que podem resolver problemas organizacionais identificados (HEVNER et al., 2004).

\subsection{Visão geral}

A Figura 11 ilustra, em alto nível, a relação dos requisitos levantados a partir do referencial teórico do Capítulo 4 e que foram implementados no modelo de infraestrutura proposto nesta tese. Os requisitos relacionados ao ecossistema, que trata dos compromissos de compartilhamento de dados entre produtores e consumidores dos dados usando arquitetura básica da Web, são atendidos pelas práticas do Data on the Web Best Practices (W3C, 2017). Algumas de suas práticas também atendem ao pilar de colaboração com a comunidade do governo aberto. O pilar do governo aberto é parcialmente atendido (exceto o pilar de Empoderamento), por meio das práticas de controle da qualidade embutidas no processo. Os metadados aportam práticas, padrões e modelos de informações a serem incorporados no ciclo de vida e adequados ao contexto de dados conectados. Em relação ao formato dos dados, é adotado o esquema de 5 estrelas de Berners-Lee, que tem por mais alto grau aquele em que os dados estão anotados semanticamente e ligados a outras fontes de dados. Por fim, ao abordar certas áreas consolidadas (especialmente no modelo de ciclo de vida), optamos por reutilizar os mesmos passos das diferentes propostas, integrando-as e fazendo adaptações onde cabível.

Figura 11 - Implementação dos requisitos derivados da conjuntura teórica.

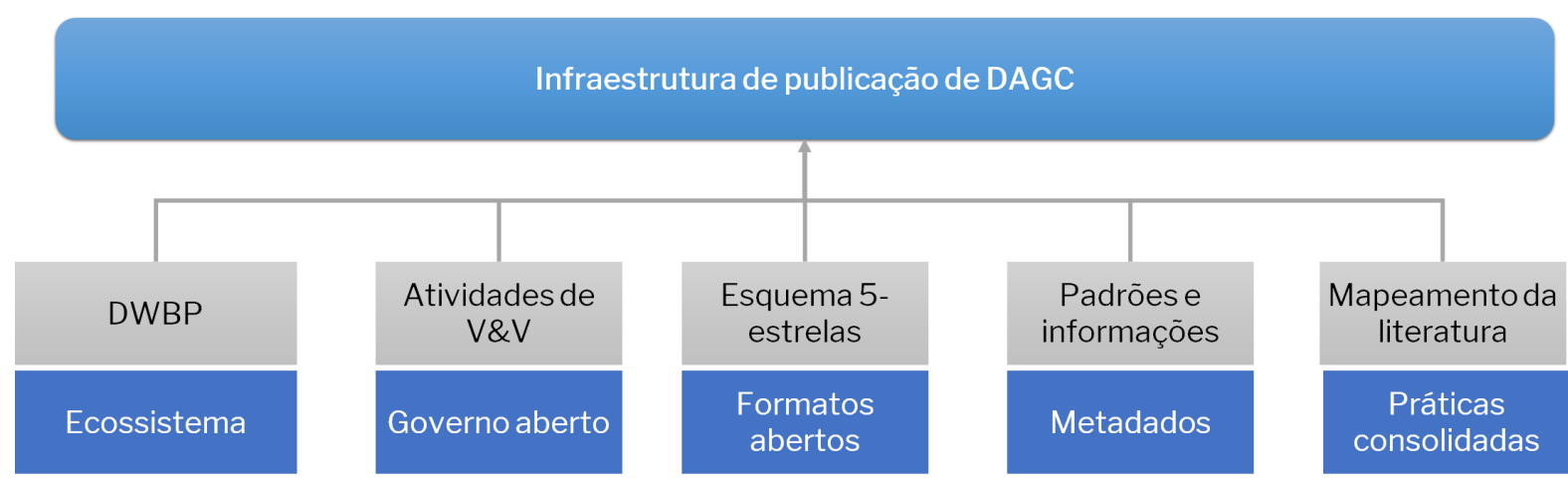

Fonte: Elaborada pelo autor. 
Como apontado por van den Broek, van Veenstra e Folmer (2014), um ciclo de vida é uma verificação de um sistema ou de uma proposta de sistema que aborda todas as fases de sua existência. Frequentemente, modelos de ciclo de vida estão associados com o desenvolvimento de produtos tangíveis, serviços ou outros ativos como o desenvolvimento de software. Neste contexto, um modelo de ciclo de vida define os processos que se aplicam ao software por todo seu ciclo. Junto a esses processos, também especifica papéis, atividades, tarefas e saídas de cada fase do ciclo, servindo como um corpo comum de linguagem. Modelos de ciclo de vida servem a dois propósitos (LANE; RICHARDSON, 2011): i) descrevem o desenvolvimento de certo fenômeno e ii) prediz os próximos passos no desenvolvimento. Em contraste aos modelos de maturidade, os modelos de ciclo de vida não estabelecem estágios organizacionais.

Na Figura 13 ilustramos uma visão geral do modelo de ciclo de vida proposto, com suas 6 fases (Especificação, Modelagem, Conversão, Publicação, Exploração e Manutenção), respectivas atividades e saídas, pontos de verificação de qualidade e de registro de metadados. A Figura 12 demonstra a organização de seus componentes. Cada camada representa uma fase, se desenvolvendo no sentido das flechas. Cada fase contém suas atividades, podendo elas serem obrigatórias ou opcionais. Ao final da fase, são especificados quais os produtos esperados. Ainda, são apontadas a existência de mecanismos de controle de qualidade durante a fase e a geração de metadados.

Figura 12 - Componentes do modelo de ciclo de vida proposto.

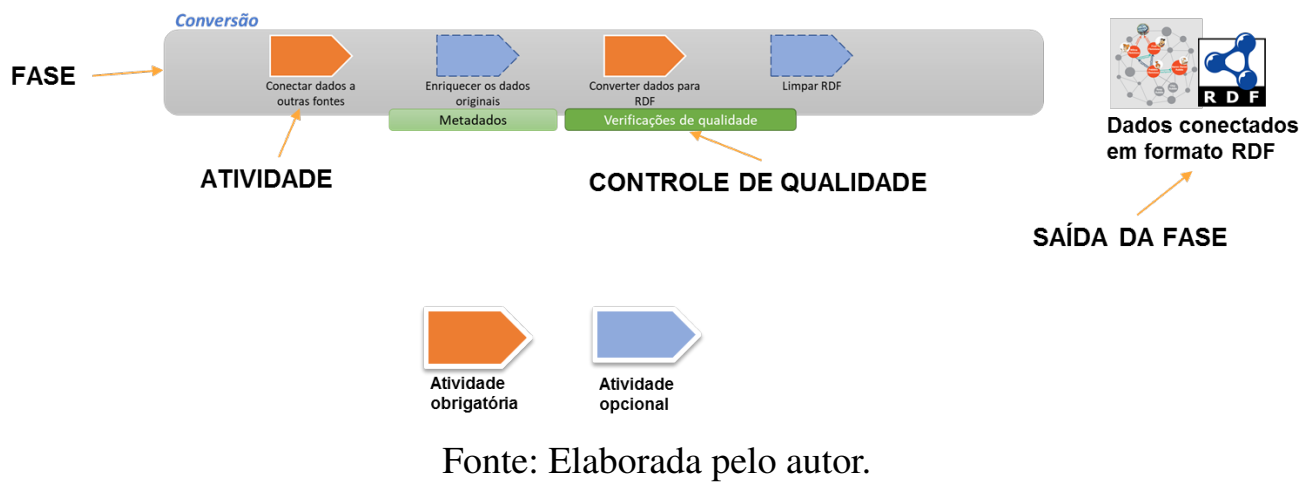

Como este modelo pode ser aplicado em diferentes cenários, cada um pode demandar diferentes graus de adaptação ou de formalidade na sua execução. Em uma análise mais simples, o processo pode ser conduzido somente com as atividades obrigatórias (como adotado em boa parte da literatura), no entanto, o potencial de reuso das bases de dados ficam comprometidos, uma vez que se torna mais difícil que potenciais consumidores possam encontrar, interpretar, reutilizar e analisar os dados sem a execução das outras atividades. Do mesmo modo, a escolha de não executar um passo ou outro não implica em produzir os dados com menor qualidade, mas sim em não abordar certos aspectos (mais severos ou menos) que podem influenciar na sua reutilização. Por exemplo, podem existir casos em que os dados já estão em um determinado formato que não necessite de limpeza ou de normalização. Portanto, essas atividades não precisam ser conduzidas 
e, mesmo assim, a qualidade e o potencial de reuso dos dados se mantém. Outro fator que pode influenciar a seleção dos passos é o esforço e custo necessários para sua execução. Pode haver situações em que determinada atividade se mostre custosa demais para o contexto e que, portanto, não valem a pena de serem conduzidas. Por exemplo, a existência de dados faltantes na base de dados. Em vez de aplicar algum algoritmo estatístico para inferir esses dados, pode-se simplesmente publicá-los como foram coletados (faltando informações). Isso desloca o esforço de adotar ou não esta prática para o consumidor - o que pode ser desejável em muitas situações.

Entre as fases, são ilustrados os artefatos de saída esperados ao seu fim. A cada fase, também, são conduzidas atividades de controle da qualidade, de modo a se obter possíveis desvios de qualidade o mais cedo possível. O ciclo se completa ao coletar, analisar e considerar os as sugestões de melhoria por meio dos feedbacks dados pela comunidade em torno dos dados publicados.

A Seção 5.3 descreve cada uma das atividades, suas principais tarefas, saídas esperadas, controles de verificação de qualidade e possíveis ferramentas. O apêndice A traz o detalhamento completo de cada passo, com suas justificativas e referências da literatura.

A seguir, descrevemos as características do modelo proposto. 

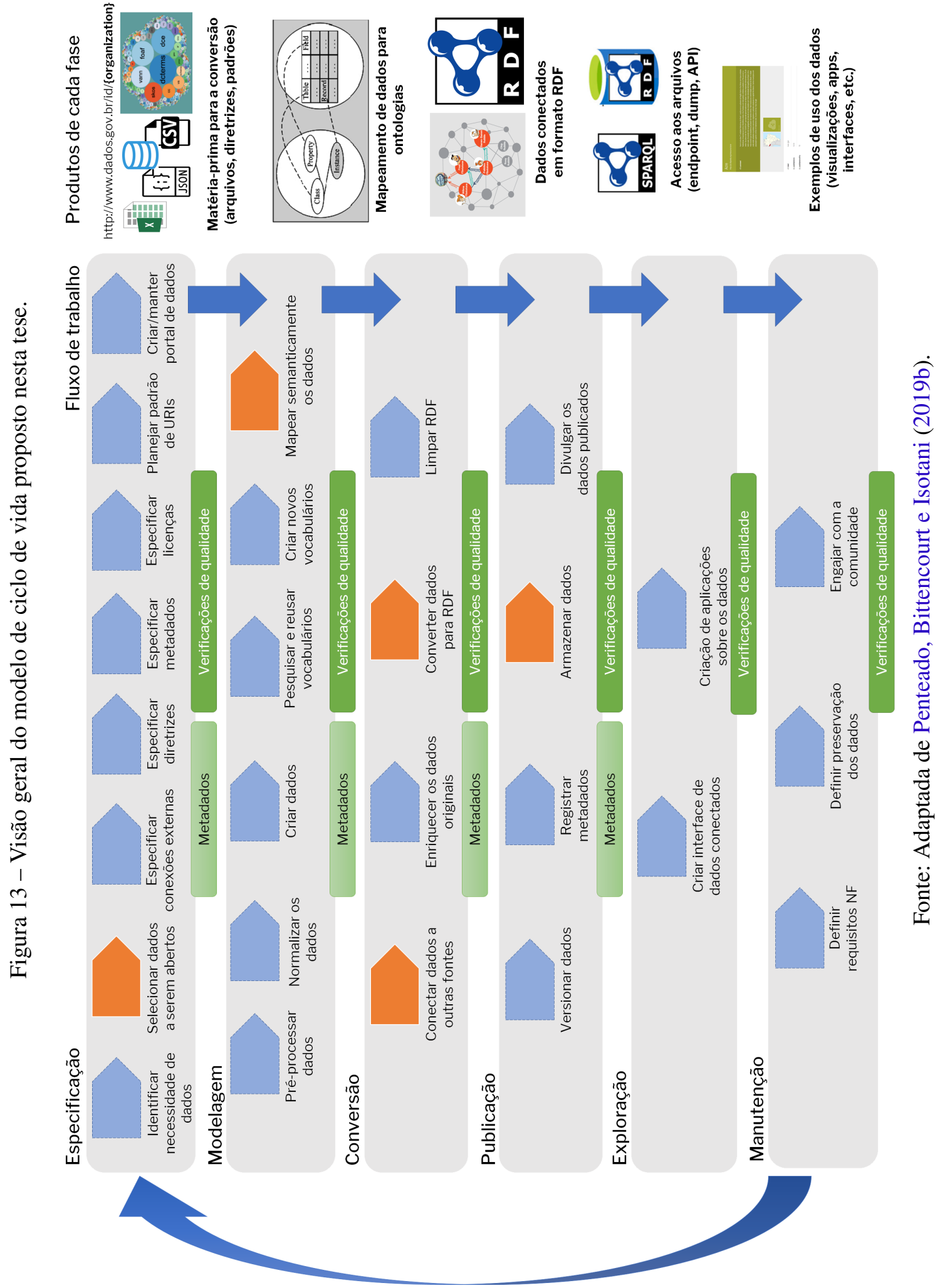


\subsection{Papéis}

Uma equipe de publicação de DAGC deve apresentar características multidisciplinares e compilar os conhecimentos e habilidades necessários para a condução apropriada de todas as atividades. $\mathrm{Na}$ literatura de ecossistema de dados, foram encontrados poucos trabalhos que especificam papéis internos à publicação. Immonen, Palviainen e Ovaska (2014) definem 7 papéis: armazenador, desenvolvedor, agregador, harmonizador, atualizador, publicador e registrador. Necaský et al. (2014) trazem 10 papéis com diferentes graus de responsabilidade: proprietário, publicador, curador, proprietário do catálogo de dados abertos, coordenador de dados abertos, publicador do catálogo de dados abertos, profissional de TI, gerente de qualidade de dados, especialista em qualidade de dados e especialista legal. Nesta tese, utilizamos alguns desses papéis, mas foi necessária a criação de outros mais adequados ao contexto das atividades aqui propostas.

A especificação é feita em função dos conhecimentos necessários às atividades, que podem ser atendidas por um grupo menor de pessoas - como é o caso mais comum - porém, usamos um nível de detalhamento mais granular para poder mapear quais tipos de conhecimentos e habilidades são necessárias para conduzir o processo. Nesta proposta, consideramos 8 perfis profissionais diferentes que agregam seus conhecimentos ao processo:

- Publicador de dados: responsável por gerenciar o ciclo completo dos dados em sua função operacional (coleta, higienização, processamento, publicação e manutenção) bem como o atendimento em nível de prestação de contas (custos, cronograma, atendimento de requisitos);

- Especialista de domínio: conhecedor das regras de negócio e dos conceitos envolvidos no conteúdo dos dados, usa de seu conhecimento para validar a qualidade representacional dos dados e sua correspondência com o mundo real;

- Alta gestão: responsável institucional pelo processo de abertura dos dados, define as prioridades, as estratégias, as diretrizes e o escopo dos dados a serem abertos;

- Engenheiro de ontologias: responsável por modelar os dados e metadados de domínio em formato semântico e publicar os vocabulários criados, bem como fazer a seleção e correspondências entre vocabulários já existentes;

- Administrador de sistemas: responsável pela infraestrutura tecnológica para que o portal de dados esteja em funcionamento contínuo; auxilia na dimensionalização dos recursos necessários para o funcionamento apropriado das interfaces dos dados e no gerenciamento do ferramental, dos ambientes computacionais e de seus planos de manutenção; responsável também por criar, configurar e administrar o portal de dados, desde o gerenciamento de identidades até registro dos conjuntos de dados e metadados; 
- Analista de qualidade: responsável por conduzir as verificações de qualidade e acompanhar a execução das atividades, bem como propor melhorias no processo visando produto de melhor qualidade;

- Especialista jurídico: responsável por definir e validar quais licenças são as mais indicadas para um determinado dataset;

- Comunidade de dados: atores da sociedade civil (pesquisadores, órgãos públicos, ONGs, empresas) que reusam os dados de alguma forma;

- Gestor de comunidade: responsável por interagir com membros da comunidade de dados, de modo a obter feedback sobre a relevância ou a qualidade dos dados, de modo colaborativo.

A Figura 14 detalha como cada papel interage em cada atividade. Foi utilizado o modelo RACI de atribuição de responsabilidades (JACKA; KELLER, 2009). Trata-se de uma ferramenta, comum em práticas de gestão de projetos, que possibilita explicitar como os membros da equipe visualizam suas responsabilidades no ciclo de vida do projeto. RACI significa: R (Responsible), A (Accountable), C (Consulted) e I (Informed) - em português: o Responsável, a Autoridade, o Consultado e o Informado.

A matriz RACI é formada por um acrônimo que também define os papéis e as atribuições dos envolvidos:

- $R$ (Responsible): grupo de pessoas (ou indivíduo) responsável pela execução, pelo desenvolvimento, pela conclusão e pela entrega da atividade. "Quem é designado para trabalhar nessa atividade?";

- A (Accountable): corresponde à parte que tem autoridade para organizar a tarefa, acompanhar seu desenvolvimento e aceitar ou recusar formalmente uma entrega. O papel do Accountable é o do aprovador, que será cobrado caso algo se desvie do esperado. Deve haver somente uma autoridade por tarefa e, mesmo se essa pessoa delegar a responsabilidade pela aprovação de um entregável para outra, será ela quem responderá pelo aceite daquela entrega. "Quem tem a autoridade para tomar a decisão?";

- $C$ (Consulted): são todos aqueles que podem dar dicas, opiniões e sugestões para melhorar o desenvolvimento da atividade ou aperfeiçoar o entregável. Essas pessoas possuem o dever de responder aos questionamentos do responsável (Responsible), enquanto este último deve solicitar o envolvimento delas para agregar valor ou tirar dúvidas sobre a tarefa que está sendo executada. "Quem deve ser consultado e participar da decisão da atividade no momento em que for executada?"; 


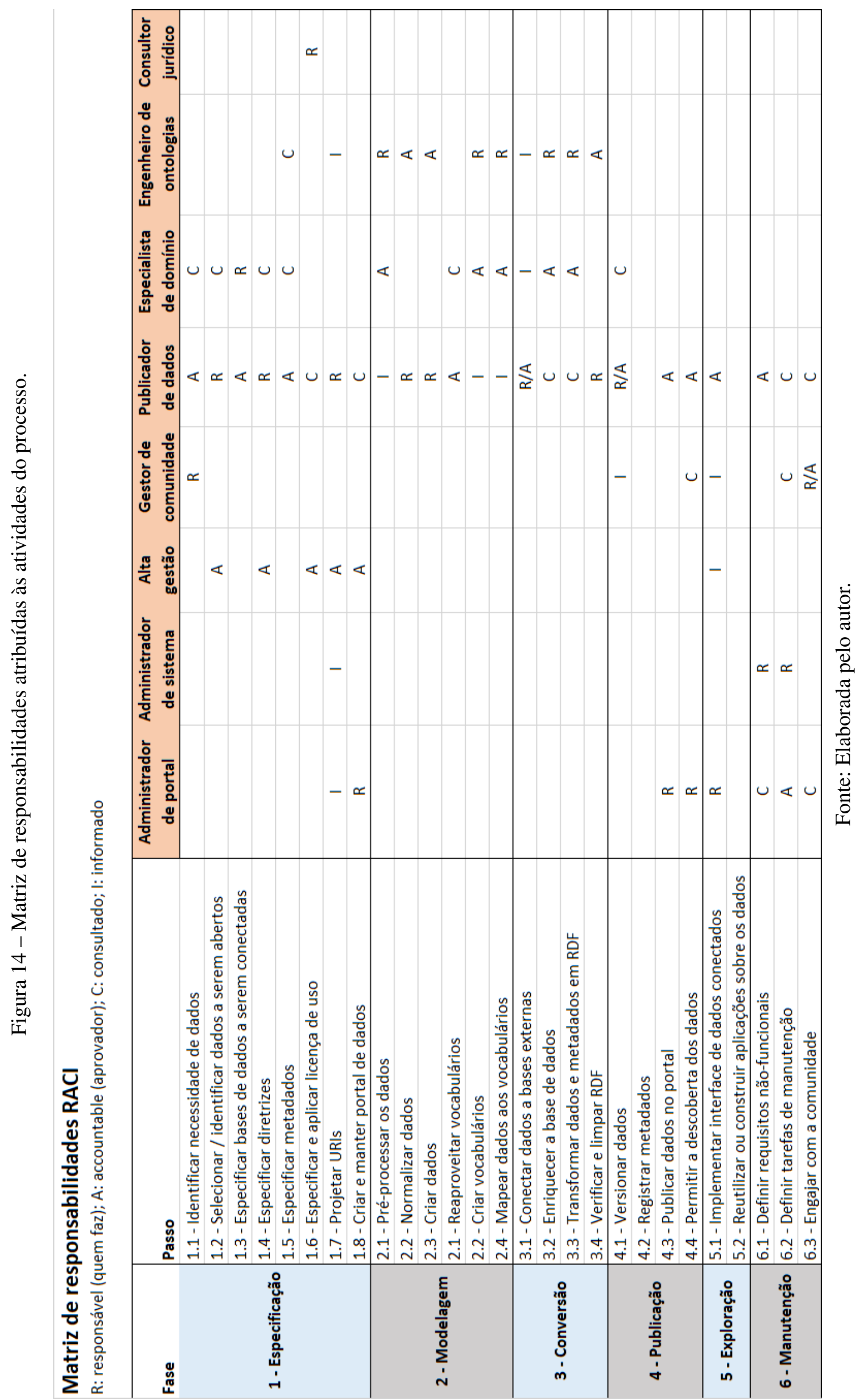


- I (Informed): são todas as pessoas que precisam receber a informação sobre o início e a conclusão de uma atividade (ou até de uma entrega) que gere uma mudança impactante em seu cotidiano. Neste grupo, estão: usuários-chave, colegas de projeto, gestor ou interessados diretamente no projeto. "Quem deve receber a informação de que uma atividade foi executada?".

Novamente, enfatizamos que diferentes papéis podem ser desempenhados pela mesma pessoa. Dependendo do tamanho e da complexidade do cenário de publicação de DAGC, é possível que nem todos os papéis descritos sejam necessários.

\subsection{Processo}

O modelo de ciclo de vida proposto foi criado e aplicado na produção de diferentes domínios de dados abertos governamentais. Ele consiste de 6 fases principais, com suas atividades subjacentes: i) especificação, ii) modelagem, iii) conversão, iv) publicação, v) exploração e vi) manutenção. Estas fases e atividades são permeadas por atividades de verificação e validação ao longo de todo o processo.

As fases e atividades propostas são sequenciais e pressupõem um ciclo, uma vez que os feedbacks dados pelos usuários dos dados (a comunidade) permitem aprimorar os dados disponibilizados em seu conteúdo, estrutura ou formato. A seguir são especificados os passos de cada fase. As atividades completas são encontradas na seção de anexos desta tese.

\subsubsection{Especificação - planejar para a publicação}

O primeiro passo, comum explicitamente à maioria das metodologias levantadas, consiste em conhecer os dados e seu domínio em profundidade. Este entendimento da estrutura dos dados e de sua semântica é crucial para as fases seguintes. Como as iniciativas de dados abertos governamentais são derivadas de políticas públicas de acesso à informação, é necessário também conhecer quais são as leis e diretrizes estabelecidas sobre esse aspecto e que podem influenciar em todos os passos do processo, tais como o uso de URIs oficiais, vocabulários adotados, metadados obrigatórios e opcionais, licenças adotadas e o contexto de outras bases de dados complementares. Como pré-requisitos dessa fase é importante que o responsável pelo processo de abertura de dados no âmbito da entidade governamental conheça o esquema de 5 estrelas de Berners-Lee, os 4 princípios dos dados conectados e a nuvem de DAC (JOVANOVIK; TRAJANOV, 2017). A Figura 15 especifica e a Quadro 15 descreve os passos desta fase, que essencialmente traz o planejamento e os materiais básicos para as próximas fases.

Um primeiro passo seria definir as necessidades de dados a serem publicados no formato conectado, o que influencia em quais conjuntos de dados e os respectivos campos de dados que devem ser abertos. Em uma abordagem tradicional de DAG, isto é especificado no plano de 
Figura 15 - Atividades da fase de Especificação.

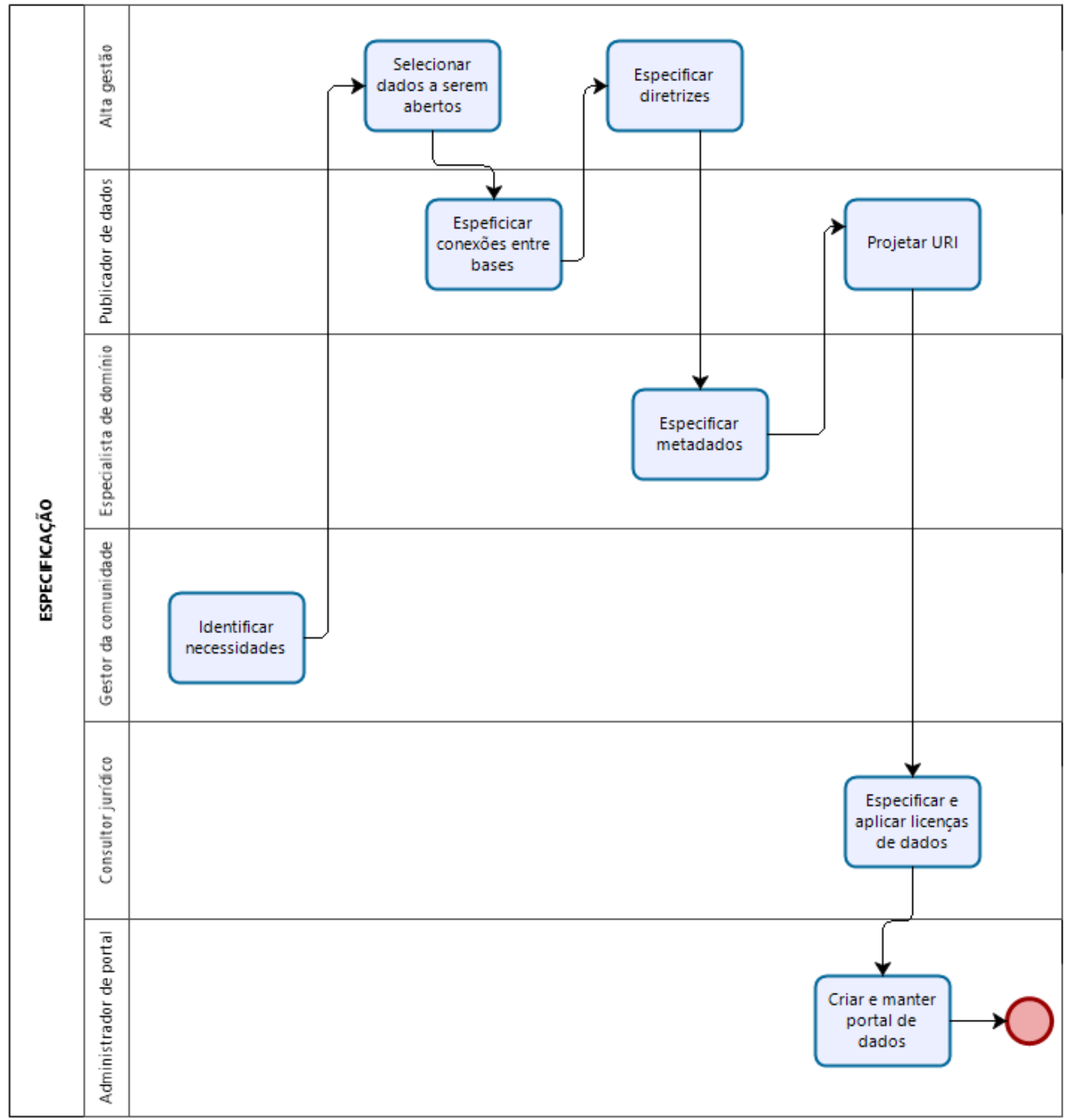

Fonte: Elaborada pelo autor.

dados da organização, definido pela alta gestão mediante pedidos de acesso à informação ou de opção política do órgão. No presente modelo, este passo liga o final do ciclo aos feedbacks fornecidos pela comunidade que usa os dados, e o que define cenários de uso para os dados. $\mathrm{O}$ passo seguinte é o de selecionar os conjuntos de dados a serem transformados em conectados. A partir dos cenários de uso e os dados disponíveis, deve-se mapear quais são as conexões entre os dados (quais os pontos de relacionamento entre os conjuntos de dados) e possíveis fontes externas.

Outro passo importante é o de levantar as diretrizes que influenciam a publicação 
dos DAGC. Isso pode incluir desde o formato de arquivos até protocolos de comunicação, vocabulários usados pela organização, vocabulário de temas e padrão de metadados, dentre outras definições. Com isso, são especificados também os metadados obrigatórios e opcionais, tanto para os conjuntos de dados e suas distribuições individuais como para o serviço de catálogo de dados como um todo.

É necessário também selecionar e aplicar um modelo de licenciamento de uso dos dados. Trata-se de um passo importante, no qual a organização que publica os dados deve concordar com o proprietário do conjunto de dados (e que pode ser diferente da licença do publicador). Sem essa licença, não é possível estabelecer o grau de reuso desses dados por parte da comunidade.

Outro ponto necessário para gerar dados conectados é o de modelar como serão as URIs dos dados publicados pela organização. Como as URIs são identificadores únicos, elas devem ser cuidadosamente escolhidas, de modo a reter requisitos importantes como serem curtas, serem persistidas ao longo do tempo e serem interpretáveis por humanos, dentre outras características desejáveis.

Um passo essencial é a criação de um portal de dados, entendido aqui como um catálogo de dados ou um ponto de extremidade SPARQL. Muitas vezes um dos dois já existe, sendo necessário criar o outro, já que ambos são complementares entre si. Eles deverão ser configurados para armazenar os dados gerados, bem como fornecer funcionalidades de segurança de acesso, organização de metadados e gerenciamento de identidade, dentre outras funcionalidades.

Quadro 15 - Atividades da fase de Especificação.

\begin{tabular}{|l|l|l|l|l|}
\hline Atividade & Tarefas & Saída & V\&V & Ferramentas \\
\hline Identificar & Mapear demandas & Plano de co- & Plano de comuni- & Hackathons ou \\
necessi- & novas ou corretivas & municação; & cação com mem- & omunidades on- \\
dades de & de potenciais usuá- & conjunto & bros da comuni- \\
dados & rios dos dados & de cenários & dade e infome- & line para coletar \\
feedbacks; para os \\
\end{tabular}

Continua na próxima página 


\begin{tabular}{|c|c|c|c|c|}
\hline Atividade & Tarefas & Saída & $\mathbf{V} \& \mathrm{~V}$ & Ferramentas \\
\hline $\begin{array}{l}\text { Selecionar } \\
\text { dados a } \\
\text { serem } \\
\text { abertos }\end{array}$ & $\begin{array}{l}\text { organizar inventá- } \\
\text { rio de dados da } \\
\text { instituição, priori- } \\
\text { zar quais dados se- } \\
\text { rão abertos, definir } \\
\text { estratégias de aber- } \\
\text { tura, definir crono- } \\
\text { gramas e marcos, } \\
\text { definir o responsá- } \\
\text { vel por cada con- } \\
\text { junto de dados a ser } \\
\text { aberto }\end{array}$ & $\begin{array}{l}\text { Plano } \\
\text { de ação } \\
\text { contendo } \\
\text { cronograma } \\
\text { de execução } \\
\text { da liberação } \\
\text { dos dados }\end{array}$ & $\begin{array}{l}\text { Plano de ação } \\
\text { com metas para } \\
\text { a liberação dos } \\
\text { dados }\end{array}$ & $\begin{array}{l}\text { Editores ou planilhas } \\
\text { de texto }\end{array}$ \\
\hline $\begin{array}{l}\text { Especificar } \\
\text { conexões } \\
\text { entre fontes } \\
\text { de dados }\end{array}$ & $\begin{array}{l}\text { Especificar que ou- } \\
\text { tras bases de dados } \\
\text { podem ser reutili- } \\
\text { zadas para compor } \\
\text { soluções para os ce- } \\
\text { nários de uso levan- } \\
\text { tados }\end{array}$ & $\begin{array}{l}\text { Lista de ba- } \\
\text { ses de dados } \\
\text { externas que } \\
\text { deverão ser } \\
\text { usadas para } \\
\text { responder às } \\
\text { questões dos } \\
\text { cenários de } \\
\text { uso }\end{array}$ & $\begin{array}{l}\text { Lista de bases de } \\
\text { dados, com suas } \\
\text { respectivas URIs } \\
\text { e pontos de liga- } \\
\text { ção com o con- } \\
\text { junto de dados } \\
\text { em questão }\end{array}$ & $\begin{array}{l}\text { Editores ou planilhas } \\
\text { de texto }\end{array}$ \\
\hline $\begin{array}{l}\text { Especificar } \\
\text { diretrizes }\end{array}$ & $\begin{array}{l}\text { Levantar documen- } \\
\text { tação que norteia } \\
\text { a publicação de } \\
\text { dados em termos } \\
\text { institucionais } \\
\text { (padrões internos } \\
\text { da organização), } \\
\text { legais (por ex.: } \\
\text { privacidade e } \\
\text { anonimidade de } \\
\text { dados pessoais) } \\
\text { ou tecnológicos } \\
\text { (tecnologias re- } \\
\text { comendadas ou } \\
\text { obrigatórias) }\end{array}$ & $\begin{array}{l}\text { Conjunto de } \\
\text { documentos } \\
\text { que influ- } \\
\text { enciam o } \\
\text { processo de } \\
\text { publicação } \\
\text { dos dados }\end{array}$ & $\begin{array}{l}\text { Mapeamento de } \\
\text { todas diretrizes } \\
\text { que impactam a } \\
\text { publicação }\end{array}$ & $\begin{array}{l}\text { Editores e planilhas } \\
\text { de texto }\end{array}$ \\
\hline
\end{tabular}




\begin{tabular}{|c|c|c|c|c|}
\hline Atividade & Tarefas & Saída & $\mathbf{V} \& \mathbf{V}$ & Ferramentas \\
\hline $\begin{array}{l}\text { Especificar } \\
\text { metadados }\end{array}$ & $\begin{array}{l}\text { Levantar metada- } \\
\text { dos obrigatórios } \\
\text { e opcionais para } \\
\text { cada dataset; } \\
\text { preencher os me- } \\
\text { tadados com os } \\
\text { valores correspon- } \\
\text { dentes }\end{array}$ & $\begin{array}{l}\text { Conjunto de } \\
\text { metadados } \\
\text { preenchidos }\end{array}$ & $\begin{array}{l}\text { metadados em } \\
\text { conformidade } \\
\text { com diretrizes } \\
\text { institucionais e } \\
\text { com vocabulá- } \\
\text { rios validados } \\
\text { por sua sintaxe e } \\
\text { sua validade de } \\
\text { domínio }\end{array}$ & $\begin{array}{l}\text { Editores ou planilhas } \\
\text { de texto. No caso bra- } \\
\text { sileiro, existe a Car- } \\
\text { tilha Técnica para } \\
\text { publicação de dados } \\
\text { abertos no Brasil que } \\
\text { contém essa lista }\end{array}$ \\
\hline $\begin{array}{l}\text { Especificar, } \\
\text { aplicar } \\
\text { e validar } \\
\text { licenças }\end{array}$ & $\begin{array}{l}\text { Catalogar as licen- } \\
\text { ças existentes dis- } \\
\text { poníveis para pu- } \\
\text { blicação; associar } \\
\text { uma licença a uma } \\
\text { versão do dataset; } \\
\text { caso reutilize da- } \\
\text { dos de outras fon- } \\
\text { tes, analisar licença } \\
\text { de uso dos dados } \\
\text { originais, de modo } \\
\text { a garantir que ne- } \\
\text { nhum direito de } \\
\text { uso é violado }\end{array}$ & $\begin{array}{l}\text { Licença } \\
\text { especificada } \\
\text { e atribuída } \\
\text { ao dataset }\end{array}$ & $\begin{array}{l}\text { A licença está as- } \\
\text { sociada ao data- } \\
\text { set em formato } \\
\text { legível por má- } \\
\text { quina; verificar } \\
\text { se existe a ver- } \\
\text { são legível por } \\
\text { humanos }\end{array}$ & $\begin{array}{l}\text { Busca de modelos de } \\
\text { licenças de uso: Cre- } \\
\text { ative Commons Cho- } \\
\text { ose ou na página da } \\
\text { Open Definition, se- } \\
\text { ção de Licenses. Para } \\
\text { aplicar, o CKAN dis- } \\
\text { ponibiliza como pos- } \\
\text { sível metadado, mas } \\
\text { não com representa- } \\
\text { ção semântica. }\end{array}$ \\
\hline
\end{tabular}

Continua na próxima página 


\begin{tabular}{|c|c|c|c|c|}
\hline Atividade & Tarefas & Saída & $\mathbf{V} \& \mathbf{V}$ & Ferramentas \\
\hline $\begin{array}{l}\text { Projetar } \\
\text { URIs }\end{array}$ & $\begin{array}{l}\text { Definir o padrão de } \\
\text { como serão repre- } \\
\text { sentadas as URIs } \\
\text { dos dados, levando } \\
\text { em conta as diretri- } \\
\text { zes e organização } \\
\text { de domínios da ins- } \\
\text { tituição }\end{array}$ & $\begin{array}{l}\text { Formato } \\
\text { das URIs a } \\
\text { serem ado- } \\
\text { tadas para a } \\
\text { publicação } \\
\text { dos recursos } \\
\text { de dados e } \\
\text { metadados } \\
\text { selecio- } \\
\text { nados; } \\
\text { expressão } \\
\text { regular que } \\
\text { define como } \\
\text { interpretar } \\
\text { as URIs do } \\
\text { dataset }\end{array}$ & $\begin{array}{l}\text { Verificar se o } \\
\text { formato é válido; } \\
\text { verificar a boa } \\
\text { prática de ta- } \\
\text { manho máximo } \\
\text { de caracteres } \\
\text { na URI (80); } \\
\text { verificar a inter- } \\
\text { pretação sobre } \\
\text { o significado } \\
\text { literal das URIs; } \\
\text { existência de ex- } \\
\text { pressão regular } \\
\text { que expressa as } \\
\text { URIs do dataset }\end{array}$ & $\begin{array}{l}\text { Cool URIs, Style } \\
\text { Guidelines for On- } \\
\text { tologies (modelo } \\
\text { do Reino Unido } \\
\text { para URIs), e-VoG } \\
\text { (Brasil). }\end{array}$ \\
\hline $\begin{array}{l}\text { Criar e man- } \\
\text { ter portal } \\
\text { de dados } \\
\text { conectados } \\
\text { (triplestore) }\end{array}$ & $\begin{array}{l}\text { Gerenciar identida- } \\
\text { des e permissões; } \\
\text { catalogar datasets; } \\
\text { garantir funciona- } \\
\text { mento das APIs de } \\
\text { dados ou de end- } \\
\text { points SPARQL; } \\
\text { gerir vocabulários, } \\
\text { metadados e licen- } \\
\text { ças; sincronizar } \\
\text { portais federados; } \\
\text { configurar identi- } \\
\text { dade visual; definir } \\
\text { configuração de } \\
\text { caracteres em } \\
\text { ambientes mul- } \\
\text { tilíngues;aplicar } \\
\text { diretrizes de se- } \\
\text { gurança; atender } \\
\text { SLA }\end{array}$ & $\begin{array}{l}\text { Portal confi- } \\
\text { gurado para } \\
\text { o contexto da } \\
\text { comunidade- } \\
\text { alvo }\end{array}$ & 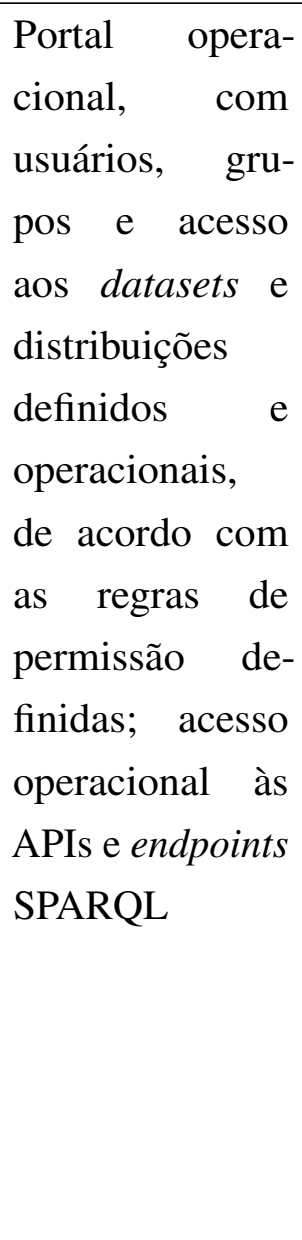 & $\begin{array}{l}\text { CKAN, Socrata, } \\
\text { OpenDataSoft para } \\
\text { portais de catálogos } \\
\text { de dados; Virtuoso, } \\
\text { Fuseki, Linked } \\
\text { Media Framework, } \\
\text { Jena TDB, Sesame, } \\
\text { 4Store para ar- } \\
\text { mazenamento de } \\
\text { triplas RDF com } \\
\text { endpoint SPARQL; } \\
\text { Hydra, para APIs } \\
\text { semânticas }\end{array}$ \\
\hline
\end{tabular}




\subsubsection{Modelagem - como representar os dados semanticamente}

Nesta fase, o publicador dos dados foca-se na modelagem e alinhamento com outros datasets e com a especificação semântica precisa de cada dado fornecida no esquema dos dados abertos. Para isto, são indispensáveis os conhecimentos de especialistas de domínio, engenheiros de ontologia e/ou de profissionais das ciências da informação, que detenham o conhecimento para reconhecer, selecionar ou criar quando necessário vocabulários, ontologias ou taxonomias que descrevam os dados. Como regra geral desta fase, deve-se reutilizar o máximo possível de vocabulários existentes, poupando tempo e esforços de desenvolvimento (BIZER RICHARD CYGANIAK, 2007). A Figura 16 traz os passos desta fase e a Quadro 16 detalha seus componentes.

Figura 16 - Atividades da fase de Modelagem.

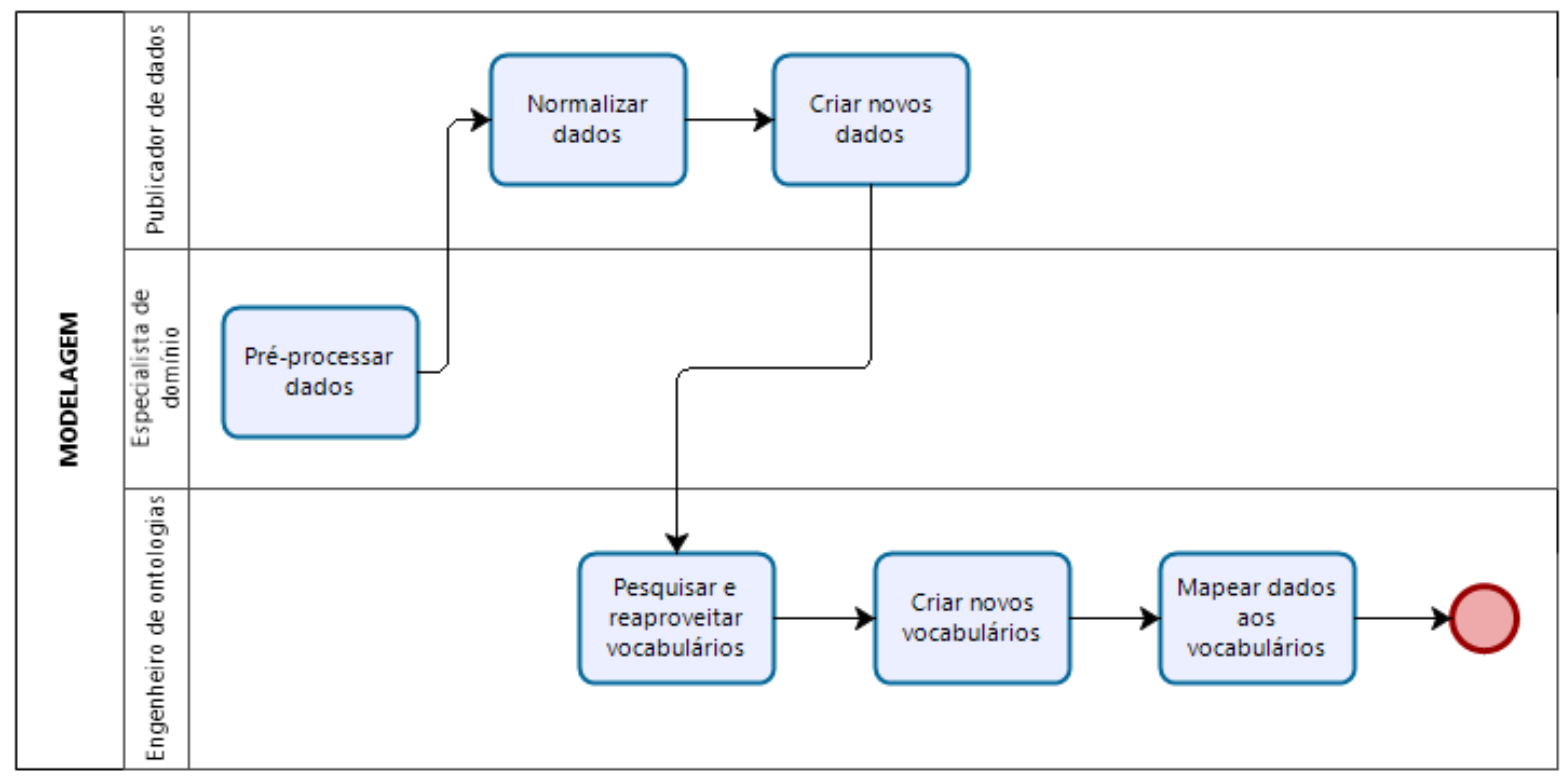

Fonte: Elaborada pelo autor.

O passo inicial é o de pré-processar os dados, de modo a garantir que os dados estejam apropriadamente estruturados e validados conforme o domínio representado. Em seguida, deve-se normalizá-los, no sentido de torná-los atômicos em relação a possíveis informações compostas de unidade + valor presentes num mesmo campo (comuns: representações de moedas, medidas espaciais ou temporais, etc.). Além disso, existe a possibilidade de se combinar ou adicionar campos calculados ao conjunto de dados original, podendo fazer com que essa tarefa seja facilitada e padronizada para seus consumidores. Com os dados devidamente estruturados, devese anotá-los semanticamente. Assim, um passo essencial é o de pesquisar vocabulários existentes que podem ser usados para representar o domínio em questão, conforme as boas práticas de dados conectados. No entanto, os vocabulários existentes são, em sua maioria, genéricos e não 
irão cobrir todos os dados que se deseja publicar. Para complementar os dados não cobertos, é necessário criar novos vocabulários, mais adaptados aos cenários específicos sendo modelados. Uma vez que os vocabulários levantados e criados atendem a todos os dados que se quer abrir, deve ser feito seu mapeamento. Diferentes técnicas podem ser utilizadas para representar os dados de forma linear, hierárquica, agregada ou de outras formas - o que conta é que todos os dados devem estar cobertos por algum termo dos vocabulários selecionados. Além dos dados em si, é necessário também mapear semanticamente os metadados de todos os níveis (catálogo, conjunto de dados e distribuições), especificados na fase anterior.

Quadro 16 - Atividades da fase de Modelagem.

\begin{tabular}{|c|c|c|c|c|}
\hline Atividade & Tarefas & Saída & $\mathbf{V} \& \mathbf{V}$ & Ferramentas \\
\hline $\begin{array}{l}\text { Pré-processar } \\
\text { os dados }\end{array}$ & $\begin{array}{l}\text { Checar a consis- } \\
\text { tência dos dados, } \\
\text { transformá-los } \\
\text { em formato } \\
\text { estruturado, } \\
\text { verificar tipos de } \\
\text { dados e estrutura } \\
\text { correspondentes } \\
\text { aos esperados }\end{array}$ & $\begin{array}{l}\text { Dados em for- } \\
\text { mato estrutu- } \\
\text { rado, em ní- } \\
\text { vel de granu- } \\
\text { laridade, codi- } \\
\text { ficação e for- } \\
\text { matação dese- } \\
\text { jados }\end{array}$ & $\begin{array}{l}\text { Especialista de } \\
\text { domínio valida } \\
\text { conteúdo do ar- } \\
\text { quivo estruturado } \\
\text { em função de cor- } \\
\text { retude dos dados, } \\
\text { correspondência } \\
\text { entre cabeçalho e } \\
\text { conteúdo, corres- } \\
\text { pondência entre } \\
\text { tipos de dados } \\
\text { esperados, nú- } \\
\text { mero de campos } \\
\text { esperados em } \\
\text { cada registro de } \\
\text { dados }\end{array}$ & $\begin{array}{l}\text { OpenRefine, Data- } \\
\text { Wrangler, DataClea- } \\
\text { ner, editores de pla- } \\
\text { nilhas }\end{array}$ \\
\hline
\end{tabular}

Continua na próxima página 


\begin{tabular}{|c|c|c|c|c|}
\hline Atividade & Tarefas & Saída & $\mathbf{V} \& V$ & Ferramentas \\
\hline $\begin{array}{l}\text { Normalizar } \\
\text { dados }\end{array}$ & $\begin{array}{l}\text { Mapear campos } \\
\text { de dados que } \\
\text { utilizam padrão } \\
\text { específico de } \\
\text { formatação, } \\
\text { como por exem- } \\
\text { plo datas (ex.: } \\
\text { 03-07-2019 ou } \\
\text { 07-03-2019), mo- } \\
\text { edas e números, } \\
\text { formatando-os } \\
\text { para algum pa- } \\
\text { drão do domínio }\end{array}$ & $\begin{array}{l}\text { Lista de trans- } \\
\text { formações } \\
\text { para cada } \\
\text { campo que } \\
\text { seja detectado } \\
\text { ser feita a } \\
\text { normalização }\end{array}$ & $\begin{array}{l}\text { Cada campo lis- } \\
\text { tado deve ser ma- } \\
\text { peado para seu va- } \\
\text { lor normalizado }\end{array}$ & $\begin{array}{l}\text { OpenRefine, Data- } \\
\text { Wrangler, DataClea- } \\
\text { ner, editores de pla- } \\
\text { nilhas }\end{array}$ \\
\hline Criar dados & $\begin{array}{l}\text { Especificar novos } \\
\text { campos de dados } \\
\text { que devem ser in- } \\
\text { seridos no data- } \\
\text { set original; criar } \\
\text { os novos campos } \\
\text { calculados; regis- } \\
\text { trar processo de } \\
\text { criação (memória } \\
\text { de cálculo) }\end{array}$ & $\begin{array}{l}\text { Conjunto } \\
\text { de dados } \\
\text { acrescido de } \\
\text { novos campos } \\
\text { calculados }\end{array}$ & $\begin{array}{l}\text { Verificar integri- } \\
\text { dade dos campos } \\
\text { criados; verificar } \\
\text { se dados faltan- } \\
\text { tes estão preenchi- } \\
\text { dos conforme es- } \\
\text { perado (caso espe- } \\
\text { cificado) }\end{array}$ & $\begin{array}{l}\text { OpenRefine, Data- } \\
\text { Wrangler, DataClea- } \\
\text { ner, editores de pla- } \\
\text { nilhas }\end{array}$ \\
\hline
\end{tabular}

Continua na próxima página 


\begin{tabular}{|c|c|c|c|c|}
\hline Atividade & Tarefas & Saída & $\mathbf{V} \& \mathbf{V}$ & Ferramentas \\
\hline $\begin{array}{l}\text { Pesquisar e } \\
\text { reaproveitar } \\
\text { vocabulários }\end{array}$ & $\begin{array}{l}\text { buscar, para cada } \\
\text { campo dos dados } \\
\text { e dos metadados, } \\
\text { se já existe sua } \\
\text { representação } \\
\text { semântica defi- } \\
\text { nida em algum } \\
\text { vocabulário } \\
\text { conhecido }\end{array}$ & $\begin{array}{l}\text { mapeamento } \\
\text { de cada valor } \\
\text { para seu res- } \\
\text { pectivo valor } \\
\text { semântico, } \\
\text { assinalando } \\
\text { quais campos } \\
\text { não foram } \\
\text { atendidos e } \\
\text { que precisam } \\
\text { ser criados } \\
\text { em novos } \\
\text { vocabulários }\end{array}$ & $\begin{array}{l}\text { Todos os campos } \\
\text { dos dados e dos } \\
\text { metadados devem } \\
\text { ter um valor espe- } \\
\text { cificado (quando } \\
\text { for encontrado } \\
\text { um termo cor- } \\
\text { respondente) ou } \\
\text { marcado como 'a } \\
\text { ser desenvolvido' }\end{array}$ & $\begin{array}{l}\text { LOV, para a busca } \\
\text { de vocabulários; } \\
\text { vocabulários } \\
\text { genéricos: DBpe- } \\
\text { dia, Schema.org, } \\
\text { WSG84 (geolo- } \\
\text { calização), Time } \\
\text { Ontology (tempo), } \\
\text { RDF Data Cube } \\
\text { (estatísticas), Du- } \\
\text { blin Core (obras } \\
\text { digitais), FOAF } \\
\text { (pessoas e relacio- } \\
\text { namentos), SKOS } \\
\text { (categorias e re- } \\
\text { lacionamentos), } \\
\text { BIBO (citações } \\
\text { bibliográficas), } \\
\text { Creative Com- } \\
\text { mons (licenças), } \\
\begin{array}{l}\text { DUV (feedback de } \\
\text { usuários). }\end{array}\end{array}$ \\
\hline $\begin{array}{l}\text { Criar vocabu- } \\
\text { lários }\end{array}$ & $\begin{array}{l}\text { Criar ou estender } \\
\text { vocabulários } \\
\text { para anotar os } \\
\text { campos marca- } \\
\text { dos em passo } \\
\text { anterior como } \\
\text { não cobertos } \\
\text { por vocabulários } \\
\text { existentes }\end{array}$ & $\begin{array}{l}\text { Lista de cam- } \\
\text { pos de dados } \\
\text { e metadados } \\
\text { mapeados } \\
\text { para os novos } \\
\text { termos de } \\
\text { vocabulários } \\
\text { criados e a } \\
\text { publicação } \\
\text { dos novos } \\
\text { vocabulários } \\
\text { na Web }\end{array}$ & $\begin{array}{l}\text { Verificar que to- } \\
\text { dos os campos } \\
\text { da lista inicial te- } \\
\text { nham sido ma- } \\
\text { peados para al- } \\
\text { gum novo termo } \\
\text { e/ou vocabulário; } \\
\text { os novos vocabu- } \\
\text { lários devem es- } \\
\text { tar publicados na } \\
\text { Web }\end{array}$ & $\begin{array}{l}\text { Protégé, NeOn Tool- } \\
\text { kit, TopBraid Com- } \\
\text { poser, Altova, Neo- } \\
\text { logism }\end{array}$ \\
\hline
\end{tabular}

Continua na próxima página 


\begin{tabular}{|c|c|c|c|c|}
\hline Atividade & Tarefas & Saída & $V \& V$ & Ferramentas \\
\hline $\begin{array}{l}\text { Mapear } \\
\text { semantica- } \\
\text { mente os } \\
\text { dados }\end{array}$ & $\begin{array}{l}\text { Criar scripts de } \\
\text { mapeamento de } \\
\text { cada campo para } \\
\text { sua representa- } \\
\text { ção semântica, } \\
\text { definida anterior- } \\
\text { mente }\end{array}$ & $\begin{array}{l}\text { Script ou mo- } \\
\text { delo contendo } \\
\text { o mapea- } \\
\text { mento e que } \\
\text { será usado por } \\
\text { ferramenta de } \\
\text { conversão }\end{array}$ & $\begin{array}{l}\text { O script ou mo- } \\
\text { delo de conversão } \\
\text { existe, sua sintaxe } \\
\text { está correta e co- } \\
\text { bre todos os cam- } \\
\text { pos de dados e } \\
\text { metadados especi- } \\
\text { ficados no dataset }\end{array}$ & $\begin{array}{l}\text { OpenRefine, D2RQ } \\
\text { stack, UnBGOLD, } \\
\text { Semantic Media } \\
\text { Wiki, OntoWiki, } \\
\text { WebDAV, Sponger, } \\
\text { StdTrip, } \\
\text { Wrap, RDF123, } \\
\text { NOR2O, UltraWrap, } \\
\text { GRDDL, TopBraid } \\
\text { Composer, ReDeFer, } \\
\text { any23, Stats2RDF }\end{array}$ \\
\hline
\end{tabular}

Fonte: Elaborada pelo autor.

\subsubsection{Conversão - transformar e conectar}

Nesta fase, os dados em seus formatos originais são transformados para o formato RDF - que é o modelo padrão de acordo com os princípios de dados conectados (BERNERS-LEE, 2006). Assim, em posse dos dados selecionados na Fase 1 e modelados na Fase 2, podemos transformá-los neste formato semântico. É importante lembrar que os metadados também devem ser convertidos para RDF e adicionados junto ao arquivo de dados. Além disso, um dos princípios fundamentais dos dados conectados diz respeito a incluir conexões a outras bases de dados, de modo a se descobrir novos dados (BERNERS-LEE, 2006), o que é feito por meio da conexão entre diferentes fontes. A Figura 17 ilustra os passos desta fase, bem como a Quadro 17 que especifica os componentes de cada passo.

Figura 17 - Atividades da fase de Conversão.

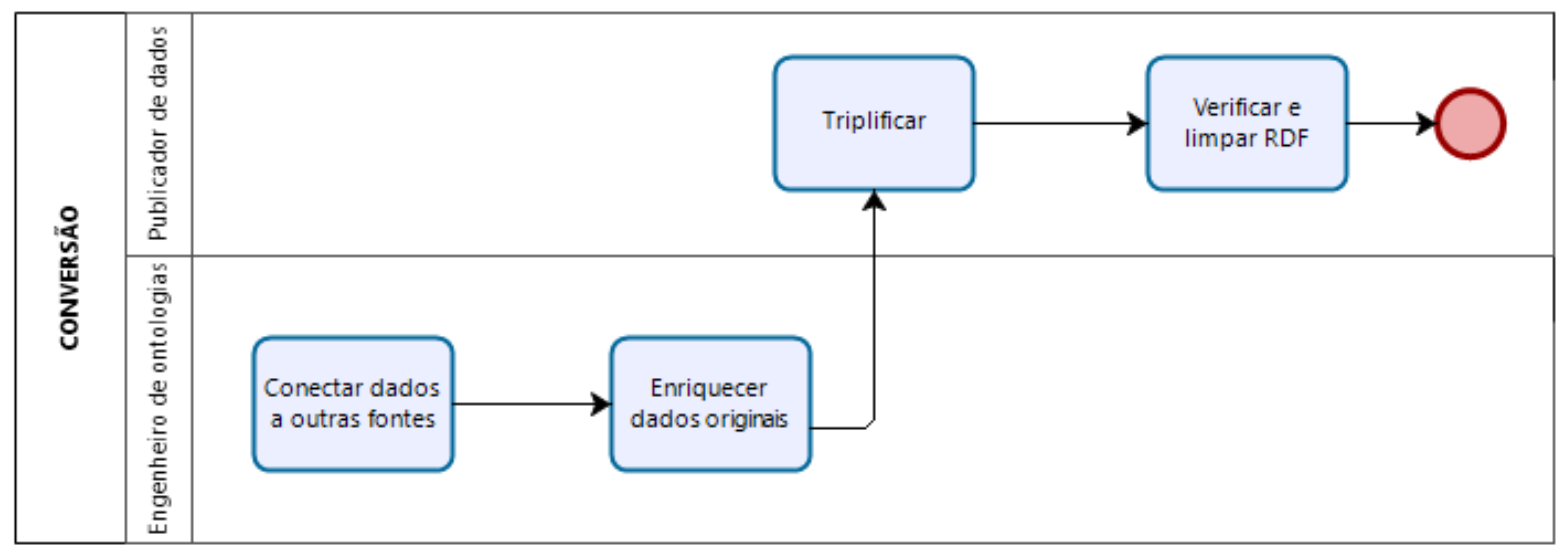

Fonte: Elaborada pelo autor. 
Em posse de todos os dados e metadados mapeados para suas representações semânticas, pode-se fazer suas conversões para o formato RDF no processo chamado de triplificação. Uma vez gerados os dados, pode-se fazer o processo de reconciliação, ou seja, criar conexões que permitam conectar diferentes bases de dados ao estabelecer que uma entidade identificada por diferentes URIs é de fato a mesma entidade, mesmo estando presentes em diferentes fontes de dados. Essas conexões foram especificadas na fase de Especificação e geram os chamados linksets, que mapeiam quais entidades podem ser consideradas como as mesmas entre diferentes fontes de dados, obtendo-se assim um efeito em rede. Uma vez reconciliados, é possível adicionar novos dados ao conjunto original, importados de outras fontes na Web. Em determinados cenários, isso é desejável, pois esta ação permite que os dados importados sejam incorporados no mesmo arquivo de dump, evitando novo acesso à Web. Por fim, deve-se igualmente verificar o grafo RDF gerado, tanto por possíveis inconsistências no mapeamento, na reconciliação ou nos dados enriquecidos.

Quadro 17 - Atividades da fase de Conversão.

\begin{tabular}{|l|l|l|l|l|}
\hline Atividade & Tarefas & Saída & V\&V & Ferramentas \\
\hline Conectar & Estabelecer cone- & Para cada & Testagem dos mapea- & OpenRefine, SILK, \\
as bases de & xões entre fontes: & base de dados & mentos, buscando en- & LIMES, RKBEplo- \\
dados & i) os identificado- & listada, criar & contrar instâncias que & rer, GNAT, RDF- \\
& res comuns entre & mapeamento & não foram pareadas, & AI, Pundit; sameAs \\
& elas, de modo a & para os ca- & seja por erro nos da- & Link Validator para \\
& permitir sua junção & sos: i) o & dos, má especificação & validação das cone- \\
& ou ii) heurísticas & identificador & de identificador ou & xões descobertas \\
& que façam com que & comparti- & heurísticas fracas de & \\
& essa junção seja es- & lhado entre & conexão; estimar va- & \\
& timada automatica- & as bases ou & lores de precisão e re- & \\
& mente via software & ii) conjunto & vocação das heurísti- & \\
& (esta opção deve & de heurísti- & cas adotadas; verifi- & \\
& ser validada pelo & cas para a & car se as URIs das & \\
& especialista de do- & determinação & triplas que apontam & \\
& mínio, de modo a & automática & para recursos exter- & \\
& se medir seu grau & da junção das & nos são desreferenciá- & \\
& de sucesso) & instâncias & veis & \\
\hline
\end{tabular}

Continua na próxima página 


\begin{tabular}{|c|c|c|c|c|}
\hline Atividade & Tarefas & Saída & $\mathbf{V} \& \mathbf{V}$ & Ferramentas \\
\hline $\begin{array}{l}\text { Enriquecer } \\
\text { a base de } \\
\text { dados }\end{array}$ & $\begin{array}{l}\text { Estender o con- } \\
\text { junto de dados } \\
\text { inicial com novas } \\
\text { informações ex- } \\
\text { traídas das bases } \\
\text { externas, fazendo } \\
\text { com que ambos } \\
\text { sejam parte do } \\
\text { mesmo arquivo } \\
\text { (observando as res- } \\
\text { trições de licença } \\
\text { de uso) }\end{array}$ & $\begin{array}{l}\text { Conjunto de } \\
\text { dados inicial } \\
\text { enriquecido } \\
\text { com novos } \\
\text { campos, vin- } \\
\text { dos das fontes } \\
\text { externas de } \\
\text { dados }\end{array}$ & $\begin{array}{l}\text { O conjunto de dados } \\
\text { apresenta novos cam- } \\
\text { pos, mantendo váli- } \\
\text { das suas propriedades } \\
\text { estruturais e sintáti- } \\
\text { cas }\end{array}$ & $\begin{array}{l}\text { LODRefine, MO- } \\
\text { MIS, Fusepool P3, } \\
\text { csv2rdf4lod, DL- } \\
\text { Learner, Protégé } \\
\text { reasoners, plugins } \\
\text { do OntoWiki }\end{array}$ \\
\hline $\begin{array}{l}\text { Converter } \\
\text { dados e } \\
\text { metadados } \\
\text { para RDF }\end{array}$ & $\begin{array}{l}\text { Executar progra- } \\
\text { mas de conversão } \\
\text { de formatos, } \\
\text { usando os dados } \\
\text { selecionados na } \\
\text { Fase } 1 \text { e mapeados } \\
\text { para vocabulários } \\
\text { na Fase } 2\end{array}$ & $\begin{array}{l}\text { Arquivo con- } \\
\text { tendo todos os } \\
\text { dados e meta- } \\
\text { dados em for- } \\
\text { mato RDF }\end{array}$ & $\begin{array}{l}\text { o arquivo de saída } \\
\text { deve conter todos } \\
\text { os dados mapeados, } \\
\text { empregando os mape- } \\
\text { amentos realizados; } \\
\text { para os casos de } \\
\text { conversão on-line } \\
\text { (via mapeamento } \\
\text { direto em bases de } \\
\text { dados operacionais), } \\
\text { deve-se verificar se é } \\
\text { possível consultar es- } \\
\text { ses dados; além disso, } \\
\text { deve-se verificar, ao } \\
\text { menos, sua validade } \\
\text { sintática }\end{array}$ & \begin{tabular}{l}
\multicolumn{2}{l}{ OpenRefine, } \\
D2RQ, \\
Kettle,
\end{tabular} \\
\hline
\end{tabular}

Continua na próxima página 


\begin{tabular}{|c|c|c|c|c|}
\hline Atividade & Tarefas & Saída & $V \& V$ & Ferramentas \\
\hline $\begin{array}{l}\text { Verificar } \\
\text { e limpar } \\
\text { RDF }\end{array}$ & $\begin{array}{l}\text { Checar integridade } \\
\text { do arquivo e das tri- } \\
\text { plas contidas nele, } \\
\text { em níveis sintático } \\
\text { e semântico; tomar } \\
\text { as ações corretivas } \\
\text { para sanar os pro- } \\
\text { blemas identifica- } \\
\text { dos, seja para aper- } \\
\text { feiçoar um dos pas- } \\
\text { sos anteriores ou } \\
\text { para adaptar o ser- } \\
\text { viço que disponibi- } \\
\text { liza os dados }\end{array}$ & $\begin{array}{l}\text { Arquivo de da- } \\
\text { dos com cor- } \\
\text { reções feitas e } \\
\text { registradas }\end{array}$ & $\begin{array}{l}\text { O arquivo RDF de } \\
\text { saída passa em to- } \\
\text { dos os critérios de } \\
\text { testes estabelecidos, } \\
\text { como por ex. os pre- } \\
\text { sentes em Hogan et } \\
\text { al. (2010), Villazon- } \\
\text { Terrazas et al. (2011): } \\
\text { resolução das URIs } \\
\text { não retornarem có- } \\
\text { digos } 400 \text { ou 500; } \\
\text { erros de grafia no } \\
\text { mapeamento semân- } \\
\text { tico, termo inexis- } \\
\text { tente no vocabulário } \\
\text { reutilizado) }\end{array}$ & $\begin{array}{l}\text { RDFUnit, OOPS!, } \\
\text { RDF Alerts, W3C } \\
\text { RDF Validator, Va- } \\
\text { pour, Jena Eyeball, } \\
\text { sameAs Link Vali- } \\
\text { dator, OWL Valida- } \\
\text { tor, VRP (Valida- } \\
\text { ting RDF Parser) }\end{array}$ \\
\hline
\end{tabular}

Fonte: Elaborada pelo autor.

\subsubsection{Publicação - expor e divulgar os dados}

Uma vez em posse dos dados transformados para seu formato semântico, é necessário que ele seja disponibilizado para acesso público na Web, usando diferentes formas de acesso (W3C, 2014a). Para isso, tanto os dados em si quanto seus metadados e os mecanismos de auxílio à descoberta são considerados (VILLAZON-TERRAZAS et al., 2011). O anúncio da disponibilização do dataset à comunidade, tanto por meio dos metadados e de sua indexação em mecanismos de busca quanto pelo registro de catálogos de dados oficiais ou extra-oficiais (ex.: Datahub), permite uma maior visibilidade sobre o dataset. Além disso, é considerada uma boa prática divulgar a disponibilização de novos datasets ou distribuições tanto por meio de mídias tradicionais quanto ao facilitar sua indexação a diferentes mecanismos de buscas. De modo a garantir a auditoria e sua rastreabilidade, é necessário versionar os arquivos de dados, por meio do gerenciamento de sua configuração. A Figura 18 mostra como são executados os passos e a Quadro 18 detalha cada passo desta atividade.

Com os dados gerados, é necessário gerenciar sua configuração ao atribuir um identificador de versionamento que possa ser interpretado por humanos e máquinas, reconhecendo sua ordem e características. Outro passo essencial é o de especificar e registrar nos metadados uma licença de uso para os dados a serem publicados, buscando pela licença que mais se adequar ao contexto. Com todos esses metadados registrados, deve-se publicar os dados e seus metadados 
Figura 18 - Atividades da fase de Publicação

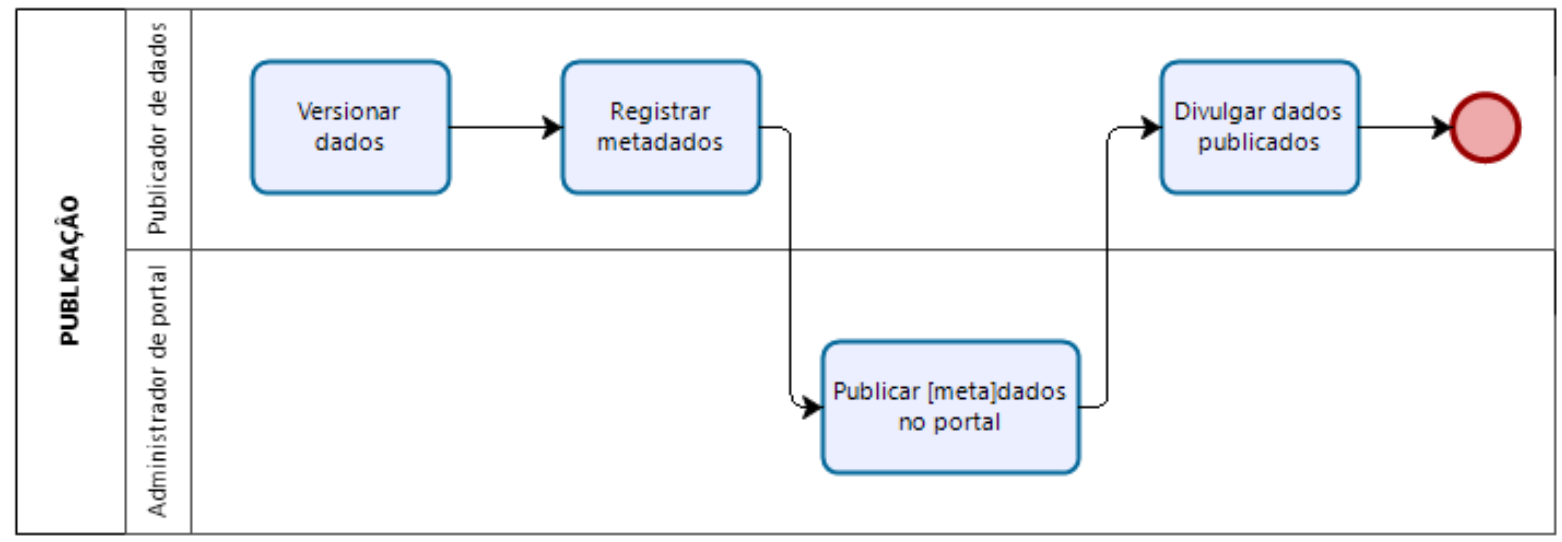

Fonte: Elaborada pelo autor.

no formato desejado no portal. E, por fim, deve-se divulgar os dados publicados, para que tanto humanos quanto mecanismos de buscas possam encontrá-los e interpretá-los.

Freire et al. (2018) apontam diferentes mecanismos para divulgação em meios automáticos: especificações para imagens ( $\mathrm{IIIF}^{2}$ ), protocolo sitemap, sincronização de recursos, especificações de publicações abertas, menções e notificações de uso de dados na Web e o uso do vocabulário Schema.org em páginas que hospedam os datasets, para que estas possam ser indexadas a serviços de busca como o Google Dataset Search ${ }^{3}$. Além disso, recomenda-se que a divulgação ocorra também por meio de comunidades de usuários dos dados, em mídias sociais ou fóruns especializados. 
Quadro 18 - Atividades da fase de Publicação.

\begin{tabular}{|c|c|c|c|c|}
\hline Atividade & Tarefas & Saída & $V \& V$ & Ferramentas \\
\hline $\begin{array}{l}\text { Versionar } \\
\text { dados }\end{array}$ & $\begin{array}{l}\text { Atribuir identifi- } \\
\text { cador de versão } \\
\text { ao dataset a cada } \\
\text { modificação feita } \\
\text { sobre ele (a orga- } \\
\text { nização deve es- } \\
\text { tabelecer um pa- } \\
\text { drão para o for- } \\
\text { mato do versiona- } \\
\text { mento e um ra- } \\
\text { cional de como } \\
\text { incrementá-lo, de } \\
\text { acordo com a re- } \\
\text { levância da altera- } \\
\text { ção); atribuir uma } \\
\text { nova URI para a } \\
\text { nova versão }\end{array}$ & $\begin{array}{l}\text { Conjunto de } \\
\text { dados com as } \\
\text { modificações } \\
\text { necessárias e } \\
\text { com acréscimo } \\
\text { no valor da } \\
\text { versão (por } \\
\text { ex.: } 1.1 \text { para } \\
\text { pequenas } \\
\text { modificações } \\
\text { ou } 2.0 \text { para } \\
\text { uma grande } \\
\text { modificação) }\end{array}$ & $\begin{array}{l}\text { O conjunto de da- } \\
\text { dos inicial foi mo- } \\
\text { dificado; o versiona- } \\
\text { mento foi incremen- } \\
\text { tado conforme as re- } \\
\text { gras; foi atribuída } \\
\text { uma nova URI para } \\
\text { a versão; foi mape- } \\
\text { ada qual a versão an- } \\
\text { terior }\end{array}$ & $\begin{array}{l}\text { Semantic Versio- } \\
\text { ning, que fornece } \\
\text { um racional para } \\
\text { a escolha no incre- } \\
\text { mento da versão; } \\
\text { repositórios de } \\
\text { código como GIT e } \\
\text { Mercurial }\end{array}$ \\
\hline $\begin{array}{l}\text { Anotar } \\
\text { metada- } \\
\text { dos dos } \\
\text { datasets }\end{array}$ & $\begin{array}{l}\text { Executar progra- } \\
\text { mas de conversão } \\
\text { de formatos, } \\
\text { usando os dados } \\
\text { selecionados } \\
\text { na Fase } 1 \text { e } \\
\text { mapeados para } \\
\text { vocabulários na } \\
\text { Fase } 2\end{array}$ & $\begin{array}{l}\text { Arquivo con- } \\
\text { tendo todos } \\
\text { os dados e } \\
\text { metadados em } \\
\text { formato RDF }\end{array}$ & $\begin{array}{l}\text { O arquivo deve con- } \\
\text { ter todos os metada- } \\
\text { dos mapeados; para } \\
\text { os casos de conver- } \\
\text { são on-line (via ma- } \\
\text { peamento direto em } \\
\text { bases de dados ope- } \\
\text { racionais), deve-se } \\
\text { verificar se é possí- } \\
\text { vel consultar esses } \\
\text { dados; deve-se veri- } \\
\text { ficar, ao menos, sua } \\
\text { validade sintática }\end{array}$ & $\begin{array}{l}\text { Vocabulários VoID, } \\
\text { Dublin Core, DCAT, } \\
\text { Service Description, } \\
\text { PROV, ADSM, PAV, } \\
\text { OWL, DQV. Confe- } \\
\text { rir o apêndice B }\end{array}$ \\
\hline
\end{tabular}

Continua na próxima página 


\begin{tabular}{|c|c|c|c|c|}
\hline Atividade & Tarefas & Saída & $\mathbf{V} \& V$ & Ferramentas \\
\hline $\begin{array}{l}\text { Publicar } \\
\text { dados }\end{array}$ & $\begin{array}{l}\text { Carregar os da- } \\
\text { dos convertidos } \\
\text { em RDF para } \\
\text { um repositório } \\
\text { com acesso via } \\
\text { Web, fornecendo } \\
\text { acesso total e/ou } \\
\text { parcial aos dados, } \\
\text { via parâmetros de } \\
\text { busca }\end{array}$ & $\begin{array}{l}\text { Conjuntos } \\
\text { de dados } \\
\text { disponíveis } \\
\text { para acesso ao } \\
\text { público, por } \\
\text { meio de URIs } \\
\text { resolvíveis (re- } \\
\text { presentada por } \\
\text { API, endpoint } \\
\text { SPARQL ou } \\
\text { RDF dump) }\end{array}$ & $\begin{array}{l}\text { URIs de acesso aos } \\
\text { dados devem estar } \\
\text { resolvíveis (respos- } \\
\text { tas HTTP } 200 \text { ou } \\
\text { 303), trazendo os } \\
\text { dados solicitados } \\
\text { conforme os parâ- } \\
\text { metros, para cada } \\
\text { uma das formas } \\
\text { de acesso (dump, } \\
\text { API, endpoint) } \\
\text { especificadas nos } \\
\text { metadados }\end{array}$ & $\begin{array}{l}\text { Importação em pla- } \\
\text { taforma específica, } \\
\text { como: CKAN, So- } \\
\text { crata, OpenDataSoft } \\
\text { para portais de catá- } \\
\text { logos de dados; Vir- } \\
\text { tuoso, Apache Jena } \\
\text { Fuseki, Linked Me- } \\
\text { dia Framework, Se- } \\
\text { same, 4Store para } \\
\text { armazenamento de } \\
\text { triplas RDF com } \\
\text { endpoint SPARQL; } \\
\text { Elda, Puelia (Linked } \\
\text { Data API), para ge- } \\
\text { rar APIs semânticas }\end{array}$ \\
\hline $\begin{array}{l}\text { Divulgar } \\
\text { os dados } \\
\text { publica- } \\
\text { dos }\end{array}$ & $\begin{array}{l}\text { Gerar arquivo site- } \\
\text { map; indexar da- } \\
\text { tasets em meca- } \\
\text { nismos de buscas; } \\
\text { integrar o data- } \\
\text { set à LOD Cloud; } \\
\text { comunicar junto } \\
\text { à comunidade os } \\
\text { dados disponibili- } \\
\text { zados }\end{array}$ & $\begin{array}{l}\text { Ao menos } \\
\text { uma das ações: } \\
\text { plano de comu- } \\
\text { nicação com a } \\
\text { comunidade; } \\
\text { protocolo } \\
\text { sitemap im- } \\
\text { plementado; } \\
\text { registro no } \\
\text { LODcloud; } \\
\text { registro em } \\
\text { mecanismo de } \\
\text { busca }\end{array}$ & $\begin{array}{l}\text { Arquivo } \\
\text { registrado; } \\
\text { tro em regis- } \\
\text { (CKAN ou } \\
\text { cloud); rogos } \\
\text { comunicação feita } \\
\text { com stakeholders } \\
\text { da comunidade de } \\
\text { dados }\end{array}$ & $\begin{array}{l}\text { sitemap4rdf } \\
\text { gerar o arquivo } \\
\text { XML; } \\
\text { em } \text { cadastro } \\
\text { de buscas comismo } \\
\text { Google Dataset Se- } \\
\text { arch; diretrizes para } \\
\text { conectar à LOD } \\
\text { Cloud; metadados } \\
\text { VoID. }\end{array}$ \\
\hline
\end{tabular}




\subsubsection{Exploração - o que é possível de se fazer com os dados?}

O universo de dados abertos governamentais contém uma quantidade muito grande de informações e, por vezes, fica difícil para que o consumidor (ou mesmo o produtor) consiga ter consciência de tudo o que foi disponibilizado. Uma forma eficiente de tratar este problema é fornecer apresentações complementares dos dados, de modo que o usuário possa navegar pelos dados, descobrindo sua natureza, distribuição, relacionamentos - sem ter que baixá-los, já que, por vezes, trata-se de arquivos muito grandes. Outra forma é disponibilizar softwares com demonstrações de aplicações em cima de certos conjuntos de dados, de modo a demonstrar a reusabilidade dos dados e possíveis mashups. Exemplos simples incluem disponibilizar consultas SPARQL de exemplo. Portais nacionais de dados geralmente catalogam aplicações desenvolvidas sobre seus dados. Por exemplo, o portal dados.gov.br traz uma página com algumas aplicações desenvolvidas. A Figura 19 e a Quadro 19 trazem os passos necessários para esta fase.

Figura 19 - Atividades da fase de Exploração.

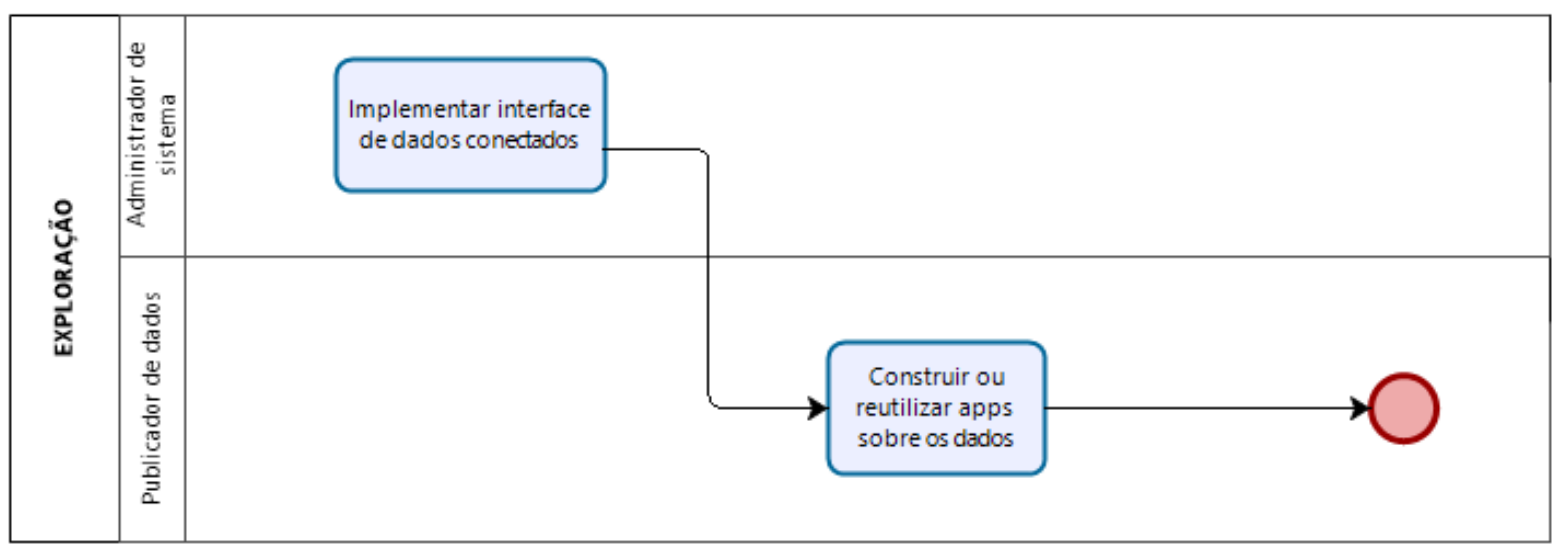

Fonte: Elaborada pelo autor.

Uma aplicação genérica que facilita a visualização dos recursos informacionais publicados no portal é a chamada interface de dados conectados, em que os recursos são desreferenciados via negociação de conteúdo, permitindo descobrir suas propriedades e suas relações com outros recursos. Além disso, outros componentes podem ser usados para criar visualizações ou outras análises que possam demonstrar como os dados publicados podem ser reutilizados, fazendo com que os dados não precisem ser baixados para que sejam analisados pelos consumidores. 
Quadro 19 - Atividades da fase de Exploração.

\begin{tabular}{|c|c|c|c|c|}
\hline Atividade & Tarefas & Saída & $\mathbf{V} \& V$ & Ferramentas \\
\hline $\begin{array}{l}\text { Implantar } \\
\text { interface } \\
\text { de dados } \\
\text { conecta- } \\
\text { dos }\end{array}$ & $\begin{array}{l}\text { Implementar } \\
\text { ferramenta de } \\
\text { interface de da- } \\
\text { dos conectados } \\
\text { que fornece } \\
\text { acesso às triplas } \\
\text { de um endpoint } \\
\text { SPARQL em } \\
\text { diferentes re- } \\
\text { presentações } \\
\text { (HTML, CSV, } \\
\text { JSON, etc.) }\end{array}$ & $\begin{array}{l}\text { Interface de da- } \\
\text { dos conectados } \\
\text { operacional }\end{array}$ & $\begin{array}{l}\text { Acessar os recursos } \\
\text { pelo navegador (desre- } \\
\text { ferenciação das URIs } \\
\text { por acesso direto); con- } \\
\text { seguir navegar pelas } \\
\text { conexões feitas entre } \\
\text { os dados (desreferenci- } \\
\text { ação das URIs pelo va- } \\
\text { lor da propriedade das } \\
\text { instâncias) }\end{array}$ & $\begin{array}{l}\text { LODView, } \\
\text { Pubby, Virtuoso } \\
\text { Facets } \\
\text { Service, Elda, } \\
\text { djubby, D2R } \\
\text { Server (no caso } \\
\text { de mapeamento } \\
\text { direto à bases } \\
\text { de dados) para } \\
\text { navegadores dos } \\
\text { dados conectados }\end{array}$ \\
\hline \begin{tabular}{l}
\multicolumn{2}{l}{ Construir } \\
exemplos \\
de uso \\
sobre os \\
dados
\end{tabular} & $\begin{array}{l}\text { Especificar e } \\
\text { implementar } \\
\text { ferramentas } \\
\text { que facilitam } \\
\text { aos usuários } \\
\text { dos dados sua } \\
\text { compreensão }\end{array}$ & $\begin{array}{l}\text { Aplicações } \\
\text { criadas sobre } \\
\text { os dados ou } \\
\text { consultas } \\
\text { SPARQL que } \\
\text { respondam às } \\
\text { questões de } \\
\text { competência } \\
\text { ou casos de } \\
\text { uso levantados } \\
\text { na fase } 1\end{array}$ & $\begin{array}{l}\text { Implementar e respon- } \\
\text { der (ou ao menos tra- } \\
\text { tar) as questões de } \\
\text { competência ou casos } \\
\text { de uso postos na fase } 1\end{array}$ & $\begin{array}{l}\text { Plugins dos } \\
\text { catálogos de } \\
\text { dados; página de } \\
\text { aplicativos no } \\
\text { portal brasileiro } \\
\text { de dados abertos, } \\
\text { softwares de } \\
\text { visualização } \\
\text { como Tableau }\end{array}$ \\
\hline
\end{tabular}




\subsubsection{Manutenção - como mantê-los por décadas sem causar proble- mas no consumo?}

Uma vez com os dados conectados publicados, o ciclo de vida dos dados ainda não foi finalizado. Os dados precisam ser mantidos em serviços estáveis, que resolvam as URIs dos dados usados por aplicações consumidoras ou que contenham informações sobre sua indisponibilidade (seja redirecionando para outro local ou comunicando que os dados não estão mais disponíveis). O uso de URLs permanentes (PURL) é uma técnica comum para a preservação das URLs. Uma URL permanente se comporta como uma URI normal, mas, em vez de redirecionar para o recurso, a PURL redireciona para um serviço intermediário de resolução de nomes, que pode ser atualizado sem mudar o nome publicado. Simplesmente apagar os dados é considerada uma má prática (W3C, 2017). Este costuma ser uma fonte de erros e uma das possíveis causas da baixa reutilização dos dados conectados, afetando a percepção de qualidade das fontes de dados. Além disso, é necessário criar um canal de comunicação com a comunidade que utiliza esses dados, de modo a garantir sua evolução e depuração ao longo do tempo. A Figura 20 ilustra os passos desta fase e a Quadro 20 detalha suas características.

Figura 20 - Atividades da fase de Manutenção.

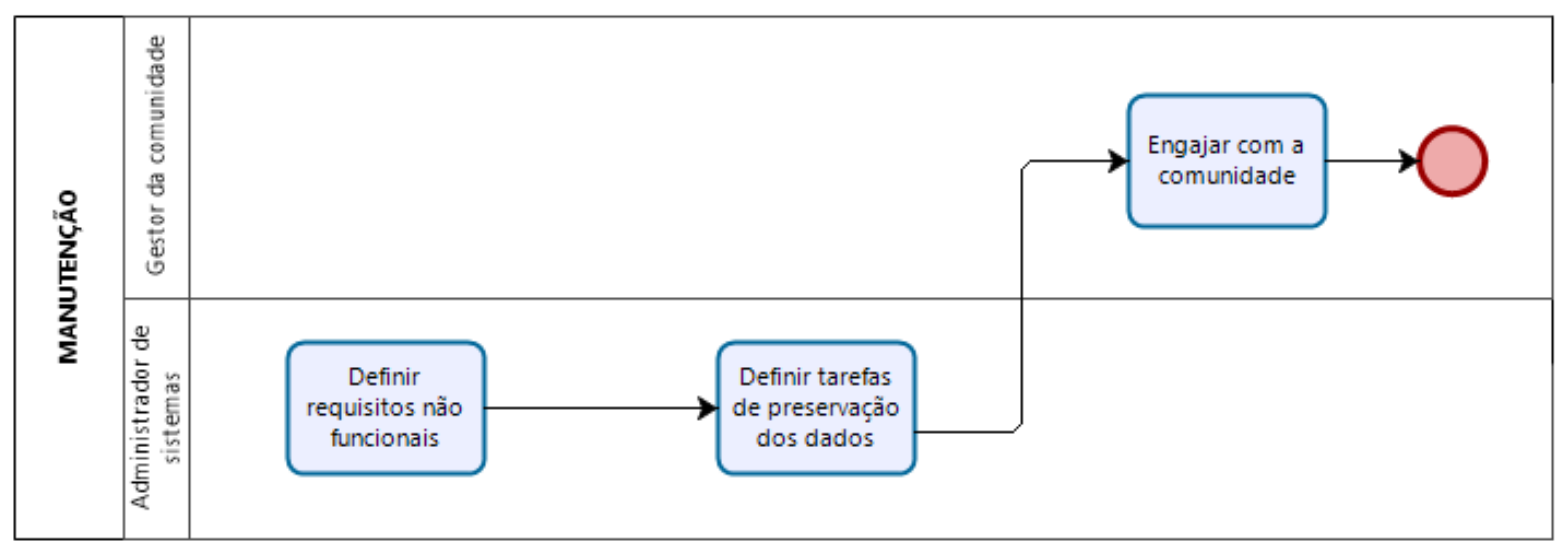

Fonte: Elaborada pelo autor.

Tendo os dados publicados e passíveis de exploração por seus consumidores, é necessário garantir que eles estejam disponíveis, de fácil descoberta e tenham um bom desempenho, dentre outros requisitos não funcionais essenciais para que os consumidores possam ter confiança. A intenção é que os dados persistam por muitos anos (ou décadas), logo o passo seguinte consiste em definir tarefas que auxiliem na preservação dos dados, retornando respostas adequadas quando eles tiverem se movido ou deixado de existir na Web. Por fim, é necessário que sejam coletados feedbacks junto à comunidade, para aprimorar os dados em seu conteúdo ou forma. Com isso, os dados são apurados tanto em seu conteúdo quanto no estabelecimento de novos critérios de qualidade, mais contextualizados ao domínio a que os dados pretende representar. 
Quadro 20 - Atividades da fase de Manutenção.

\begin{tabular}{|c|c|c|c|c|}
\hline Atividade & Tarefas & Saída & $V \& V$ & Ferramentas \\
\hline $\begin{array}{l}\text { Definir } \\
\text { requisitos } \\
\text { não- } \\
\text { funcionais }\end{array}$ & $\begin{array}{l}\text { Definir conjunto } \\
\text { de requisitos } \\
\text { não-funcionais } \\
\text { mensuráveis; } \\
\text { implementar } \\
\text { mecanismos } \\
\text { que garantam } \\
\text { o atendimento } \\
\text { desses requisitos }\end{array}$ & $\begin{array}{l}\text { Mecanismos } \\
\text { de mensu- } \\
\text { ração e } \\
\text { atendi- } \\
\text { mento dos } \\
\text { requisitos } \\
\text { especifica- } \\
\text { dos; }\end{array}$ & $\begin{array}{l}\text { Validar se valores de taxa } \\
\text { de transferência e de la- } \\
\text { tência estão conforme es- } \\
\text { perado. Outras verifica- } \\
\text { ções podem ser estabele- } \\
\text { cidas conforme as diretri- } \\
\text { zes da organização. Por } \\
\text { exemplo: disponibilidade } \\
\text { do serviço Web, comuni- } \\
\text { cação via HTTPS, dentre } \\
\text { outras }\end{array}$ & $\begin{array}{l}\text { Variável con- } \\
\text { forme os } \\
\text { requisitos es- } \\
\text { pecificados. } \\
\text { SPARQLES } \\
\text { (verificação dos } \\
\text { requisitos mí- } \\
\text { nimos) Luzzu } \\
\text { (métricas de } \\
\text { qualidade), Apa- } \\
\text { che Marmotta, } \\
\text { LDCache (ca- } \\
\text { ching), Jena } \\
\text { SPARQL API. }\end{array}$ \\
\hline $\begin{array}{l}\text { Definir pre- } \\
\text { servação } \\
\text { dos dados }\end{array}$ & $\begin{array}{l}\text { Caso o conjunto } \\
\text { de dados não } \\
\text { esteja mais } \\
\text { disponível no } \\
\text { URI solicitado, } \\
\text { é necessário } \\
\text { indicar como } \\
\text { chegar a ele } \\
\text { (códigos HTTP } \\
\text { 401, 303 ou } \\
\text { 503); Entrada: } \\
\text { conjuntos de } \\
\text { dados a serem } \\
\text { monitorados }\end{array}$ & $\begin{array}{l}\text { Indicação } \\
\text { automática } \\
\text { de quais } \\
\text { dados não } \\
\text { estão mais } \\
\text { disponíveis } \\
\text { e qual a } \\
\text { razão }\end{array}$ & $\begin{array}{l}\text { para conjuntos de dados } \\
\text { não resolvidos pela URI, } \\
\text { checar códigos HTTP } 401 \\
\text { (caso os dados tenham } \\
\text { sido deliberadamente re- } \\
\text { movidos da Web), código } \\
\text { HTTP 303, caso ele tenha } \\
\text { se mudado para outra URI } \\
\text { e seja possível fazer o re- } \\
\text { direcionamento ou código } \\
\text { HTTP 503, caso o serviço } \\
\text { que oferece os dados es- } \\
\text { teja indisponível; mostrar } \\
\text { mensagem descritiva so- } \\
\text { bre a mudança dos dados }\end{array}$ & $\begin{array}{l}\text { SPARQLES, } \\
\text { para monitorar } \\
\text { disponibilidade } \\
\text { de endpoints }\end{array}$ \\
\hline
\end{tabular}




\begin{tabular}{|c|c|c|c|c|}
\hline Atividade & Tarefas & Saída & $\mathbf{V} \& \mathbf{V}$ & Ferramentas \\
\hline $\begin{array}{l}\text { Engajar } \\
\text { com a co- } \\
\text { munidade } \\
\text { de dados }\end{array}$ & $\begin{array}{l}\text { Fornecer meca- } \\
\text { nismos que regis- } \\
\text { trem feedbacks } \\
\text { dos membros da } \\
\text { comunidade }\end{array}$ & $\begin{array}{l}\text { Mecanismo } \\
\text { de feedback } \\
\text { operacional }\end{array}$ & $\begin{array}{l}\text { Comentários de qualquer } \\
\text { membro da comuni- } \\
\text { dade são direcionados } \\
\text { a um ponto focal } \\
\text { (prov:wasAttributedTo); } \\
\text { os comentários são regis- } \\
\text { trados e disponibilizados } \\
\text { para exame de outros } \\
\text { membros; os dados } \\
\text { reutilizados de outras } \\
\text { fontes são mapeados, } \\
\text { quando o publicador } \\
\text { não for a fonte primária } \\
\text { do conjunto de dados } \\
\text { (prov:wasDerivedFrom) }\end{array}$ & $\begin{array}{l}\text { Catálogos de da- } \\
\text { dos geralmente } \\
\text { já incluem - na- } \\
\text { tivamente ou via } \\
\text { extensões - a op- } \\
\text { ção de coleta } \\
\text { de feedback; sis- } \\
\text { tema de aber- } \\
\text { tura ao público } \\
\text { como o e-SIC } \\
\text { para gerenciar } \\
\text { a transparência } \\
\text { passiva }\end{array}$ \\
\hline
\end{tabular}

Fonte: Elaborada pelo autor.

O processo completo, com a descrição de todas as atividades, sugestões de ferramentas e atividades de $\mathrm{V} \& \mathrm{~V}$, encontra-se no apêndice A desta tese.

\subsection{Ferramentas de suporte}

As ferramentas de suporte podem ser especificadas conforme a fase do ciclo de vida em que elas são aplicadas. No entanto, outros fatores, como características e limitações das próprias ferramentas, podem fazer com que a escolha seja modificada. Na Quadro 21 é feito um mapeamento de alguns fatores conhecidos, baseado em relatos da literatura e na experiência do autor desta tese. Embora não se trate de uma lista extensiva, traz sugestões que acreditamos serem importantes para os publicadores de dados que ainda não tiveram contato suficiente com a área de dados conectados.

Quadro 21 - Critérios para a definição de ferramentas a serem usadas durante o ciclo de vida proposto.

\begin{tabular}{|l|l|l|l|}
\hline Fase & Fator & Níveis & $\begin{array}{l}\text { Exemplos de ferramentas / } \\
\text { diretrizes }\end{array}$ \\
\hline \multirow{2}{*}{ Especificação } & URI & Modelagem & Cool URI \\
\cline { 2 - 4 } & Licenças de uso & $\begin{array}{l}\text { Recomendações das di- } \\
\text { retrizes de e-gov ou } \\
\text { Creative Commons }\end{array}$ & $\begin{array}{l}\text { e-PING (governo brasileiro), } \\
\text { Open Data Commons }\end{array}$ \\
\hline
\end{tabular}




\begin{tabular}{|c|c|c|c|}
\hline Fase & Fator & Níveis & $\begin{array}{l}\text { Exemplos de ferramentas / } \\
\text { diretrizes }\end{array}$ \\
\hline & Metadados & $\begin{array}{l}\text { Obrigatórios e opcio- } \\
\text { nais }\end{array}$ & $\begin{array}{l}\text { Seção de Metadados e apên- } \\
\text { dice B desta tese }\end{array}$ \\
\hline \multirow{10}{*}{ Modelagem } & \multirow[t]{3}{*}{ Anotação } & $\begin{array}{l}\text { Vocabulários existen- } \\
\text { tes }\end{array}$ & $\begin{array}{l}\text { Busca: LOV, Swoogle; e- } \\
\text { PING (para governo brasi- } \\
\text { leiro). Anotação: OpenRefine }\end{array}$ \\
\hline & & $\begin{array}{l}\text { Vocabulários novos - } \\
\text { Colaborativo }\end{array}$ & OntoWiki, Protégé Web \\
\hline & & $\begin{array}{l}\text { Vocabulários novos - } \\
\text { Individual }\end{array}$ & $\begin{array}{l}\text { Protégé Desktop, TopBraid } \\
\text { Composer }\end{array}$ \\
\hline & Verificação & $\begin{array}{l}\text { Verificação de erros co- } \\
\text { muns em ontologias }\end{array}$ & OWL Validator, Oops \\
\hline & Limpeza dos dados & Dados estruturados & $\begin{array}{l}\text { OpenRefine, DataWrangler, } \\
\text { DataCleaner, Excel }\end{array}$ \\
\hline & \multirow{2}{*}{$\begin{array}{l}\text { Conexão } \\
\text { entre fontes } \\
\text { de dados }\end{array}$} & Mesmo identificador & OpenRefine \\
\hline & & $\begin{array}{l}\text { Identificadores diferen- } \\
\text { tes - Heurísticas }\end{array}$ & SILK, LIMES \\
\hline & \multirow[t]{3}{*}{$\begin{array}{l}\text { Formato da cone- } \\
\text { xão }\end{array}$} & (Semi) Estruturado & OpenRefine \\
\hline & & Não estruturado & $\begin{array}{l}\text { Dbpedia Spotlight, OpenCa- } \\
\text { lais }\end{array}$ \\
\hline & & Geográfico & geometry2rdf, ESRI2Open \\
\hline \multirow{6}{*}{ Conversão } & \multirow{2}{*}{$\begin{array}{l}\text { Dinamicidade } \\
\text { dos dados }\end{array}$} & Arquivos estáticos & OpenRefine \\
\hline & & Bases de dados & D2RQ, Triplify \\
\hline & \multirow[t]{3}{*}{$\begin{array}{l}\text { Verificação do } \\
\text { RDF }\end{array}$} & Sintática & $\begin{array}{l}\text { IDLab Turtle Validator, W3C } \\
\text { RDF Validator e Vapour }\end{array}$ \\
\hline & & Semântica & $\begin{array}{l}\text { Jena Eyeball, VRP (Validating } \\
\text { RDF Parser) e RDF Alerts }\end{array}$ \\
\hline & & Baseada em critérios & $\begin{array}{l}\text { RDFUnit, Luzzu, LOD } \\
\text { Washing Machine }\end{array}$ \\
\hline & $\begin{array}{l}\text { Verificação das co- } \\
\text { nexões }\end{array}$ & $\begin{array}{l}\text { Acurácia das equiva- } \\
\text { lências }\end{array}$ & sameAs Link Validator \\
\hline \multirow[b]{2}{*}{ Publicação } & \multirow[b]{2}{*}{ Infraestrutura } & Acesso por download & CKAN, Socrata \\
\hline & & Servidores SPARQL & Virtuoso, Fuseki, Dydra \\
\hline
\end{tabular}




\begin{tabular}{|c|c|c|c|}
\hline Fase & Fator & Níveis & $\begin{array}{l}\text { Exemplos de ferramentas / } \\
\text { diretrizes }\end{array}$ \\
\hline & & $\begin{array}{l}\text { API para acesso aos da- } \\
\text { dos }\end{array}$ & $\begin{array}{l}\text { Elda, Puelia (Linked Data } \\
\text { API) }\end{array}$ \\
\hline \multirow[t]{3}{*}{ Exploração } & \multirow[t]{3}{*}{ Propósito } & $\begin{array}{l}\text { Interface de dados co- } \\
\text { nectados }\end{array}$ & LodView, Pubby, Disco \\
\hline & & $\begin{array}{l}\text { Visualização do con- } \\
\text { teúdo }\end{array}$ & CubeViz, SemMap \\
\hline & & $\begin{array}{l}\text { Conectores a outros } \\
\text { ambientes }\end{array}$ & RapidMiner, Sparql R \\
\hline \multirow[t]{3}{*}{ Manutenção } & $\begin{array}{l}\text { Monitoramento de } \\
\text { disponibilidade }\end{array}$ & $\begin{array}{l}\text { Métricas de disponibi- } \\
\text { lidade }\end{array}$ & SPARQLES \\
\hline & \multirow[t]{2}{*}{$\begin{array}{l}\text { Preservação de } \\
\text { URI }\end{array}$} & Serviço na Web & PURL, W3ID \\
\hline & & Infraestrutura própria & PURLZ (Linked Data API) \\
\hline
\end{tabular}

Fonte: Adaptada de Penteado, Bittencourt e Isotani (2019b).

\subsection{Arquitetura da infraestrutura}

O modelo de ciclo de vida de dados proposto nesta tese é composto pela arquitetura conceitual ilustrada na Figura 21. Nela, pode-se observar a infraestrutura básica necessária para atender aos requisitos levantados para os DAGC e as interações possíveis dos principais atores desse ecossistema (produtor/publicador de dados e consumidor/usuário) com os componentes especificados. Na figura, é delimitada a infraestrutura interna à organização, dividida em três camadas, e o ambiente externo, na Web. Trata-se de uma arquitetura conceitual, de alto nível, que pode ser combinada com arquiteturas propostas mais recentemente como para big data abertos ou para Internet das Coisas (IoT).

A dinâmica da infraestrutura se inicia com as requisições de dados feitas por iniciativa do próprio governo ou por cidadãos, e que são centralizados em um sistema de informação do governo (no governo federal brasileiro é o sistema eletrônico do serviço de informação ao cidadão - e-SIC). Outros compromissos de abertura de dados vêm do documento de Plano de Dados Abertos, que cada órgão é obrigado a criar e pelo qual ele é acompanhado por órgãos de controle. Este mecanismo é uma das ações estabelecidas pelos países que aderem à OGP. A partir dessas demandas, o publicador tem seu escopo de abertura de dados determinado em termos de conjuntos de dados, metadados e seu cronograma de execução. Para uma uniformização dessas publicações, as instituições publicadoras criam manuais, kits de apoio, cartilhas e especificações que determinam quais são as diretrizes que devem ser seguidas, incluindo o padrão de URI a ser 
Figura 21 - Arquitetura geral dos componentes propostos.

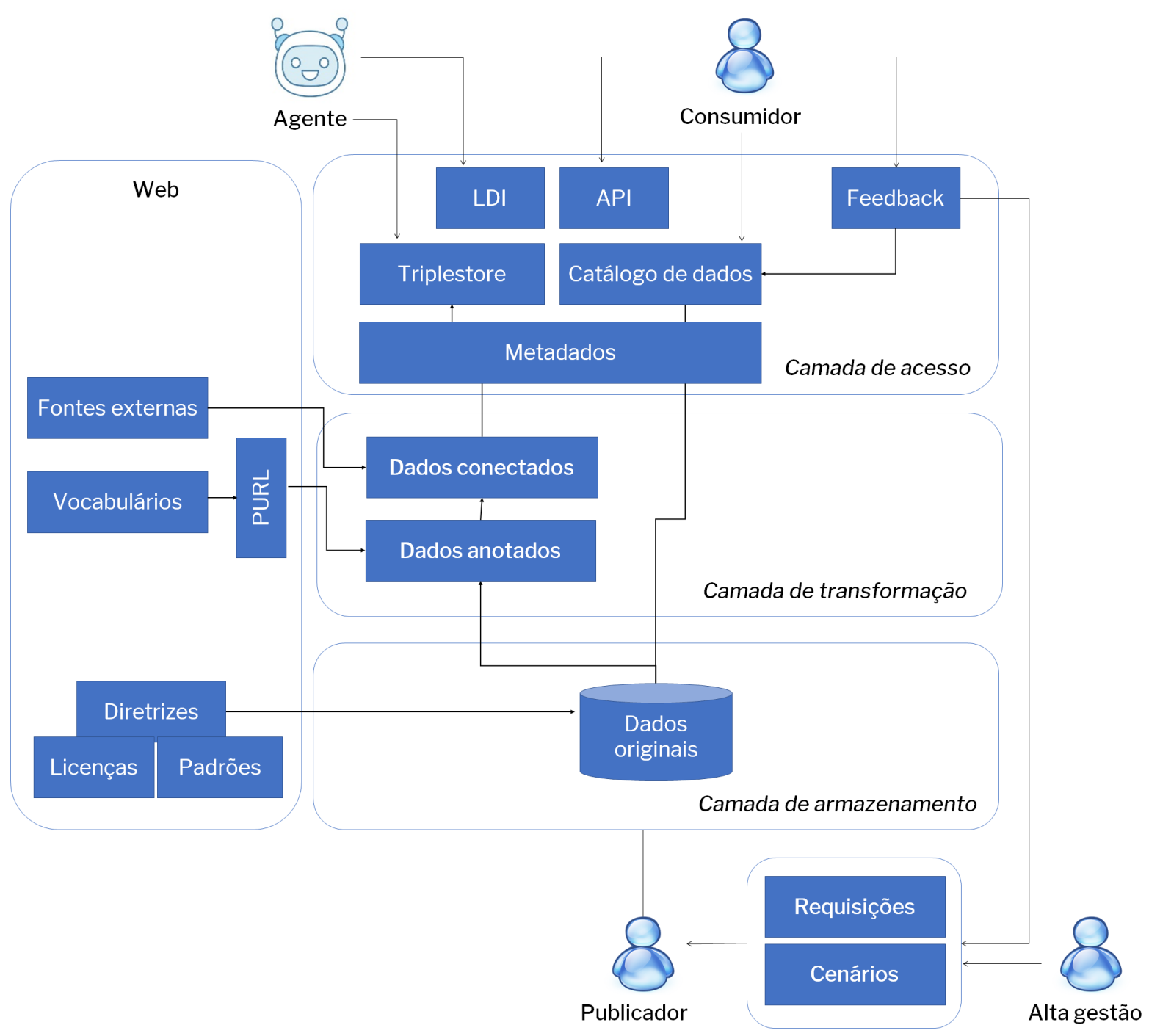

Fonte: Elaborada pelo autor.

seguido. Certos domínios também apresentam suas diretrizes e regras de dados a serem seguidas (por exemplo, HIPPA ${ }^{4}$ para dados de saúde nos EUA).

A Figura 22 mostra, em alto nível, o diagrama de sequência de ações do publicador de dados e suas interações com os componentes da infraestrutura proposta. Com o escopo de publicação já definido, o publicador de dados realiza os passos de tratamento de dados (pré-processamento, normalização e criação de dados). Em seguida, o publicador busca por vocabulários disponíveis na Web que possam ser reutilizados sobre seus dados e cria vocabulários necessários para os dados específicos, não atendidos por esses artefatos. Um passo necessário para o planejamento da manutenção dos dados ao longo de décadas é o de utilizar um serviço de preservação de URIs, de modo que todas as referências aos recursos de dados sejam modeladas conforme essa URI modificada. Por exemplo, o vocabulário Dublin Core utiliza essa abordagem,

$4<$ https://www.hhs.gov/hipaa/index.html $>$ 
usando <http://purl.org/dc/terms/> para apontar para termos em: <https://www.dublincore.org/ specifications/dublin-core/dcmi-terms/2012-06-14/?v=terms\#> (sua URI atual).

Figura 22 - Diagrama de sequência das ações do publicador de dados no ciclo de vida.

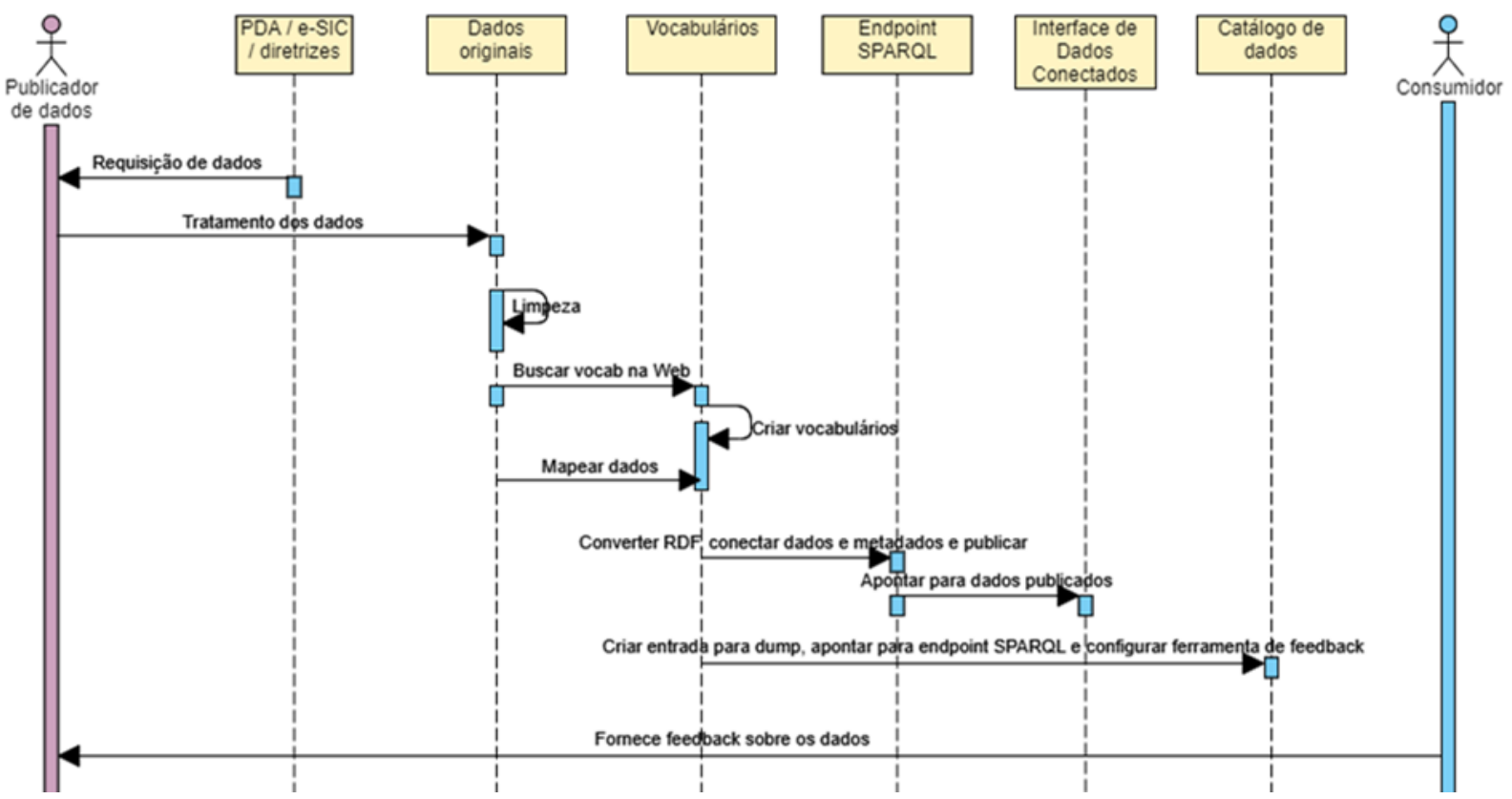

Fonte: Elaborada pelo autor.

Com os dados mapeados, o publicador pode fazer a reconciliação de seus dados com dados externos (na Web ou mesmo em sua organização), de diferentes formas (ligação por instâncias, por equivalência de classes ou por relacionamentos por apontamentos) e com diferentes padrões de atualização (diretamente no banco de dados de origem ou por arquivos de dados exportados), e usa ferramentas para gerar os dados em formato RDF. Os metadados também devem estar convertidos para formato RDF, sendo parte do mesmo grafo RDF. O versionamento e o licenciamento apropriados dos dados gerados também são aplicados.

Com os dados convertidos para este formato, o publicador de dados deve registrá-lo na triplestore. Ao mesmo tempo, para garantir formas alternativas de acesso, o publicador deve registrar esse dump RDF no portal de catálogo de dados, que deve possuir duas funcionalidades adicionais: uma API para o acesso parcial aos dados e ferramentas com mecanismos de interação e comunicação (wiki, fórum, FAQ, votações, etc.) com a comunidade. Outro componente importante da infraestrutura é o de interface de dados conectados, que funciona como uma camada acima do ponto de extremidade SPARQL e é responsável por desreferenciar as URI e por retornar, via negociação de conteúdo, o recurso de dados consultado no formato requisitado.

A Figura 23 traz quais são as possíveis ações de um indivíduo consumidor de dados dentro da infraestrutura proposta.

Uma outra visão possível sobre a arquitetura da infraestrutura, visando a garantia da qualidade, é a de apontar quais são as possíveis atividades de verificação que podem ser feitas e 
Figura 23 - Diagrama de sequência de possíveis ações do consumidor dos dados.

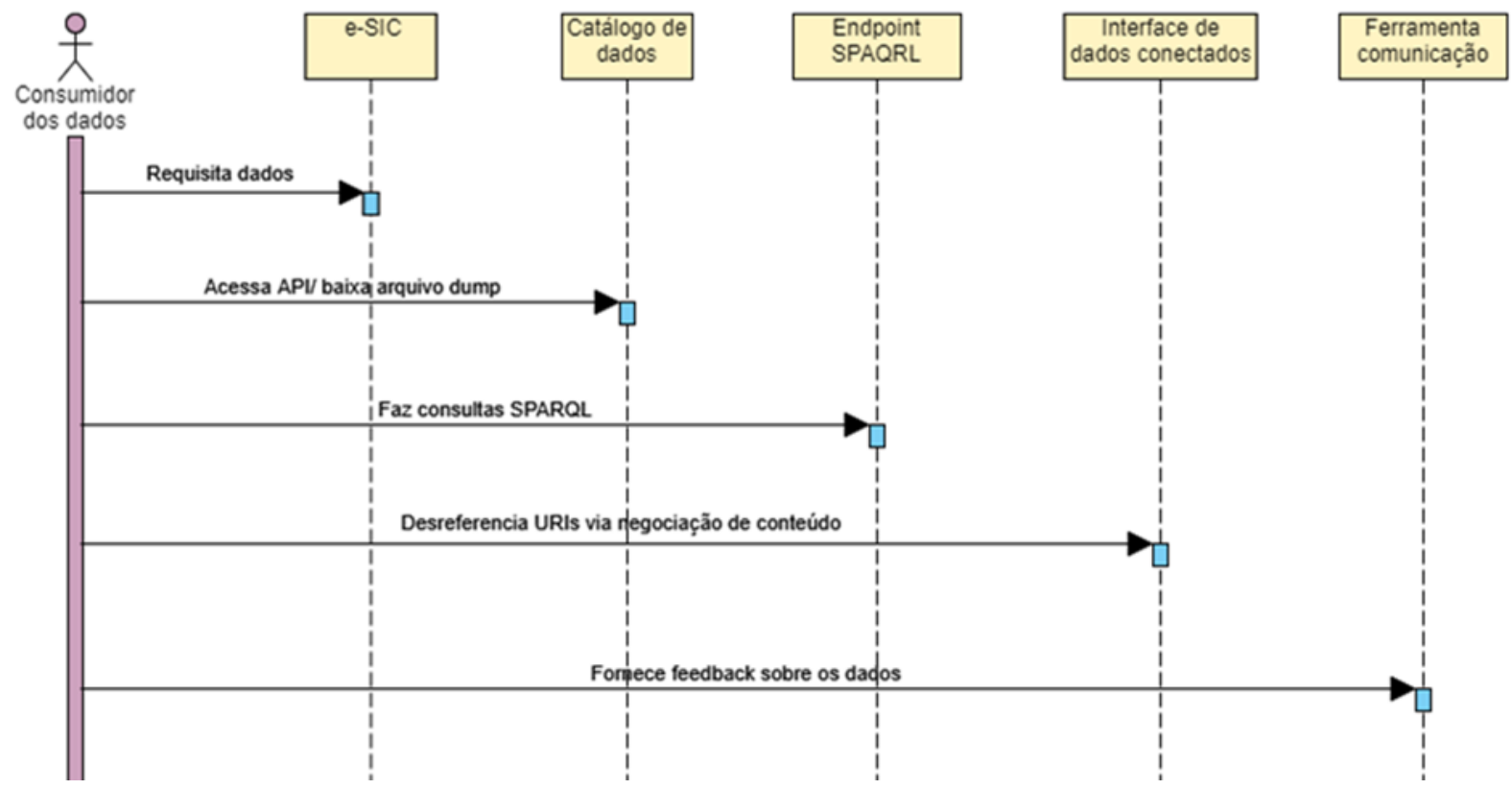

Fonte: Elaborada pelo autor.

mantidas continuamente sobre seus componentes. A Figura 24 ilustra os pontos de verificação dos produtos intermediários e finais dos dados.

Inicialmente, os dados brutos, em formatos diversos (texto, CSV, JSON, XML) são verificados para detectar possíveis problemas de estrutura ou inconsistência. Ferramentas como OpenRefine $^{5}$, DataWrangler ${ }^{6}$, DataCleaner ${ }^{7}$ ou mesmo ferramentas mais comuns como planilhas de dados - para dados estruturados em linhas e colunas - podem fazer a detecção e o tratamento desses problemas. Iniciativas mais recentes, como o Frictionless Data ${ }^{8}$, trazem práticas e ferramentas que buscam validar a estrutura de arquivos tabulares ao mesmo tempo que padronizam os dados em pacotes.

Para a verificação de ontologias, ferramentas como OWL Validator ${ }^{9}$ e Oops! $!^{10}$ (OntOlogy Pitfall Scanner!) existem para detectar problemas comuns quando da construção de termos na ontologia. Uma vez feitas as ligações com dados externos, pode-se fazer também a análise de qualidade dos links criados, usando ferramentas como sameAs Link Validator ${ }^{11}$ para verificação de reconciliação de instâncias.

Uma vez mapeados semanticamente e convertidos para RDF, os dados podem ser verificados em termos de sua acurácia sintática e semântica. Para verificações sintáticas sobre os

\footnotetext{
$<$ https://openrefine.org/>

$<$ http://vis.stanford.edu/wrangler/>

$<$ https://datacleaner.org/>

$<$ https://frictionlessdata.io/>

$9<\mathrm{http}: / /$ visualdataweb.de/validator/>

$10<\mathrm{http} / / /$ oops.linkeddata.es/>

$11<$ http://oeg-dev.dia.fi.upm.es:8080/sameAs/>
} 
Figura 24 - Pontos de controle de qualidade da infraestrutura proposta.

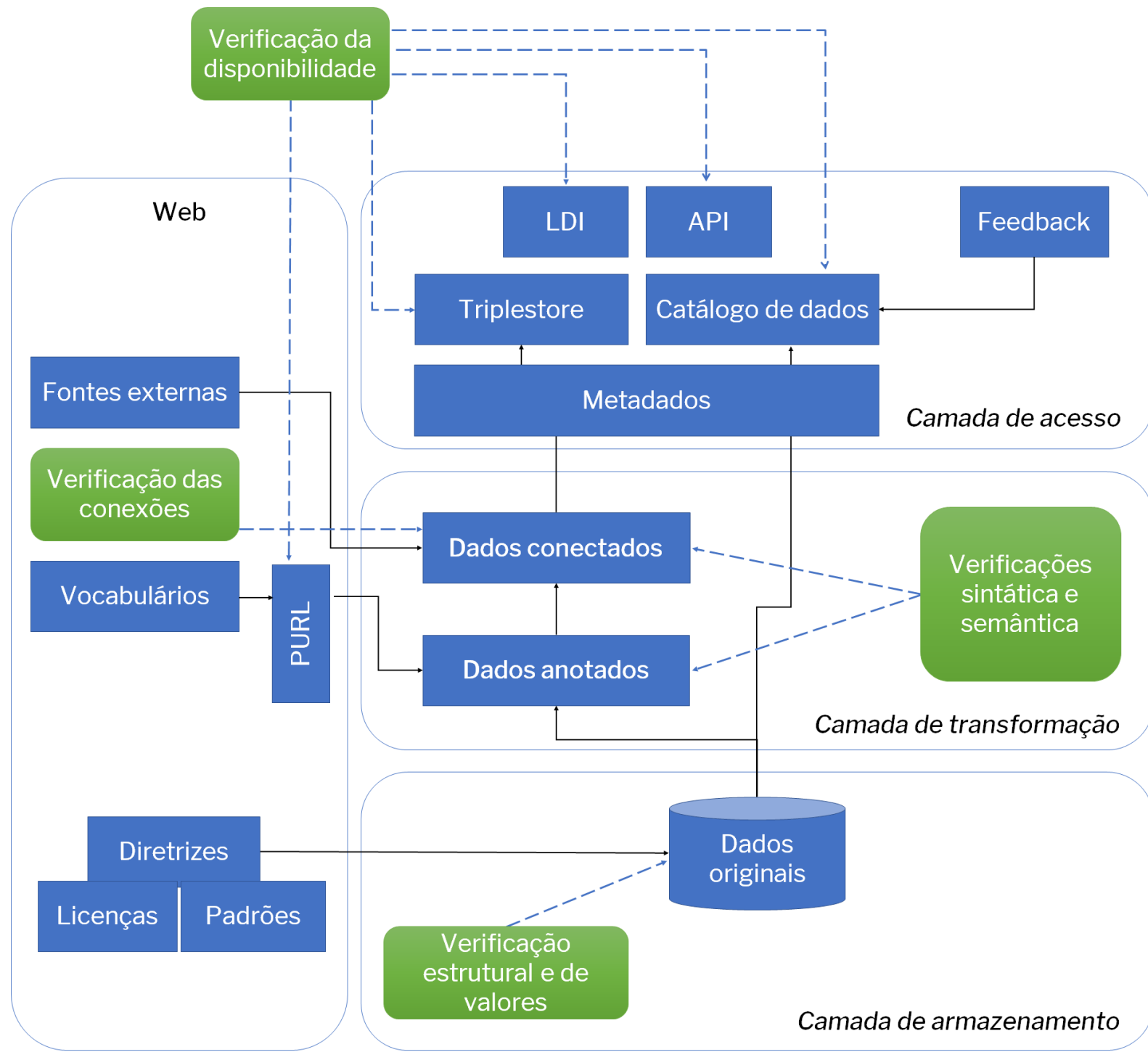

Fonte: Elaborada pelo autor.

dados existem ferramentas como IDLab Turtle Validator ${ }^{12}$, W3C RDF Validator $^{13}$ e Vapour ${ }^{14}$. Para verificações semânticas, Jena Eyeball ${ }^{15}$, VRP (Validating RDF Parser) ${ }^{16}$ e RDF Alerts ${ }^{17}$. Além dessas verificações, é possível especificar critérios para serem aplicados sobre os dados em RDF (por ex.: verificações que data de nascimento é anterior à data de morte de uma pessoa). Para isso, foram desenvolvidas ferramentas como RDFUnit ${ }^{18}$ e $L u z z u^{19}$ e a ferramenta $L O D$

\footnotetext{
$12<$ http://ttl.summerofcode.be/>

$13<$ https://www.w3.org/RDF/Validator/>

$14<$ http://linkeddata.uriburner.com:8000/vapour>

$15<$ https://jena.apache.org/documentation/tools/eyeball-getting-started>

$16<\mathrm{http} / / /$ www.ics.forth.gr/isst/proj/RDF)>

$17<$ https://github.com/timrdf/DataFAQs/wiki/RDFAlerts>

$18<$ http://aksw.org/Projects/RDFUnit.html>

$19<$ https://eis-bonn.github.io/Luzzu/>
} 
Washing Machine ${ }^{20}$, que corrige automaticamente os erros encontrados. A linguagem SHACL (Shapes Constraint Language), recomendada pela W3C, pode ser usada para criar casos de testes de acordo com o cenário e com as características dos dados e que podem ser usadas por essas ferramentas bem como por validadores disponíveis na Web, como o SHACL Playground ${ }^{21}$ e o ELI Validator ${ }^{22}$.

Por fim, outro aspecto de verificação da infraestrutura são os pontos de acesso que os consumidores de dados podem consultar os dados (dump RDF, API, interface de dados conectados e ponto de extremidade SPARQL). Uma ferramenta citada na literatura para o monitoramento da disponibilidade de pontos de extremidade é a SPARQLES ${ }^{23}$. Como forma da garantia da manutenção, é necessário também testar se o serviço de preservação de URL redireciona apropriadamente para os recursos de dados e com os códigos de resposta HTTP corretos.

\subsection{Metadados}

Metadados são, essencialmente, dados sobre dados, fazendo com que, dentre outras coisas, os recursos de dados presentes na Web possam ser processáveis por máquinas - um dos fundamentos básicos da Web de dados. Nos últimos anos, diversos vocabulários para catalogação e descrição, dentre outros aspectos, foram desenvolvidos para dar suporte ao avanço dos dados conectados sendo publicados na Web. Esta pesquisa buscou contribuir para a prática de publicadores de dados, ao compilar um conjunto mínimo de metadados para DAGC, de diferentes vocabulários e práticas, de modo a atender às boas práticas da DWBP e dos requisitos da qualidade de dados conectados.

O modelo completo, em formato Turtle, encontra-se no apêndice B desta tese. Nesta lista, existe a divisão em 4 níveis principais de metadados descritivos: i) serviço, em que os metadados descrevem características de descoberta do serviço SPARQL, suas capacidades e a descrição do serviço; ii) catálogo, que descreve o ponto de acesso aos dados, como por exemplo um catálogo nacional de DAG, que centraliza a coleção de conjuntos de dados; iii) conjunto de dados, que contém uma coleção de dados, publicados e curados por um único agente, e disponível para acesso em um ou mais formatos de serialização; iv) distribuição, que denota uma forma física do conjunto de dados (um mesmo conjunto de dados pode, por exemplo, ser disponibilizado em formato XML, JSON e CSV ao mesmo tempo, ou seja, 3 distribuições para o mesmo conjunto de dados). Para que os DAGC possam ser devidamente descobertos e analisados automaticamente, e também por humanos, é necessário registrar esse conjunto de metadados.

Os níveis de catálogo, conjunto de dados e distribuição não são exclusivos para dados

$20<$ https://svn.aksw.org/papers/2016/Semantics_DevOps/public.pdf>

$21<\mathrm{https} / / /$ shacl.org/playground/>

$22<$ https://webgate.ec.europa.eu/eli-validator/documentation>

$23<$ https://sparqles.ai.wu.ac.at/> 
conectados; no entanto, ao se optar por publicar os dados em formato conectados, outros padrões de metadados se tornam aplicáveis. A Figura 25 ilustra a relação entre esses componentes.

Os vocabulários mais adequados para descrever esta estrutura são o DCAT ${ }^{24}$ (para a estruturação e interligação de catálogos de dados e seus componentes na Web), o VoID ${ }^{25}$ (para expressar metadados em conjuntos de dados RDF) e o Service Description ${ }^{26}$ (para descrever a disponibilidade e características do servidor SPARQL). Eles contêm os termos que descrevem, catalogam, fazem a descoberta e o arquivamento. Além desses vocabulários descritivos, o modelo conta com o vocabulário PROV ${ }^{27}$, de descrição de proveniência dos dados, registrando como ele foi criado, por quem, quando e usando quais dados.

Figura 25 - Estruturação dos níveis dos metadados.

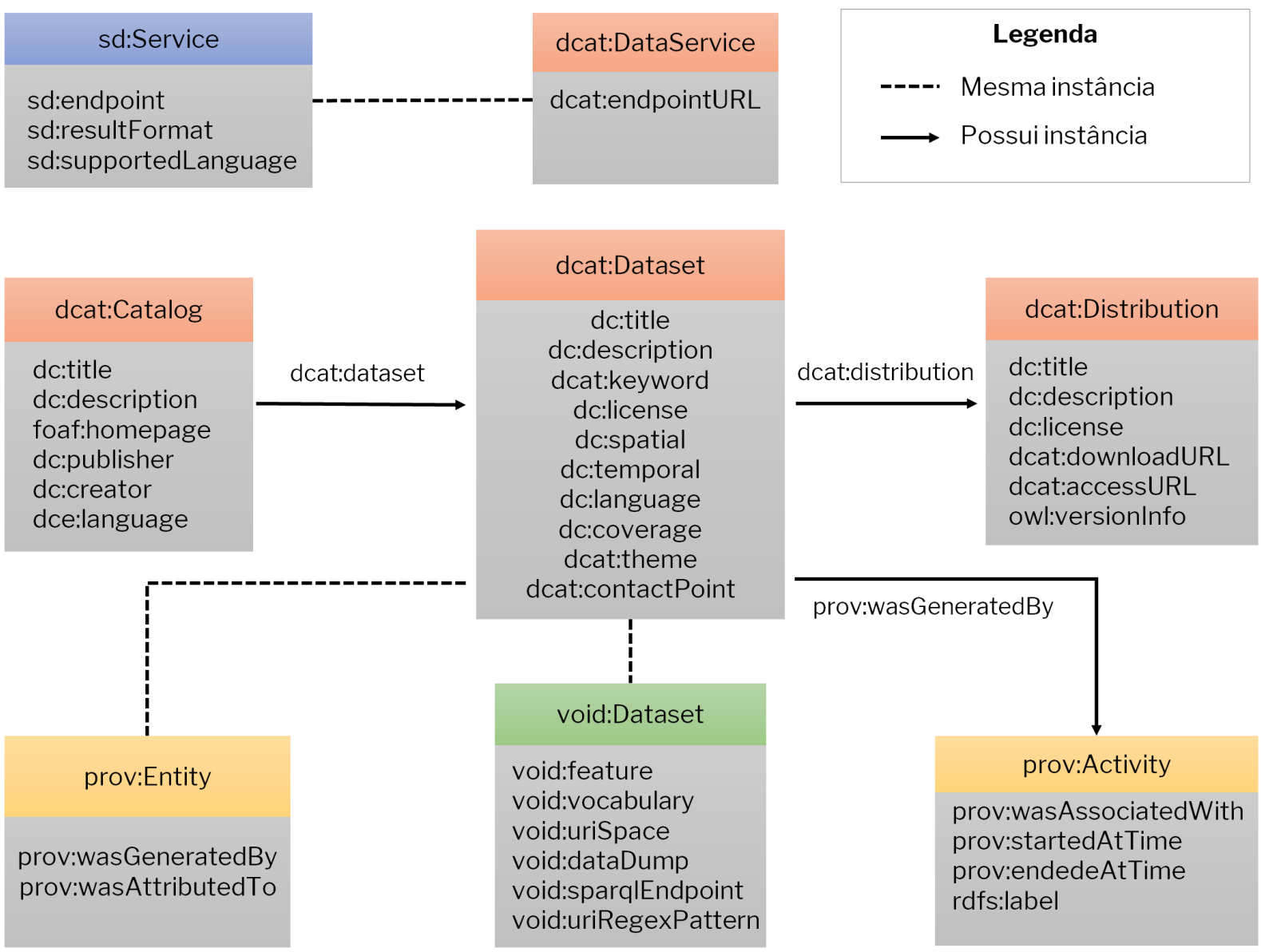

Fonte: Elaborada pelo autor.

Quanto maior a complexidade necessária para descrever um domínio, mais termos podem ser empregados, com outras propriedades ou mesmo classes que representem melhor os metadados necessários para o domínio dos dados sendo publicados. No entanto, buscamos

\footnotetext{
$24<$ https://www.w3.org/TR/vocab-dcat-2/>

$25<$ https://www.w3.org/TR/void/>

$26<$ https://www.w3.org/TR/sparql11-service-description/>

$27<$ http://www.w3.org/ns/prov\#>
} 
trazer um conjunto mínimo comum a todos os tipos de vocabulários, como ponto de partida para eventuais adaptações.

\subsection{Considerações finais}

Neste capítulo, descrevemos o artefato construído - o modelo de ciclo de vida e seus artefatos de suporte (arquitetura, ferramentas, metadados e papéis), integrando as diferentes teorias usadas para concebê-lo e atendendo aos requisitos do produto de dados especificado no Capítulo 2. Os requisitos de processo para publicação de DAGC levantados no Capítulo 2 foram atendidos da seguinte forma pelo artefato criado (Quadro 22):

Quadro 22 - Atendimento dos requisitos em função do conjunto de artefatos propostos.

\begin{tabular}{|c|c|}
\hline Requisito & Atendimento \\
\hline Definir papéis & $\begin{array}{l}\text { A Seção } 5.2 \text { deste capítulo trata da especificação de papéis } \\
\text { assumidos no processo de publicação. }\end{array}$ \\
\hline $\begin{array}{l}\text { Garantir conformidade } \\
\text { com legislação }\end{array}$ & $\begin{array}{l}\text { A fase de Especificação viabiliza o levantamento de diretrizes } \\
\text { legais aplicáveis aos dados em questão. }\end{array}$ \\
\hline $\begin{array}{l}\text { Garantir licenciamento dos } \\
\text { dados }\end{array}$ & $\begin{array}{l}\text { A fase de Publicação traz uma atividade específica para este } \\
\text { requisito, bem como sua verificação. }\end{array}$ \\
\hline $\begin{array}{l}\text { Especificar processo de pu- } \\
\text { blicação }\end{array}$ & $\begin{array}{l}\text { A Seção } 5.3 \text { deste capítulo descreve o processo, detalhando } \\
\text { quais papéis assumem quais atividades em qual sequência e com } \\
\text { quais saídas esperadas. }\end{array}$ \\
\hline Catalogar os dados & $\begin{array}{l}\text { Os metadados necessários para a catalogação apropriada dos } \\
\text { dados são fornecidos na Seção } 5.6 \text { deste capítulo, bem como sua } \\
\text { especificação, modelagem semântica e verificação, durante todo } \\
\text { o processo. }\end{array}$ \\
\hline $\begin{array}{l}\text { Garantir a qualidade dos } \\
\text { dados }\end{array}$ & $\begin{array}{l}\text { A adoção de práticas de garantia de qualidade de dados permitiu } \\
\text { especificar tarefas de verificação e validação ao longo de todas } \\
\text { as atividades do ciclo de vida. }\end{array}$ \\
\hline $\begin{array}{l}\text { Garantir acesso simplifi- } \\
\text { cado aos dados }\end{array}$ & $\begin{array}{l}\text { A atividade de publicar os dados (fase Publicação) especifica que } \\
\text { eles devem ser acessíveis por diferentes formas: dump, ponto de } \\
\text { extremidade SPARQL e API. }\end{array}$ \\
\hline $\begin{array}{l}\text { Garantir a manutenção dos } \\
\text { dados }\end{array}$ & $\begin{array}{l}\text { Foi incluída uma fase específica para este requisito, contendo } \\
\text { práticas de manutenção e preservação de dados. }\end{array}$ \\
\hline
\end{tabular}




\begin{tabular}{|l|l|}
\hline Requisito & Atendimento \\
\hline $\begin{array}{l}\text { Fornecer estratégias de co- } \\
\text { municação }\end{array}$ & $\begin{array}{l}\text { Foram criados diferentes mecanismos para comunicação com } \\
\text { a comunidade de usuários de dados: ferramentas de software, } \\
\text { papel de gestor de comunidade, atividades de interação e coleta } \\
\text { de feedback junto ao público. }\end{array}$ \\
\hline Recomendar softwares & $\begin{array}{l}\text { A Seção 5.4 deste capítulo fornece um guia para adoção de } \\
\text { ferramentas de software para apoiar o processo. }\end{array}$ \\
\hline $\begin{array}{l}\text { Considerar diferentes tama- } \\
\text { nhos de publicadores de da- } \\
\text { dos }\end{array}$ & $\begin{array}{l}\text { A modelagem do artefato considera a existência de atividades } \\
\text { obrigatórias e opcionais, se adequando ao contexto e limitações } \\
\text { dentro de diferentes organizações. }\end{array}$ \\
\hline
\end{tabular}

Fonte: Elaborada pelo autor.

O modelo de ciclo de vida aqui proposto se diferencia de outros na literatura pela integração de duas práticas ainda pouco exploradas no contexto da publicação de DAGC: o arcabouço Data on the Web Best Practices, as práticas da garantia da qualidade, aplicadas durante todo o ciclo de vida, além de seus elementos de suporte. No próximo capítulo apresentamos a aplicação e avaliação dos artefatos desenvolvidos, por meio de validações do uso dos artefatos, suas implicações e lições aprendidas. 
CAPÍTULO

\section{6}

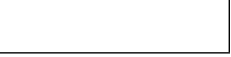

AVALIAÇÃO

A avaliação do artefato tem grande importância na DSR (HEVNER; CHATTERJEE, 2010; MARCH; SMITH, 1995). Ela pode ser definida como "a determinação sistemática de mérito, valor e significância de algo" (HEVNER; CHATTERJEE, 2010) e se refere à atividade de "comparar diferentes partes de um processo de design a critérios selecionados e tirar conclusões no sentido de satisfatório ou insatisfatório" (VERSCHUREN; HARTOG, 2005, p.738).

Em sua maioria, as pesquisas na Engenharia de Software objetivam averiguar como as fases de desenvolvimento, operação e manutenção são realizadas por engenheiros de software e outras partes interessadas em diferentes condições de desenvolvimento. Dessa maneira, a característica da multidisciplinaridade na Engenharia de Software a torna propícia para a elaboração e aplicação de estudos de caso (RUNESON; HÖST, 2009).

Esta tese traz por contribuições a modelagem de um processo de ciclo de vida de publicação de DAGC bem como a arquitetura de suporte para atender aos requisitos estabelecidos no Capítulo 2. Neste capítulo avaliamos como a arquitetura atende aos requisitos dentro da proposta, por meio de lista de verificação em um cenário ilustrativo. Em seguida, avaliamos por meio de um quasi-experimento o processo proposto em termos de viabilidade e de avaliação do artefato gerado de acordo com um arcabouço de métricas de qualidade em dados conectados.

\subsection{Análise da arquitetura}

A arquitetura da infraestrutura de publicação de DAGC foi definida no Capítulo 5, de modo genérico, contendo os componentes funcionais e como eles são usados pelos atores do ecossistema (publicador ou consumidor). Neste capítulo, objetivamos a seguinte questão de pesquisa: como especificar e avaliar uma arquitetura conceitual que integra as práticas de compartilhamento de dados na Web e de controle de qualidade em um processo de publicação de DAGC? 
A avaliação da aplicabilidade, das fortalezas e das limitações da arquitetura proposta é feita por meio de um caso ilustrativo, conforme definido por (PEFFERS et al., 2012, p.402): “a aplicação de um artefato a uma situação sintética ou do mundo real que objetiva ilustrar a aptidão ou a utilidade do artefato". Esta abordagem é uma das mais utilizadas em estudos que utilizam DSR, nas áreas de ciência da computação e sistemas de informação (PEFFERS et al., 2012) e geralmente busca replicar um contexto ideal para a aplicação do artefato. Aqui esta escolha foi feita para demonstrar a sua aptidão para esta tarefa, antes de sua experimentação por usuários externos e como parte do processo de design da proposta desta tese.

Esta abordagem é adequada para demonstrar como um artefato pode ser implementado e avaliado em situações "ideais", em que presume-se que o cenário pode ser replicado em outros contextos em que se tenha liberdade para implementar as tecnologias e processos conforme projetado. Casos ilustrativos são usados comumente na avaliação de arquiteturas, validados com o desenvolvimento de um protótipo de software que as implementa, e são muitas vezes confundidos como estudo de caso, mesmo que a arquitetura não seja aplicada em um ambiente real de uso - característica que diferencia o caso ilustrativo do estudo de caso. Esta abordagem de avaliação apresenta a desvantagem de não considerar contextos reais, medindo seus efeitos no ambiente (estudos de caso) ou de isolar sua intervenção, controlando possíveis fatores que causam um determinado resultado (experimentos controlados). Argumentamos que a escolha de um caso ilustrativo para a avaliação da arquitetura é válida para demonstrar como combinar os componentes estruturais e como cada um atende aos requisitos levantados no Capítulo 2, utilizando dados reais extraídos de fontes oficiais.

Para validar a arquitetura proposta, utilizamos a avaliação por lista de verificação (checklist) a partir dos requisitos levantados no Capítulo 2 e especificados a partir da recomendação DWBP e das atividades de controle de qualidade. Esta abordagem é uma das formas mais comuns de inspeção e avaliação de qualidade em arquitetura de software (DOBRICA; NIEMELA, 2002).

\subsubsection{Cenário}

Utilizamos os seguintes critérios para a seleção do cenário a ser implementado: i) usar dados reais, publicados oficialmente por algum órgão do governo federal brasileiro; ii) usar dados de alta procura, como um indicativo de sua relevância; iii) apresentar dados maduros, que tenham sido publicados em mais de uma versão; iv) os dados originais terem instâncias (registros) de dados correspondentes em outra base de dados; v) serem do domínio educacional, de conhecimento do autor desta tese. Além desses critérios, foi estabelecido o uso de questões relevantes à comunidade educacional a serem respondidas com os dados.

Usamos os dados do censo escolar da educação básica ${ }^{1}$, disponibilizados anualmente pelo INEP em escala nacional desde 1995 para descrever e acompanhar as características de escolas, alunos, docentes e turmas nas unidades de educação básica de todo o Brasil, em todas

\footnotetext{
1 <http://www.dados.gov.br/dataset/microdados-do-censo-escolar>
} 
as modalidades. Este é um dos conjuntos de dados mais requisitados pelos cidadãos por meio de pedidos de acesso à informação, conforme descrito no Plano de Dados do INEP ${ }^{2}$. Como aplicação dos dados conectados, ilustramos sua conexão com dados complementares publicados pela secretaria municipal de educação do de São Paulo. Esta base estende os dados do censo escolar para outras variáveis de interesse do município e que não são contemplados nos dados originais (localização geográfica, participação em programas municipais, organização regional das unidades escolares, etc.).

Para a delimitação do cenário ilustrativo, abordamos o problema da rotatividade docente, que conforme literatura - por exemplo, (JUNIOR; OLIVEIRA, 2016; GUARINO; SANTIBAÑEZ; DALEY, 2006) - é um dos principais problemas em escolas públicas, conforme apontado por quase um terço dos diretores escolares em questionário contextual da Prova Brasil de 2011 (JUNIOR; OLIVEIRA, 2016, p.39). Allensworth, Ponisciak e Mazzeo (2009) apontam que altas taxas de rotatividade podem produzir problemas organizacionais, como a impossibilidade de consolidar o trabalho em equipe entre professores e a interrupção do trabalho pedagógico realizado durante o ano letivo, podendo gerar consequências para o processo de aprendizagem dos alunos - principalmente em escolas que atendem a alunos com condições financeiras menos favoráveis (GUARINO; SANTIBAÑEZ; DALEY, 2006).

São postas as seguintes questões: i) como se dão as transferências de professores? ii) Quais são as escolas que mais perdem professores para uma mesma outra unidade? Por se tratar de uma grande quantidade de dados, é uma tarefa difícil para que gestores possam compreender a dinâmica em que a rotatividade acontece. Para isso, foram geradas visualizações desses padrões para tornar essa informação mais fácil de ser compreendida.

Deste modo, foram usados os dados do censo escolar, transformados para seu formato conectado por meio do modelo de ciclo de vida proposto nesta tese, para ajudar na conscientização de como se dá a rotatividade docente entre escolas do ensino público sob a ótica de pesquisadores ou de gestores de políticas públicas do município de São Paulo. Para isso, foi implementada a arquitetura proposta no Capítulo 5, com seus componentes e validações e que atendem aos requisitos levantados no Capítulo 2.

\subsubsection{Instanciação da arquitetura}

As atividades do modelo de ciclo de vida foram aplicadas sobre o cenário descrito e organizadas conforme a arquitetura proposta e ilustrada na Figura 26. O processo do ciclo de vida foi adotado conforme demonstrado a seguir:

- Especificação: os dados e as questões motivadoras foram colocadas na apresentação do cenário. Foram usados os dados do censo escolar dos anos de 2016 e 2017, que contém

2 Plano de dados abertos do INEP: <http://download.inep.gov.br/institucional/legislacao/2016/portaria_ n370.pdf> 
Figura 26 - Instanciação da arquitetura de suporte proposta.

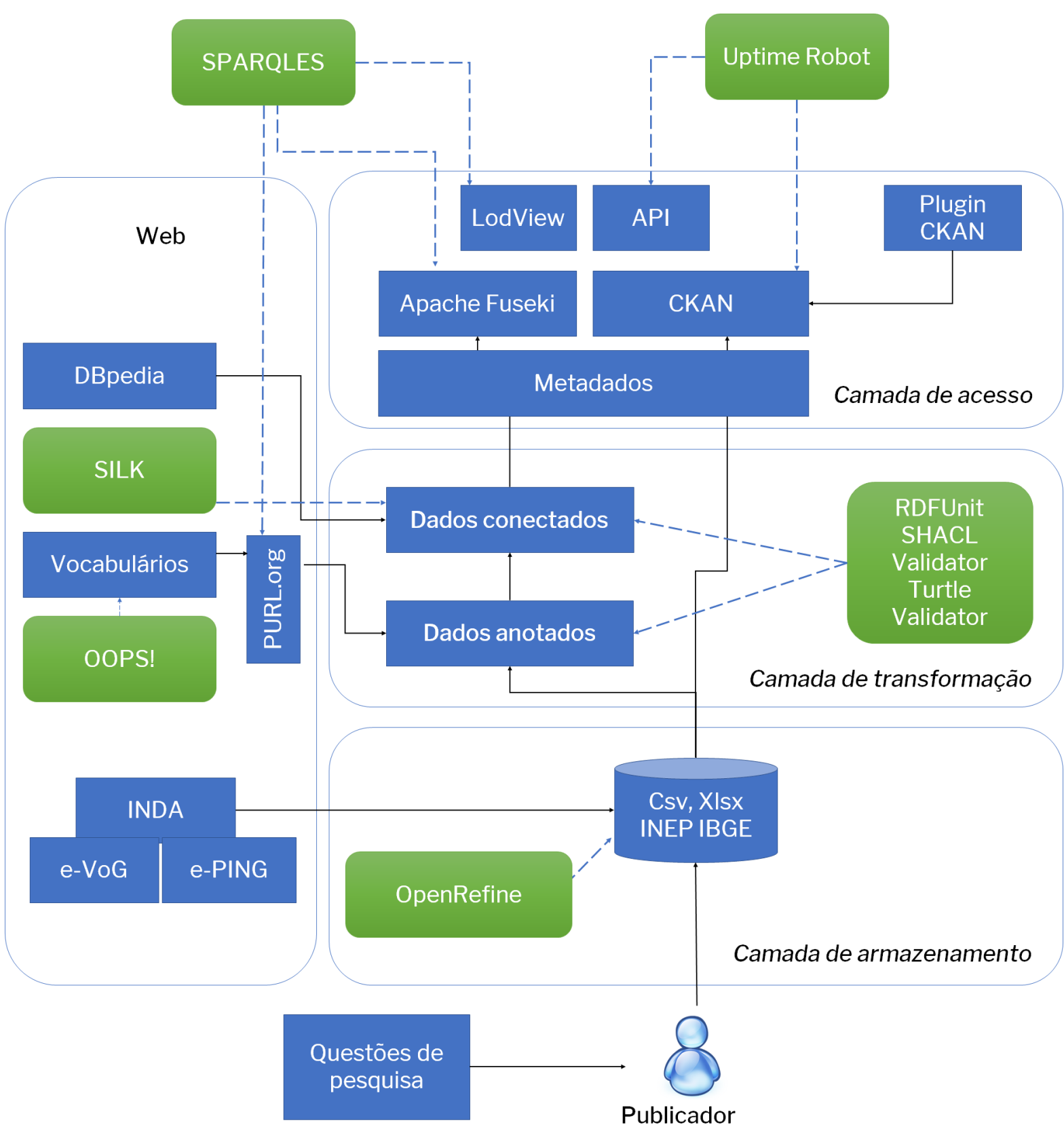

Fonte: Elaborada pelo autor.

os dados de todas as escolas do Brasil e das lotações dos professores nas escolas onde lecionam, dentre outros dados. Além disso, foi usado o conjunto de dados das escolas municipais de São Paulo ${ }^{3}$. Assim, duas conexões foram modeladas: a escola e seus professores e as escolas entre diferentes níveis (INEP e SME-SP). Foram seguidas as diretrizes do governo federal, do e-PING, recomendações da INDA e o uso de termos do vocabulário e-VoG. Os metadados usados são os presentes no B, que denotam um superconjunto que abarca todos os metadados especificados como obrigatórios ou opcionais para conjuntos 
de dados do governo federal e adiciona outros importantes para a descoberta e processamento automático dos dados. Por fim, o padrão de URIs foi seguido conforme disposto no documento e-PING.

- Modelagem: foi necessário o pré-processamento dos dados das escolas municipais, em formato de planilha Excel. Neste arquivo, os dados de latitude e longitude das escolas estavam desconfigurados, sendo necessária uma transformação para torná-los úteis. Foi usada a ferramenta OpenRefine para essa transformação. Para a modelagem dos dados, foram pesquisados vocabulários que pudessem se encaixar neste contexto. No entanto, não foram encontrados vocabulários educacionais que pudessem descrever os dados selecionados. Por fim, foi criado, como subproduto desta tese, um modelo de referência com as principais entidades para representação de dados em nível macro ${ }^{4}$ (PENTEADO; BITTENCOURT; ISOTANI, 2019c), que foi estendido e utilizado para cobrir todos os dados. A ferramenta Protégé foi usada para criar o novo vocabulário. Por se tratar de uma grande quantidade de dados, os dados foram importados para uma base de dados relacional e foi necessário usar a plataforma D2RQ via arquivo de mapeamento entre os objetos do banco de dados relacional e os termos semânticos especificados. Aqui, descobriu-se a limitação de ferramentas de modelagem não processarem grandes quantidades de dados, por carregarem todos eles na memória principal.

- Conversão: neste cenário, a conexão entre as fontes (delimitadas na fase de especificação) se deu de duas maneiras: i) por referência de instâncias (owl:sameAs) entre as instâncias do censo escolar e do cadastro municipal, usando a ferramenta SILK e ii) por apontamento, em que os recursos de dados tem ligação com recursos externos via ObjectProperties. A referência de instâncias foi facilitada pois ambas as fontes de dados compartilham de um mesmo identificador, único por escola. Com os dados cadastrados no banco de dados relacional e especificados por meio de arquivo de mapeamento, foi usada a ferramenta dump-rdf para exportar os dados em formato RDF. Em seguida, esses dados foram importados para o Fuseki. Os dados foram validados sintaticamente por meio da ferramenta Turtle Validator. Também foram validados semanticamente usando um grafo de formas SHACL (SHACL shape graphs) dentro da ferramenta RDFUnit, que cria regras personalizadas de validação do RDF em termos de cardinalidade, faixas de valores, tipos de dados, domínio e alcance, dentre outras possibilidades.

- Publicação: inicialmente, foram projetadas duas interfaces para armazenamento dos dados: o catálogo de dados CKAN e a triplestore Apache Jena Fuseki. Foram escolhidos dois portais de dados, pois cada um apresenta suas vantagens, complementando-se entre si. $\mathrm{O}$ CKAN foi projetado para que humanos possam estruturar, buscar e consumir dados de forma facilitada; porém não traz funcionalidades para consumo automático por agentes de

4 Denominamos nível macro as informações relativas a instituições em nível municipal, estadual ou nacional, conforme taxonomia de (SANTOS, 2014). 
software (dados semânticos); já o Fuseki traz todo o ferramental para o armazenamento e as consultas semânticas, que podem ser feitas por agentes de software sobre os dados publicados, entretanto, não possui ferramentas que facilitem a busca, a consulta ou a visualização dos dados. Os dados originais foram publicados em uma instalação do CKAN, disponível como demonstração gratuita ${ }^{5}$. Neste mesmo ambiente, foi criado um pacote de dados, que contém metadados estruturais sobre os dados originais, usando a especificação Data Package. Além disso, o portal contém ferramentas de coleta de feedback do usuário como os comentários e a consulta de dados via API, disponíveis por meio de plugins que podem ser instalados no CKAN. Para os dados conectados, foi usada a ferramenta Apache Jena Fuseki, para importar os armazenar os dados produzidos: as ontologias, os dados convertidos e o conjunto de metadados. Foi também usada a ferramenta sitemap4rdf para gerar o mapa. Para que ele seja lido por máquinas de busca, ele foi colocado na raiz do site.

- Exploração: para facilitar a descoberta dos dados pelos usuários foi implantada uma ferramenta de interface de dados conectados, LodView (a mesma utilizada pela Dbpedia Brasil $^{6}$ ). Esta ferramenta se conecta a um endpoint SPARQL e permite visualizar quais são as propriedades de um determinado recurso de dados e as referências a outros recursos em que ele foi utilizado. Esta ferramenta também permite que os recursos sejam desreferenciáveis via negociação de conteúdo. Por exemplo, ao acessar via navegador uma URI mapeada por esse software, ele trará em formato HTML. Outro programa de computador pode fazer a requisição para a mesma URI requisitando em formato JSON e as mesmas informações serão retornadas, neste outro formato. Além disso, como forma de exemplificar a utilidade dos dados, foram criadas consultas SPARQL sobre os dados, buscando responder às questões postas no cenário.

- Manutenção: devido ao contexto do cenário de validação, esta fase não foi executada em toda sua extensão; optou-se por simular possíveis eventos que podem causar a disrupção de serviços que consumam esses dados. Foi testada a URL permanente, que foi atualizada para retornar outro código HTTP (410 - Gone, ou seja, não está mais disponível) quando feita uma requisição à ontologia nela referenciada. Com isso, é exemplificado como uma possível terminação dos dados pode ser conduzida. Para monitorar a disponibilidade dos serviços de catálogo de dados (CKAN) e do serviço de URL permanentes (PURL.org ${ }^{7}$ ) foi utilizado o software online e gratuito UptimeRobot ${ }^{8}$, que emite alertas por e-mail quando uma determinada URL da Web não responde com código HTTP 200 (com sucesso). Para o monitoramento do endpoint SPARQL foi usada a ferramenta SPARQLES, personalizada para observar a disponibilidade de triplestores. Além disso, foi feito, ainda na fase anterior,

\footnotetext{
$<$ https://demo.ckan.org>

Ver por exemplo: <http://pt.dbpedia.org/resource/Acre>

$<$ http://purl.org/>

$<$ https://www.uptimerobot.com/>
} 
o upload da ontologia para o servidor de triplas, para garantir que os termos dos vocabulários criados estejam disponíveis junto com os dados, ajudando assim sua preservação. Por fim, os resultados das consultas foram colocados à disposição de especialistas do domínio para que avaliassem a coerência dos resultados.

\subsubsection{Resultados}

A Quadro 23 traz as 35 práticas da recomendação DWBP, consideradas como requisitos para a arquitetura proposta. Para cada prática, é indicado como ela foi implementada dentro da arquitetura e o seu grau de atendimento (segundo os critérios 'A': Atendida; 'P': Parcialmente atendida; 'N': Não atendida; 'NA': Não se aplica).

Quadro 23 - Implementação das melhores práticas da DWBP no arquitetura do cenário.

\begin{tabular}{|l|l|l|l|}
\hline & Requisito & Implementação & Grau \\
\hline BP1 & $\begin{array}{l}\text { Metadados para huma- } \\
\text { nos e computadores }\end{array}$ & $\begin{array}{l}\text { Os metadados estão disponíveis em formato se- } \\
\text { mântico (Fuseki) e HTML (CKAN) }\end{array}$ & A \\
\hline BP2 & $\begin{array}{l}\text { Fornecer metadados } \\
\text { descritivos }\end{array}$ & $\begin{array}{l}\text { Metadados descritivos foram publicados em for- } \\
\text { mato semântico (Fuseki, contendo boas práticas } \\
\text { de vocabulários de descrição de serviços e ca- } \\
\text { tálogos de dados) e em formato amigável para } \\
\text { humanos (CKAN, contendo os metadados obri- } \\
\text { gatórios) }\end{array}$ & A \\
\hline BP3 & $\begin{array}{l}\text { Fornecer metadados es- } \\
\text { truturais }\end{array}$ & $\begin{array}{l}\text { Tipo de dados, descrição disponibilizados em } \\
\text { container Data Package no CKAN }\end{array}$ & A \\
\hline BP4 & $\begin{array}{l}\text { Fornecer informações a licença dos da- } \\
\text { dos }\end{array}$ & $\begin{array}{l}\text { Metadados semânticos (dct:license) e na página } \\
\text { do dataset e da distribuição no CKAN. }\end{array}$ & A \\
\hline BP5 & $\begin{array}{l}\text { Fornecer dados de pro- } \\
\text { veniência }\end{array}$ & $\begin{array}{l}\text { Metadados semânticos de criação e publicação } \\
\text { (dct:creator e dct:publisher para cada Dataset } \\
\text { e Distribution) bem como da atividade, usando } \\
\text { termos do vocabulário PROV-O. }\end{array}$ & A \\
\hline
\end{tabular}




\begin{tabular}{|c|c|c|c|}
\hline & Requisito & Implementação & Grau \\
\hline BP6 & $\begin{array}{l}\text { Definir requisitos de } \\
\text { qualidade }\end{array}$ & $\begin{array}{l}\text { Foi adotado uma pequena amostra de métricas } \\
\text { do modelo de avaliação de qualidade de De- } \\
\text { battista, Lange e Auer (2018), calculados por } \\
\text { consulta SPARQL e com seus resultados adi- } \\
\text { cionados aos metadados semânticos por meio } \\
\text { do vocabulário DQV (Data Quality Vocabulary). } \\
\text { Para o CKAN foi utilziada a extensão ckanext- } \\
\text { qa, que atribui certas métricas automaticamente } \\
\text { aos datasets cadastrados. }\end{array}$ & A \\
\hline BP7 & $\begin{array}{l}\text { Fornecer indicador de } \\
\text { versão }\end{array}$ & $\begin{array}{l}\text { Metadados semânticos atribuídos a cada Dataset } \\
\text { e Distribution. Metadados de versão no CKAN. }\end{array}$ & A \\
\hline BP8 & $\begin{array}{l}\text { Fornecer acesso ao his- } \\
\text { tórico de versões }\end{array}$ & $\begin{array}{l}\text { Metadados semânticos descrevendo as atua- } \\
\text { lizações da versão (adms:versionNotes) e li- } \\
\text { gando as diferentes versões de um Dataset } \\
\text { (pav:previous Version). No CKAN, as versões } \\
\text { são cadastradas como diferentes recursos em um } \\
\text { mesmo dataset. }\end{array}$ & A \\
\hline BP9 & $\begin{array}{l}\text { Usar URIs persistentes } \\
\text { para identificar datasets }\end{array}$ & $\begin{array}{l}\text { Cada Dataset recebeu uma URI para representá- } \\
\text { lo, a partir do qual foram atribuídas outras pro- } \\
\text { priedades semânticas. }\end{array}$ & A \\
\hline BP10 & $\begin{array}{l}\text { Usar URIs persistentes } \\
\text { dentro dos datasets }\end{array}$ & $\begin{array}{l}\text { Todos as instâncias de dados foram representa- } \\
\text { das por URIs, derivadas da URI base estabele- } \\
\text { cida na fase de Especificação. }\end{array}$ & $\mathrm{A}$ \\
\hline BP11 & $\begin{array}{l}\text { Usar URIs para diferen- } \\
\text { tes versões dos datasets }\end{array}$ & $\begin{array}{l}\text { A cada versão do Dataset foi atribuída uma Dis- } \\
\text { tribuição com indicador de versão embutida na } \\
\text { URI e que continha, por sua vez, um metadado } \\
\text { de indicador de versão (owl:versionInfo). No } \\
\text { CKAN, as versões são cadastradas como dife- } \\
\text { rentes recursos em um mesmo dataset. }\end{array}$ & A \\
\hline BP12 & $\begin{array}{l}\text { Usar formato de dados } \\
\text { padronizados }\end{array}$ & $\begin{array}{l}\text { Os dados são acessados via endpoint SPARQL e } \\
\text { retornados em modelo RDF, em diferentes for- } \\
\text { mato de serialização }\end{array}$ & A \\
\hline BP13 & Usar dados neutros & $\begin{array}{l}\text { Embora o processo contemple a normalização } \\
\text { dos dados, este cenário não implementou esta } \\
\text { prática. }\end{array}$ & NA \\
\hline
\end{tabular}




\begin{tabular}{|c|c|c|c|}
\hline & Requisito & Implementação & Grau \\
\hline BP14 & $\begin{array}{l}\text { Fornecer acesso a múlti- } \\
\text { plos formatos }\end{array}$ & $\begin{array}{l}\text { Os dados ficaram disponíveis em seu formato } \\
\text { original (CKAN) e em formato semântico, que } \\
\text { podia ser acessado em diversos formatos, via } \\
\text { negociação de conteúdo. }\end{array}$ & A \\
\hline BP15 & $\begin{array}{l}\text { Reusar vocabulários pa- } \\
\text { dronizados }\end{array}$ & $\begin{array}{l}\text { Durante a fase de modelagem foram mapeados } \\
\text { diversos vocabulários de conhecimento geral } \\
\text { e tornados explícitos por meio dos metadados } \\
\text { (void:vocabulary). }\end{array}$ & A \\
\hline BP16 & $\begin{array}{l}\text { Escolher nível ade- } \\
\text { quado de formalização }\end{array}$ & $\begin{array}{l}\text { Foi criado um vocabulário simples para os dados, } \\
\text { complementando os vocabulários gerais comu- } \\
\text { mente usados em outros projeto na Web, usando } \\
\text { expressividade OWL. Os cenários foram usados } \\
\text { para calibrar o nível de formalismo. }\end{array}$ & A \\
\hline BP17 & $\begin{array}{l}\text { Fornecer acesso aos da- } \\
\text { dos completos (bulk) }\end{array}$ & $\begin{array}{l}\text { Os dados completos podem ser acessados tanto } \\
\text { por download direto pelo CKAN quanto por con- } \\
\text { sultas ao endpoint SPARQL. }\end{array}$ & $\mathrm{A}$ \\
\hline BP18 & $\begin{array}{l}\text { Fornecer acesso a } \\
\text { subconjuntos de dados } \\
\text { grandes }\end{array}$ & $\begin{array}{l}\text { É possível fazer consultas em diferentes níveis } \\
\text { de granularidade tanto no endpoint SPARQL } \\
\text { quanto na API do CKAN. }\end{array}$ & A \\
\hline BP19 & $\begin{array}{l}\text { Usar negociação de con- } \\
\text { teúdo para múltiplos for- } \\
\text { matos }\end{array}$ & $\begin{array}{l}\text { É possível fazer consultas e escolher qual o re- } \\
\text { torno dos dados, tanto pelo endpoint SPARQL } \\
\text { quanto pela interface de dados conectados. }\end{array}$ & A \\
\hline BP20 & $\begin{array}{l}\text { Fornecer acesso aos da- } \\
\text { dos em tempo real }\end{array}$ & $\begin{array}{l}\text { O cenário escolhido não adota dados em tempo } \\
\text { real. }\end{array}$ & NA \\
\hline BP21 & $\begin{array}{l}\text { Fornecer dados atualiza- } \\
\text { dos }\end{array}$ & $\begin{array}{l}\text { Os dados mais recentes foram disponibilizados } \\
\text { e registrados nos metadados sua frequência de } \\
\text { atualização (dct:accrualPeriodicity) }\end{array}$ & $\mathrm{P}$ \\
\hline BP22 & $\begin{array}{l}\text { Fornecer explicação } \\
\text { para dados que não } \\
\text { estão mais disponíveis }\end{array}$ & $\begin{array}{l}\text { O mecanismo de PURL.org foi usado para ma- } \\
\text { pear uma URL permanente apontando para o } \\
\text { endereço de download dos dados originais. Para } \\
\text { efeitos de teste, o mapeamento foi programado } \\
\text { para retornar código } 401 \text { (movido permanente- } \\
\text { mente). }\end{array}$ & $\mathrm{P}$ \\
\hline
\end{tabular}




\begin{tabular}{|c|c|c|c|}
\hline & Requisito & Implementação & Grau \\
\hline $\mathrm{BP} 23$ & $\begin{array}{l}\text { Fornecer acesso aos da- } \\
\text { dos via API }\end{array}$ & $\begin{array}{l}\text { É possível fazer consultas em diferentes níveis } \\
\text { de granularidade tanto no endpoint SPARQL } \\
\text { quanto na API do CKAN (extensão DataStore). }\end{array}$ & A \\
\hline BP24 & $\begin{array}{l}\text { Usar Web Standards } \\
\text { para as APIs }\end{array}$ & $\begin{array}{l}\text { O protocolo SPARQL oferece diferentes ações } \\
\text { para consultar, adicionar ou remover informa- } \\
\text { ções, sobre o protocolo HTTP. }\end{array}$ & A \\
\hline BP25 & $\begin{array}{l}\text { Fornecer documentação } \\
\text { para as APIs }\end{array}$ & $\begin{array}{l}\text { A API de acesso direto aos dados do CKAN } \\
\text { (via plugin DataStore) traz documentação so- } \\
\text { bre como acessar os dados, com exemplos ilus- } \\
\text { trativos. O LodView fornece acesso aos dados } \\
\text { semânticos, que por sua vez contém rótulos e } \\
\text { comentários. }\end{array}$ & A \\
\hline BP26 & $\begin{array}{l}\text { Evitar mudanças que } \\
\text { quebrem as APIs }\end{array}$ & $\begin{array}{l}\text { A API de acesso diretos aos dados do CKAN } \\
\text { traz versionamento para atenuar a atualização de } \\
\text { versões da API. }\end{array}$ & $\mathrm{P}$ \\
\hline BP27 & $\begin{array}{l}\text { Preservar identificado- } \\
\text { res }\end{array}$ & $\begin{array}{l}\text { O mecanismo de PURL.org foi usado para ma- } \\
\text { pear uma URL permanente apontando para a } \\
\text { ontologia e as URLs de download dos dados ori- } \\
\text { ginais. Para efeitos de teste, o mapeamento foi } \\
\text { programado para retornar código } 401 \text { (movido } \\
\text { permanentemente). }\end{array}$ & $\mathrm{P}$ \\
\hline BP28 & $\begin{array}{l}\text { Avaliar a cobertura de } \\
\text { um dataset antes de sua } \\
\text { preservação }\end{array}$ & $\begin{array}{l}\text { Além dos dados em si, tanto a ontologia quantos } \\
\text { os metadados são todos importados no servidor } \\
\text { de triplas, sendo armazenados juntos. Assim, a } \\
\text { preservação dos dados também cobre a preserva- } \\
\text { ção destas informações referidas nos dados. }\end{array}$ & A \\
\hline BP29 & $\begin{array}{l}\text { Colher feedback da co- } \\
\text { munidade }\end{array}$ & $\begin{array}{l}\text { Mecanismos de feedback via CKAN, pelo plu- } \\
\text { gin Disqus. Metadados semânticos especifi- } \\
\text { cam ponto de contato, com o qual deve ser } \\
\text { possível se comunicar (dcat:contactPoint e dc- } \\
\text { terms:publisher). }\end{array}$ & A \\
\hline BP30 & $\begin{array}{l}\text { Tornar feedback dispo- } \\
\text { nível }\end{array}$ & $\begin{array}{l}\text { Mecanismo de feedback do CKAN (Disqus) per- } \\
\text { mite que os comentários feitos sejam públicos } \\
\text { para que outros usuários vejam. }\end{array}$ & $\mathrm{P}$ \\
\hline
\end{tabular}




\begin{tabular}{|c|c|c|c|}
\hline & Requisito & Implementação & Grau \\
\hline BP31 & $\begin{array}{l}\text { Enriquecer os dados ao } \\
\text { gerar novos dados }\end{array}$ & $\begin{array}{l}\text { Por meio do mecanismo de equivalência de ins- } \\
\text { tâncias (owl:sameAs) o conjunto original de es- } \\
\text { colas foi estendido para novas propriedades pre- } \\
\text { sentes no dataset da SME-SP. }\end{array}$ & A \\
\hline BP32 & $\begin{array}{l}\text { Fornecer apresentações } \\
\text { complementares }\end{array}$ & $\begin{array}{l}\text { A fase de Exploração trouxe os componentes } \\
\text { LodView para poder navegar pelos recursos de } \\
\text { dados e suas relações. Além disso, foram geradas } \\
\text { as visualizações mostradas na seção de Resulta- } \\
\text { dos. No catálogo CKAN existe a extensão Data } \\
\text { Explorer para dados tabulares. }\end{array}$ & A \\
\hline BP33 & $\begin{array}{l}\text { Fornecer feedback ao } \\
\text { publicador original }\end{array}$ & $\begin{array}{l}\text { Este requisito foi atendido parcial- } \\
\text { mente, por meio do metadado semântico } \\
\text { (prov:wasDerivedFrom), indicando o reuso de } \\
\text { outras fontes de dados combinadas. }\end{array}$ & $\mathrm{P}$ \\
\hline BP34 & $\begin{array}{l}\text { Validar seguimento de } \\
\text { licença atribuída dos da- } \\
\text { dos originais }\end{array}$ & $\begin{array}{l}\text { A combinação de dados não apresentou conflitos. } \\
\text { A análise foi manual. }\end{array}$ & $\mathrm{P}$ \\
\hline BP35 & $\begin{array}{l}\text { Citar publicação origi- } \\
\text { nal }\end{array}$ & $\begin{array}{l}\text { É possível rastrear, por meio dos metadados se- } \\
\text { mânticos, a derivação de datasets e seus respon- } \\
\text { sáveis. O requisito é atendido parcialmente, pois } \\
\text { não é visível em interfaces ao usuário. }\end{array}$ & $\mathrm{P}$ \\
\hline
\end{tabular}

Fonte: Elaborada pelo autor.

De acordo com o Quadro 23, dos 35 requisitos da DWBP, 25 foram atendidos plenamente, 8 foram atendidos parcialmente e 2 não foram implantados pois não foram aplicáveis ao cenário selecionado (normalização dos dados e fornecimento de dados em tempo real). Dentre os requisitos parcialmente atendidos, estão os de disponibilidade de dados (dados atualizados e explicação para dados não mais disponíveis), manutenção (evitar quebra de API, preservação de indicadores) e de republicação dos dados (feedback ao publicador original, seguir os termos de licença e citar a publicação original) ao considerar que elas foram atendidas mas não testadas, sendo um produto secundário das implementações feitas em outras atividades. Muitos dos requisitos são atendidos pela ferramenta de catálogo de dados (CKAN), enquanto outros são atendidos pela modelagem e implementação das práticas nos dados e nos metadados, disponibilizados no servidor de triplas (Fuseki). Além disso, os mecanismos de controle foram instanciados como no Quadro 24. Outros mecanismos de verificação foram adotados, mas não utilizaram ferramentas, como por exemplo, a checagem das diretrizes a serem obedecidas - feita manualmente. 
Quadro 24 - Implementação dos mecanismos de controle de qualidade ao longo do processo.

\begin{tabular}{|l|l|l|}
\hline $\begin{array}{l}\text { Controle de qua- } \\
\text { lidade }\end{array}$ & Implementação & $\begin{array}{l}\text { Ferramenta } \\
\text { adotada }\end{array}$ \\
\hline $\begin{array}{l}\text { Pré- } \\
\text { processamento } \\
\text { dos dados }\end{array}$ & Correção no formato de dados de localização espacial. & OpenRefine \\
\hline $\begin{array}{l}\text { Interligação dos } \\
\text { dados }\end{array}$ & $\begin{array}{l}\text { Ligação entre as instâncias de dados, entre dois datasets } \\
\text { triplificados, compartilhando o mesmo código INEP de } \\
\text { escola, presente em ambas as fontes de dados. Foi gerado } \\
\text { um novo arquivo (linkset), com os mapeamentos entre as } \\
\text { instâncias (owl:sameAs). }\end{array}$ & SILK \\
\hline $\begin{array}{l}\text { Validação da onto- } \\
\text { logia }\end{array}$ & $\begin{array}{l}\text { Verificação de propriedades em termos funcional, es- } \\
\text { trutural, consistência, concisão e completude . Foram } \\
\text { detectados e corrigidos problemas relacionados a licença } \\
\text { de dados, comentários e disponibilização da ontologia. }\end{array}$ & OOPS! \\
\hline $\begin{array}{l}\text { Validação } \\
\text { RDF do }\end{array}$ & $\begin{array}{l}\text { Foram criadas regras por meio do padrão SHACL para } \\
\text { validar as classes e suas propriedades, tanto para os dados } \\
\text { quanto para os metadados. Foram identificados proble- } \\
\text { mas de cardinalidade e de tipo de dados aceitos pelas } \\
\text { propriedades, além de comentários das classes. }\end{array}$ & RDF Unit \\
\hline $\begin{array}{l}\text { Requisitos } \\
\text { funcionais }\end{array}$ & $\begin{array}{l}\text { Foram configurados os serviços para monitoramento de } \\
\text { disponibilidade do servidor de triplas e do catálogo de } \\
\text { dados e identificados os metadados necessários para que } \\
\text { fossem acessíveis por mecanismos de buscas. }\end{array}$ & $\begin{array}{l}\text { SPARQLES, } \\
\text { UptimeRo- } \\
\text { bot }\end{array}$ \\
\hline
\end{tabular}

Fonte: Elaborada pelo autor.

Do ponto de vista do cenário em si, foram geradas pelo software Gephi ${ }^{9}$ as visualizações de dados ilustradas nas Figura 27, Figura 28 e Figura 29.

A Figura 27 ilustra o grafo de movimentações, onde cada nó representa uma escola geograficamente situada e as arestas indicam a existência de ao menos uma transferência entre as escolas ligadas. O tamanho dos nós representa a quantidade de movimentações feitas na escola (entradas + saídas) e sua cor representa a "direção"dessas movimentações (quanto mais branco, mais professores chegaram; quanto mais verde, mais professores deixaram a escola). Nesta análise foram filtradas escolas recém-criadas ou recém-fechadas e considerou somente movimentações dentro da rede pública municipal e somente em escolas do município de São Paulo.

A Figura 28 aproxima a figura anterior para ilustrar melhor a dinâmica de movimentação em torno das escolas que mais apresentaram rotatividade no período em questão (tamanho do

$9<$ https://gephi.org/> 
nó). Neste exemplo, vemos que a escola "EMEI PEDREIRA I" foi a escola que mais perdeu professores no período, apresentando também uma grande movimentação geral de professores. Já a "CEMEI JARDIM ANGELA" foi a que mais recebeu, mas não apresentou tanta saída - por isso, o raio do círculo que representa o nó é menor que o da outra escola.

A Figura 29 demonstra movimentações que ocorreram em grande quantidade (maior que 5) ao mesmo tempo entre um mesmo par de escolas, no período considerado. As outras arestas foram removidas para isolar esses casos extremos. Esta situação deve gerar um alerta para gestores públicos, de modo a compreenderem quais problemas podem ter ocorrido entre essas escolas.

Figura 27 - Grafo da movimentação de docentes nas escolas municipais de São Paulo, no período 20162017.

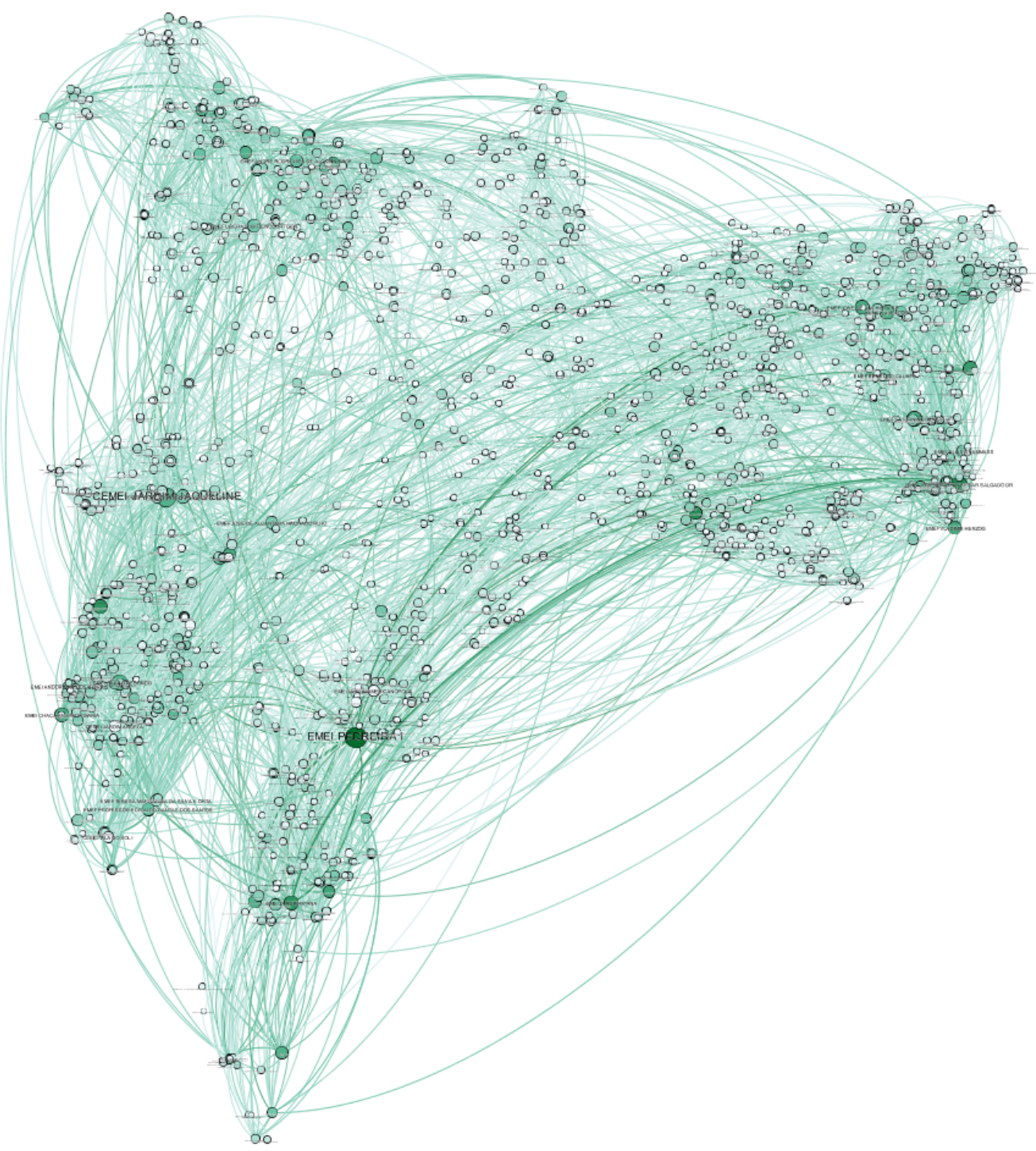

Fonte: Elaborada pelo autor. 
Figura 28 - Aproximação da visualização do grafo, dando destaque às escolas.

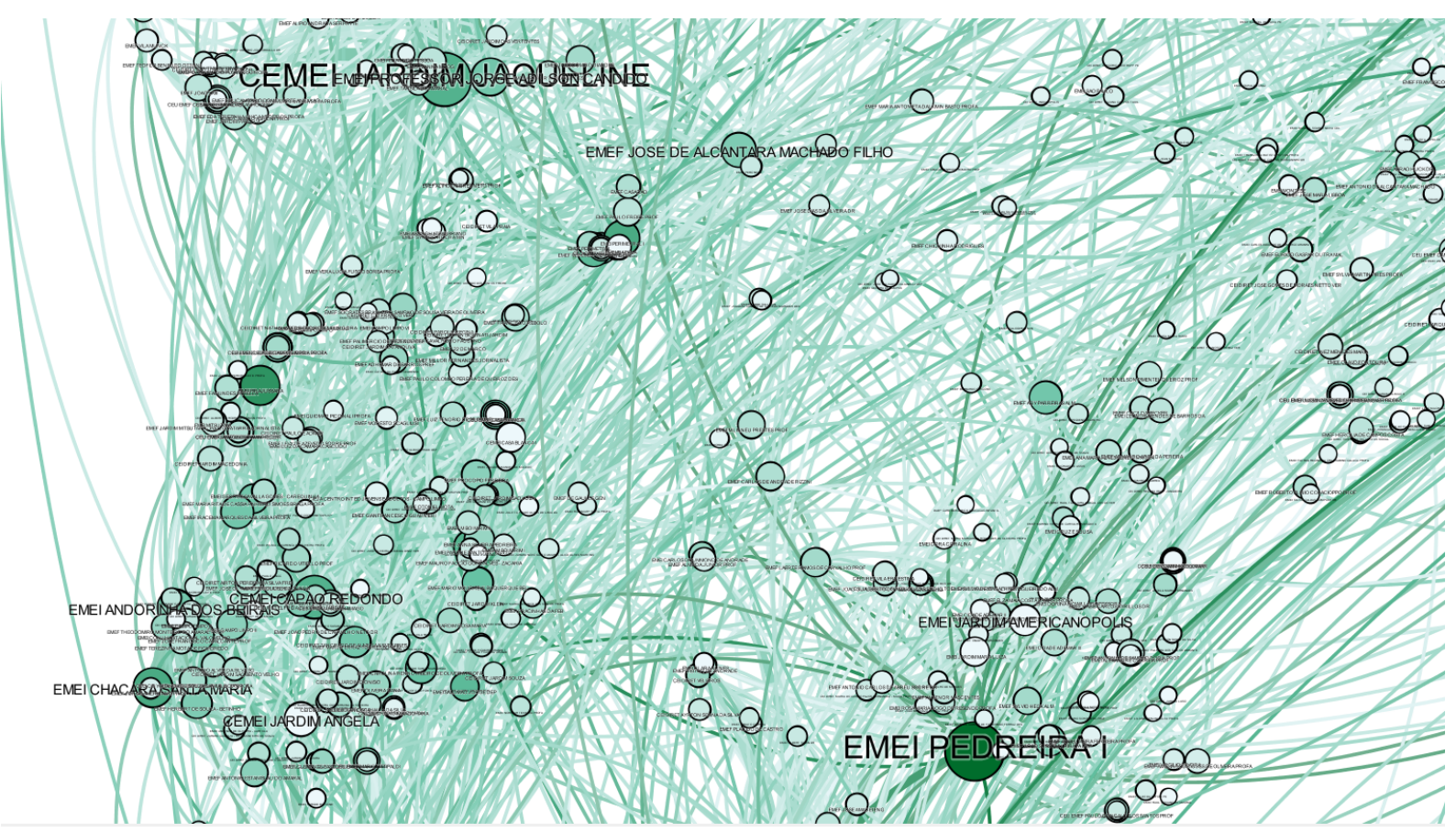

Fonte: Elaborada pelo autor.

Deste modo, foi possível demonstrar a capacidade da arquitetura proposta em atender aos requisitos levantados no Capítulo 2, viabilizados pela recomendação DWBP e pelas práticas de controle de qualidade integradas aos passos do processo.

\subsubsection{Desafios e lições aprendidas}

Para a instanciação da arquitetura neste cenário ilustrativo, alguns desafios foram enfrentados, para os quais deve ser dedicada uma atenção especial quando de sua implementação e que são comentados a seguir.

- As ferramentas de gerenciamento de dados foram desenvolvidas para atender a objetivos pertinentes a finalidades diferentes: consumo por humanos (catálogo de dados) ou por máquinas (triplestore). Devido às limitações dessas plataformas, elas foram combinadas de forma a complementar as fraquezas uma da outra. Como efeito disso, são geradas duplicações de esforços para o registro e a manutenção das informações.

- Modelagem: o processo de modelagem é talvez o passo mais trabalhoso de todo o processo, pois envolve um conhecimento adequado do domínio que os dados representam, de vocabulários e ontologias existentes e dos tipos de dados, restrições e relacionamentos para a criação de novas taxonomias; além disso, uma vez que os dados tenham sido gerados, é frequentemente necessário aplicar refinamentos, de modo iterativo, até se chegar a um formato desejado para as URIs e a estrutura das triplas. Por exemplo, neste cenário foi 
Figura 29 - Mapeamento de grandes movimentações entre pares de escolas.

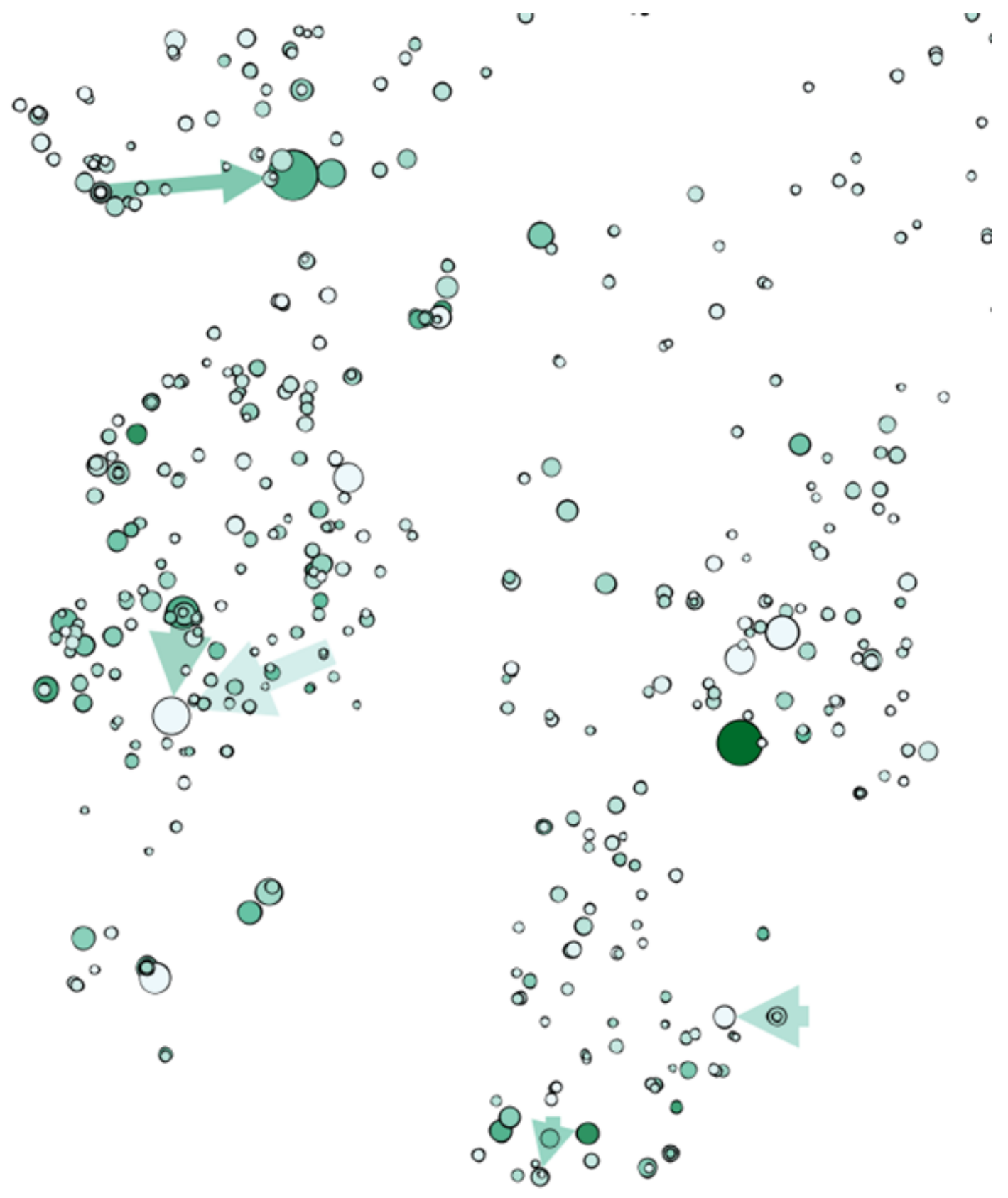

Fonte: Elaborada pelo autor.

necessário modelar a informação temporal dos indicadores via URL, metadados e dentro dos nós do grafo, com diferentes padrões e em diferentes iterações até sua versão final.

- Processamento de grandes arquivos: cenário comum na maior parte de dados governamentais, o tamanho grande de arquivos influencia diretamente na escolha da ferramenta para processá-los e convertê-los para RDF. Inicialmente, foi adotada a ferramenta OpenRefine para o mapeamento e triplificação dos dados. Entretanto, essa ferramenta carrega todo o conjunto de dados em memória, o que a torna inviável para arquivos muito grandes, e foi preciso usar mecanismos de base de dados relacionais que são especializados no trata- 
mento de arquivos muito grandes e que têm à disposição ferramentas para mapeamento semântico.

- Conhecimento da linguagem SPARQL para consultas mais complexas: apesar de ter uma sintaxe parecida com o SQL, certas construções desta linguagem são muito diferentes (ex.: junções e filtros) e, mesmo com a otimização da consulta, demoram muitas vezes mais para processar e retornar os dados do que uma consulta em banco de dados relacionais com SQL.

- Ferramentas: muitas das ferramentas citadas na literatura de projetos de pesquisa foram finalizadas e/ou não foram continuadas, ou mesmo não foi possível encontrá-las (por ex.: RDF Alerts, Vapour, sameAs Link Validator). Além disso, para outras foi necessário alterar e compilar o código-fonte disponível para que funcionassem (ex.: Sitemap4rdf, SPARQLES), Houve também instabilidade dos serviços Web usados, que por vezes não eram executados ou geravam erros em seu processamento sem indicação da causa, por falta de documentação (ex.: OOPS!, serviço web do RDFUnit).

\subsection{Quasi-experimento}

Neste estudo, buscamos avaliar tanto o processo em si como o produto resultante. $\mathrm{O}$ arcabouço teórico adotado ainda é incipiente na área, o que não permitiu a testagem de hipóteses, portanto seguimos uma abordagem mais exploratória. O intuito foi avaliar se é possível, a partir dos artefatos projetados nesta tese, criar um ambiente de publicação de dados conectados que atenda aos requisitos esperados para dados abertos governamentais conectados, por meio da implementação dos elementos funcionais adotados em seu design (garantia de qualidade, ecossistema de dados, metadados e esquema 5 estrelas).

\subsubsection{Questões de pesquisa}

Por se tratar de uma pesquisa de caráter exploratório, as questões de pesquisa não foram colocadas em forma de hipóteses, já que as teorias que a embasam não são maduras o suficiente para derivar hipóteses testáveis, o que implicaria em utilizar um número maior de participantes. Logo, foram propostas as seguintes questões de pesquisa, em torno de duas características: eficácia e facilidade de uso (Quadro 25). Por eficácia, entende-se, no escopo desta pesquisa, como o atendimento aos objetivos pretendidos - no caso, medidos objetivamente sobre os requisitos derivados no Capítulo 2. Com esse construto, objetivamos analisar qual o resultado em utilizar cada um dos artefatos produzidos, considerando o que foi efetivamente produzido. Por facilidade de uso, entende-se o grau de esforço percebido pelo indivíduo em desempenhar determinada tarefa. Com esses construtos, objetivamos entender quais são os pontos a serem melhorados. 
Quadro 25 - Questões avaliadas no estudo empírico.

\begin{tabular}{|l|l|l|}
\hline Artefato & Eficácia & Facilidade de uso \\
\hline Processo & $\begin{array}{l}\text { O processo gerou dados conforme } \\
\text { os requisitos? }\end{array}$ & O processo foi de fácil execução? \\
\hline Arquitetura & $\begin{array}{l}\text { A arquitetura foi instanciada con- } \\
\text { forme os requisitos? }\end{array}$ & $\begin{array}{l}\text { A arquitetura foi de fácil instancia- } \\
\text { ção? }\end{array}$ \\
\hline Metadados & $\begin{array}{l}\text { Os metadados foram corretamente } \\
\text { gerados? }\end{array}$ & $\begin{array}{l}\text { Os metadados foram fáceis de pre- } \\
\text { encher? }\end{array}$ \\
\hline
\end{tabular}

Fonte: Elaborada pelo autor.

\subsubsection{Estratégia de pesquisa}

A estratégia de pesquisa trata do plano geral de como o pesquisador responderá às questões de pesquisa, ao fornecer uma direção geral da pesquisa, incluindo o processo pelo qual ela é conduzida (SAUNDERS; LEWIS; THORNHILL, 2009).

Para analisar as questões de pesquisa definidas anteriormente, foi adotado o delineamento de quasi-experimento sem grupo de controle e com pós-teste, em que uma variável dependente é medida para um grupo de participantes seguindo um único tratamento, aplicável em situações de fatores que restringem a aplicação ou quando uma amostra grande de participantes não pode ser obtida (REICHARDT, 2009). Esta abordagem traz uma limitação importante: a falta de um grupo de controle ou de comparação. Para contornar parcialmente este problema, selecionamos conjuntos de dados de alta qualidade tanto em nível brasileiro (disponível em https://dados.gov.br) quanto no internacional (disponível na LOD Cloud: https://lod-cloud.net/).

Esta pesquisa tem por objetivo contribuir para produzir artefatos que possam desenvolver uma teoria de DAGC, em vez de testar teorias deste campo de pesquisa. DAGC e seus conceitos relacionados de publicação, compartilhamento, busca, uso, arquivamento são um campo recente de pesquisa, em estágios iniciais de desenvolvimento Oliveira, Lima e Lóscio (2019), Zuiderwijk (2015), no qual teorias existentes frequentemente parecem inadequadas, o que demonstra a necessidade do desenvolvimento teórico.

Embora à primeira vista tenha sido considerada a condução de um experimento controlado para cotejamento com outras metodologias de publicação de DAGC existentes na literatura, consideramos que se trataria de algo inadequado. Como reportado no Capítulo 1, as metodologias são consideradas genéricas por produtores e publicadores de dados conectados, pois não fornecem detalhes da implementação. Por exemplo, a criação de metadados é uma atividade presente em algumas metodologias de publicação de DAGC, no entanto não são fornecidos direcionamentos de quais metadados devem ser usados. Talvez seja uma das razões por que os que produziram e publicaram DAGC o fizeram sob os conceitos fundamentais dos dados conectados - uma vez que estes fornecem algo mais concreto. Assim, ficaria difícil a comparação 
pormenorizada sobre os efeitos da nova proposta sobre metodologias existentes. Ou mesmo sobre uma abordagem ad-hoc, que adota um conjunto mínimo de passos para sua execução. Como o objetivo é comparar a eficácia do produto de dados gerado, optamos por selecionar conjuntos de dados de alta qualidade já disponíveis na Web (brasileiros e internacionais) e pelos quais é possível comparar as diferentes métricas de qualidade adotadas nesta pesquisa.

Além disso, concebemos que a contribuição desta tese não se dá somente pela metodologia de publicação, mas sim por uma concepção mais completa, na qual novos requisitos de compartilhamento de dados são incorporados. Segundo, por se tratar de um processo complexo, no qual diversas atividades estão envolvidas, é muito difícil controlar a influência de fatores externos. Terceiro, seria necessária uma grande quantidade de participantes para se chegar a uma significância estatística, o que seria muito difícil de se conseguir dada a duração e complexidade do estudo.

\subsubsection{Participantes}

Foram recrutados 5 participantes (4 homens e 1 mulher), sendo 2 estudantes de pósgraduação em computação, 2 estudantes de graduação em computação e 1 profissional de tecnologia com mestrado em computação, de três universidades: Universidade de São Paulo (USP), Universidade Tecnológica Federal do Paraná (UTFPR) e Universidade Federal de Alagoas (UFAL). A idade média dos participantes foi de 26 anos (desvio-padrão de 4 anos; faixa de 22 a 29) e com tempo médio de experiência em tecnologia de aproximadamente 6 anos. Sobre a experiência específica com dados abertos governamentais ou dados conectados, foi obtida a seguinte caracterização, ilustrada na Figura 30.

Os participantes foram selecionados de maneira não probabilística, com diferentes níveis de experiência com publicação de dados conectados e demonstraram a intenção de participar do estudo. Ainda que não seja uma quantidade grande de participantes, julgamos que este pode ser considerado um número adequado para pesquisas de caráter qualitativo, baseadas em questões de pesquisa amplas, com baixo número de participantes, coletando grande quantidade de dados e com dados sumarizados sem usar técnicas estatísticas.

Como explicado anteriormente, a pesquisa tem caráter exploratório, já que a fundamentação teórica adotada para o contexto de publicação de DAGC ainda está em processo de desenvolvimento e existem poucas hipóteses a serem testadas - cenário em que seria necessário um contingente maior de pessoas para fins de testes estatísticos em estudos quantitativos. Embora nenhum profissional publicador de dados tenha participado do estudo, argumentamos se tratar de um recorte representativo de publicadores de dados, pois, em muitos casos, não são profissionais formados em tecnologia - especialmente em órgãos públicos de menor porte. 
Figura 30 - Experiência dos participantes com DAG e DAC.

\section{Qual sua experiência com Dados Abertos Governamentais?}

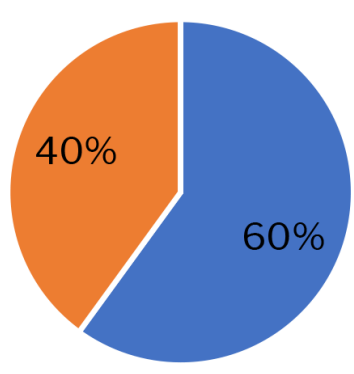

- Nunca havia trabalhado com Dados Abertos Governamentais

- Já trabalhei com Dados Abertos Governamentais em algum projeto

- Já trabalhei com Dados Abertos Governamentais em algum curso

- Trabalho com Dados Abertos Governamentais diariamente

\section{Qual sua experiência com Dados Conectados?}

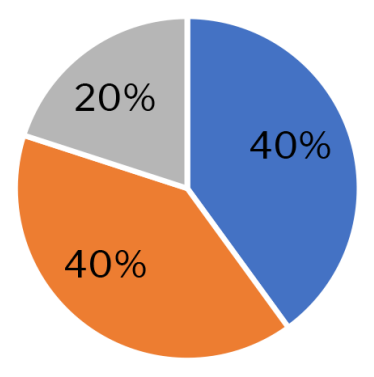

- Nunca havia trabalhado com Dados Conectados

- Já trabalhei com Dados Conectados em algum projeto

- Já trabalhei com Dados Conectados em algum curso

- Trabalho com Dados Conectados diariamente

Fonte: Elaborada pelo autor.

\subsubsection{Procedimento}

Antes de iniciar a execução do roteiro, foi feita uma apresentação com duração média de 30 minutos sobre a proposta da tese, o formato do roteiro, seus detalhes, o significado do cenário e os artefatos que deveriam ser gerados. Foi também informado sobre a confidencialidade do estudo e que para cada participante foi atribuído um código, para que não fosse possível rastrear os dados coletados ao indivíduo que os gerou.

A atividade consistiu na definição de um cenário simples, do domínio educacional. Foram mapeados dados reais de dois conjuntos de dados: estados brasileiros e o desempenho do Índice de Desenvolvimento da Educação Básica (IDEB), medido a cada dois anos) de cada um desses estados ${ }^{10}$. Para o desempenho do IDEB, foram usadas duas distribuições: a versão medida em 2015 e a medida em 2017 - as duas mais recentes disponibilizadas no portal. Por fim, foi proposta a conexão com a DBpedia. O esquema básico é ilustrado na Figura 31. Os participantes assumiram o papel do publicador de dados e desempenharam suas respectivas atividades (cf. 5.2); as atividades dos outros papeis foram fornecidas no roteiro do experimento.

${ }_{10}$ Disponível em: <http://www.dados.gov.br/dataset/ideb-por-estados> 
Foram postas duas questões a serem respondidas com esses dados, de modo a validar se as mesmas podem ser respondidas em seu formato semântico. O roteiro foi construído para que exercitasse todas as atividades do processo proposto, com exceção da atividade de normalização de dados, que não foi necessária neste contexto. O roteiro também contemplou a implementação da arquitetura e, ao final de cada fase, foi pedido explicitamente para que o participante fizesse um conjunto de verificações e preenchesse os metadados elicitados naquela fase.

Figura 31 - Ilustração do cenário proposto no roteiro do estudo de caso.

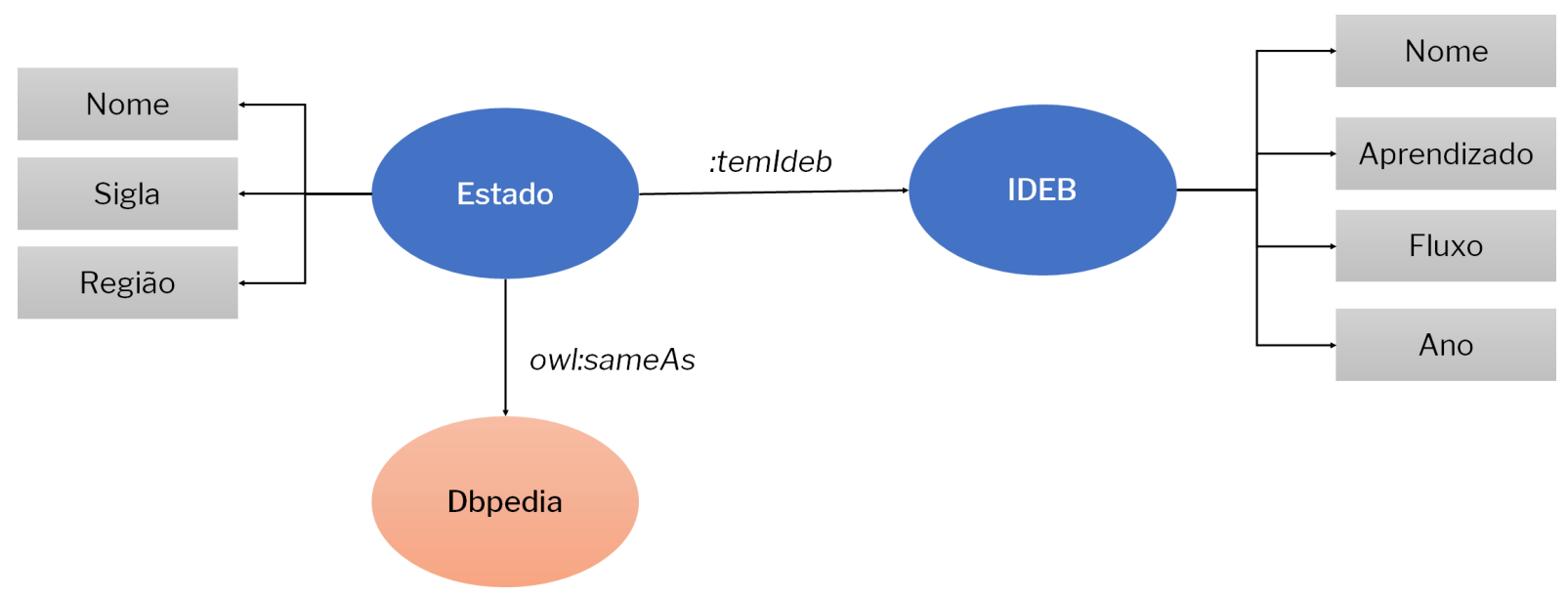

Fonte: Elaborada pelo autor.

A aplicação se deu de modo individual e assíncrono, em que os participantes executaram seus scripts remotamente, sem observação direta do pesquisador. Foi feita esta escolha por se tratar de um roteiro de longa duração (variação entre 5 e 12 horas, a depender da experiência do participante com as tecnologias e conceitos envolvidos) e devido à baixa disponibilidade diária dos participantes para a esta tarefa - razões que também dificultaram o recrutamento dos participantes, principalmente dos mais experientes. Como o roteiro estava dividido pelas fases propostas no modelo do Capítulo 5, foi instruído aos participantes que parassem ao final de uma fase e antes de começar a próxima, para minimizar efeitos de fadiga.

O pesquisador esteve à disposição em tempo real, via Skype, para tirar todas as dúvidas que foram surgindo, principalmente em relação ao uso das ferramentas ou à clareza dos passos do roteiro (observação participante). A abordagem da observação participante (YIN, 2009) se mostrou a mais adequada para este estudo, já que permitiu que o pesquisador interviesse em certos momentos - ao contrário da tradicional observação passiva, em que o pesquisador apenas assiste aos eventos sem possibilidade de intervenção. Como exemplos de eventos, podem ser citados: contorno de bugs em ferramentas, dúvidas sobre os conceitos relacionados, correções em consultas e explicação sobre os metadados. Embora esta abordagem possa trazer desvantagens como possível influência sobre o processo, argumentamos que a falta de participação poderia trazer mais prejuízos à pesquisa em si, podendo fazer com que os participantes desistissem do estudo ao se perceberem em uma situação sobre a qual não tivessem domínio técnico completo, 
como o uso de uma ferramenta específica.

As atividades do processo de publicação foram implementadas ao longo do roteiro, seguindo a divisão por fases e a sequência das atividades propostos no Capítulo 5. Assim, optouse por adotar um roteiro mais fechado, em que as alternativas propostas no processo original já estivessem concretizadas de acordo com o contexto do cenário, o que diminuiu o tempo de execução do roteiro e facilitou para que pessoas sem experiência profissional pudessem participar do estudo. A fase de manutenção não foi contemplada, pois sua implementação exigiria simular problemas futuros com a disponibilidade dos dados ou dos serviços, o que acrescentaria uma grande esforço ao roteiro já extenso. Foi pedido também para que os participantes mantivessem o registro do tempo que levaram para executar cada uma das fases, de modo a se obter uma noção do esforço relativo de cada fase dentro do processo como um todo. O roteiro completo está disponível no apêndice D.

Em relação às ferramentas adotadas, o roteiro prescreveu quais deveriam ser utilizadas, seguindo o racional de escolha de ferramentas proposto no Capítulo 5, inclusive com os passos necessários para executar as ações pedidas no roteiro. Podemos, assim, considerar que foi também uma instanciação deste modelo de decisão. Essa abordagem foi adotada para que o usuário não precisasse gastar tempo para aprender a usar a ferramenta - já que as ferramentas em si não eram o foco do estudo. Foram selecionadas ferramentas tanto para auxiliar o processo quanto para concretizar a arquitetura. Além do uso do racional de escolha das ferramentas, foram considerados como critérios de escolha: i) a facilidade de configuração e uso por usuários de pouca experiência; ii) ferramentas computacionais de uso gratuito; iii) preferência de uso por serviços na Web, em que não foi preciso instalar novas ferramentas. Foi pedido para que o participante usasse seu próprio computador para instalar os softwares e executar os passos estabelecidos no roteiro.

Para a instanciação da arquitetura, foi pedido para que os participantes instalassem e configurassem seus componentes, conforme a arquitetura proposta no Capítulo 5. Foi especificado no roteiro como fazê-lo, de modo que o participante devesse garantir que os componentes estavam interligados e que fossem utilizados de fato.

Para a criação dos metadados foi fornecido aos participantes um modelo de documento, contendo todos os metadados especificados no Capítulo 5 e que deveria ser adaptado ao contexto do cenário proposto. $\mathrm{O}$ modelo dos metadados continha marcadores a serem substituídos por valores que foram trabalhados durante o roteiro, de modo que, ao final, todos os marcadores tivessem sido preenchidos, gerando um arquivo completo que descrevesse o cenário em questão. A Figura 32 mostra uma trecho do arquivo de template usado no roteiro, com recorte para alguns metadados relacionados ao nível de conjunto de dados. Esta abordagem foi adotada devido à grande quantidade de metadados, ao conhecimento subjacente necessário para interpretálos (tanto em relação ao formato de triplas quanto aos usos corretos de valores) e à falta de ferramentas, o que faria com que o estudo fosse ainda mais extenso. 
Figura 32 - Trecho do arquivo de modelo de metadados, contendo os marcadores a serem substituídos ao longo do roteiro.

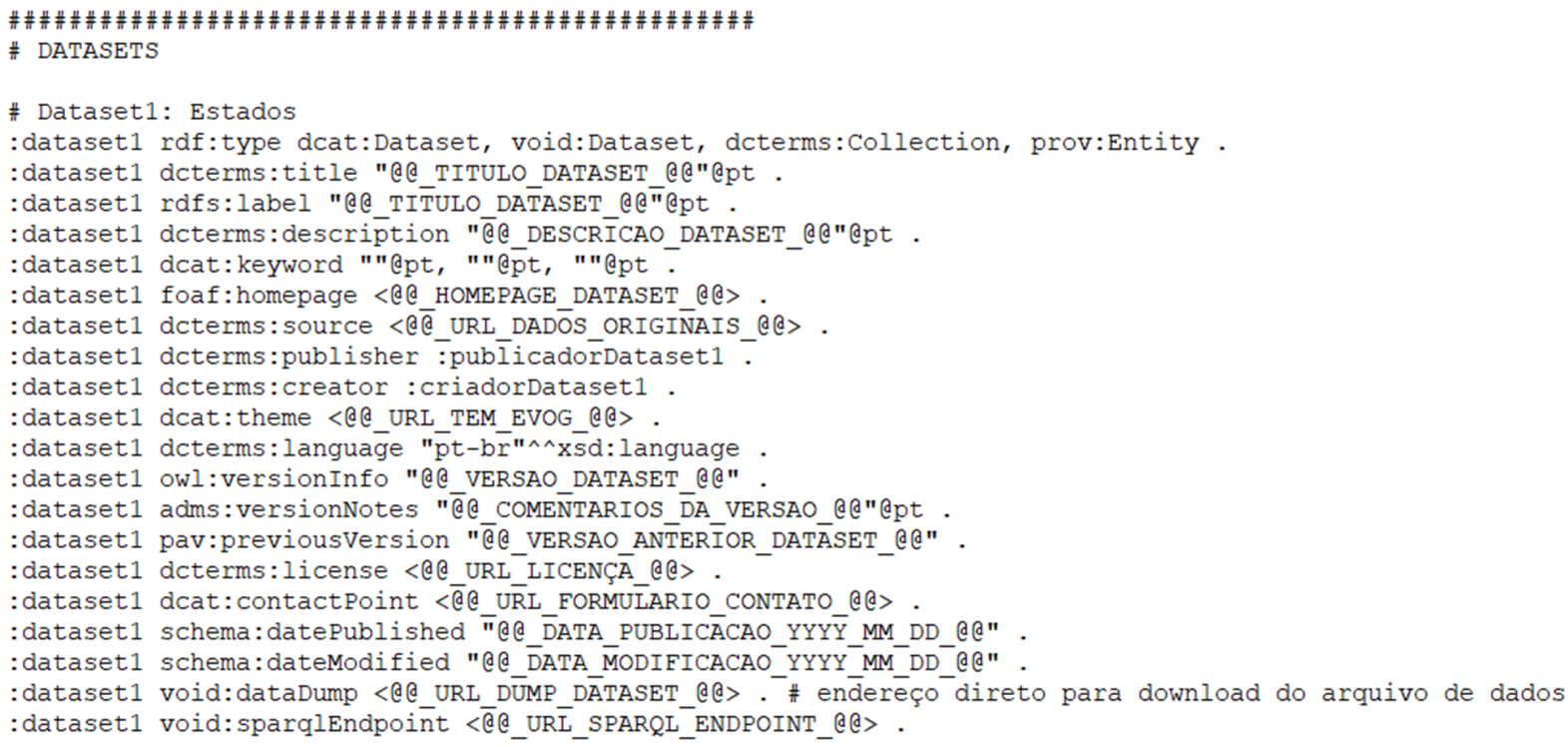

Fonte: Elaborada pelo autor.

Por trazer um escopo maior que outras metodologias similares, não foi possível estabelecer uma comparação. Não se trata apenas de um método de publicação em si, a ser comparado equivalentemente, mas a infraestrutura aqui proposta apresenta também o atendimento a diferentes aspectos não abordados em outras metodologias (passos relacionados à manutenção, normalização, metadados de qualidade e proveniência).

\subsubsection{Coleta dos dados}

Para oferecer maior confiabilidade à análise dos dados, é altamente recomendável que o pesquisador utilize o princípio da triangulação, ou seja, a oportunidade de utilizar fontes diferentes para a obtenção de evidências (YIN, 2009). A triangulação pode ser feita em diferentes níveis e, para este estudo, foi adotada a triangulação de fontes de dados. Foram coletados dados a partir de 3 fontes: observação (indireta), questionário e artefato produzido, conforme indicado no Quadro 26.

A observação foi feita de modo indireto (observação participante), pois o acompanhamento foi remoto. Para cada participante, o pesquisador ficou à disposição via Skype durante a execução do roteiro, para tirar dúvidas sobre o que era pedido no roteiro ou sobre problemas no uso das ferramentas. Ao final da aplicação do estudo, foi aplicado um questionário on-line contendo as impressões sobre as contribuições: processo, ferramentas, arquitetura e metadados, onde foi possível que os participantes elaborassem mais sobre esses artefatos, contendo itens em escala Likert e de texto aberto para poderem sugerir melhorias sobre esses artefatos. Por fim, dois outros instrumentos foram usados para a coleta dos dados: i) as planilhas de acompanhamento, diários de bordo em que o participante registrou as escolhas no seu passo a passo; ii) o dump dos 
Quadro 26 - Instrumentos de coleta dos dados.

\begin{tabular}{|c|c|c|}
\hline Observação & Questionário & Artefato \\
\hline $\begin{array}{c}\text { Indireta e participante, } \\
\text { acompanhando remotamente } \\
\text { os comentários e dúvidas que } \\
\text { surgiram ao longo da } \\
\text { execução do roteiro e } \\
\text { auxiliando em pontos que } \\
\text { não eram foco da pesquisa }\end{array}$ & $\begin{array}{l}\text { Aplicado ao final da sessão, } \\
\text { contendo dados de } \\
\text { caracterização do } \\
\text { participante e percepções } \\
\text { sobre os artefatos do estudo. }\end{array}$ & $\begin{array}{l}\text { Dump dos dados conectados } \\
\text { gerados, contendo a } \\
\text { ontologia, os dados e os } \\
\text { metadados criados e } \\
\text { disponibilizados no servidor } \\
\text { SPARQL e as planilhas de } \\
\text { acompanhamento. }\end{array}$ \\
\hline
\end{tabular}

Fonte: Elaborada pelo autor.

dados cadastrados no servidor SPARQL, que continha as triplas do vocabulário criado, os dados de cada arquivo de dados, as ligações dos dados com a LOD Cloud e os metadados.

\subsubsection{Análise dos dados}

As análises foram feitas em torno de dois eixos: o processo e o produto gerado. A análise da arquitetura é feita mediante uma lista de verificação (checklist) a partir dos requisitos. Para os metadados, calculamos o total de metadados preenchidos corretamente. Para o processo, usamos a planilha de acompanhamento para verificar se as atividades foram seguidas. Além disso, foram coletadas as percepções tanto dos participantes, via questionário, como mediante a observação do pesquisador, de modo a contextualizar os dados coletados.

Em relação ao produto gerado, foi analisada a eficácia do processo, no sentido de o produto apresentar características aferidas por meio de métricas de avaliação da qualidade. Como foi discutido no Capítulo 2, existem várias formas de analisar a qualidade de dados, dependendo do contexto e da característica dos dados. Nas áreas de DAC e DAG os arcabouços ainda parecem incipientes, evoluindo de modo empírico, baseado em erros encontrados em dados já produzidos (por exemplo, (DEBATTISTA; LANGE; AUER, 2018; KONTOKOSTAS et al., 2014). Não foram encontrados na literatura arcabouços de avaliação de qualidade de DAGC. Para este estudo, utilizamos o arcabouço de Debattista, Lange e Auer (2018), que traz uma compilação de métricas objetivas e como elas podem ser medidas para o contexto de dados conectados. Ele é um subconjunto das métricas de Zaveri et al. (2016), reutilizando 25 métricas e acrescentando mais 2, relacionadas a metadados de proveniência. Em Zaveri et al. (2016), os autores realizaram uma compilação de estudos sobre avaliação de qualidade de dados conectados disponíveis na literatura e que resultou num total de 69 métricas em 18 dimensões e 4 categorias.

O Quadro 27 lista as 27 métricas propostas por Debattista, Lange e Auer (2018). As justificativas sobre a importância de cada métrica e os critérios objetivos adotados para a avaliação podem ser encontradas no artigo original. 
Quadro 27 - Arcabouço de métricas aplicadas (DEBATTISTA; LANGE; AUER, 2018).

\begin{tabular}{|c|c|c|c|}
\hline Categoria & Dimensão & Métrica & Explicação \\
\hline \multirow{7}{*}{$\begin{array}{l}\text { Representacional } \\
\text { - revela em que } \\
\text { forma a } \\
\text { informação está } \\
\text { disponível }\end{array}$} & \multirow[t]{2}{*}{$\begin{array}{l}\text { Concisão } \\
\text { representacional }\end{array}$} & $\begin{array}{l}\text { RC1 - Manter as } \\
\text { URIs curtas }\end{array}$ & $\begin{array}{l}\text { Mede a proporção de URIs } \\
\text { curtas (<80 caracteres) den- } \\
\text { tre todas as URIs do con- } \\
\text { junto de dados }\end{array}$ \\
\hline & & $\begin{array}{l}\text { RC2 - Uso mínimo } \\
\text { de estruturas de da- } \\
\text { dos RDF }\end{array}$ & $\begin{array}{l}\text { Mede o grau de uso de es- } \\
\text { truturas RDF (listas, sequên- } \\
\text { cias, reificações etc.) usadas } \\
\text { para representar os dados }\end{array}$ \\
\hline & Interoperabilidade & $\begin{array}{l}\text { IO1 - Reuso de ter- } \\
\text { mos existentes }\end{array}$ & $\begin{array}{l}\text { Proporção de termos reusa- } \\
\text { dos dentre os mais comuns } \\
\text { para o tema do conjunto de } \\
\text { dados }\end{array}$ \\
\hline & \multirow[t]{2}{*}{ Interpretabilidade } & $\begin{array}{l}\text { IN3 - Uso de clas- } \\
\text { ses e propriedades } \\
\text { indefinidas }\end{array}$ & $\begin{array}{l}\text { Proporção de classes e pro- } \\
\text { priedades usadas nas triplas } \\
\text { e que não foram definidas } \\
\text { em um esquema explícito }\end{array}$ \\
\hline & & $\begin{array}{l}\text { IN4 - Uso de blank } \\
\text { nodes }\end{array}$ & $\begin{array}{l}\text { Proporção de blank nodes } \\
\text { dentre todas as URIs }\end{array}$ \\
\hline & \multirow[t]{2}{*}{ Versatilidade } & $\begin{array}{l}\text { V1 - Diferentes for- } \\
\text { matos de serializa- } \\
\text { ção }\end{array}$ & $\begin{array}{l}\text { Quantidade de formatos de } \\
\text { serialização disponíveis para } \\
\text { os dados, conforme apon- } \\
\text { tado nos metadados }\end{array}$ \\
\hline & & $\begin{array}{l}\text { V2 - Uso de múlti- } \\
\text { plas línguas }\end{array}$ & $\begin{array}{l}\text { Quantidade de línguas repre- } \\
\text { sentadas nos dados }\end{array}$ \\
\hline \multirow[t]{2}{*}{$\begin{array}{l}\text { Contextual - traz } \\
\text { informações para } \\
\text { o reuso dos } \\
\text { dados }\end{array}$} & \multirow[t]{2}{*}{ Proveniência } & $\begin{array}{l}\text { P1 - Provisão de in- } \\
\text { formações básicas } \\
\text { de proveniência }\end{array}$ & $\begin{array}{l}\text { Fornecimento de metadados } \\
\text { indicando o criador e o pu- } \\
\text { blicador dos conjuntos de } \\
\text { dados }\end{array}$ \\
\hline & & $\begin{array}{l}\text { P2 - Rastreamento } \\
\text { dos dados }\end{array}$ & $\begin{array}{l}\text { Fornecimento de metadados } \\
\text { indicando a geração de cada } \\
\text { entidade da base }\end{array}$ \\
\hline
\end{tabular}




\begin{tabular}{|c|c|c|c|}
\hline Categoria & Dimensão & Métrica & Explicação \\
\hline & \multirow[t]{3}{*}{ Compreensibilidade } & $\begin{array}{l}\text { U1 - Leitura de ró- } \\
\text { tulos e comentários } \\
\text { por humanos }\end{array}$ & $\begin{array}{l}\text { Completude de um conjunto } \\
\text { de dados em fornecer rótu- } \\
\text { los e descrições para as suas } \\
\text { entidades }\end{array}$ \\
\hline & & $\begin{array}{l}\text { U3 - Presença de ex- } \\
\text { pressão regular de } \\
\text { URI base }\end{array}$ & $\begin{array}{l}\text { Existência de metadados } \\
\text { com expressão regular que } \\
\text { define a estrutura das URI } \\
\text { usadas no conjunto de da- } \\
\text { dos, facilitando sua desco- } \\
\text { berta por agentes de soft- } \\
\text { ware. }\end{array}$ \\
\hline & & $\begin{array}{l}\text { U5 - Indicação dos } \\
\text { vocabulários usados }\end{array}$ & $\begin{array}{l}\text { Fornecimento de metadados } \\
\text { que indicam quais foram os } \\
\text { vocabulários usados na mo- } \\
\text { delagem do conjunto de da- } \\
\text { dos }\end{array}$ \\
\hline \multirow{5}{*}{$\begin{array}{l}\text { Intrínseca - checa } \\
\text { se a informação } \\
\text { reflete a realidade } \\
\text { e é logicamente } \\
\text { consiste }\end{array}$} & Concisão & $\begin{array}{l}\text { CN2 - Concisão ex- } \\
\text { tensional }\end{array}$ & $\begin{array}{l}\text { Mede a unicidade de repre- } \\
\text { sentações dos objetos, evi- } \\
\text { tando duplicidade }\end{array}$ \\
\hline & \multirow[t]{4}{*}{ Consistência } & $\begin{array}{l}\text { CS1 - Entidades } \\
\text { como membros de } \\
\text { classes disjuntas }\end{array}$ & $\begin{array}{l}\text { Mede o grau de disjunção } \\
\text { entre tipos de recursos defi- } \\
\text { nidos por múltiplos tipos }\end{array}$ \\
\hline & & $\begin{array}{l}\text { CS2 - Classes e pro- } \\
\text { priedades mal posi- } \\
\text { cionadas }\end{array}$ & $\begin{array}{l}\text { Checa o grau de classes es- } \\
\text { tão posicionadas como pre- } \\
\text { dicados em triplas e proprie- } \\
\text { dades como objetos }\end{array}$ \\
\hline & & $\begin{array}{l}\text { CS3 - Propriedades } \\
\text { OWL (Object e Da- } \\
\text { tatype) mal empre- } \\
\text { gadas }\end{array}$ & $\begin{array}{l}\text { Checa o grau de inconsistên- } \\
\text { cias entre os valores espera- } \\
\text { dos pelas propriedades lite- } \\
\text { rais }\end{array}$ \\
\hline & & $\begin{array}{l}\text { CS4 - Uso de clas- } \\
\text { ses e propriedades } \\
\text { descontinuadas }\end{array}$ & $\begin{array}{l}\text { Checa o uso de classes e pro- } \\
\text { priedades que foram marca- } \\
\text { das como descontinuadas }\end{array}$ \\
\hline
\end{tabular}




\begin{tabular}{|c|c|c|c|}
\hline Categoria & Dimensão & Métrica & Explicação \\
\hline & & $\begin{array}{l}\text { CS5 - Uso válido de } \\
\text { propriedades funci- } \\
\text { onais inversas }\end{array}$ & $\begin{array}{l}\text { Checa a existência de recur- } \\
\text { sos diferentes mas que pos- } \\
\text { suem mesmos valores em } \\
\text { propriedades do tipo Inverse- } \\
\text { FunctionalProperty (ou seja, } \\
\text { que deveriam ser iguais) }\end{array}$ \\
\hline & & $\begin{array}{l}\text { CS6 - Sequestro de } \\
\text { ontologia }\end{array}$ & $\begin{array}{l}\text { Mede o grau de redefini- } \\
\text { ção de termos vindos de ou- } \\
\text { tras ontologias, como por } \\
\text { ex., mudando o valor espe- } \\
\text { rado de uma propriedade ou } \\
\text { usando classes em domínio } \\
\text { ou alcance não permitidos } \\
\text { nas triplas }\end{array}$ \\
\hline & & $\begin{array}{l}\text { CS9 - Uso de tipos } \\
\text { de dados incorretos } \\
\text { de domínios e alcan- } \\
\text { ces }\end{array}$ & $\begin{array}{l}\text { Mede o grau de consistên- } \\
\text { cia entre os tipos de valores } \\
\text { esperados e os atribuídos ao } \\
\text { domínio e alcance entre to- } \\
\text { das as triplas }\end{array}$ \\
\hline & Validade sintática & $\begin{array}{l}\text { SV3 - Tipos de da- } \\
\text { dos compatíveis }\end{array}$ & $\begin{array}{l}\text { Mede o grau de consistên- } \\
\text { cia entre os tipos de valores } \\
\text { literais e os valores de fato } \\
\text { atribuídos }\end{array}$ \\
\hline \multirow{3}{*}{$\begin{array}{l}\text { Acessibilidade - } \\
\text { determina como } \\
\text { os dados podem } \\
\text { ser acessados }\end{array}$} & Disponibilidade & $\begin{array}{l}\text { A3 - Desreferencia- } \\
\text { bilidade das URIs }\end{array}$ & $\begin{array}{l}\text { Mede a proporção de URIs } \\
\text { que são resolvíveis dentre to- } \\
\text { das as entidades presentes } \\
\text { nos dados }\end{array}$ \\
\hline & \multirow[t]{2}{*}{ Licenciamento } & $\begin{array}{l}\text { L1 - Licença legível } \\
\text { por máquina }\end{array}$ & $\begin{array}{l}\text { Fornecimento de metadados } \\
\text { que indicam as URIs das li- } \\
\text { cenças atribuídas aos dados }\end{array}$ \\
\hline & & $\begin{array}{l}\text { L2 - Licença legível } \\
\text { por humanos }\end{array}$ & $\begin{array}{l}\text { Fornecimento de metadados } \\
\text { que indicam o texto das li- } \\
\text { cenças atribuídas aos dados }\end{array}$ \\
\hline
\end{tabular}

Continua na próxima página 


\begin{tabular}{|l|l|l|l|}
\hline Categoria & Dimensão & Métrica & Explicação \\
\hline & Interligação & $\begin{array}{l}\text { I1 - Links para for- } \\
\text { necedores de da- } \\
\text { dos externos conec- } \\
\text { tados }\end{array}$ & $\begin{array}{l}\text { Total de conexões feitas a en- } \\
\text { tidades externas e que sejam } \\
\text { desreferenciáveis }\end{array}$ \\
\cline { 2 - 4 } & Desempenho & PE2 - Alta vazão & $\begin{array}{l}\text { Mede a quantidade de requi- } \\
\text { sições respondidas por se- } \\
\text { gundo a um servidor de tri- } \\
\text { plas }\end{array}$ \\
\cline { 2 - 4 } & PE3 - Baixa latên- \\
& cia & $\begin{array}{l}\text { Mede o tempo médio levado } \\
\text { para que 10 recursos locais } \\
\text { sejam retornados pelo servi- } \\
\text { dor de triplas }\end{array}$ \\
\hline
\end{tabular}

Fonte: Elaborada pelo autor.

Para efeitos comparativos, selecionamos 3 outros conjuntos de dados para serem avaliados sob as mesmas métricas. Dois deles já foram mencionados no Capítulo 3. Um deles é o conjunto de dados do Orçamento Federal, distribuição de $2018^{11}$. Outro dataset vem da Previdência Social, especificamente o de "Acidentes do trabalho por atividade econômica"12, de 2015. Por fim, utilizamos um dataset mencionado no artigo, o do Banco Mundial ${ }^{13}$, cujos metadados estão disponíveis na página do LOD Cloud. Este dataset foi listado como o melhor da categoria "governo"dentre todos os analisados no repositório. Não existem dados de qualidade baseados em métricas específicas para DAGC. No trabalho de Debattista, Lange e Auer (2018), o arcabouço é aplicado a todos os conjuntos de dados registrados na LOD Cloud, em sua versão de 2014, independentemente de seu domínio. Os dados governamentais são um subconjunto desses dados que não foi analisado separadamente.

Com essas escolhas, buscamos comparar o resultado do processo e dos metadados com o estado da arte nacional e internacional. Para a avaliação dessas métricas foi utilizado o software Luzzu ${ }^{14}$, desenvolvido pelos autores deste mesmo arcabouço (DEBATTISTA; LANGE; AUER, 2018), para medir automaticamente as métricas propostas a partir de uma fonte de dados triplificados.

$11<$ http://www.dados.gov.br/dataset/orcamento-federal>

$12<\mathrm{http} / / / \mathrm{www}$.dados.gov.br/dataset/acidentes-do-trabalho-por-atividade-economica-cnae-2-0>

$13<$ https://lod-cloud.net/dataset/imf-linked-data>

$14<$ https://github.com/Luzzu/Framework> 


\subsubsection{Resultados}

Nesta seção são detalhadas as evidências levantadas pelos dados coletados durante o estudo. Os resultados foram divididos pela percepção da facilidade do processo e pela eficácia dos produtos gerados.

\subsubsection{Processo}

O tempo total para a execução de todos os passos do roteiro variou muito conforme o grau de conhecimento dos participantes sobre as tecnologias envolvidas (média de 8h50, com variação entre $5 \mathrm{~h} 45$ e 14h). Ademais, buscamos trazer uma medida proporcional de tempo médio entre as fases, para detectar quais fases foram mais predominantes em termos de esforço. A Figura 33 mostra a distribuição média do tempo de cada fase relativo ao tempo total de execução de todo o processo. A fase de Modelagem foi a que mais demandou esforços, tanto na criação do vocabulário quanto do mapeamento dos dados aos vocabulários.

Figura 33 - Distribuição relativa média de tempo entre as fases.

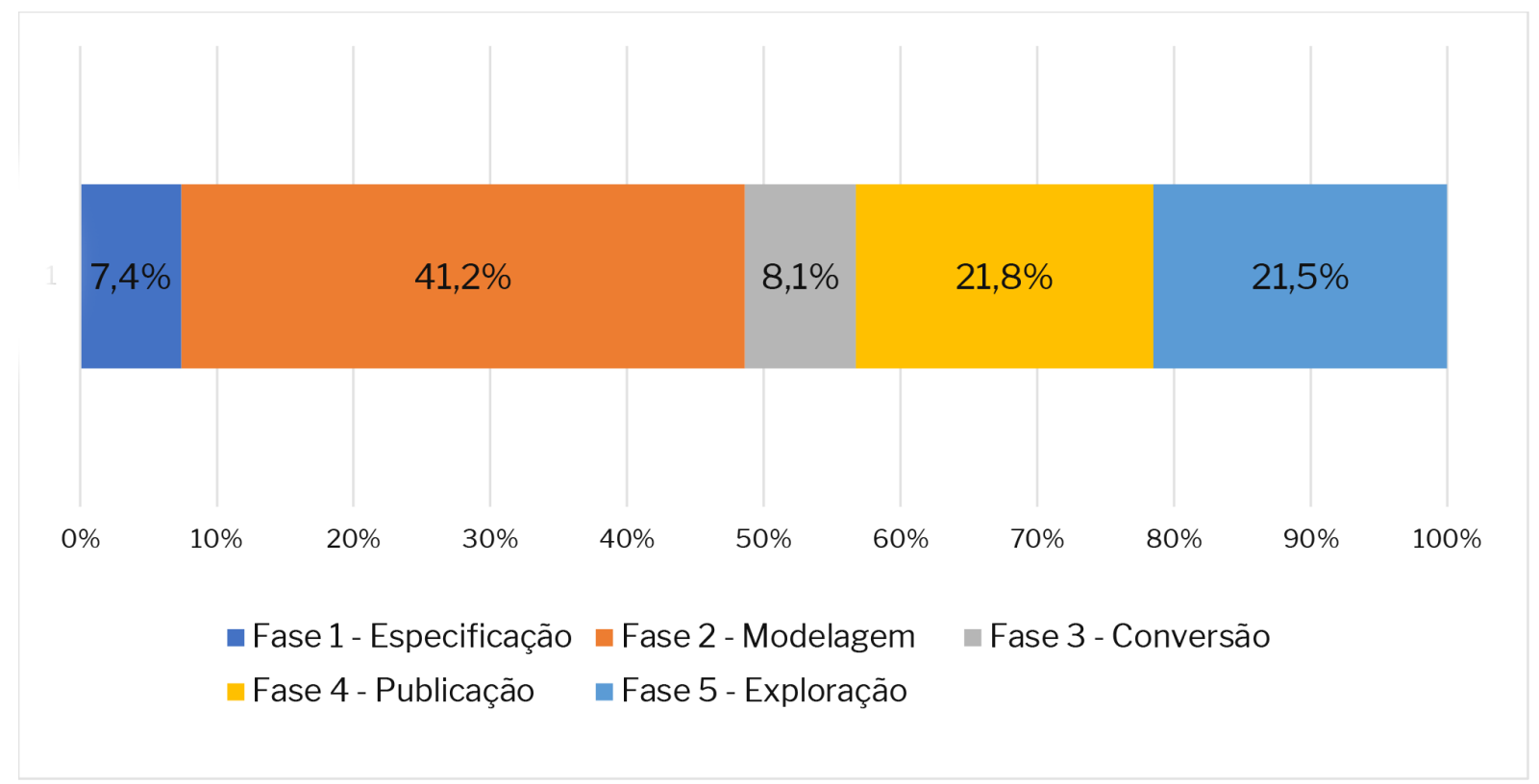

Fonte: Elaborada pelo autor.

Quanto à facilidade de uso, foi aplicado um instrumento de questionário contendo um item em escala Likert de 5 pontos, pedindo a percepção do grau de facilidade de uso de cada um desses artefatos propostos. O resultado está ilustrado na Figura 34.

O processo foi considerado simples de executar, com a ordem considerada apropriada. Um dos participantes considerou que o balanceamento de atividades entre as fases poderia ser melhorado: "Tentar reduzir, simplificar ou transferir (talvez para a primeira) algumas atividades da segunda fase". Houve certa confusão dos participantes entre o que era o processo e o que era o roteiro em si, mesmo sendo explicada a diferença entre eles. Um dos participantes 
Figura 34 - Percepção da facilidade de uso dos artefatos propostos.
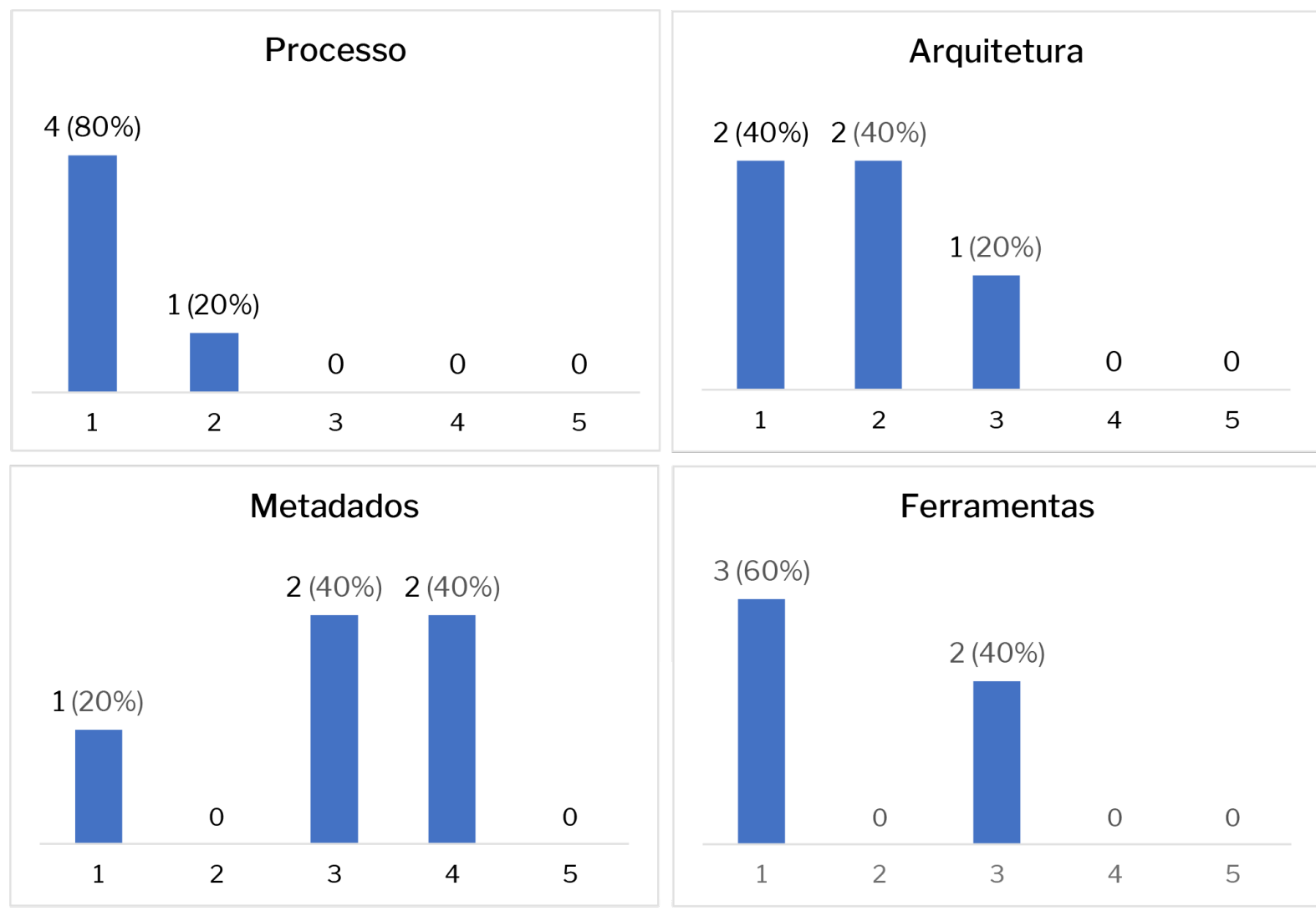

Legenda:

Extremamente fácil

1

\section{Fonte: Elaborada pelo autor.}

comentou: "Seria interessante simplificar a linguagem e inserir imagens para possibilitar que qualquer pessoa, cientistas, acadêmicos e governantes possam realizar o processo". Ao serem questionados sobre qual fase foi a mais difícil, 4 dos 5 respondentes responderam a fase de Modelagem. Conforme apontou um dos participantes: "Qualquer passo errado ou mal compreendido pode levar a resultados diferentes no fim do processo." e replicado por outro: "um erro durante a execução desta pode comprometer elou atrasar todas as demais". O outro participante mencionou as atividades de preenchimento dos metadados que, embora não seja uma fase, perpassa todas as fases do processo (exceto a de exploração) e foi feita de forma manual.

Quanto à arquitetura, a percepção foi parecida. Ela foi instanciada e configurada sem grandes problemas. Como com a concepção do processo, o design da arquitetura foi confundido com o roteiro: "(devia haver) imagens tutoriais" ou "Preparar imagens docker para cada aplicação web (LODRefine, Fuseki, etc.)". Ressaltamos que a escolha de instalar as ferramentas foi devido ao funcionamento em diferentes plataformas e à uniformidade de pré-requisitos. As ferramentas escolhidas executavam sobre Java e alternativas como o Docker não são suportadas 
em certos sistemas operacionais (como os adotados pelos participantes do estudo).

Em relação aos metadados, a percepção dos participantes é de que foi uma atividade de difícil execução. O template de metadados foi fornecido como um arquivo em formato Turtle, contendo os marcadores a serem substituídos conforme o processo era conduzido. No entanto, não foram encontradas ferramentas que auxiliassem nesse processo. Era possível fazer a edição em um software de edição de texto, e foram adotados o Notepad++ e o Sublime. Outra sugestão foi o uso da ferramenta Protégé, em que as triplas poderiam ser também editadas, mas foi considerado mais difícil pelos participantes. Um deles comentou: "Um sistema próprio pra isso, pois sem um editor de texto com marcação fica um pouco difícil de controlar as mudanças".

Outro ponto notado durante o estudo foi o desconhecimento do que são e para que servem os metadados, mesmo para os participantes que tinham experiência com dados conectados. Um dos participantes sugeriu: "Um guia explicando como o arquivo de metadados funciona e para que ele serve" e o mesmo foi observado pelo pesquisador em outros dois casos, em que os participantes fizeram comentários semelhantes durante seu preenchimento. Para este caso, o pesquisador propôs o arquivo de metadados em formato de template para diminuir o esforço de preenchimento de triplas e a probabilidade de cometer erros devido ao seu mau preenchimento.

O grau de facilidade de uso das ferramentas variou conforme a experiência dos participantes com os dados conectados. Os participantes que responderam ter algum tipo de experiência prévia responderam ser muito fácil o uso das ferramentas propostas, mesmo sem uso prévio, conforme reportado durante o estudo. Um dos respondentes comentou: "As ferramentas todas são simples, o que facilita a utilização, principalmente para usuários novos em LOD”.

Além disso, pôde-se notar que o processo segue um fluxo iterativo para a criação do modelo final dos dados conectados (Figura 35). Nos casos observados, a fase de Modelagem teve papel central, para a qual foi necessário retornar para corrigir problemas de nomenclatura, atribuição de URIs, codificação de caracteres, valores das propriedades, dentre outros problemas que só foram percebidos ao final do processo. Ocorreram também problemas e dúvidas em fases específicas que foram corrigidas dentro das próprias fases (por exemplo: erros de sintaxe nas consultas SPARQL).

Figura 35 - Fluxo linear sugerido e o fluxo iterativo ocorrido.

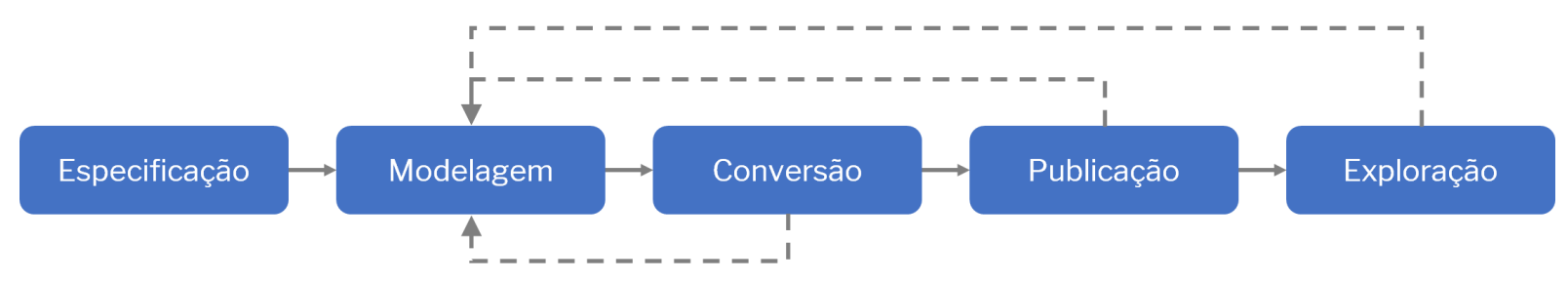

Fonte: Elaborada pelo autor. 


\subsubsection{Produto}

Em relação à eficácia dos metadados, foi considerada a proporção de erros gerados durante sua produção, a partir do arquivo template fornecido. No total, havia 100 valores a serem preenchidos, de acordo com os vocabulários selecionados e já com os as triplas configuradas, delimitando os valores como sendo literais ou URIs, com suas respectivas definições de tipo. A Tabela 1 traz os marcadores que faltaram ser preenchidos e os erros encontrados. Dentre os metadados que faltaram, a maioria foi relacionada ao não preenchimento das palavras-chave que descreviam os conjuntos de dados. Dentre os erros, a maior parte foi devido a URIs com formatos errados e a inversão de tipos no objeto das triplas (uso de URI no lugar de literais e vice-versa).

Tabela 1 - Erros e metadados faltantes no template dos participantes.

\begin{tabular}{|l|c|c|c|c|c|}
\hline Métrica & P1 & P2 & P3 & P4 & P5 \\
\hline Faltantes & 4 & 2 & 3 & 2 & 5 \\
\hline Erros & 4 & 1 & 2 & 0 & 1 \\
\hline
\end{tabular}

Fonte: Elaborada pelo autor.

Em relação à eficácia da arquitetura, foi considerado o atendimento aos requisitos especificados pela recomendação DWBP, ilustrado na Quadro 28.

Quadro 28 - Atendimento aos requisitos da DWBP pelos participantes.

\begin{tabular}{|l|c|c|c|c|c|c|}
\hline & P1 & P2 & P3 & P4 & P5 & Obs. \\
\hline BP1 & A & A & A & A & A & \\
\hline BP2 & P & P & P & P & P & $\begin{array}{l}\text { Os metadados descritivos não } \\
\text { foram preenchidos no CKAN }\end{array}$ \\
\hline BP3 & A & A & A & A & A & A \\
\hline BP4 & A & A & A & N & A & P4 carregou arquivos errados. \\
\hline BP5 & A & A & A & A & A & P \\
\hline BP6 & P & P & P & P & P & $\begin{array}{c}\text { Métricas de qualidade disponíveis } \\
\text { no Fuseki, mas não no CKAN }\end{array}$ \\
\hline BP7 & P & P & P & P & A & Metadados de versão disponíveis \\
no Fuseki, mas não no CKAN
\end{tabular}

Continua na próxima página 


\begin{tabular}{|c|c|c|c|c|c|c|}
\hline & P1 & P2 & P3 & P4 & P5 & Obs. \\
\hline BP10 & A & A & A & A & A & \\
\hline BP11 & A & A & A & A & A & \\
\hline $\mathrm{BP} 12$ & A & A & A & A & A & \\
\hline BP13 & A & A & A & A & A & \\
\hline BP14 & A & A & A & A & A & \\
\hline $\mathrm{BP} 15$ & A & A & A & A & A & \\
\hline BP16 & A & A & A & A & A & \\
\hline BP17 & A & A & A & A & A & \\
\hline BP18 & A & A & A & A & A & \\
\hline BP19 & A & A & A & A & A & \\
\hline $\mathrm{BP} 20$ & NA & NA & NA & NA & NA & O cenário não aplicou esta prática. \\
\hline $\mathrm{BP} 21$ & A & A & A & A & A & \\
\hline $\mathrm{BP} 22$ & NA & NA & NA & NA & NA & O cenário não aplicou esta prática. \\
\hline $\mathrm{BP} 23$ & A & A & A & A & A & \\
\hline $\mathrm{BP} 24$ & A & A & A & A & A & \\
\hline $\mathrm{BP} 25$ & A & A & A & A & A & \\
\hline $\mathrm{BP} 26$ & A & A & A & A & A & \\
\hline $\mathrm{BP} 27$ & A & A & A & A & A & \\
\hline BP28 & A & A & A & A & A & \\
\hline BP29 & A & A & A & A & A & \\
\hline BP30 & $\mathrm{P}$ & $\mathrm{P}$ & $\mathrm{P}$ & $\mathrm{P}$ & $\mathrm{P}$ & $\begin{array}{l}\text { Os comentários não são acessíveis } \\
\text { semanticamente. }\end{array}$ \\
\hline BP31 & A & A & A & A & A & \\
\hline BP32 & A & A & A & A & A & \\
\hline BP33 & $\mathrm{P}$ & $\mathrm{P}$ & $\mathrm{P}$ & $\mathrm{P}$ & $\mathrm{P}$ & \\
\hline BP34 & $\mathrm{P}$ & $\mathrm{P}$ & $\mathrm{P}$ & $\mathrm{P}$ & $\mathrm{P}$ & \\
\hline BP35 & $\mathrm{P}$ & $\mathrm{P}$ & $\mathrm{P}$ & $\mathrm{P}$ & $\mathrm{P}$ & \\
\hline
\end{tabular}

Fonte: Elaborada pelo autor.

Em relação à eficácia do processo, foram aferidas as métricas para dados conectados sobre os dados gerados pelos participantes ao final do estudo ${ }^{15}$. Como a aferição foi feita em ambiente 15 Disponível em: <https://purl.org/caed/dumps> 
local (não publicado na Web), três medidas da categoria Acessibilidade não foram usadas, pois dependem da configuração do servidor das triplas (vazão, latência e desreferenciabilidade das URIs) e são adequadas para medições em conjuntos de dados publicados em ambiente de produção na Web. Das 24 métricas restantes, 19 apresentam valores contínuos entre 0 e 1 , representados como porcentagem, 3 delas apresentam valores lógicos e 2 apresentam valores absolutos, de contagem. Das 24 métricas, o software Luzzu forneceu suporte para o cálculo de 21 delas. As 3 restantes (I1, IO1, U1) foram calculadas utilizando consultas SPARQL sobre os dados, seguindo as orientações do artigo original (DEBATTISTA; LANGE; AUER, 2018).

A Figura 36 e a Tabela 2 trazem os valores medidos para cada conjunto de dados conectados gerados pelos 5 participantes. Para a maioria das métricas, o processo seguido - e apoiado pelo modelo de metadados - mostrou que pode gerar resultados estáveis, ao passo que as métricas que dependem mais de escolhas da fase de modelagem trouxeram valores mais variáveis. Por exemplo, para a métrica U1, o participante P2 escolheu criar uma nova propriedade em vez de reutilizar o vocabulário externo sugerido e esta propriedade não era subpropriedade de outras propriedades.

Figura 36 - Comparação das métricas de qualidade dos dados conectados gerados pelos participantes.

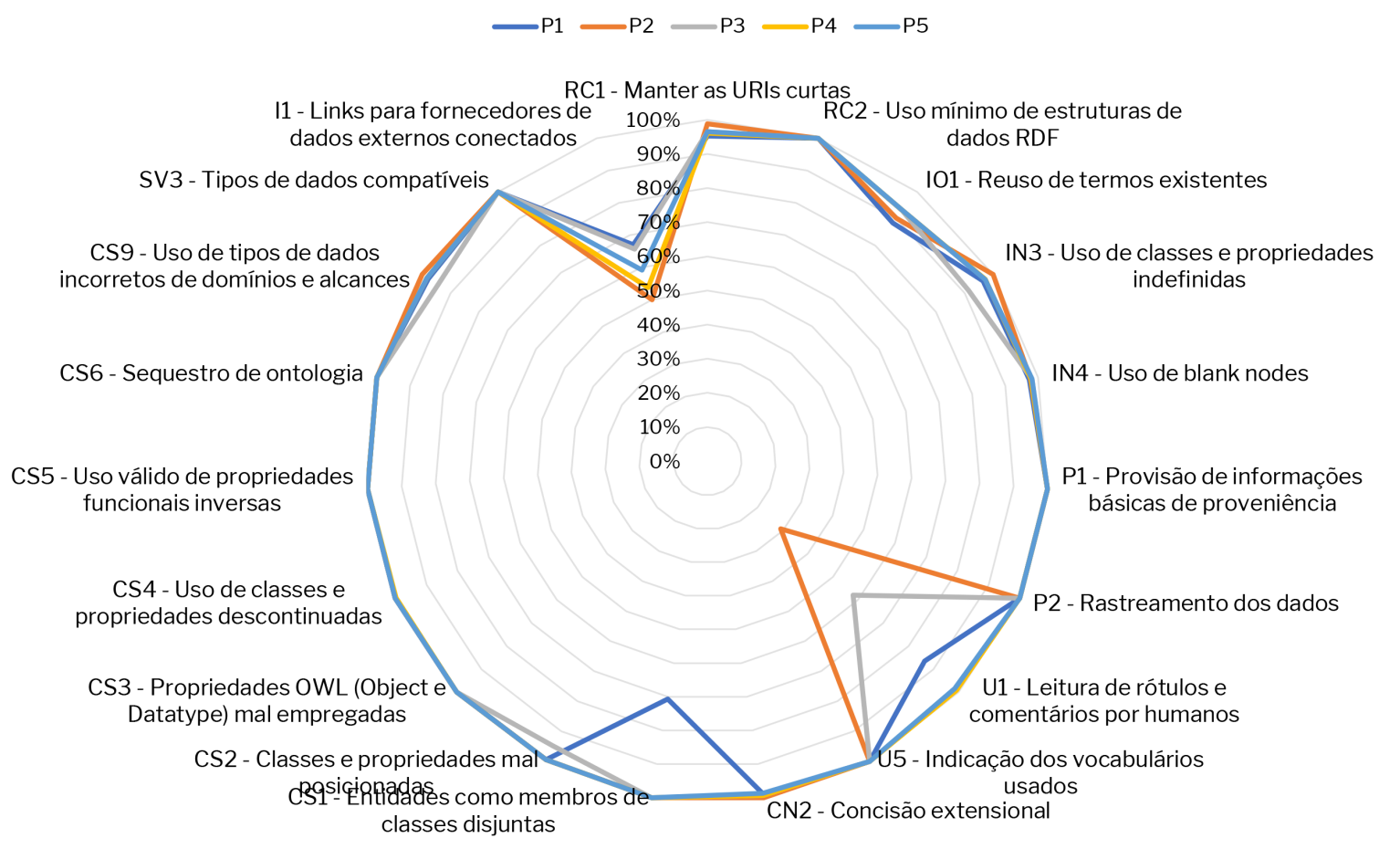

Fonte: Elaborada pelo autor.

Além das métricas contínuas, a Tabela 3 mostra as outras variáveis aferidas pela ferramenta. A partir dos artefatos propostos, os participantes puderam usar os templates para determinar as licenças dos datasets e sua expressão regular que determina a URI de estrutura para 
Tabela 2 - Tabela detalhada dos valores aferidos das métricas contínuas de qualidade.

\begin{tabular}{|c|c|c|c|c|c|}
\hline Métrica & $\mathbf{P 1}$ & $\mathbf{P 2}$ & P3 & P4 & P5 \\
\hline $\mathrm{RC} 1$ - Manter as URIs curtas & $95,2 \%$ & $98,8 \%$ & $96,5 \%$ & $96,1 \%$ & $96,5 \%$ \\
\hline $\begin{array}{l}\text { RC2 - Uso mínimo de estruturas de } \\
\text { dados RDF }\end{array}$ & $100 \%$ & $100 \%$ & $100 \%$ & $100 \%$ & $100 \%$ \\
\hline IO1 - Reuso de termos existentes & $88,5 \%$ & $90,2 \%$ & $93,0 \%$ & $93,1 \%$ & $93,1 \%$ \\
\hline $\begin{array}{l}\text { IN3 - Uso de classes e propriedades } \\
\text { indefinidas }\end{array}$ & $96,5 \%$ & $100 \%$ & $91,4 \%$ & $97,3 \%$ & $97,2 \%$ \\
\hline IN4 - Uso de blank nodes & $97,4 \%$ & $97,8 \%$ & $98,1 \%$ & $97,8 \%$ & $98 \%$ \\
\hline $\begin{array}{l}\text { P1 - Provisão de informações básicas } \\
\text { de proveniência }\end{array}$ & $100 \%$ & $100 \%$ & $100 \%$ & $100 \%$ & $100 \%$ \\
\hline P2 - Rastreamento dos dados & $100 \%$ & $100 \%$ & $100 \%$ & $100 \%$ & $100 \%$ \\
\hline $\begin{array}{l}\text { U1 - Leitura de rótulos e comentários } \\
\text { por humanos }\end{array}$ & $86,4 \%$ & $29,2 \%$ & $58,0 \%$ & $99,2 \%$ & $98,5 \%$ \\
\hline $\begin{array}{l}\text { U5 - Indicação dos vocabulários usa- } \\
\text { dos }\end{array}$ & $100 \%$ & $100 \%$ & $100 \%$ & $100 \%$ & $100 \%$ \\
\hline CN2 - Concisão extensional & $98,9 \%$ & $100 \%$ & $99,3 \%$ & $99,3 \%$ & $98,6 \%$ \\
\hline $\begin{array}{l}\text { CS1 - Entidades como membros de } \\
\text { classes disjuntas }\end{array}$ & $70,7 \%$ & $100 \%$ & $100 \%$ & $100 \%$ & $100 \%$ \\
\hline $\begin{array}{l}\text { CS2 - Classes e propriedades mal po- } \\
\text { sicionadas }\end{array}$ & $99,5 \%$ & $99,5 \%$ & $94,9 \%$ & $99,4 \%$ & $99,4 \%$ \\
\hline $\begin{array}{l}\text { CS3 - Propriedades OWL (Object e } \\
\text { Datatype) mal empregadas }\end{array}$ & $100 \%$ & $100 \%$ & $100 \%$ & $100 \%$ & $100 \%$ \\
\hline $\begin{array}{l}\text { CS4 - Uso de classes e propriedades } \\
\text { descontinuadas }\end{array}$ & $100 \%$ & $100 \%$ & $100 \%$ & $100 \%$ & $100 \%$ \\
\hline $\begin{array}{l}\text { CS5 - Uso válido de propriedades } \\
\text { funcionais inversas }\end{array}$ & $100 \%$ & $100 \%$ & $100 \%$ & $100 \%$ & $100 \%$ \\
\hline CS6 - Sequestro de ontologia & $100 \%$ & $100 \%$ & $100 \%$ & $100 \%$ & $100 \%$ \\
\hline $\begin{array}{l}\text { CS9 - Uso de tipos de dados incorre- } \\
\text { tos de domínios e alcances }\end{array}$ & $97,7 \%$ & $100 \%$ & $94,4 \%$ & $98,2 \%$ & $98,2 \%$ \\
\hline SV3 - Tipos de dados compatíveis & $100 \%$ & $100 \%$ & $100 \%$ & $100 \%$ & $100 \%$ \\
\hline $\begin{array}{l}\text { I1 - Links para fornecedores de da- } \\
\text { dos externos conectados }\end{array}$ & $67,1 \%$ & $50,0 \%$ & $65,7 \%$ & $53,8 \%$ & $59,2 \%$ \\
\hline
\end{tabular}

Fonte: Elaborada pelo autor.

acesso aos recursos. Além disso, foram especificados os formatos de serialização disponíveis pelo servidor de triplas e a linguagem padrão utilizada, o português.

Para a comparação com conjuntos de dados externos, optamos por calcular uma média entre as métricas do grupo de participantes, de modo a se ter uma visão geral e mais robusta 
Tabela 3 - Tabela detalhada dos valores aferidos das métricas discretas de qualidade.

\begin{tabular}{|l|c|c|c|c|c|}
\hline Métrica & P1 & P2 & P3 & P4 & P5 \\
\hline Presença de expressão regular de URIs & S & S & S & S & S \\
\hline Licença legível para humanos & S & S & S & S & S \\
\hline Licença legível para máquinas & S & S & S & S & S \\
\hline Diferentes formatos de serialização & 9 & 9 & 9 & 9 & 9 \\
\hline Uso de múltiplas linguagens & 1 & 1 & 1 & 1 & 1 \\
\hline
\end{tabular}

Fonte: Elaborada pelo autor.

do grau de qualidade do produto gerado no processo. A Figura 37 e a Tabela 4 demonstram o comparativo entre as métricas dos conjuntos de dados externos e a média aritmética das métricas aferidas a partir dos produtos gerados pelos participantes. O conjunto de dados do Banco Mundial não está disponível, mas preservou suas métricas na página. As métricas não disponíveis na página estão marcadas com 'ND'.

Figura 37 - Comparação das métricas de qualidade dos dados conectados gerados pelos participantes.

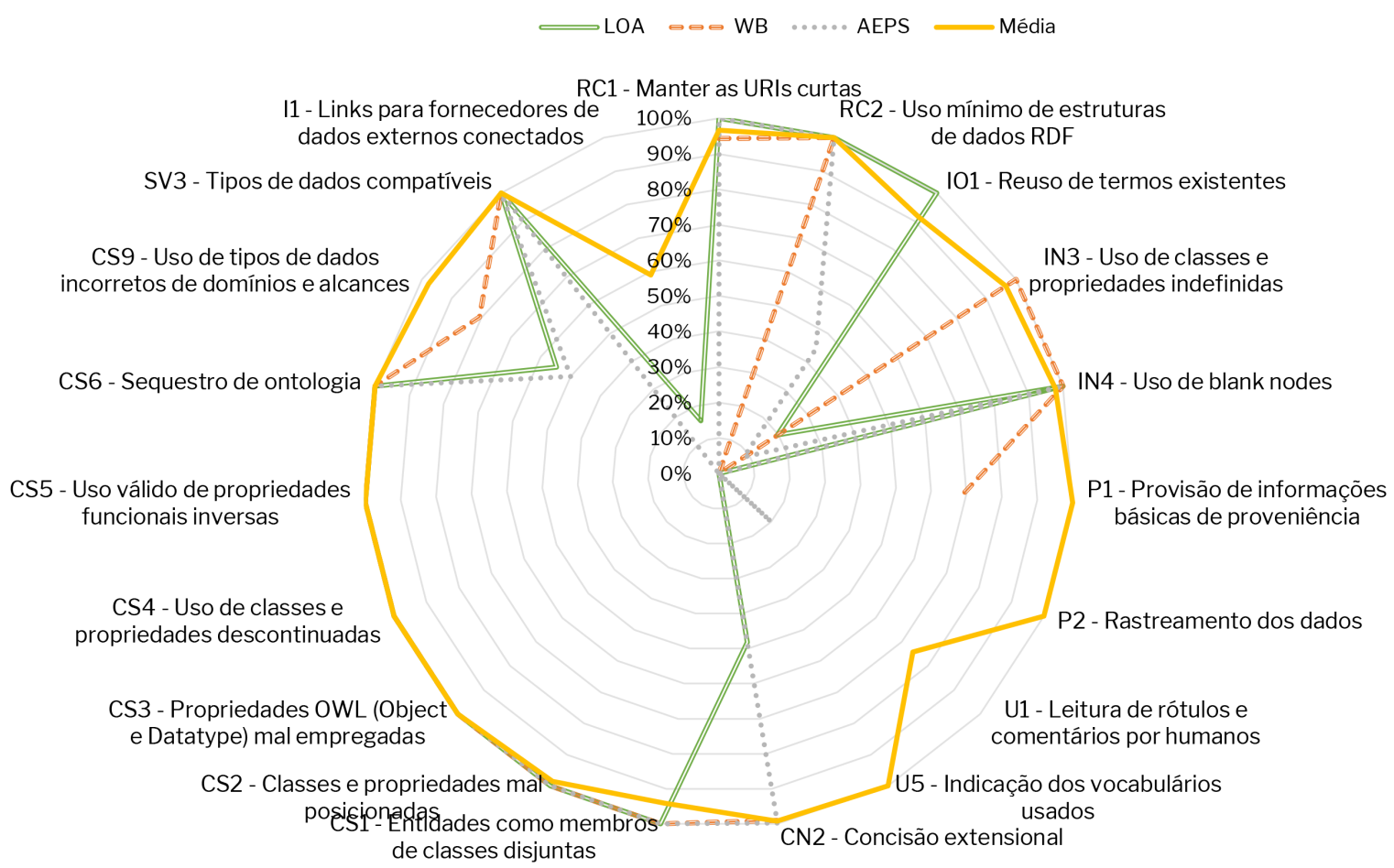

Fonte: Elaborada pelo autor.

Podemos notar, a partir do gráfico e da tabela, que o valor médio das métricas dos participantes se mostra maior ou muito próximo para a maioria das métricas. Na categoria Intrínseca (CN2 a SV3, na tabela), que trata da corretude e coerência dos dados, os valores já 
Tabela 4 - Comparação das métricas de qualidade dos dados conectados gerados pelos participantes com iniciativas oficiais.

\begin{tabular}{|c|c|c|c|c|}
\hline Métrica & Média & $\begin{array}{l}\text { Orçamento } \\
\text { (LOA) }\end{array}$ & $\begin{array}{c}\text { Banco } \\
\text { Mundial } \\
\text { (WB) }\end{array}$ & $\begin{array}{l}\text { Previdência } \\
\text { (AEPS) }\end{array}$ \\
\hline RC1 - Manter as URIs curtas & $96,6 \%$ & $100 \%$ & $94,3 \%$ & $100 \%$ \\
\hline $\begin{array}{l}\text { RC2 - Uso mínimo de estruturas de } \\
\text { dados RDF }\end{array}$ & $100 \%$ & $100 \%$ & $100 \%$ & $100 \%$ \\
\hline IO1 - Reuso de termos existentes & $91,6 \%$ & $100 \%$ & $0,0 \%$ & $44,4 \%$ \\
\hline $\begin{array}{l}\text { IN3 - Uso de classes e propriedades } \\
\text { indefinidas }\end{array}$ & $96,5 \%$ & $19,7 \%$ & $100 \%$ & $8,3 \%$ \\
\hline IN4 - Uso de blank nodes & $97,8 \%$ & $100 \%$ & $100 \%$ & $100 \%$ \\
\hline $\begin{array}{l}\text { P1 - Provisão de informações básicas } \\
\text { de proveniência }\end{array}$ & $100 \%$ & $0 \%$ & $69,1 \%$ & $0 \%$ \\
\hline P2 - Rastreamento dos dados & $100 \%$ & $0 \%$ & ND & $0 \%$ \\
\hline $\begin{array}{l}\text { U1 - Leitura de rótulos e comentários } \\
\text { por humanos }\end{array}$ & $74,3 \%$ & $0,0 \%$ & $20,1 \%$ & $20,0 \%$ \\
\hline $\begin{array}{l}\text { U5 - Indicação dos vocabulários usa- } \\
\text { dos }\end{array}$ & $100 \%$ & $0 \%$ & ND & $0 \%$ \\
\hline CN2 - Concisão extensional & $99,2 \%$ & $48,2 \%$ & $99,1 \%$ & $99,7 \%$ \\
\hline $\begin{array}{l}\text { CS1 - Entidades como membros de } \\
\text { classes disjuntas }\end{array}$ & $94,1 \%$ & $100 \%$ & $100 \%$ & $100 \%$ \\
\hline $\begin{array}{l}\text { CS2 - Classes e propriedades mal po- } \\
\text { sicionadas }\end{array}$ & $98,5 \%$ & $100 \%$ & $99,9 \%$ & $100 \%$ \\
\hline $\begin{array}{l}\text { CS3 - Propriedades OWL (Object e } \\
\text { Datatype) mal empregadas }\end{array}$ & $100 \%$ & $100 \%$ & $100 \%$ & $100 \%$ \\
\hline $\begin{array}{l}\text { CS4 - Uso de classes e propriedades } \\
\text { descontinuadas }\end{array}$ & $99,9 \%$ & $100 \%$ & $100 \%$ & $100 \%$ \\
\hline $\begin{array}{l}\text { CS5 - Uso válido de propriedades } \\
\text { funcionais inversas }\end{array}$ & $100 \%$ & $100 \%$ & $100 \%$ & $100 \%$ \\
\hline CS6 - Sequestro de ontologia & $100 \%$ & $100 \%$ & $100 \%$ & $100 \%$ \\
\hline $\begin{array}{l}\text { CS9 - Uso de tipos de dados incorre- } \\
\text { tos de domínios e alcances }\end{array}$ & $97,7 \%$ & $54,7 \%$ & $80,6 \%$ & $50,0 \%$ \\
\hline SV3 - Tipos de dados compatíveis & $100 \%$ & $100 \%$ & $100 \%$ & $100 \%$ \\
\hline $\begin{array}{l}\text { I1 - Links para fornecedores de da- } \\
\text { dos externos conectados }\end{array}$ & $59,1 \%$ & $15,7 \%$ & ND & $0,0 \%$ \\
\hline
\end{tabular}

Fonte: Elaborada pelo autor.

eram muito altos e foram mantidos. Estão são as características em que validadores já são mais aplicados na prática. 
O maior ganho se deu na categoria Contextual (P1 a U5, na tabela) que agrupa as métricas dependentes da tarefa a ser executada sobre os dados, em termos de relevância, credibilidade da origem, compreensibilidade e atualização dos dados (ZAVERI et al., 2016). Essas informações são pouco produzidas e parece não ter sido dada tanta importância a elas quanto às outras características.

\subsubsection{Limitações}

O delineamento adotado para esta avaliação foi o quasi-experimento de grupo único com pós-teste. A falta de um grupo de controle limita a validação interna dos resultados, ao não estabelecer uma base comparativa direta e não haver controle necessário para demonstrar causalidade. Para minimizar esta limitação, foram escolhidas bases públicas nacionais e internacionais de alta qualidade de dados conectados para sua comparação, conforme comprovada na literatura científica. Tais bases não descrevem se houve alguma metodologia formal para sua criação e organização. No entanto, argumentamos que se trata de uma abordagem válida, uma vez que o objetivo foi demonstrar que, com os artefatos especificados, foi possível chegar a um resultado similar ou superior em relação a métricas de qualidade de dados conectados.

O estudo contou com participantes que demonstraram disponibilidade e interesse para um estudo longo, o que pode ter influenciado positivamente nos resultados. Os participantes do estudo empírico também não apresentaram grande experiência no processo de publicação de dados, tendo atuado apenas em pequenos projetos acadêmicos. É possível que profissionais da área, quando adotarem os artefatos aqui propostos, possam identificar lacunas ou inconsistências sobre as exigências cotidianas da publicação de dados. Futuros trabalhos podem explorar este caminho, da observação da aplicação da infraestrutura proposta em casos reais e ao longo do tempo - particularmente em questões relacionadas à manutenção dos dados.

Foi adotada apenas uma perspectiva de qualidade de dados conectados ao cenário e aos conjuntos de dados de referência. Embora seja a mais detalhada e objetiva do estado da arte, ela aborda um recorte do que pode ser considerado qualidade em um conjunto de dados governamentais e outras perspectivas poderiam ser avaliadas. Arcabouços de qualidade de dados governamentais poderiam também ser aplicados, porém as avaliações encontradas traziam métricas mais relacionadas a questões gerenciais do processo do que à publicação de dados em si (por ex.: avaliando o grau de atualização dos dados disponíveis ou a acurácia dos mesmos em relação aos fenômenos do mundo real representados por esses dados).

Os dados utilizados foram apenas do domínio educacional. Por ele ser um dos mais antigos do governo brasileiro, ele apresenta características particulares, como ter sido depurado ao longo dos anos em relação ao conteúdo e ao formato disponibilizados ao público. Além disso, a maior parte dos dados educacionais são tabulares ou semiestruturados, o que os torna mais simplificados para serem processados. 


\subsection{Considerações finais}

Este capítulo demonstrou e validou dois artefatos da infraestrutura: i) o projeto de uma arquitetura para o compartilhamento de dados seguindo os preceitos do ecossistema da Web e com seus pontos de verificação e ii) o modelo de ciclo de vida, instanciado por meio de um processo para execução de um cenário com exemplo de dados reais.

As evidências coletadas sugerem que os artefatos propostos atendem o objetivo geral posto para esta tese: desenvolver uma infraestrutura de publicação de dados abertos governamentais conectados (DAGC) de qualidade para o ecossistema de dados da Web.

A arquitetura proposta se mostrou robusta para integrar as diferentes perspectivas de publicadores e consumidores de dados, ao especificar quais são os seus componentes e a que requisitos eles atendem com o cenário proposto, atendendo aos princípios de dados abertos governamentais e conectados.

O processo contido no modelo de ciclo de vida se mostrou eficaz quanto ao objetivo de publicar dados de qualidade. Mesmo participantes com pouco conhecimento sobre as tecnologias envolvidas puderam publicar dados usando a arquitetura proposta e apresentando características de qualidade de dados conectados, em um nível semelhante aos melhores conjuntos de dados aferidos na $L O D$ Cloud presentes na literatura.

O modelo de metadados complementou esses outros artefatos, ao atender aos requisitos de qualidade de dados conectados, necessários para fornecer o contexto para que humanos e máquinas possam descobrir, explorar e conectar diferentes fontes de dados. No entanto, seu preenchimento se mostrou uma atividade trabalhosa e manual, propensa a erros.

No próximo capítulo, discutimos as contribuições e conclusões desta tese e revisitamos como os objetivos propostos no Capítulo 1 foram atendidos ao longo deste trabalho. 
CAPÍTULO

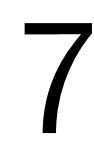

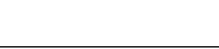

\section{CONSIDERAÇÕES FINAIS}

Neste capítulo são apresentadas as considerações finais desta tese de doutorado. $\mathrm{Na}$ Seção 7.1 é feita uma compilação das principais conclusões obtidas com a metodologia adotada e com a infraestrutura proposta. A Seção 7.2 traz potenciais contribuições teóricas e práticas em torno da ciência do design, da publicação de DAGC e de sua infraestrutura de suporte. $\mathrm{Na}$ Seção 7.3 revisitamos as questões de pesquisa postas no Capítulo 1 e como elas foram respondidas ao longo desta tese. A Seção 7.4 traz um conjunto de desafios encontrados e ainda persistentes na área de publicação de DAGC e que podem ser pesquisadas em trabalhos futuros na área. A Seção 7.5 aborda algumas das principais limitações relacionadas a este estudo. Por fim, a Seção 7.6 lista as publicações geradas ao longo desta tese e em projetos correlatos.

\subsection{Conclusões}

A disponibilidade de dados abertos governamentais tem crescido em quantidade e qualidade na última década e sua utilização pela sociedade como um todo (cidadãos, empresas, ONGs, infomediários, etc.) tem sido importante para sua constante expansão. No entanto, ainda existem diversos desafios quanto ao reaproveitamento desses dados, como a interoperabilidade entre diferentes fontes de dados e a adoção de boas práticas para facilitar o compartilhamento e o consumo de dados usando a arquitetura já existente da Web. É neste cenário que as tecnologias da Web Semântica e dos dados conectados podem contribuir para aumentar o valor dos dados disponíveis.

Este trabalho se insere na pesquisa e na prática da área de publicação de dados abertos governamentais, ao trazer contribuições para a produção de DAG visando a Web de dados. Como investigado na literatura, algumas lacunas foram identificadas e exploradas nesta tese: a especificação detalhada de um modelo de ciclo de vida, desde a especificação dos dados até a manutenção desses dados para seu consumo a longo prazo; a qualidade durante o processo de publicação como um princípio básico do governo aberto, para que cidadãos possam confiar nos 
dados disponibilizados; a exploração da Web como meio de publicação de dados, garantindo a consistência em estilo e extraindo todo o potencial da Web como uma plataforma para conectar fatos uns aos outros.

Para cobrir essas lacunas, buscamos na literatura por teorias e corpos de conhecimento que pudessem fornecer princípios para a criação de artefatos que atendessem a esses princípios e requisitos. Mais que apenas um artefato, foi necessário especificar e desenvolver um conjunto de artefatos que formam uma infraestrutura de publicação de DAGC, para abordar tanto seus aspectos estruturais (de especificação e organização de componentes e suas funcionalidades, exemplificados aqui por uma arquitetura conceitual e um modelo integrado de metadados) quanto seus aspectos dinâmicos (de conjunto ordenado de atividades, adotado aqui como um modelo de ciclo de vida de publicação dos dados, enriquecidos de modo iterativo conforme a evolução dos dados publicados).

A arquitetura se mostrou flexível e, ao mesmo tempo, robusta. Flexível no sentido de se adaptar facilmente aos contextos propostos sem grandes modificações. Acreditamos que ela possa ser estendida sem grandes modificações a cenários emergentes na literatura como os dados abertos conectados de grande escala (BOLD) e os dados provenientes de sensores, como para a Internet das Coisas (IoT). E robusta ao atender a quase todas as práticas recomendadas pela DWBP, pela qual ela foi avaliada. Ao conceber a premissa da DWBP de que os dados devem ser buscáveis, acessíveis e processáveis tanto por máquinas quanto por humanos, a arquitetura proposta fez com que dois grandes componentes de serviço de dados tivessem que ser empregados (triplestore e catálogo de dados), já que cada um deles é especializado em uma finalidade. Isso adiciona complexidade à sua implementação, já que são softwares diferentes, com diferentes regras de configuração e controle de acesso. Muitos desafios técnicos ainda estão presentes, em particular para o tratamento de grandes quantidades de dados. $\mathrm{O}$ formato de triplas não é otimizado para armazenamento e padrões como o HDT (Header-Dictionary-Triples) têm sido propostos ${ }^{1}$ para diminuir o espaço exigido por dados triplificados, sem perder suas características semânticas. Além disso, muitas das ferramentas citadas na literatura não são mais mantidas, o que impede ou complica sua aplicação em casos reais.

Os resultados de nosso estudo empírico sugerem que a arquitetura é implementada com relativa facilidade por pessoas com experiência em computação. Ao seguir os passos propostos, foi possível instanciar a arquitetura e fazer uso do modelo de metadados para atingir o objetivo de dados conectados de alta qualidade. Houve pequenas modificações em relação à ordenação do processo, com algumas atividades mudando de fase até chegar no modelo proposto no Capítulo 5. Embora ele tenha sido proposto de forma linear, considerando apenas o ciclo de feedback em futuras iterações, durante sua aplicação ficou evidente que na prática ele é feito de modo iterativo, tenho a fase de Modelagem como seu principal ponto focal. Certos erros ou inconsistências ocorridos nessa fase são percebidos em fases posteriores e demandam 
que o publicador volte até essa fase para realizar as adequações. $\mathrm{O}$ resultado do processo, os dados conectados, apresentaram características de qualidade de nível comparativo a alguns dos conjuntos de dados reconhecidamente de alta qualidade, sendo até mesmo melhores em determinadas dimensões.

Outros modelos de ciclo de vida para publicação de DAGC foram propostos, na mesma direção que o modelo proposto nesta tese, como os de Charalabidis et al. (2018), Ávila (2015), van den Broek, van Veenstra e Folmer (2014) e Necaský et al. (2014). O trabalho de Necaský et al. (2014) apresenta um modelo parecido com o aqui proposto, ao trazer papeis, fases e atividades; porém ele é mais reduzido em certos aspectos. Por exemplo: a fase de publicação e exploração não são abordadas. Neste modelo, o controle da qualidade também é contemplado, mas não foi detalhado como realizá-lo. van den Broek, van Veenstra e Folmer (2014) trazem um modelo com foco no alinhamento estratégico dos dados, validado por meio de estudo de caso, apresentando fases similares às apresentadas nesta tese, diferenciando apenas pela inexistência da fase de manutenção. Como outro limitante, os autores não detalharam como se dão as atividades do processo. O trabalho de Ávila (2015) se concentra mais em questões de gestão do processo e do nível de maturidade organizacional, contendo atividades da LD-BP (W3C, 2014a) e o modelo de 5 estrelas. $\mathrm{O}$ autor apresenta um processo mais granular em termos de atividades, mas não detalha papéis e ferramentas. Charalabidis et al. (2018) também compartilha da visão do ecossistema de dados, indo além da simples acessibilidade aos dados, e propõe um modelo de ciclo de vida que espelha a publicação e o consumo dos dados. Além disso, seu modelo contempla big data e Web 2.0, habilitando mecanismos mais sofisticados para coleta de feedback dos consumidores dos dados. No entanto, não trazem os artefatos de suporte para sua operacionalização (ferramentas, arquitetura e metadados) e não os avalia.

De modo geral, esta tese estende a literatura ao detalhar um modelo de ciclo de vida de publicação de DAGC que incorpora os princípios técnicos do ecossistema de dados e controle de qualidade. Além disso, de forma complementar, propõe outros artefatos de suporte como o uso da arquitetura conceitual e o modelo de metadados, visando como resultado dados conectados de qualidade. Do ponto de visto metodológico, ela estende a literatura ao usar os princípios de DSR para a criação deste tipo de artefatos.

Os metadados desempenharam um papel crucial nesta infraestrutura. Como uma das premissas da Web Semântica é o processamento automático por agentes de software, a escolha de metadados é fundamental. Por meio deles, os agentes podem descobrir que tipos de protocolos são aceitos e estão disponíveis, quais padronizações foram adotadas, como as informações estão estruturadas, licenciadas e versionadas e podem, com isso, decidir a melhor forma de processar os dados. No entanto não foram encontradas ferramentas eficientes para a gestão desses metadados, tornando o processo manual e propenso a erros e sendo percebido como um dos pontos mais trabalhosos de todo o processo. 


\subsection{Contribuições desta pesquisa}

Esta seção sumariza e revisa as contribuições desta tese. No Capítulo 1 foram evidenciados alguns problemas apontados pela literatura: i) os processos atuais são considerados genéricos, no sentido de apresentarem práticas de alto nível para os passos da publicação de dados. Como resultado, são adotadas abordagens $a d-h o c$, que se baseiam nos princípios básicos dos dados conectados como forma de pautar o processo de publicação; ii) a baixa qualidade dos dados produzidos - aqui considerada tanto em relação aos atributos estruturais, sintáticos e semânticos dos dados, quanto à sua utilidade junto os consumidores finais dos dados - que demonstra padrões recorrentes de defeitos gerados durante o processo; iii) a falta de adoção de práticas de compartilhamento de dados tendo a Web e sua arquitetura básica como meio de troca. Ao mesmo tempo, no contexto governamental, a publicação de dados deve atender aos princípios de governo aberto, considerado como um pilar moderno da democracia.

Nesta tese, buscamos atender ao tratamento destes problemas. Primeiro, ao propor um modelo de processo de publicação de DAGC. De fato, é um grande desafio encontrar o ponto ótimo de prescrição de passos, padrões e ferramentas para as atividades de um processo. Por um lado, sugerir passos muito abstratos pode afastar profissionais de publicação de DAG(C), que devem se aprofundar em cada um dos passos para poder executá-los apropriadamente. Com restrições de pessoal, capacitação e de recursos para a publicação de dados, é algo difícil de acontecer. Pelo outro lado, ao sugerir passos muito restritos, corre-se o risco de se ajustar às práticas de apenas um determinado cenário, não permitindo sua generalização. Buscamos nesta tese encontrar um ponto de equilíbrio, ao detalhar cada uma das atividades envolvidas e propor um conjunto de passos, ferramentas e verificações. A especificação de uma fase de manutenção também pode ser considerada uma contribuição, já que as metodologias existentes trataram de forma superficial essa etapa.

Segundo, ao propor mecanismos de controle de qualidade inserido ao longo deste ciclo de vida, verificando as características dos produtos intermediários a cada passo. Como identificado na revisão da literatura, existia a lacuna de embutir atividades sistemáticas de controle de qualidade. Assim, buscamos encontrar quais mecanismos deveriam ser aplicados e em quais momentos do processo de publicação. Embora muitas das ferramentas referenciadas na literatura desta área tenham sido descontinuadas, outras têm surgido recentemente e com um alto grau de flexibilidade e atendimento a padrões recentes como SHACL, DQV e arcabouços de métricas de qualidade.

Terceiro, ao incorporar um conjunto de boas práticas, compilados pela própria comunidade, para o compartilhamento de dados na Web (a recomendação Data on the Web Best Practices), de modo que tanto humanos quanto agentes de software possam descobrir, avaliar e conectar dados, usando a infraestrutura e os padrões consolidados da Web. Entretanto, conforme 
apontado no relatório de implementação da $\mathrm{DWBP}^{2}$ e em Penteado, Bittencourt e Isotani (2019a), são necessários diferentes frentes de esforços para atender a essas práticas.

Aqui citamos as práticas que dependem: i) da infraestrutura de componentes de software, principalmente os que hospedam os dados e que os servem para que usuários possam consumi-los; ii) da modelagem dos dados, ao fazer com que os dados sejam semanticamente anotados, reutilizando vocabulários e ligados a outras fontes de dados; iii) dos metadados, que fornecem o contexto para descrever as características sobre os dados disponibilizados.

Além disso, esse conjunto de práticas traz outros dois princípios desafiadores: i) atender a humanos e máquinas, que podem obter os mesmos dados e metadados de diferentes formas e ii) utilizar padrões da Web, sem a necessidade de novas ferramentas ou protocolos específicos para esta finalidade.

Para isso, lançamos mão de teorias kernel que trouxeram corpos de conhecimento que puderam fundamentar o projeto e desenvolvimento dos artefatos. Por meio dessas teorias foram fornecidos conhecimentos que deram a base e a explicação para o design dos artefatos. Duas dimensões foram consideradas: a estrutural e a dinâmica, ao propor componentes estruturais, por meio da arquitetura conceitual e do modelo de metadados mínimos a serem usados para montar a infraestrutura de DAGC. De forma complementar, foi proposto um modelo de processo para instanciar essa infraestrutura e gerar os dados em formato conectado.

A Figura 38 ilustra a organização desses conceitos. Os princípios dos dados abertos governamentais conectados, foram transformados em requisitos mínimos para o resultado do processo, conforme apontado no Capítulo 2. Com base nesses requisitos foram selecionadas as teorias kernel que atendessem a esses requisitos e que forneceram os princípios para a criação dos artefatos propostos nesta tese.

\subsubsection{Objetivos específicos}

Desta forma, argumentamos que as contribuições desta tese atendem ao objetivo geral de desenvolver uma infraestrutura de publicação de dados abertos governamentais conectados (DAGC) de qualidade para o ecossistema de dados da Web.

A seguir, revisitamos os objetivos postos no Capítulo 1.

1. Compreender como as iniciativas de dados abertos governamentais evoluíram no governo federal brasileiro, como exemplo ilustrativo da complexidade organizacional em que um processo deste tipo está inserido;

No Capítulo 3 trouxemos uma perspectiva formativa sobre os DAG no Brasil. Como parte da análise histórica da evolução dos dados abertos no Brasil, pudemos entender como eles foram concebidos, como se relacionaram a outras iniciativas ao redor do mundo

$2<$ https://w3c.github.io/dwbp/dwbp-implementation-report.html> 
Figura 38 - Relacionamento dos conceitos trabalhados nesta tese.

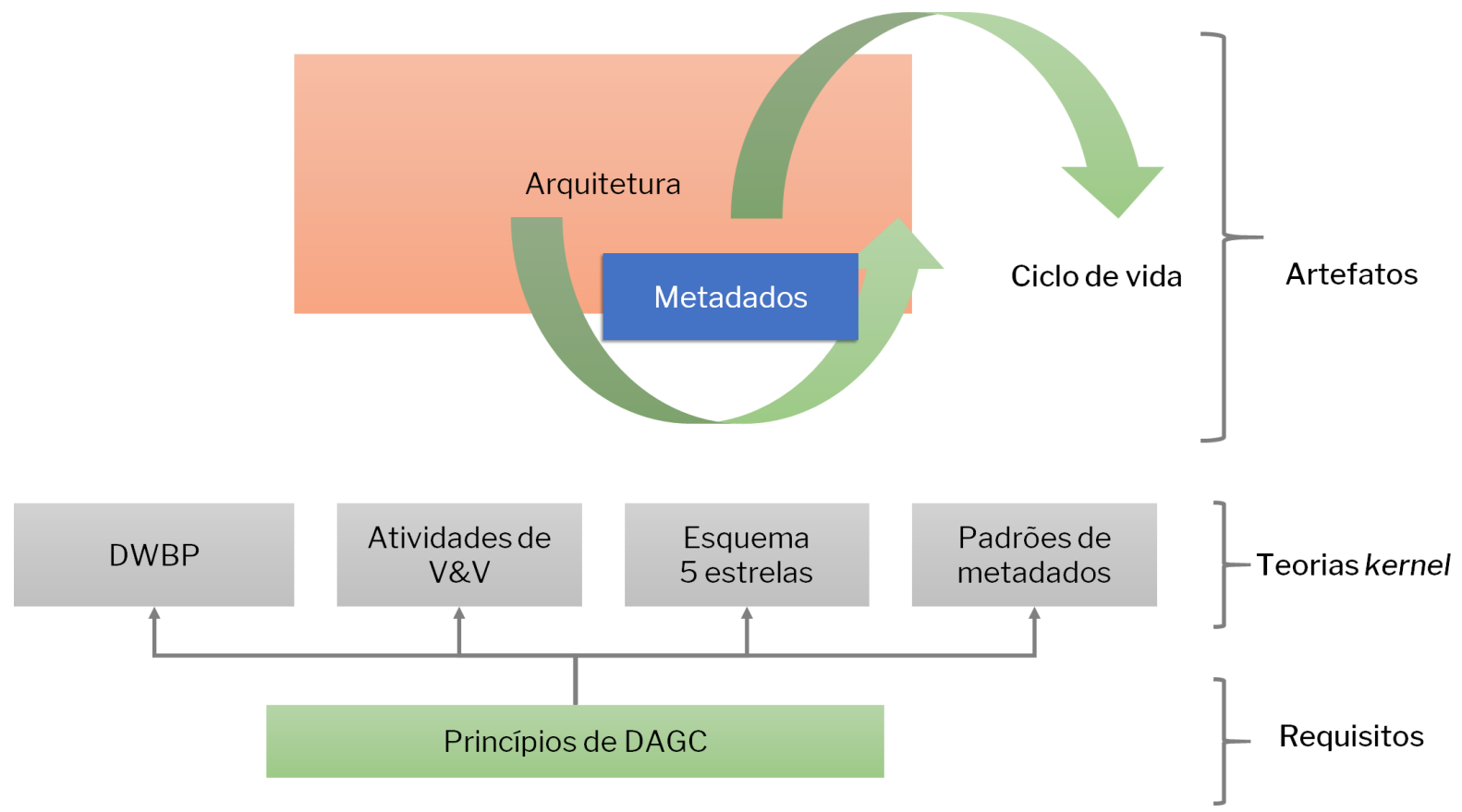

Fonte: Elaborada pelo autor.

e quais os principais fatores legais, institucionais ou tecnológicos que impulsionaram esta iniciativa. Acreditamos ser importante para que futuros pesquisadores ou praticantes possam compreender quais são as contingências e complexidades que moldaram e que ainda influenciam a publicação de dados abertos no Brasil (conectados ou não), devendo ser considerados para futuras intervenções.

2. Identificar como os processos do estado da arte operacionalizam a publicação dos DAGC;

No mapeamento sistemático da literatura do Capítulo 3, pudemos levantar quais foram as metodologias propostas, qual o núcleo comum de atividades, quais as diferenças entre elas, as ferramentas usadas ou sugeridas para conduzi-las, como foi feito o controle de qualidade ao longo do processo e como elas foram avaliadas. Com isso pudemos mapear as lacunas da literatura para avançar nesta área bem como os desafios tecnológicos e operacionais.

3. Propor uma arquitetura conceitual para a publicação e o compartilhamento de dados na Web que contenha práticas que atendam às necessidades dos DAGC, em termos de requisitos de compartilhamento e controle de qualidade;

A arquitetura proposta no Capítulo 5 apresentou os componentes que permitem integrar os diferentes componentes da infraestrutura de publicação, com recursos dispostos localmente ou na Web, e permitindo que os dados sejam disponibilizados de diferentes formas para consumo - por humanos ou máquinas. A arquitetura foi instanciada com um cenário ilustrativo a partir de dados reais e avaliada de acordo com um checklist sobre as práticas da recomendação DWBP e práticas de verificação dos produtos intermediários do processo. 
4. Especificar detalhadamente como cada atividade pode ser atendida, em termos de tarefas, ferramentas, verificações e papéis envolvidos;

Foi proposto o modelo de ciclo de vida detalhado no Capítulo 5 e no apêndice A. Foram sugeridos diferentes modos de executar as atividades seguindo uma ordenação prédeterminada, além de ferramentas de suporte e quais possíveis verificações a serem feitas a cada passo. As práticas de compartilhamento de dados que dependem da modelagem ou dos metadados também são mapeados no processo. Espera-se, com isso, melhorar a percepção de que as metodologias existentes são muito genéricas. O modelo de processo foi avaliado empiricamente por participantes que o utilizaram para publicar dados sobre a arquitetura.

5. Desenvolver e validar o modelo de ciclo de vida. O uso da metodologia nesta demonstração deve ser útil também como referência e guia prático.

No Capítulo 6, avaliamos os artefatos propostos em cenários ilustrativos e por meio de um estudo empírico com usuários que puderam publicar dados em seu formato conectado. Do ponto de vista da prática, argumentamos que ela pode ser usada para ilustrar como instanciar a infraestrutura de publicação de DAGC em diferentes contextos.

\subsection{Respostas às questões de pesquisa}

Discutimos nesta seção as descobertas de nosso estudo para cada uma das questões de pesquisa.

QP1 - Quais são os problemas encontrados com DAGC?

Conforme apresentado no início deste capítulo, detalhamos os principais problemas tecnológicos relacionados a DAGC e presentes na literatura:

- i) a percepção de que as metodologias atuais são muito genéricas;

- ii) os problemas recorrentes de qualidade em diferentes aspectos, como na representação, na disponibilidade, na validade sintática e semântica e na dimensão contextual;

- iii) a baixa adoção de práticas recentes de compartilhamento de dados na Web, reaproveitando seus princípios arquiteturais.

Outros fatores podem ser considerados como barreiras ou impeditivos em outras dimensões que não a técnica, como a falta de políticas de dados abertos, de financiamento e de organização, dentre outras.

QP2 - Quais são as metodologias de produção de DAGC atuais?

Ao revisar a literatura existente dessa área, foi levantado como as metodologias existentes estabeleceram seus processos de publicação de dados conectados, especificando cada atividade 
relacionada, quais foram as ferramentas adotadas, quais foram os controles de qualidade adotados e como as metodologias foram empiricamente avaliadas. Foi descoberto um núcleo de atividades comuns aos processos propostos, muito relacionado aos princípios básicos dos dados conectados. No entanto, outros passos foram propostos buscando tornar a sua publicação mais que uma mera conversão de dados brutos em dados semânticos e colocá-los na Web. Alguns desses passos, inclusive, foram posteriormente adotados como boas práticas para compartilhamento de dados na Web. Outra lacuna encontrada foi quanto à adoção sistemática de controle de qualidade durante o processo de publicação. Poucas metodologias especificaram explicitamente essas atividades. Os que o fizeram, isolaram as atividades em uma fase ao final do processo, geralmente verificando aspectos sintáticos do RDF gerado.

QP3 - Quais são os requisitos para uma infraestrutura que gere DAGC de qualidade para o ecossistema de dados na Web?

Para estabelecer os requisitos fundamentais para a publicação de DAGC, buscamos formalizar em forma de requisitos os princípios de dados abertos, governo aberto, dados abertos governamentais e dados conectados. Esses princípios, em sua maioria, foram formulados e aprimorados pela própria comunidade (representantes de governos, ativistas, pesquisadores de diferentes áreas, empreendedores), logo sua validade externa é levada em consideração.

QP4 - Que elementos caracterizam uma infraestrutura que gere DAGC de qualidade para o ecossistema de dados na Web?

Os requisitos levantados na $Q P 3$ foram agrupados e foram buscados elementos para auxiliar no design de artefatos que pudessem atender a esses requisitos. Foi escolhido um conjunto que pudesse atender às diferentes perspectivas técnicas que delimitavam os requisitos, concebidas como teorias kernel para guiar as decisões de design e fornecer princípios para seu desenvolvimento. Para isso, as seguintes teorias kernel foram selecionadas e integradas aos requisitos básicos:

- i) o ecossistema de dados, teoria incipiente sobre a organização e evolução sociotécnica do compartilhamento de dados, aqui concretizado por meio das práticas da DWBP;

- ii) a garantia da qualidade, que estabelece mecanismos, padrões e práticas para melhoria e avaliação de processo e de produto;

- iii) os metadados, que trazem conceitos e padrões que foram utilizados para caracterizar melhor os dados, uma vez que se espera que os mesmos sejam descobertos e manipulados por agentes autônomos de software;

- iv) o esquema 5-estrelas, para delimitar os padrões técnicos a serem adotados quanto ao formato dos dados produzidos. 
QP5 - Como é a infraestrutura desenvolvida que gera DAGC de qualidade para o ecossistema de dados na Web?

No Capítulo 5 detalhamos os artefatos principais para a infraestrutura proposta. Foi apresentado o modelo de ciclo de vida com seu processo embutido, indo desde a especificação de insumos, padrões, diretrizes e recursos tecnológicos, passando pela modelagem semântica dos dados, sua conversão e ligação a outras fontes de dados, até a publicação, exploração e manutenção dos dados. Para cada uma das fases foram especificadas atividades com suas respectivas entradas, saídas, possíveis ferramentas e verificações a serem feitas. Foi mapeado também um conjunto de papéis para conceber a execução do processo, agrupados por meio dos conhecimentos específicos necessários em cada atividade. De modo geral, foi proposto também um racional de decisão de ferramentas que podem ser utilizadas em diferentes contextos de publicação, baseado na literatura e na experiência prática do pesquisador. Para organizar os diferentes artefatos produzidos durante o processo, foi proposta uma arquitetura que fornece os subsídios para a publicação dos dados ao mesmo tempo que oferece diversidade de consumo para os usuários desses dados. Por fim, foi compilado um grupo mínimo de metadados, que atendesse às necessidades de descrição dos catálogos e conjuntos de dados, de qualidade de dados conectados e do ecossistema de dados.

QP6 - Qual a eficácia da infraestrutura desenvolvida em relação à qualidade e ao ecossistema de dados na Web?

Por fim, avaliamos como os artefatos gerados foram instanciados para atender aos requisitos básico de DAGC. Para ilustrar a viabilidade da arquitetura, instanciamos um cenário ilustrativo com dados reais do domínio educacional, a partir do qual foram criados e configurados cada componente, gerados como parte do processo. Em sua validação, utilizamos listas de verificação com as práticas da DWBP e da qualidade de software - utilizados como proxy para os requisitos básicos de DAGC. Para analisar a apropriação do processo, investigamos como potenciais profissionais desempenharam as atividades de processo propostas, por meio de um estudo empírico em que os participantes exercitavam a publicação de dados de um cenário simples. Em relação ao processo, as evidências sugerem que o processo foi adequado, porém com possibilidades de melhorias em especial na produção correta dos metadados necessários. Em relação ao produto final, avaliamos em relação a métricas especificamente desenvolvidas para avaliação de dados abertos conectados e os resultados foram consistentes em demonstrar altos níveis de qualidade, quando comparados aos encontrados na literatura.

\subsection{Desafios na área de publicação de DAGC}

A seguir são descritos alguns desafios encontrados durante o desenvolvimento desta pesquisa e ainda presentes na área de publicação de dados conectados. 


\subsubsection{Ferramentas}

A revisão da literatura conduzida no Capítulo 3 mapeou quais foram as ferramentas recomendadas ou utilizadas nos processos e metodologias desenvolvidas para a publicação de DAGC. No entanto, ferramentas comumente referenciadas na literatura encontram-se descontinuadas (código-fonte disponível, mas com necessidade de compilação, como por exemplo sitemap4rdf, RDFUnit) e muitas vezes indisponíveis (por exemplo: sameAs LinkValidator, Vapour, RDFAlerts, DSNotify, dentre outros).

Ficou evidente durante o estudo empírico que existe a necessidade de ferramentas para a criação e o gerenciamento de metadados. Não foram encontradas ferramentas para esta finalidade. Ainda que possível, a utilização de ferramenta de modelagem semântica como Protégé ou de ferramentas de edição de texto como Notepad++ trazem limitações devido ao tamanho dos metadados e de suas características de representação RDF e seus mapeamentos semânticos. Muitos dos problemas dos metadados vêm de erros gerados a partir do preenchimento incorreto dos dados. A escalabilidade também traz desafios, uma vez que o número de metadados é proporcional à quantidade de conjuntos de dados presentes no repositório. Mesmo no cenário simples aplicado no estudo empírico, a quantidade de metadados a ser preenchida era muito grande. Além disso, a presença dos conjuntos de dados em mais de uma plataforma (ex.: CKAN e Fuseki) traz o problema da replicação dos metadados entre as plataformas.

De modo geral, o processo proposto ainda é muito manual e pode ser otimizado. Uma vez que ele é bem estruturado, é possível criar ferramentas para suportá-lo, automatizando parte de suas atividades. Nesta direção, Oliveira et al. (2018) propuseram um modelo de referência para gerenciamento de dados na Web e que pode ser usado em conjunto com os artefatos desta tese para facilitar a implementação de uma infraestrutura otimizada de publicação de DAGC.

\subsubsection{Práticas da DWBP}

Algumas práticas se mostraram subjetivas para implementação sistemática em um processo. Por exemplo, as práticas relacionadas à republicação de dados, como fornecer feedback ao publicador original. Foram propostos mecanismos que notificam automaticamente o uso de dados, como em Popitsch e Haslhofer (2010). Porém, no cenário conectado, fica mais difícil mapear quem usa os dados, já que os dados podem ser automaticamente estendidos.

Embora um dos princípios da DWBP seja o consumo de dados por humanos e máquinas, ele é de difícil implementação. Um dos desafios é como fazer com que os dados e os metadados estejam disponíveis nestes dois padrões de consumo. Nesta tese, esse princípio foi parcialmente tratado, já que foi necessário replicar os dados para que fossem consumidos pelos dois tipos de consumidores. Uma possível solução seria o desenvolvimento de extensões ao catálogo de dados que, ao apresentar os dados e metadados em página HTML (para humanos) também os disponibilizassem em formato RDFa, ou seja, com mapeamento semântico nas tags HTML, 
podendo ser automaticamente interpretados por máquinas.

$\mathrm{O}$ atendimento às práticas traz atividades em diferentes dimensões: seja por meio do catálogo de dados que os servem (acesso aos dados, preservação dos dados, armazenamento e gerenciamento de dados e metadados, interface com o usuário, interação com comunidade), pela modelagem dos dados (identificadores, formatos, vocabulários, enriquecimento) ou pela organização dos metadados (metadados estruturais e descritivos, proveniência, qualidade, licenciamento, versionamento, etc.).

\subsubsection{Dados conectados no governo}

Um dos pontos principais para a publicação de dados conectados diz respeito ao reaproveitamento de vocabulários e ontologias existentes para o domínio a ser representado. No entanto, são poucos os vocabulários que podem ser considerados maduros e que realmente se encaixam em um determinado contexto. Conjuntos de dados governamentais costumam trazer muitas informações (até mesmo centenas de colunas em um arquivo tabular), fazendo com que o processo de seleção de vocabulários seja extenso. Embora repositórios como o LOV possam ser usados para registrar e consultar possíveis casos de reaproveitamento, a maior parte dos dados não é prontamente mapeada para esses vocabulários, sendo necessária a criação de vocabulários complementares. Todavia, a criação de ontologias é um processo muito caro e demorado, pois envolve profissionais especialistas de domínio por muito tempo e que devem entrar em acordo em torno dos conceitos sendo modelados. Como a disponibilidade de DAG já é grande, futuros trabalhos podem ser desenvolvidos para extrair vocabulários a partir de dados já existentes, de forma semiautomática ou que evoluam de forma colaborativa.

Os dados conectados parecem ainda estar em fase de provar sua utilidade prática. Experiências recentes na Comissão Europeia têm conduzido estudos piloto em determinadas áreas governamentais para explorar a viabilidade das tecnologias envolvidas para a interoperabilidade semântica entre diferentes membros da comunidade ${ }^{3}$. Como o esforço em termos de infraestrutura, ferramentas e capacitações é grande, deve-se ter muito claro quais são os benefícios de se publicar DAG em formato conectado.

As barreiras já mapeadas na literatura de DAG (falta de recursos humanos, financeiros, infraestrutura) parecem ainda ser um grande obstáculo para a implementação de dados conectados. Pressões por parte de órgãos fiscalizadores, agentes políticos e da comunidade de dados fazem com que o foco atual de publicadores seja o de atender à demanda, cada vez maior, por dados.

$3<$ https://joinup.ec.europa.eu/collection/semantic-interoperability-community-semic/ linked-data-showcase-lds-pilot-value-interlinking-data> 


\subsection{Limitações e trabalhos futuros}

Esta tese traz contribuições importantes para a área, mas é necessário também compreender suas limitações. Esta seção explora algumas delas, sugerindo possíveis pesquisas futuras na área.

A seleção, compilação e transformação dos princípios de dados abertos, governamentais e conectados foram feitas pelo pesquisador, de acordo com sua experiência e subjetividade. A replicação por diferentes pesquisadores pode trazer resultados diferentes ou serem complementados por outros princípios. Do mesmo modo, as teorias kernel selecionadas não atendem a todos os requisitos, podendo ser adicionadas outras teorias ou mesmo substituindo as abordadas nesta tese, levando a diferentes implementações dos requisitos.

Mapeamentos sistemáticos da literatura trazem consigo suas próprias limitações. $\mathrm{O}$ número baixo de artigos retornados pode ser devido a diferentes fatores, como a escolha dos termos-chave e seus sinônimos, já que outros trabalhos podem ter usados termos não cobertos pela string executada nas bases de dados. Também não foram incluídos resultados de mecanismos de busca genéricos (ex.: Google) ou de execução manual em determinadas conferências ou periódicos que não estivessem indexados nas bases de dados selecionadas. Além disso, não foram feitas revisões sistemáticas sobre as ferramentas disponíveis para as atividades de publicação de DAGC. Embora no Capítulo 3 tenham sido levantadas ferramentas da literatura, elas ficaram restritas às ferramentas mencionadas em artigos que tinham como foco os processos de publicação. Assim, outras ferramentas relevantes a essa finalidade podem não ter sido consideradas.

A metodologia Design Science Research postula que devem ser testadas teorias de sentido mais estrito, de caráter preditivo e explicativo, geralmente de áreas do comportamento humano e organizacional, explicando como o artefato impacta ou é impactado pelos construtos teóricos selecionados. Nesta tese, usamos uma definição mais flexível do que seriam essas teorias, considerando-as como um corpo de conhecimento que incorpora práticas, padrões, tecnologias e conceitos. Foi feita esta escolha pois as teorias envolvidas na engenharia de produção de dados abertos e de seu ecossistema de dados são ainda incipientes, não apresentando um corpo teórico que possibilite a derivação de hipóteses a serem testadas empiricamente e com rigor estatístico.

Foi feito um estudo empírico para avaliar a eficácia do uso em atingir os objetivos de qualidade e requisitos. Entretanto, o modelo de ciclo de vida ainda não foi validado em casos reais e nem comparado com o uso de outras metodologias devido a restrições de recursos disponíveis (tempo, orçamento e disponibilidade de casos reais). A comparação realizada foi entre os requisitos que este modelo atende frente aos requisitos de outras metodologias da literatura, as quais não integram as diferentes áreas propostas neste trabalho (qualidade, metadados e ecossistema). Desse modo, ainda não é possível concluir quantitativamente as vantagens de utilizar a metodologia criada. A generalização dos resultados para outros participantes também deve ser melhor explorada, especialmente porque a formação de profissionais de publicação de 
dados é diversificada - logo, o modelo de ciclo de vida deve ser familiar a pessoas de outras formações e características demográficas.

A infraestrutura proposta nesta tese buscou atender aos requisitos e exigências de um cenário governamental. Logo, a validação mais apropriada dos artefatos produzidos deve ser feita pela incorporação dos artefatos em projetos de DAGC reais. No entanto, não foi possível encontrar órgãos oficiais que demonstraram abertura para um estudo aprofundado. Como percebido pelo autor desta tese, as equipes de publicação de DAG são pequenas (geralmente uma pessoa, com auxílio pontual de outras) e com uma demanda cada vez maior pela publicação de novos conjuntos de dados, até mesmo por força de lei. Por se tratar de um processo complexo, que demanda novos conhecimentos - em especial de tecnologias semânticas - era exigido grande esforço desses profissionais em um cenário real.

O cenário validado no estudo empírico foi simples, em termos de i) formatos dos arquivos: embora tenham sido usados os casos típicos em DAG (CSV e planilha tabulares), outros tipos de formatos poderiam ter sido utilizados, como PDF, XML, JSON ou GeoJSON; ii) conteúdo das informações: foram utilizados dados tabulares. Outros tipos de conteúdos poderiam ter sido utilizados, como campos contendo informação textual (por ex.: textos de leis), textos ricos (por ex.: HTML ou XML) ou dados geográficos (por ex.: polígonos espaciais); iii) dinamicidade da informação: foram usados conjuntos de dados de baixo grau de atualização; iv) domínio: foi trabalho apenas um cenário educacional, por motivo de conhecimento do pesquisador. Outros conjuntos dados poderiam ser usados, até mesmo os que se aproximassem de dados em tempo real (por ex.: APIs de indicadores financeiros). A opção do cenário simplificado foi de diminuir a complexidade inerente ao um processo já demorado, que demanda diferentes ferramentas e conhecimentos.

A aferição da qualidade de dados conectados adotada na avaliação do modelo de ciclo de vida traz apenas um recorte do que pode ser considerada qualidade em DAGC. Devido à sua natureza contextual, diferentes fatores podem pesar para o julgamento sobre o que é um dado de qualidade. Buscamos na literatura recente da área um possível arcabouço genérico para esta avaliação, que trouxesse indicadores objetivos mensuráveis a partir dos dados. No entanto, estamos cientes de que diferentes aplicações em diferentes contextos podem usar outros tipos de indicadores e considerar dados de alta qualidade mesmo sem atender a alguns dos critérios selecionados. Além disso, outras formas de avaliação de verificação de qualidade poderiam ser testadas, como a implantação de defeitos nos dados. No entanto, dado o baixo conhecimento em tecnologias semânticas, não era possível que os participantes soubessem a origem do erro e tivessem o conhecimento para consertá-lo em tempo viável para um estudo.

O modelo de processo proposto neste ciclo de vida segue uma abordagem mais próxima das metodologias em cascata de desenvolvimento de software, com fases muito bem definidas, grande foco no planejamento e pouco feedback dos usuários dos dados. Algumas iniciativas recentes, como em Meissner e Junghanns (2016), têm sido propostas na direção de desenvolver 
processos ágeis, adotando princípios como a de integração automática de dados, entregas contínuas, maior interação com clientes e maior foco no produto do que no planejamento. Enquanto algumas das práticas ágeis podem ser integradas ao modelo proposto, deve-se levar em consideração que o cenário governamental traz uma série de contingências que devem ser atendidas, em termos de legislação, planejamento e imparcialidade (para o caso de não priorizar certo grupo de usuários em detrimento a outros). Outro limitante foi a ausência de avaliação das atividades de manutenção, que envolveriam a simulação de tarefas operacionais de manutenção ou seu uso contínuo por longos períodos de tempo.

\subsection{Principais publicações e trabalhos correlatos}

A seguir, uma lista de publicações de autoria do pesquisador realizadas durante o período desta tese.

\subsubsection{Periódicos}

- PENTEADO, Bruno Elias; BITTENCOURT, Ig Ibert; ISOTANI, SEIJI (2019). Análise exploratória sobre a abertura de dados educacionais no Brasil: como torná-los prontos para o ecossistema da Web?. Revista Brasileira de Informática na Educação (RBIE), v. 27, p. 175-195, 2019. <https://doi.org/10.5753/rbie.2019.27.01.175>

- PENTEADO, Bruno Elias; ISOTANI, Seiji (2020) [em processo de revisão]. Methodologies for publishing linked open government data for the data on the web: a systematic mapping. Semantic Web Journal.

- PENTEADO, Bruno Elias; ISOTANI, Seiji (2020) [em processo de revisão]. Process model with quality control for the production of high quality linked open government data. IEEE Latin America.

Outros projetos:

- PENTEADO, Bruno Elias; PAIVA, Paula Maria Pereira; MORETTIN-ZUPELARI, Marina; ISOTANI, Seiji; FERRARI, Deborah Viviane. Toward Better Outcomes in Audiology Distance Education: An Educational Data Mining Approach. American Journal of Audiology, v. 27, p. 513-525, 2018. <https://doi.org/10.1044/2018_AJA-IMIA3-18-0020>

- DANTAS, J.; PENTEADO, Bruno Elias. Las redes de conocimiento de documentales online: un análisis del documental The Power of Gold en la plataforma Twitter. RAZÓN Y PALABRA, v. 21, p. 229-247, 2017. <https://www.revistarazonypalabra.org/index.php/ ryp/article/view/993> 


\subsubsection{Conferências}

- PENTEADO, Bruno Elias; BITTENCOURT, Ig Ibert; ISOTANI, Seiji. Metaprocesso para transformação de dados educacionais em dados conectados. In: XXX Simpósio Brasileiro de Informática na Educação SBIE (Brazilian Symposium on Computers in Education), 2019, Brasília. p. 526. <https://doi.org/10.5753/cbie.sbie.2019.1808>

- PENTEADO, Bruno Elias; BITTENCOURT, Ig Ibert; ISOTANI, Seiji. Modelo de referência para dados abertos educacionais em nível macro. In: XXX Simpósio Brasileiro de Informática na Educação SBIE (Brazilian Symposium on Computers in Education), 2019, Brasília. p. 526. <https://doi.org/10.5753/cbie.sbie.2019.1601>

- PENTEADO, Bruno Elias; ISOTANI, Seiji. Dados abertos educacionais: que informações temos disponíveis?. In: Congresso Brasileiro de Educação, 2017, Bauru. Anais do VI CBE - Congresso Brasileiro de Educação, 2017. < https://www.researchgate.net/publication/ 320507942_DADOS_ABERTOS_EDUCACIONAIS_QUE_INFORMACOES_TEMOS_ DISPONIVEIS>

- PENTEADO, Bruno Elias; BITTENCOURT, Ig Ibert; ISOTANI, Seiji. Dados abertos educacionais no Brasil e sua preparação para os dados abertos na web. In: XXVIII Simpósio Brasileiro de Informática na Educação SBIE (Brazilian Symposium on Computers in Education), 2017, Recife. p. 526. <https://doi.org/10.5753/cbie.sbie.2017.526>

- PENTEADO, Bruno Elias. Correlational Analysis Between School Performance and Municipal Indicators in Brazil Supported by Linked Open Data. In: the 25th International Conference Companion, 2016, Montréal. Proceedings of the 25th International Conference Companion on World Wide Web - WWW'16 Companion. p. 507-512<https://doi.org/10. $1145 / 2872518.2890459>$

Outros projetos:

- PENTEADO, Bruno Elias; OCHS, Magalie; BERTRAND, Roxane; BLACHE, Philippe. Evaluating Temporal Predictive Features for Virtual Patients Feedbacks. In: the 19th ACM International Conference, 2019, Paris. Proceedings of the 19th ACM International Conference on Intelligent Virtual Agents - IVA '19. New York: ACM Press, 2019. p. 88. <https://doi.org/10.1145/3308532.3329426>

- PENTEADO, Bruno Elias; ISOTANI, Seiji; PAIVA, Paula Maria Pereira; MORETTINZUPELARI, Marina; FERRARI, Deborah Viviane. Discovery of Study Patterns that Impacts Students Discussion Performance in Forum Assignments. Lecture Notes in Computer Science. 1ed.: Springer International Publishing, 2019, v. 11626, p. 220-225. $<$ https://doi.org/10.1007/978-3-030-23207-8_41> 
- PENTEADO, Bruno Elias; ISOTANI, Seiji; PAIVA, Paula Maria Pereira; MORETTINZUPELARI, Marina; FERRARI, Deborah Viviane. Prediction of Interpersonal HelpSeeking Behavior from Log Files in an In-Service Education Distance Course. Lecture Notes in Computer Science. 1ed.: Springer International Publishing, 2018, v. 10948, p. 266-270. <https://doi.org/10.1007/978-3-319-93846-2_49>

- PENTEADO, Bruno Elias; PAIVA, P. M. P.; ZUPELARI, M. M.; FREDERIGUE, N. B.; COSTA, O. A.; ISOTANI, S.; FERRARI, D. V. Educational data mining methods: opportunities for teaching and learning in Audiology. In: International Meeting on Internet \& Audiology, 2017, Louisville. Third International Meeting on Internet \& Audiology, 2017. v. 1. p. 17-17. <http://www.internetaudiology.com/2017/files/IA2017_Abstracts.pdf>

- PENTEADO, Bruno Elias; TIOSSO, Fernando. Eliciting features to build collaborative learning objects. In: Frontiers in Education (FIE), 2016, Eerie. Proceedings of the 46th Annual Frontiers in Education (FIE) Conference, 2016. p. 1-5.

- PENTEADO, Bruno. Geração automática de modelo de relações de pré-requisitos a partir de avaliação de larga escala brasileiras: um estudo preliminar. In: Workshops do Congresso Brasileiro de Informática na Educação, 2016, Uberlândia, 2016. p. 990-998. $<$ http://dx.doi.org/10.5753/cbie.wcbie.2016.990>

- PENTEADO, Bruno Elias. A Concentração De Desempenho Escolar E Sua Relação Socioeconômica: Análise Sobre Os Microdados Do Enem 2013. In: CBE - Congresso Brasileiro de Educação, 2015, Bauru. <http://li327-81.members.linode.com:8080/vcbe-anais/api/ arquivo/14018.pdf> 


\section{REFERÊNCIAS}

ABU-SHANAB, E. A. Electronic Government, a tool for good governance and better service. Jordan: Irbid, 2013. Citado na página 43.

Reengineering the open government concept: An empirical support for a proposed model. Government Information Quarterly, v. 32, n. 4, p. 453 - 463, 2015. ISSN 0740-624X. Disponível em: <http://www.sciencedirect.com/science/article/pii/S0740624X15000787>. Citado nas páginas 43 e 44.

AL-KHALIFA, H. S. A lightweight approach to semantify saudi open government data. In: 2013 16th International Conference on Network-Based Information Systems. [S.1.]: IEEE, 2013. p. 594-596. Citado na página 58.

ALEXOPOULOS, C.; SPILIOTOPOULOU, L.; CHARALABIDIS, Y. Open data movement in greece: A case study on open government data sources. In: Anais do the 17th Panhellenic Conference on Informatics. New York, NY, USA: Association for Computing Machinery, 2013. (PCI '13), p. 279-286. ISBN 9781450319690. Disponível em: <https://doi.org/10.1145/2491845. 2491876>. Citado na página 28.

ALLENSWORTH, E.; PONISCIAK, S.; MAZZEO, C. The schools teachers leave - Teacher mobility in Chicago public schools. Chicago, EUA, 2009. Disponível em: <https://files.eric.ed. gov/fulltext/ED505882.pdf>. Citado na página 143.

ARZBERGER, P.; SCHROEDER, P.; BEAULIEU, A.; BOWKER, G.; CASEY, K.; LAAKSONEN, L.; MOORMAN, D.; UHLIR, P.; WOUTERS, P. An international framework to promote access to data. Science, American Association for the Advancement of Science, v. 303, n. 5665, p. 1777-1778, 2004. ISSN 0036-8075. Disponível em: <https://science.sciencemag.org/content/ 303/5665/1777>. Citado na página 27.

ASSAF, A.; SENART, A.; TRONCY, R. Towards an objective assessment framework for linked data quality. International journal on Semantic Web and information system, IGI Global, v. 12, n. 3, p. 111-133, 2016. Citado na página 86.

ATTARD, J.; ORLANDI, F.; SCERRI, S.; AUER, S. A systematic review of open government data initiatives. Government Information Quarterly, v. 32, n. 4, p. 399 - 418, 2015. ISSN 0740-624X. Disponível em: <http://www.sciencedirect.com/science/article/pii/ S0740624X1500091X>. Citado nas páginas 29 e 47.

ÁVILA, T. J. T. Uma proposta de modelo de processo para publicação de dados abertos conectados governamentais. 219 p. Dissertação (Mestrado) - Instituto de Computação, Universidade Federal de Alagoas, Maceió, AL, 2015. Citado na página 181.

AXELOS. ITIL Update. 2019. Disponível em: <https://www.axelos.com/itil-update>. Acesso em: 30/07/2019. Citado na página 236.

BATINI, C.; SCANNAPIECO, M. Data Quality: Concepts, Methodologies and Techniques.

Berlin, Heidelberg: Springer-Verlag Berlin Heidelberg, 2006. Citado na página 84. 
BEEK, W.; ILIEVSKI, F.; DEBATTISTA, J.; SCHLOBACH, S.; WIELEMAKER, J. Literally better: Analyzing and improving the quality of literals. Semantic Web Journal, v. 9, n. 1, p. 131-150, 2018. Citado na página 225.

BEHKAMAL, B.; KAHANI, M.; BAGHERI, E.; JEREMIC, Z. A metrics-driven approach for quality assessment of linked open data. J. Theor. Appl. Electron. Commer. Res., Facultad de Ingeniería, Universidad de Talca, Talca, CHL, v. 9, n. 2, p. 64-79, maio 2014. ISSN 0718-1876. Disponível em: <https://doi.org/10.4067/S0718-18762014000200006>. Citado nas páginas 29, $30,77,85$ e 96.

BERNERS-LEE, T. Information Management: A Proposal. 1989. Disponível em: <https: //www.w3.org/History/1989/proposal.html> . Acesso em: 28/12/2019. Citado na página 40.

Linked Data - Design Issues. 2006. Disponível em: <https://www.w3.org/DesignIssues/ LinkedData.html>. Acesso em: 28/12/2019. Citado nas páginas 29, 41, 42, 60, 87, 89, 91, 119 e 226.

As 5 estrelas dos Dados Abertos. 2010. Disponível em: <https://5stardata.info/pt-BR/>. Acesso em: 03/03/2020. Citado na página 90.

BERNERS-LEE, T.; HENDLER, J.; LASSILA, O. The Semantic Web: A new form of Web content that is meaningful to computers will unleash a revolution of new possibilities. 2001 . Acesso em: 28/12/2019. Citado nas páginas 30 e 40.

BERTOT, J. C.; JAEGER, P. T.; MUNSON, S.; GLAISYER, T. Social media technology and government transparency. Computer, v. 43, n. 11, p. 53-59, Nov 2010. ISSN 1558-0814. Citado na página 43.

BIZER, C.; CYGANIAK, R. Quality-driven information filtering using the wiqa policy framework. Journal of Web Semantics, v. 7, n. 1, p. 1 - 10, 2009. ISSN 1570-8268. The Semantic Web and Policy. Disponível em: <http://www.sciencedirect.com/science/article/pii/ S157082680800019X>. Citado nas páginas 85, 97 e 226.

BIZER, C.; HEATH, T.; BERNERS-LEE, T. Linked data - the story so far. International Journal on Semantic Web and Information Systems, v. 5, n. 3, p. 1-22, 2009. Disponível em: $<$ https://eprints.soton.ac.uk/271285/>. Citado nas páginas 41 e 46.

BIZER RICHARD CYGANIAK, T. H. C. How to publish linked data on the web. 2007. Disponível em: <http://wifo5-03.informatik.uni-mannheim.de/bizer/HowtoPublishLinkedData. htm>. Citado na página 115 .

BOSELLI, R.; CESARINI, M.; MERCORIO, F.; MEZZANZANICA, M. Are the methodologies for producing linked open data feasible for public administrations? In: Anais do 3rd International Conference on Data Management Technologies and Applications. Setubal, PRT: SCITEPRESS - Science and Technology Publications, Lda, 2014. (DATA 2014), p. 399-407. ISBN 9789897580352. Disponível em: <https://doi.org/10.5220/0005143303990407>. Citado nas páginas 28 e 29.

BRASIL. Constituição da República Federativa do Brasil. Brasília, DF: Senado Federal: Centro Gráfico, 1988. Disponível em: <http://www.planalto.gov.br/ccivil_03/constituicao/ constituicao.htm>. Citado na página 68 . 
Lei Complementar $n^{0}$ 101, de 4 de maio de 2000. Estabelece normas de finanças públicas voltadas para a responsabilidade na gestão fiscal e dá outras providências. 2000 . Disponível em: <http://www.planalto.gov.br/ccivil_03/leis/lcp/lcp101.htm>. Citado na página 68.

Lei Complementar no 131, de 27 de maio de 2009. Acrescenta dispositivos à Lei Complementar no 101, de 4 de maio de 2000, que estabelece normas de finanças públicas voltadas para a responsabilidade na gestão fiscal e dá outras providências, a fim de determinar a disponibilização, em tempo real, de informações pormenorizadas sobre a execução orçamentária e financeira da União, dos Estados, do Distrito Federal e dos Municípios. 2009. Disponível em: <http://www.planalto.gov.br/ccivil_03/leis/lcp/lcp131.htm>. Citado na página 68.

Lei $\mathrm{n}^{0}$ 12.527, de 18 de novembro de 2011. Regula o acesso a informações previsto no inciso XXXIII do art. $5^{\circ}$, no inciso II do $\$ 3^{\circ}$ do art. 37 e no $\$ 2^{\circ}$ do art. 216 da Constituição Federal; altera a Lei $n^{0}$ 8.112, de 11 de dezembro de 1990; revoga a Lei $n^{0} 11.111$, de 5 de maio de 2005, e dispositivos da Lei no 8.159, de 8 de janeiro de 1991; e dá outras providências. 2011. Disponível em: <http://www.planalto.gov.br/ccivil_03/_ato2011-2014/2011/ lei/112527.htm>. Citado na página 69.

BUDGEN, D.; TURNER, M.; BRERETON, P.; KITCHENHAM, B. Using mapping studies in software engineering. Anais do PPIG 2008, v. 2, 01 2008. Citado na página 54.

BUIL-ARANDA, C.; HOGAN, A.; UMBRICH, J.; VANDENBUSSCHE, P.-Y. Sparql webquerying infrastructure: Ready for action? In: ALANI, H.; KAGAL, L.; FOKOUE, A.; GROTH, P.; BIEMANN, C.; PARREIRA, J. X.; AROYO, L.; NOY, N.; WELTY, C.; JANOWICZ, K. (Ed.). The Semantic Web - ISWC 2013. Berlin, Heidelberg: Springer Berlin Heidelberg, 2013. p. 277-293. Citado na página 236.

BURANARACH, M.; KRATAITHONG, P.; HINSHERANAN, S.; RUENGITTINUN, S.; SUPNITHI, T. A scalable framework for creating open government data services from open government data catalog. In: Anais do the 9th International Conference on Management of Digital EcoSystems. New York, NY, USA: Association for Computing Machinery, 2017. (MEDES '17), p. 1-5. ISBN 9781450348959. Disponível em: <https://doi.org/10.1145/3167020.3167021>. Citado nas páginas 58 e 224.

BURLE, C.; BELLIX, L.; MACHADO, J. How about defining Open Government principles? Open Government Partnership Blog, 2016. Disponível em: <https://www.opengovpartnership. org/stories/how-about-defining-open-government-principles/>. Citado na página 43.

BUSH, V. As we may think. The Atlantic Monthly, Jul 1945. Disponível em: <https://www. theatlantic.com/magazine/archive/1945/07/as-we-may-think/303881/>. Citado na página 39.

CHARALABIDIS, Y.; ZUIDERWIJK, A.; ALEXOPOULOS, C.; JANSSEN, M.; LAMPOLTSHAMMER, T.; FERRO, E. The multiple life cycles of open data creation and use. In: __ Public Administration and Information Technology. [S.1.]: Springer, 2018. (Public Administration and Information Technology), p. 11-31. Citado na página 181.

CHECKLAND, P. Soft systems methodology. In: Encyclopedia of Operations Research and Management Science. Boston, MA: Springer US, 2013. p. 1430-1436. ISBN 978-1-44191153-7. Disponível em: <https://doi.org/10.1007/978-1-4419-1153-7_971>. Citado na página 33. 
CIFUENTES-SILVA, F.; SIFAQUI, C.; LABRA-GAYO, J. E. Towards an architecture and adoption process for linked data technologies in open government contexts: A case study for the library of congress of chile. In: Anais do the 7th International Conference on Semantic Systems. New York, NY, USA: Association for Computing Machinery, 2011. (I-Semantics '11), p. 79-86. ISBN 9781450306218. Disponível em: <https://doi.org/10.1145/2063518.2063529>. Citado nas páginas 58, 235 e 236.

COMISSÃO EUROPEIA. Communication From The Commission To The European Parliament, The Council, The European Economic And Social Committee And The Committee Of The Regions - A Digital Agenda for Europe. 2010. Disponível em: <http://eur-lex.europa. eu/legal-content/EN/ALL/?uri=CELEX:52010DC0245R(01)>. Citado na página 69.

Data Quality Management. ISA2 Programme, 2019. Disponível em: <https: //joinup.ec.europa.eu/sites/default/files/document/2019-09/SEMIC\%20Study\%20on\%20data\% 20quality\%20management.pdf $>$. Citado na página 40.

CRESWELL, J. W. Projeto de Pesquisa: Métodos Qualitativo Quantitativo e Misto. Porto Alegre: Artmed, 2010. Citado na página 33.

CUILLIER, D.; PIOTROWSKI, S. J. Internet information-seeking and its relation to support for access to government records. Government Information Quarterly, v. 26, n. 3, p. 441 449, 2009. ISSN 0740-624X. Disponível em: <http://www.sciencedirect.com/science/article/pii/ S0740624X09000458>. Citado na página 27.

DAVIES, T.; BAWA, Z. The promises and perils of open government data (ogd). The Journal of Community Informatics, v. 8, n. 2, 2012. Citado na página 43.

DAWES, S. S. Stewardship and usefulness: Policy principles for information-based transparency. Government Information Quarterly, v. 27, n. 4, p. 377 - 383, 2010. ISSN 0740-624X. Special Issue: Open/Transparent Government. Disponível em: <http://www.sciencedirect.com/science/ article/pii/S0740624X10000651>. Citado nas páginas 30 e 89.

DAWES, S. S.; HELBIG, N. Information strategies for open government: Challenges and prospects for deriving public value from government transparency. In: WIMMER, M. A.; CHAPPELET, J.-L.; JANSSEN, M.; SCHOLL, H. J. (Ed.). Electronic Government. Berlin, Heidelberg: Springer Berlin Heidelberg, 2010. p. 50-60. ISBN 978-3-642-14799-9. Citado na página 89.

DAWES, S. S.; VIDIASOVA, L.; PARKHIMOVICH, O. Planning and designing open government data programs: An ecosystem approach. Government Information Quarterly, v. 33, n. 1, p. 15 - 27, 2016. ISSN 0740-624X. Disponível em: <http://www.sciencedirect.com/science/ article/pii/S0740624X1630003X>. Citado na página 82.

DEBATTISTA, J.; LANGE, C.; AUER, S. Evaluating the quality of the lod cloud: An empirical investigation. Semantic Web Journal, v. 9, n. 9, p. 859-901, 2018. Disponível em: <https: //content.iospress.com/articles/semantic-web/sw306>. Citado nas páginas 17, 30, 87, 148, 163, $164,167,173$ e 229.

DEBATTISTA, J.; nO, S. L.; LANGE, C.; AUER, S. Quality assessment of linked datasets using probabilistic approximation. In: Proceedings of the 12th European Semantic Web Conference on The Semantic Web. Latest Advances and New Domains - Volume 9088. Berlin, Heidelberg: Springer-Verlag, 2015. p. 221-236. ISBN 9783319188171. Disponível em: $<$ https://doi.org/10.1007/978-3-319-18818-8_14>. Citado na página 229. 
DEMPSEY, L.; HEERY, R. Metadata: a current view of practice and issues. Journal of Documentation, Emerald Group Publishing Ltd., v. 54, n. 2, p. 145-172, 1998. ISSN 0022-0418. Citado na página 88.

DENYER, D.; TRANFIELD, D.; AKEN, J. E. van. Developing design propositions through research synthesis. Organization Studies, v. 29, n. 3, p. 393-413, 2008. Disponível em: <https: //doi.org/10.1177/0170840607088020>. Citado na página 33.

DETLOR, B.; HUPFER, M. E.; RUHI, U.; ZHAO, L. Information quality and community municipal portal use. Government Information Quarterly, v. 30, n. 1, p. 23 - 32, 2013. ISSN 0740624X. Disponível em: <http://www.sciencedirect.com/science/article/pii/S0740624X12001396>. Citado na página 29.

DING, L.; LEBO, T.; ERICKSON, J. S.; DIFRANZO, D.; WILLIAMS, G. T.; LI, X.; MICHAELIS, J.; GRAVES, A.; ZHENG, J. G.; SHANGGUAN, Z.; FLORES, J.; MCGUINNESS, D. L.; HENDLER, J. A. Twc logd: A portal for linked open government data ecosystems. Journal of Web Semantics, v. 9, n. 3, p. 325 - 333, 2011. ISSN 1570-8268. Semantic Web Dynamics Semantic Web Challenge, 2010. Disponível em: <http://www.sciencedirect.com/science/article/ pii/S1570826811000382>. Citado na página 82.

DOBRICA, L.; NIEMELA, E. A survey on software architecture analysis methods. IEEE Transactions on Software Engineering, v. 28, n. 7, p. 638-653, July 2002. ISSN 2326-3881. Citado na página 142.

EASTERBROOK, S. Empirical research methods for software engineering. In: Anais do the Twenty-Second IEEE/ACM International Conference on Automated Software Engineering. New York, NY, USA: Association for Computing Machinery, 2007. (ASE '07), p. 574. ISBN 9781595938824. Disponível em: <https://doi.org/10.1145/1321631.1321749>. Citado na página 33.

EAVES, D. The Three Laws of Open Government Data. Eaves.ca Blog, 2009. Disponível em: $<$ https://eaves.ca/2009/09/30/three-law-of-open-government-data/>. Citado na página 45.

ELMEKKI, H.; DALILA, C.; LAMHARHAR, H. Open government data: Problem assessment of machine processability. In: Anais do EMENA-ISTL 2018: Information Systems and Technologies to Support Learning. [S.1.: s.n.], 2019. p. 492-501. ISBN 978-3-030-03576-1. Citado na página 58.

EVEN, A.; SHANKARANARAYANAN, G. Utility cost perspectives in data quality management. Journal of Computer Information Systems, v. 50, p. 127-135, 12 2009. Citado na página 84.

FÄRBER, M.; BARTSCHERER, F.; MENNE, C.; RETTINGER, A. Linked data quality of dbpedia, freebase, opencyc, wikidata, and yago. Semantic Web Journal, v. 9, n. 1, p. 77-129, 2018. Citado nas páginas 30 e 87.

FERNÁNDEZ-LÓPEZ, M.; GOMEZ-PEREZ, A.; JURISTO, N. Methontology: from ontological art towards ontological engineering. Engineering Workshop on Ontological Engineering (AAAI97), 03 1997. Citado na página 224.

FLEINER, R. Linking of open government data. 2018 IEEE 12th International Symposium on Applied Computational Intelligence and Informatics (SACI), p. 1-5, 2018. Citado nas páginas 58, 233 e 235. 
FLEMMING, A. Quality characteristics of linked data publishing datasources. Master's thesis, Humboldt-Universität of Berlin, 2010. Citado na página 97.

FLORINI, A. The right to know: Transparency for an open world. [S.1.]: Columbia University Press, 2007. Citado na página 27.

FREIRE, N.; ISAAC, A.; ROBSON, G.; HOWARD, J.; MANGUINHAS, H. A survey of web technology for metadata aggregation in cultural heritage. Information Services \& Use, v. 37, p. 425-436, 01 2018. Citado na página 123.

GALIN, D. Software Quality Assurance: From theory to implementation. Ruppin Academic Center, Israel: Pearson, 2004. 617 p. Citado na página 95.

GREGOR, S. The nature of theory in information systems. Management Information Systems Quarterly, v. 30, n. 3, p. 611-642, 2006. Citado na página 36.

GREGOR, S.; JONES, D. The anatomy of a design theory. Journal of the Association for Information Systems, v. 8, n. 5, p. 312-335, 2007. Citado na página 36.

GUARINO, C. M.; SANTIBAÑEZ, L.; DALEY, G. A. Teacher recruitment and retention: A review of the recent empirical literature. Review of Educational Research, v. 76, n. 2, p. 173 208, 2006. Disponível em: <https://doi.org/10.3102/00346543076002173>. Citado na página 143.

GUÉRET, C.; GROTH, P.; STADLER, C.; LEHMANN, J. Assessing linked data mappings using network measures. In: SIMPERL, E.; CIMIANO, P.; POLLERES, A.; CORCHO, O.; PRESUTTI, V. (Ed.). The Semantic Web: Research and Applications. Berlin, Heidelberg: Springer Berlin Heidelberg, 2012. p. 87-102. ISBN 978-3-642-30284-8. Citado na página 97.

HAUG, A.; PEDERSEN, A.; ARLBJØRN, J. S. A classification model of erp system data quality. Industrial Management and Data Systems, v. 109, p. 1053-1068, 09 2009. Citado na página 84.

HEATH, T.; BIZER, C. Linked Data: Evolving the Web into a Global Data Space. [S.1.: s.n.], 2011. v. 11. Citado nas páginas 62, 224 e 229.

HEIMSTÄDT, M.; SAUNDERSON, F.; HEATH, T. Conceptualizing Open Data ecosystems: A timeline analysis of Open Data development in the UK. [S.1.], 2014. Disponível em: <https: //ideas.repec.org/p/zbw/fubsbe/201412.html>. Citado na página 82.

HEVNER, A. R.; CHATTERJEE, S. Design research in information systems. In: Integrated Series in Information Systems. EUA: Springer US, 2010. v. 22, n. 1, p. 320. Citado na página 141.

HEVNER, A. R.; MARCH, S. T.; PARK, J.; RAM, S. Design science in information systems research. Management Information Systems Quarterly, Society for Information Management and The Management Information Systems Research Center, USA, v. 28, n. 1, p. 75-105, mar. 2004. ISSN 0276-7783. Citado nas páginas 31, 33, 34, 36, 61 e 102.

HOGAN, A.; HARTH, A.; PASSANT, A.; DECKER, S.; POLLERES, A. Weaving the pedantic web. In: BIZER, C.; HEATH, T.; BERNERS-LEE, T.; HAUSENBLAS, M. (Ed.). Proceedings of the WWW2010 Workshop on Linked Data on the Web, LDOW 2010, Raleigh, USA, April 27, 2010. CEUR-WS.org, 2010. (CEUR Workshop Proceedings, v. 628). Disponível em: <http://ceur-ws.org/Vol-628/ldow2010\_paper04.pdf>. Citado na página 122. 
HOGAN, A.; HITZLER, P.; JANOWICZ, K. Linked dataset description papers at the semantic web journal: A critical assessment. Semantic Web Journal, v. 7, n. 2, p. 105-116, 2016. Citado na página 30 .

HOGAN, A.; UMBRICH, J.; HARTH, A.; CYGANIAK, R.; POLLERES, A.; DECKER, S. An empirical survey of linked data conformance. Journal of Web Semantics, v. 14, p. 14 - 44, 2012. ISSN 1570-8268. Special Issue on Dealing with the Messiness of the Web of Data. Disponível em: $<$ http://www.sciencedirect.com/science/article/pii/S1570826812000352>. Citado nas páginas 225 e 229.

HOOKER, J. N. Is design theory possible? Journal of Information Technology, Theory and Application, v. 6, n. 2, p. 73-82, 2004. Citado na página 36.

HYLAND, B.; WOOD, D. The joy of data - a cookbook for publishing linked government data on the web. In: __ Linking Government Data. New York, NY: Springer New York, 2011. p. 326. ISBN 978-1-4614-1767-5. Disponível em: <https://doi.org/10.1007/978-1-4614-1767-5_1>. Citado nas páginas 58, 216 e 237.

IBÁÑEZ, L.-D.; MILLARD, I.; GLASER, H.; SIMPERL, E. An assessment of adoption and quality of linked data in european open government data. In: GHIDINI, C.; HARTIG, O.; MALESHKOVA, M.; SVÁTEK, V.; CRUZ, I.; HOGAN, A.; SONG, J.; LEFRANÇOIS, M.; GANDON, F. (Ed.). The Semantic Web - ISWC 2019. Cham: Springer International Publishing, 2019. p. 436-453. ISBN 978-3-030-30796-7. Citado na página 30.

IEEE. IEEE Std 610.12-1990 - IEEE Standard Glossary of Software Engineering Terminology. Corrected Edition. New York: The Institute of Electrical and Electronics Engineers, 1991. Citado na página 95.

IEEE Standard for System, Software, and Hardware Verification and Validation. IEEE Computer Society, 2016. Disponível em: <https://ieeexplore.ieee.org/servlet/opac? punumber $=8055460>$. Citado na página 95.

IMMONEN, A.; PALVIAINEN, M.; OVASKA, E. Requirements of an open data based business ecosystem. IEEE Access, v. 2, p. 88-103, 02 2014. Citado nas páginas 82 e 106.

ISO. ISO/IEC 25012:2008. Software engineering - Software product Quality Requirements and Evaluation (SQuaRE) - Data quality model. 2008. Disponível em: < https: //www.iso.org/standard/35736.html>. Citado nas páginas 84 e 87.

Systems and software engineering - Systems and software Quality Requirements and Evaluation (SQuaRE) - System and software quality models. 2011. Disponível em: $<$ https://www.iso.org/standard/35733.html>. Citado na página 236.

Systems and software engineering - Systems and software Quality Requirements and Evaluation (SQuaRE) - Measurement of data quality. 2015. Disponível em: <https: //www.iso.org/standard/35749.html>. Citado na página 87.

ISOTANI, S.; BITTENCOURT, I. I. Dados abertos conectados. São Paulo: Novatec, 2015. 175 p. Citado nas páginas 27, 41, 42 e 46.

JACKA, J. M.; KELLER, P. J. Business Process Mapping: Improving Customer Satisfaction. Hoboken, New Jersey: John Wiley and Sons, 2009. 336 p. Citado na página 107. 
JANEV, V.; MIJOVIć, V.; VRANEs, S. Using the linked data approach in european e-government systems: Example from serbia. Int. J. Semant. Web Inf. Syst., IGI Global, USA, v. 14, n. 2, p. 27-46, abr. 2018. ISSN 1552-6283. Disponível em: <https://doi.org/10.4018/IJSWIS. 2018040102>. Citado na página 30.

JANEV, V.; MILOEVIĆ, U.; SPASIĆ, M.; VRANE, S.; MILOJKOVIC, J.; JIREEK, B. Integrating serbian public data into the lod cloud. In: BCI '12: Anais do 5. Balkan Conference in Informatics. [S.1.: s.n.], 2012. p. 94-99. Citado nas páginas 58, 219 e 227.

JANICES, P.; AGUERRE, N. Open government partnership: Argentina action plan. ACM International Conference Proceeding Series, p. 206-209, 10 2013. Citado na página 45.

JANSEN, A.; ØLNES, S. The nature of public e-services and their quality dimensions. Government Information Quarterly, v. 33, n. 4, p. 647 - 657, 2016. ISSN 0740-624X. Disponível em: <http://www.sciencedirect.com/science/article/pii/S0740624X16301435>. Citado na página 86.

JANSSEN, K. The influence of the psi directive on open government data: An overview of recent developments. Government Information Quarterly, v. 28, n. 4, p. 446 - 456, 2011. ISSN 0740624X. Disponível em: <http://www.sciencedirect.com/science/article/pii/S0740624X11000517>. Citado na página 27.

JANSSEN, M.; CHARALABIDIS, Y.; ZUIDERWIJK, A. Benefits, adoption barriers and myths of open data and open government. Information Systems Management, Taylor \& Francis, v. 29, n. 4, p. 258-268, 2012. Disponível em: <https://doi.org/10.1080/10580530.2012.716740>. Citado nas páginas 29, 32, 43 e 46.

JANSSEN, M.; ZUIDERWIJK, A. Infomediary business models for connecting open data providers and users. Social Science Computer Review, v. 32, n. 5, p. 694-711, 2014. Disponível em: <https://doi.org/10.1177/0894439314525902>. Citado na página 214.

JEFFERY, K. Metadata: the future of information systems. In: Information Systems Engineering: State of the art and research themes. London: Springer Verlag, 2000. Disponível em: <https://www.wmo.int/pages/prog/www/WDM/ET-IDM/Doc-2-3.html\#: :text=Metadata>. Citado na página 88.

JEFFERY, K. G.; ASSERSON, A.; HOUSSOS, N.; BRASSE, V.; JÖRG, B. From open data to data-intensive science through cerif. Procedia Computer Science, v. 33, p. 191 - 198, 2014. ISSN 1877-0509. 12th International Conference on Current Research Information Systems, CRIS 2014. Disponível em: <http://www.sciencedirect.com/science/article/pii/S1877050914008229>. Citado na página 88.

JOHNSON, P. A.; GREENE, S. Who are government opendata infomediaries? a preliminary scan and classification of open data users and products. Journal of the Urban \& Regional Information Systems Association, v. 28, p. 9-18, 2017. Disponível em: <http://www.urisa.org/ clientuploads/directory/Documents/Journal/Vol28_final.pdf>. Citado na página 214.

JOVANOVIK, M.; TRAJANOV, D. Consolidating drug data on a global scale using linked data. Journal of Biomedical Semantics, v. 8, 2017. Citado nas páginas 29, 65, 109 e 213.

JUNIOR, E. A. P.; OLIVEIRA, D. A. Indicadores de retenção e rotatividade dos docentes da educação básica. Cadernos de Pesquisa, scielo, v. 46, p. 312 - 332, 062016. ISSN 0100-1574. Disponível em: <http://www.scielo.br/scielo.php?script=sci_arttext\&pid= S0100-15742016000200312\&nrm=iso>. Citado na página 143. 
JURAN, J.; GRYNA, F. The Quality Control Handbook, 4th edition. [S.1.]: Mcgraw-Hill, 1988. 1774 p. Citado na página 84.

JURISCH, M.; KAUTZ, M.; WOLF, P.; KRCMAR, H. An international survey of the factors influencing the intention to use open government. In: Anais do the Annual Hawaii International Conference on System Sciences. [S.1.: s.n.], 2015. v. 2015. Citado na página 89.

KAHN, B.; STRONG, D.; WANG, R. Information quality benchmarks: Product and service performance. Commun. ACM, v. 45, p. 184-192, 04 2002. Citado na página 85.

KASCHESKY, M.; SELMI, L. Fusepool r5 linked data framework: Concepts, methodologies, and tools for linked data. In: Anais do the 14th Annual International Conference on Digital Government Research. New York, NY, USA: Association for Computing Machinery, 2013. (dg.o '13), p. 156-165. ISBN 9781450320573. Disponível em: <https://doi.org/10.1145/2479724. 2479748>. Citado nas páginas 58 e 235.

KIM, W. On three major holes in data warehousing today. Journal of Object Technology, v. 1, n. 4, p. 39-47, set. 2002. ISSN 1660-1769. (column). Disponível em: <http://www.jot.fm/ contents/issue_2002_09/column3.html>. Citado na página 84.

KITCHENHAM, B.; CHARTERS, S. Guidelines for performing Systematic Literature Reviews in Software Engineering. [S.1.], 2007. v. 2. Citado na página 54.

KLEIN, E.; GSCHWEND, A.; NEURONI, A. C. Towards a linked data publishing methodology. 2016 Conference for E-Democracy and Open Government (CeDEM), p. 188-196, 2016. Citado na página 58.

KONSTANTINOU, N.; SPANOS, D.-E. Deploying linked open data: Methodologies and software tools. In: . Materializing the Web of Linked Data. Cham: Springer International Publishing, 2015. p. 51-71. Disponível em: <https://doi.org/10.1007/978-3-319-16074-0_3>. Citado na página 62.

KONTOKOSTAS, D.; WESTPHAL, P.; AUER, S.; HELLMANN, S.; LEHMANN, J.; CORNELISSEN, R.; ZAVERI, A. Test-driven evaluation of linked data quality. In: Anais do the 23rd International Conference on World Wide Web. New York, NY, USA: Association for Computing Machinery, 2014. (WWW '14), p. 747-758. ISBN 9781450327442. Disponível em: <https://doi.org/10.1145/2566486.2568002>. Citado nas páginas 30, 96 e 163.

KÖSTER, V.; SUÁREZ, G. Open data for development: Experience of uruguay. In: Anais do the 9th International Conference on Theory and Practice of Electronic Governance. New York, NY, USA: Association for Computing Machinery, 2016. (ICEGOV'15-16), p. 207-210. ISBN 9781450336406. Disponível em: <https://doi.org/10.1145/2910019.2910060>. Citado na página 84.

KRATAITHONG, P.; BURANARACH, M.; SUPNITHI, T. Rdf dataset management framework for data.go.th. In: THEERAMUNKONG, T.; SKULIMOWSKI, A. M.; YUIZONO, T.; KUNIFUJI, S. (Ed.). Recent Advances and Future Prospects in Knowledge, Information and Creativity Support Systems. Cham: Springer International Publishing, 2018. p. 42-53. Citado na página 58.

KROTOSKI, A. K. Data-driven research: Open data opportunities for growing knowledge, and ethical issues that arise. Insights, v. 25, n. 1, p. 28 - 32, 2011. ISSN 0740-624X. Citado na página 27. 
KUCERA, J. Open Government Data. Tese (Doutorado) - University of Economics, Prague, 2014. Citado na página 49.

KUCERA, J.; CHLAPEK, D.; KLÍMEK, J.; NEASK, M. Methodologies and best practices for open data publication. In: Anais do Databases, Texts, Specifications, Objects (DATESO). [S.1.]: CEUR-WS.org/Vol-1343, 2015. p. 52-62. Citado na página 29.

LAESSIG, M.; JACOB, B.; ABOUZAHR, C. Opening data for global health. In:

The Palgrave Handbook of Global Health Data Methods for Policy and Practice. London: Palgrave Macmillan UK, 2019. p. 451-468. ISBN 978-1-137-54984-6. Disponível em: <https://doi.org/10.1057/978-1-137-54984-6_23>. Citado nas páginas 29, 58, 216, 217 e 238.

LANE, S.; RICHARDSON, I. Process models for service-based applications: A systematic literature review. Information and Software Technology, v. 53, n. 5, p. 424-439, 2011. Citado na página 103.

LEBO, T.; ERICKSON, J. S.; DING, L.; GRAVES, A.; WILLIAMS, G. T.; DIFRANZO, D.; LI, X.; MICHAELIS, J.; ZHENG, J. G.; FLORES, J.; SHANGGUAN, Z.; MCGUINNESS, D. L.; HENDLER, J. Producing and using linked open government data in the twc logd portal. In:

Linking Government Data. New York, NY: Springer New York, 2011. p. 51-72. ISBN 978-1-4614-1767-5. Disponível em: <https://doi.org/10.1007/978-1-4614-1767-5_3>. Citado na página 58 .

LEE, D. Building an open data ecosystem: An irish experience. In: Anais do the 8th International Conference on Theory and Practice of Electronic Governance. New York, NY, USA: Association for Computing Machinery, 2014. (ICEGOV '14), p. 351-360. ISBN 9781605586113. Disponível em: <https://doi.org/10.1145/2691195.2691258>. Citado nas páginas 82, 83 e 84 .

LEWIN, K. Frontiers in group dynamics: Ii. channels of group life; social planning and action research. Human Relations, v. 1, n. 2, p. 143-153, 1947. Citado na página 33.

LÓSCIO, B. F.; BURLE, C.; CALEGARI, N. Data on the Web Best Practices. Recomendação da W3C. W3C, 2017. Disponível em: <https://www.w3.org/TR/dwbp/>. Citado na página 91.

LÓSCIO, B. F.; BURLE, C.; CALEGARI, N. Implementation of the best practices for data on the web in brazil and costa rica. In: Companion Anais do The 2019 World Wide Web Conference. New York, NY, USA: Association for Computing Machinery, 2019. (WWW '19), p. 807-810. ISBN 9781450366755. Disponível em: <https://doi.org/10.1145/3308560.3316463>. Citado na página 94.

MAALI, F.; CYGANIAK, R.; PERISTERAS, V. A publishing pipeline for linked government data. In: SIMPERL, E.; CIMIANO, P.; POLLERES, A.; CORCHO, O.; PRESUTTI, V. (Ed.). The Semantic Web: Research and Applications. Berlin, Heidelberg: Springer Berlin Heidelberg, 2012. p. 778-792. ISBN 978-3-642-30284-8. Citado na página 58.

MARCH, S. T.; SMITH, G. F. Design and natural science research on information technology. Decision Support Systems, v. 15, n. 4, p. 251 - 266, 1995. ISSN 0167-9236. Disponível em: <http://www.sciencedirect.com/science/article/pii/0167923694000412>. Citado nas páginas 31, 36 e 141.

MARTIM, H. Normas Jurídicas Brasileiras Integradas a um Legal Knowledge Graph (LKG) Global: uma abordagem baseada na proposta schema.org/legislation. 2019. Monografia (Aperfeiçoamento/Especialização em Pós-Graduação em Tecnologia da Informação Aplicada ao Poder Legislativo) - Senado Federal. Nenhuma citação no texto. 
MARTÍN, A. S.; ROSARIO, A. H. D.; PÉREZ, M. D. C. C. An international analysis of the quality of open government data portals. Social Science Computer Review, v. 34, n. 3, p. 298 311, 2016. Disponível em: <https://doi.org/10.1177/0894439315585734>. Citado na página 30 .

MARTIN, S.; FOULONNEAU, M.; TURKI, S. 1-5 stars: Metadata on the openness level of open data sets in europe. In: . [S.1.: s.n.], 2013. p. 234-245. Citado na página 89.

MARTINO, M. D.; ROSIM, S.; QUARATI, A. Hydrographic datasets in open government data portals: Mitigation of reusability issues through provenance documentation. In: GAROUFALLOU, E.; FALLUCCHI, F.; LUCA, E. W. D. (Ed.). Metadata and Semantic Research - 13th International Conference, MTSR 2019, Rome, Italy, October 28-31, 2019, Revised Selected Papers. Springer, 2019. (Communications in Computer and Information Science, v. 1057), p. 307-319. Disponível em: <https://doi.org/10.1007/978-3-030-36599-8\_27>. Citado na página 95.

MARTINS, L. C. B.; VICTORINO, M. C.; HOLANDA, M.; GHINEA, G.; GRØNLI, T.-M. Unbgold: Unb government open linked data: Semantic enrichment of open data tool. In: Anais do the 10th International Conference on Management of Digital EcoSystems. New York, NY, USA: Association for Computing Machinery, 2018. (MEDES '18), p. 1-6. ISBN 9781450356220. Disponível em: <https://doi.org/10.1145/3281375.3281394>. Citado na página 58.

MATHEUS, R.; RIBEIRO, M. M.; VAZ, J. C. Brazil towards government 2.0: Strategies for adopting open government data in national and subnational governments. In: __ Case Studies in e-Government 2.0: Changing Citizen Relationships. Cham: Springer International Publishing, 2015. p. 121-138. ISBN 978-3-319-08081-9. Disponível em: <https://doi.org/10. 1007/978-3-319-08081-9_8>. Citado na página 28.

MEISSNER, R.; JUNGHANNS, K. Using devops principles to continuously monitor rdf data quality. In: Anais do the 12th International Conference on Semantic Systems. New York, NY, USA: Association for Computing Machinery, 2016. (SEMANTiCS 2016), p. 189-192. ISBN 9781450347525. Disponível em: <https://doi.org/10.1145/2993318.2993351>. Citado na página 191.

MENDES, P. N.; MÜHLEISEN, H.; BIZER, C. Sieve: Linked data quality assessment and fusion. In: Anais do the 2012 Joint EDBT/ICDT Workshops. New York, NY, USA: Association for Computing Machinery, 2012. (EDBT-ICDT'12), p. 116-123. ISBN 9781450311434. Disponível em: <https://doi.org/10.1145/2320765.2320803>. Citado na página 97.

MERCADO-LARA, E.; GIL-GARCIA, J. R. Open government and data intermediaries: The case of aiddata. In: Anais do the 15th Annual International Conference on Digital Government Research. New York, NY, USA: Association for Computing Machinery, 2014. (dg.o '14), p. 335-336. ISBN 9781450329019. Disponível em: <https://doi.org/10.1145/2612733.2612789>. Citado na página 82.

NAÇÕES UNIDAS. The Africa Data Consensus. Economic Commission for Africa, 2000. Disponível em: <https://www.uneca.org/sites/default/files/PageAttachments/final_adc_-_english. pdf $>$. Citado na página 238.

United Nations Millennium Declaration. General Assembly, 2000. Disponível em: $<\mathrm{https}$ //undocs.org/A/RES/55/2>. Citado na página 45. 
NECASKÝ, M.; CHLAPEK, D.; KLÍMEK, J.; KUCERA, J.; MAURINO, A.; RULA, A.; KONECNY, M.; VANOVA, L. Methodology for publishing datasets as open data. COMSODE project - Seventh Framework Programme, 2014. Disponível em: <https://www.comsode.eu/ wp-content/uploads/D5.1-Methodology_for_publishing_datasets_as_open_data.pdf $>$. Citado nas páginas 106 e 181 .

NELSON, T. H. Complex information processing: A file structure for the complex, the changing and the indeterminate. In: Anais do the 1965 20th National Conference. New York, NY, USA: Association for Computing Machinery, 1965. (ACM '65), p. 84-100. ISBN 9781450374958. Disponível em: <https://doi.org/10.1145/800197.806036>. Citado na página 39.

NEUMAIER, S.; UMBRICH, J.; POLLERES, A. Automated quality assessment of metadata across open data portals. J. Data and Information Quality, Association for Computing Machinery, New York, NY, USA, v. 8, n. 1, out. 2016. ISSN 1936-1955. Disponível em: $<$ https://doi.org/10.1145/2964909>. Citado na página 46.

NGOMO, A.-C. N.; AUER, S.; LEHMANN, J.; ZAVERI, A. Introduction to linked data and its lifecycle on the web. In: Reasoning Web. Reasoning on the Web in the Big Data Era: 10th International Summer School 2014, Athens, Greece, September 8-13, 2014. Proceedings. Cham: Springer International Publishing, 2014. p. 1-99. ISBN 978-3-319-10587-1. Disponível em: <https://doi.org/10.1007/978-3-319-10587-1_1>. Citado nas páginas 58, 64, 85,96 e 224.

NOY, N. Making it easier to discover datasets. 2018. Disponível em: <https://www.blog. google/products/search/making-it-easier-discover-datasets>. Citado na página 225.

NOY, N. F.; MCGUINNESS, D. L. Ontology Development 101: A Guide to Creating Your First Ontology. [S.1.], 2001. Disponível em: <http://www.ksl.stanford.edu/people/dlm/papers/ ontology-tutorial-noy-mcguinness-abstract.html>. Citado na página 224.

OBAMA, B. Memorandum For The Heads Of Executive Departments And Agencies, A memorandum issued by the White House on Transparency and Open Government. 2009. Disponível em: <http://www.whitehouse.gov/the_press_office/Transparency_and_Open_ Government>. Citado nas páginas 43 e 68.

OECD. Open Government Data. OECD - Organisation for Economic Co-operation and Development, 2017. Disponível em: <http://www.oecd.org/gov/digital-government/ open-government-data.htm>. Citado na página 45.

OGD. Open Government Data: The Book. 2012. Disponível em: <http://opengovdata.io>. Acesso em: 17/12/2019. Citado nas páginas 45 e 46.

OGP. Open Government Partnership - Open Government Declaration. 2019. Disponível em: $<$ https://www.opengovpartnership.org/open-government-declaration>. Acesso em: 01/05/2019. Citado na página 69.

Open Government Partnership Members. 2019. Disponível em: <https://www. opengovpartnership.org/our-members/>. Acesso em: 18/12/2019. Citado na página 28.

O'HARA, K. Data quality, government data and the open data infosphere. In: AISB/IACAP World Congress 2012: Information Quality Symposium. [s.n.], 2012. Disponível em: <https: //eprints.soton.ac.uk/340045/>. Citado na página 29. 
OLIVEIRA, L. E. R. A.; OLIVEIRA, M. I. S.; SANTOS, W. C. d. R.; LÓSCIO, B. F. Data on the web management system: A reference model. In: Anais do the 19th Annual International Conference on Digital Government Research: Governance in the Data Age. New York, NY, USA: Association for Computing Machinery, 2018. (dg.o '18). ISBN 9781450365260. Disponível em: <https://doi.org/10.1145/3209281.3209355>. Citado na página 188.

OLIVEIRA, M. S.; LIMA, G. B.; LÓSCIO, B. Investigations into data ecosystems: a systematic mapping study. Knowledge and Information Systems, v. 61, p. 589-630, 11 2019. Citado nas páginas 82,83 e 157.

O'REILLY, T. Government as a platform. Innovations: Technology, Governance, Globalization, v. 6, p. 13-40, 01 2011. Citado na página 44.

PAGE, L.; BRIN, S.; MOTWANI, R.; WINOGRAD, T. The pagerank citation ranking: Bringing order to the web. In: WWW 1999. [S.l.: s.n.], 1999. Citado na página 85.

PARYCEK, P.; SACHS, M. Open government - information flow in web 2.0. European Journal of ePractice, v. 9, p. 57-68, 03 2010. Citado na página 43.

PEFFERS, K.; ROTHENBERGER, M.; TUUNANEN, T.; VAEZI, R. Design science research evaluation. In: PEFFERS, M. R. K.; KUECHLER, B. (Ed.). International Conference on Design Science Research in Information Systems. Las Vegas, EUA: Springer, Berlin, Heidelberg, 2012, 2012. p. 398-410. Citado nas páginas 61 e 142.

PEFFERS, K.; TUUNANEN, T.; ROTHENBERGER, M.; CHATTERJEE, S. A design science research methodology for information systems research. Journal of Management Information Systems, M. E. Sharpe, Inc., USA, v. 24, n. 3, p. 45-77, dez. 2007. ISSN 0742-1222. Disponível em: <https://doi.org/10.2753/MIS0742-1222240302>. Citado nas páginas 34 e 35.

PENTEADO, B.; BITTENCOURT, I.; ISOTANI, S. Análise exploratória sobre a abertura de dados educacionais no brasil: como torná-los prontos para o ecossistema da web? Revista Brasileira de Informática na Educação, v. 27, n. 01, p. 175, 2019. ISSN 2317-6121. Disponível em: <https://www.br-ie.org/pub/index.php/rbie/article/view/7801>. Citado nas páginas 73, 74, $75,95,183$ e 232 .

Metaprocesso para transformação de dados educacionais em dados conectados. In: Brazilian Symposium on Computers in Education (Simpósio Brasileiro de Informática na Educação - SBIE). [s.n.], 2019. v. 30, n. 1, p. 1601. ISSN 2316-6533. Disponível em: <https://www.br-ie.org/pub/index.php/sbie/article/view/8893>. Citado nas páginas 105 e 132.

Modelo de referência para dados abertos educacionais em nível macro. In: Simpósio Brasileiro de Informática na Educação - SBIE. [s.n.], 2019. v. 30, n. 1, p. 1808-1817. ISSN 2316-6533. Disponível em: <https://br-ie.org/pub/index.php/sbie/article/view/8914>. Citado na página 145.

PENTEADO, B. E. Correlational analysis between school performance and municipal indicators in brazil supported by linked open data. In: Proceedings of the 25th International Conference Companion on World Wide Web. Republic and Canton of Geneva, CHE: International World Wide Web Conferences Steering Committee, 2016. (WWW' 16 Companion), p. 507-512. ISBN 9781450341448. Disponível em: <https://doi.org/10.1145/2872518.2890459>. Citado nas páginas 215,227 e 231. 
PETERSEN, K.; FELDT, R.; MUJTABA, S.; MATTSSON, M. Systematic mapping studies in software engineering. In: Anais do the 12th International Conference on Evaluation and Assessment in Software Engineering. Swindon, GBR: BCS Learning \& Development Ltd., 2008. (EASE’08), p. 68-77. Citado na página 54.

PIMENTEL, M.; FILIPPO, D.; SANTORO, F. M. Design science research: fazendo pesquisas científicas rigorosas atreladas ao desenvolvimento de artefatos computacionais projetados para a educação. In: Metodologia de Pesquisa em Informática na Educação (Série de Livros da CEIE/SBC). [s.n.], 2019. cap. 5, p. 1-29. Disponível em: <https://metodologia.ceie-br.org/ wp-content/uploads/2018/10/cap1_5.pdf>. Citado na página 33.

POLLOCK, R. Building the (Open) Data Ecosystem. Open Knowledge Foundation Blog, 2011. Disponível em: <http://blog.okfn.org/2011/03/31/building-the-open-data-ecosystem>. Citado na página 82.

POPITSCH, N.; HASLHOFER, B. Dsnotify: Handling broken links in the web of data. In: . [S.1.: s.n.], 2010. p. 761-770. Citado na página 188.

PRESS, G. Cleaning Big Data: Most Time-Consuming, Least Enjoyable Data Science Task, Survey Says. 2016. Disponível em: <https://www.forbes.com/sites/gilpress/2016/03/ 23/data-preparation-most-time-consuming-least-enjoyable-data-science-task-survey-says/>. Acesso em: 31/07/2019. Citado na página 220.

PRIES-HEJE, J.; BASKERVILLE, R. L. The design theory nexus. Management Information Systems Quarterly, USA, v. 32, n. 4, p. 731-755, 2008. Disponível em: <https://www.jstor.org/ stable/25148870>. Citado na página 36.

RADULOVIC, F.; MIHINDUKULASOORIYA, N.; GARCÍA-CASTRO, R.; GÓMEZ-PÉREZ, A. A comprehensive quality model for linked data. Semantic Web Journal, v. 9, n. 1, p. 3-24, 2018. Citado na página 87.

RANI, M.; R., S.; MISHRA, S. An investigative study on the quality aspects of linked open data. In: Anais do the 2018 International Conference on Cloud Computing and Internet of Things. New York, NY, USA: Association for Computing Machinery, 2018. (CCIOT 2018), p. 33-39. ISBN 9781450365765. Disponível em: <https://doi.org/10.1145/3291064.3291074>. Citado na página 30.

REGINO, A. G.; MATSOUI, J. K. R.; REIS, J. C. dos; BONACIN, R.; MORSHED, A.; SELLIS, T. Link maintenance for integrity in linked open data evolution: Literature survey and open challenges. In: Semantic Web Journal. [s.n.], 2019. Disponível em: <http://www.semantic-web-journal.net/content/ link-maintenance-integrity-linked-open-data-evolution-literature-survey-and-open-challenges $>$. Citado na página 237.

REICHARDT, C. S. Quasi-experimental design. In: . The Sage handbook of quantitative methods in psychology. [S.1.]: Sage Publications Ltd, 2009. p. 46-71. Citado na página 157.

ROJAS, L. A. R.; BERMÚDEZ, G. M. T.; LOVELLE, J. M. C. Open data and big data: A perspective from colombia. In: UDEN, L.; OSHEE, D. F.; TING, I.-H.; LIBERONA, D. (Ed.). Knowledge Management in Organizations. Cham: Springer, 2014. p. 35-41. ISBN 978-3319-08618-7. Citado na página 28. 
RULA, A.; MAURINO, A.; BATINI, C. Data quality issues in linked open data. In: Data and Information Quality. Cham: Springer, 2016. cap. 4, p. 87-112. Citado na página 85.

RUNESON, P.; HÖST, M. Guidelines for conducting and reporting case study research in software engineering. Empirical Software Engineering, v. 14, p. 131-164, 2009. Disponível em: <https://www.jstor.org/stable/25148870>. Citado na página 141.

SALAS, P.; VITERBO, J.; BREITMAN, K.; CASANOVA, M. A. Stdtrip: Promoting the reuse of standard vocabularies in open government data. In: Linking Government Data. New York, NY: Springer New York, 2011. p. 113-133. ISBN 978-1-4614-1767-5. Disponível em: $<$ https://doi.org/10.1007/978-1-4614-1767-5_6>. Citado na página 58.

SANTOS, H. D. A. d.; OLIVEIRA, M. I. S.; LIMA, G. d. F. A. B.; SILVA, K. M. da; MUNIZ, R. I. V. C. S.; LÓSCIO, B. F. Investigations into data published and consumed on the web: a systematic mapping study. Journal of the Brazilian Computer Society, v. 24, 11 2018. Citado na página 29.

SANTOS, O. A. R. d. Minha escola transparente: uma análise comparativa do uso de dados governamentais abertos na educação básica no Brasil e Inglaterra. Dissertação (Mestrado) - EBAP, FGV, Rio de Janeiro, 2014. Disponível em: < http://bibliotecadigital.fgv.br/dspace/ handle/10438/12927>. Citado nas páginas 29, 73 e 145.

SAUNDERS, M.; LEWIS, P.; THORNHILL. Research Methods for Business Students. New York: Pearson, 2009. Citado na página 157.

SCHALKWYK, F. van; WILLMERS, M.; MCNAUGHTON, M. Viscous open data: The roles of intermediaries in an open data ecosystem. Information Technology for Development, Routledge, v. 22, n. sup1, p. 68-83, 2016. Disponível em: <https://doi.org/10.1080/02681102.2015. 1081868>. Citado na página 83.

SHEWHART, W. Economic control of quality of manufactured product. Milwaukee, WI: American Society for Quality Control, 1980. Citado na página 86.

SHIN, D.-H.; CHOI, M. J. Ecological views of big data: Perspectives and issues. Telematics and Informatics, v. 32, n. 2, p. 311 - 320, 2015. ISSN 0736-5853. Disponível em: <http: //www.sciencedirect.com/science/article/pii/S0736585314000665>. Citado nas páginas 83 e 84 .

SIMON, H. The sciences of the artificial. Cambridge, MA, EUA: MIT Press, 1996. Citado na página 32.

SMITH, M. K.; WELTY, C.; MCGUINNESS, D. L. OWL Web Ontology Language Guide. 2004. Disponível em: <https://www.w3.org/TR/owl-guide/>. Acesso em: 18/12/2019. Citado na página 224.

SOMPEL, H. V. de; NELSON, M. L.; SANDERSON, R. Http framework for time-based access to resource states - memento. RFC, v. 7089, p. 1-50, 2013. Citado na página 231.

SORRENTINO, S.; BERGAMASCHI, S.; FUSARI, E.; BENEVENTANO, D. Semantic annotation and publication of linked open data. In: MURGANTE, B.; MISRA, S.; CARLINI, M.; TORRE, C. M.; NGUYEN, H.-Q.; TANIAR, D.; APDUHAN, B. O.; GERVASI, O. (Ed.). Computational Science and Its Applications - ICCSA 2013. Berlin, Heidelberg: Springer Berlin Heidelberg, 2013. p. 462-474. ISBN 978-3-642-39640-3. Citado na página 58. 
STELLMAN, A.; GREENE, J. Applied software project management. Sebastopol: O'Reilly Media, 2005. Citado na página 47.

STVILIA, B.; GASSER, L.; TWIDALE, M.; SMITH, L. A framework for information quality assessment. JASIST, v. 58, p. 1720-1733, 10 2007. Citado na página 85.

SUÁREZ-FIGUEROA, M. C. NeOn Methodology for Building Ontology Networks: Specification, Scheduling and Reuse. 268 p. Tese (Doutorado) - Facultad de Informática, Universidad Politécnica de Madrid, Espanha, 2010. Citado na página 224.

TAELMAN, R.; SANDE, M. V.; VERBORGH, R. GraphQL-LD: Linked Data querying with GraphQL. In: Anais do the 17th International Semantic Web Conference: Posters and Demos. [s.n.], 2018. Disponível em: <https://comunica.github.io/ Article-ISWC2018-Demo-GraphQILD/>. Citado na página 42.

TAUBERER, J. Open Government Data: The Book (2nd Edition). [S.1.: s.n.], 2014. Citado na página 81 .

THÉREAUX, O. Common HTTP Implementation Problems. 2003. Disponível em: <http: //www.w3.org/TR/2003/NOTE-chips-20030128>. Acesso em: 18/12/2019. Citado na página 218.

THOMPSON, M.; FISHENDEN, J. Digital government, open architecture, and innovation: Why public sector it will never be the same again. Journal of Public Administration Research and Theory, v. 23, p. 977-1004, 10 2013. Citado na página 45.

UBALDI, B. Open Government Data: Towards Empirical Analysis of Open Government Data Initiatives. São Paulo, 2013. Acesso em: 18 nov. 2019. Citado nas páginas 82 e 86.

UHLIR, P. F.; SCHRÖDER, P. Open data for global science. Data Science Journal, v. 6, p. 36-53, 2007. Citado na página 27.

VAISHNAVI, V.; KUECHLER, W. Design Science Research Methods and Patterns: Innovating Information and Communication Technology. Boca Raton: CRC Press, 2015. Citado na página 34.

van den Broek, T.; van Veenstra, A.; FOLMER, E. Walking the extra byte: a lifecycle model for linked open data. In: _. Pilot Linked Open Data Nederland. [S.1.]: Linked Open Data, 2014. p. 98-114. Citado nas páginas 103 e 181.

VANDENBUSSCHE, P.-Y.; UMBRICH, J.; MATTEIS, L.; HOGAN, A.; BUIL-ARANDA, C. Monitoring public sparql endpoints. Semantic Web Journal, v. 8, n. 6, p. 1049-1065, 2017. Disponível em: <http://www.jstor.org/stable/40398176?origin=JSTOR-pdf>. Citado nas páginas 222,223 e 236.

VARYTIMOU, A.; LOUTAS, N.; PERISTERAS, V. Towards linked open business registers: The application of the registered organization vocabulary in greece. International Journal of Semantic Web Information Systems, IGI Global, USA, v. 11, n. 2, p. 66-92, abr. 2015. ISSN 1552-6283. Citado na página 29.

VEECKMAN, C.; JEDLIKA, K.; PAEPE, D. D.; KOZHUKH, D.; KAFKA, .; COLPAERT, P.; CERBA, O. Geodata interoperability and harmonization in transport: a case study of open transport net. Open Geospatial Data, Software and Standards, v. 2, 12 2017. Citado na página 95. 
VEENSTRA, A. F. V.; BROEK, T. V. D. A community-driven open data lifecycle model based on literature and practice. In: Case Studies in E-Government 2.0: Changing Citizen Relationships. [S.1.]: Springer International Publishing AG, 2015. cap. 11, p. 183-198. Citado nas páginas 232 e 238 .

VERSCHUREN, P.; HARTOG, R. Evaluation in design-oriented research. Quality and Quantity, v. 39, p. 733-762, 2005. Citado na página 141.

VETRÒ, A.; CANOVA, L.; TORCHIANO, M.; MINOTAS, C. O.; IEMMA, R.; MORANDO, F. Open data quality measurement framework: Definition and application to open government data. Government Information Quarterly, v. 33, n. 2, p. 325 - 337, 2016. ISSN 0740-624X. Disponível em: <http://www.jstor.org/stable/40398176?origin=JSTOR-pdf>. Citado nas páginas 30,84 e 86.

VICKERY, G. Review of recent studies on psi re-use and related market development. 01 2011. Disponível em: <https://ec.europa.eu/digital-single-market/en/news/ review-recent-studies-psi-reuse-and-related-market-developments>. Citado na página 45.

VILLAZON-TERRAZAS, B.; VILCHES-BLÁZQUEZ, L. M.; CORCHO, O.; GOMEZ-PEREZ, A. Methodological guidelines for publishing government linked data. In: Linking Government Data. [S.1.: s.n.], 2011. cap. 2, p. 27-49. Citado nas páginas 58, 122, 214, 229, 230 e 233 .

W3C. Cool URIs for the Semantic Web. 2008. Disponível em: <https://www.w3.org/TR/ cooluris/>. Acesso em: 18/12/2019. Citado na página 218.

. SPARQL Query Language for RDF - W3C Recommendation. 2008. Disponível em: <https://www.w3.org/TR/rdf-sparql-query/>. Acesso em: 18/12/2019. Citado na página 42.

.W3C Semantic Web Frequently Asked Questions. 2011. Disponível em: <https://www. w3.org/2001/sw/SW-FAQ>. Acesso em: 18/12/2019. Citado na página 40.

Best Practices for Publishing Linked Data. 2014. Disponível em: <https://www.w3.org/ TR/ld-bp/>. Acesso em: 18/12/2019. Citado nas páginas 56, 122, 181 e 230.

RDF Schema 1.1. 2014. Disponível em: <https://www.w3.org/TR/rdf-schema/>. Acesso em: 18/12/2019. Citado na página 229.

Data on the Web Best Practices. 2017. Disponível em: <https://www.w3.org/TR/dwbp/>. Acesso em: 18/12/2019. Citado nas páginas 73, 74, 88, 89, 91, 92, 102, 128, 216, 217, 221, 222, $225,229,231,234,235,236,237,238$ e 239.

WANG, R. Y.; STRONG, D. M. Beyond accuracy: what data quality means to data consumers. Journal of Management Information Systems, v. 12, n. 4, p. 5-33, 1996. Disponível em: <http://www.jstor.org/stable/40398176? origin=JSTOR-pdf>. Citado nas páginas 84, 85, 86 e 87.

WEBER, R. Design science research. In: Research Methods: Information, Systems, and Contexts. Cambridge, MA, EUA: Cambridge MA USA, 2018. cap. 7, p. 267-288. Citado nas páginas 33 e 34 .

WOOD, D.; ZAIDMAN, M.; RUTH, L. Linked Data: Structured data on the Web. [S.1.]: Manning Publications Co., 2014. Citado na página 30. 
WOOLCOTT, L. Understanding metadata: What is metadata, and what is it for?,. Cataloging \& Classification Quarterly, Routledge, v. 55, n. 7-8, p. 669-670, 2017. Disponível em: <https: //doi.org/10.1080/01639374.2017.1358232>. Citado na página 88.

WWWF. Open Data Barometer: Fourth Edition. 2019. Disponível em: <http://www. opendatabarometer.org/4thEdition/report>. Acesso em: 18/12/2019. Citado na página 28.

YI, M. Exploring the quality of government open data: Comparison study of the uk, the usa and korea. The Electronic Library, v. 37, n. 1, p. 35-48, 2019. Citado nas páginas 30, 76 e 87.

YIN, R. K. Estudo de caso: planejamento e métodos. Porto Alegre: Bookman, 2009. Citado nas páginas 160 e 162 .

YU, H.; ROBINSON, D. G. The new ambiguity of “open government". UCLA Law Review Discourse, v. 59, p. 178-208, 2012. Citado nas páginas 27 e 43.

ZAVERI, A.; KONTOKOSTAS, D.; SHERIF, M. A.; BüHMANN, L.; MORSEY, M.; AUER, S.; LEHMANN, J. User-driven quality evaluation of dbpedia. In: Anais do the 9th International Conference on Semantic Systems. New York, NY, USA: Association for Computing Machinery, 2013. (I-SEMANTICS '13), p. 97-104. ISBN 9781450319720. Disponível em: <https://doi.org/ 10.1145/2506182.2506195>. Citado na página 30.

ZAVERI, A.; RULA, A.; MAURINO, A.; PIETROBON, R.; LEHMANN, J.; AUER, S. Quality assessment for linked data: A survey. Semantic Web Journal, v. 7, n. 1, p. 63-93, 2016. Citado nas páginas 30, 64, 87, 163, 177, 218 e 229.

ZELETI, F. A.; OJO, A. Open data value capability architecture. Information Systems Frontiers, v. 19, p. 337-360, 10 2016. Citado nas páginas 82 e 83.

ZHOU, X.; JIN, Y.; ZHANG, H.; LI, S.; HUANG, X. A map of threats to validity of systematic literature reviews in software engineering. In: 23rd Asia-Pacific Software Engineering Conference (APSEC). [S.1.: s.n.], 2016. p. 153-160. Citado na página 56.

ZUIDERWIJK, A. Open Data Infrastructures: The design of an infrastructure to enhance the coordination of open data use. 390 p. Tese (Doutorado) - Delft University of Technology, Holanda, 2015. Citado nas páginas 34, 36, 79, 88 e 157.

ZUIDERWIJK, A.; JANSSEN, M. Participation and data quality in open data use: Open data infrastructures evaluated. In: Anais do the 15th European Conference on e-Government 2015: ECEG 2015. Portsmouth, UK: Academic Conferences Limited, 2015. p. 398-410. Disponível em: <http://resolver.tudelft.nl/uuid:c3e2530d-eaa2-409b-a700-b7107db7e159>. Citado na página 84 .

ZUIDERWIJK, A.; JANSSEN, M.; DAVIS, C. Innovation with open data: Essential elements of open data ecosystems. Information Polity, v. 19, p. 17-33, 01 2014. Citado nas páginas 82, 84 e 95 .

ZUIDERWIJK, A.; JANSSEN, M.; POULIS, K.; KAA, G. van de. Open data for competitive advantage: Insights from open data use by companies. In: Anais do the 16th Annual International Conference on Digital Government Research. New York, NY, USA: Association for Computing Machinery, 2015. (dg.o '15), p. 79-88. ISBN 9781450336000. Disponível em: $<$ https://doi.org/10.1145/2757401.2757411>. Citado nas páginas 83 e 84 . 
APÊNDICE

\section{A}

DETALHAMENTO DO PROCESSO

Por motivos de espaço, omitimos os detalhes das atividades do modelo de processo proposto no Capítulo 5, ilustrando de maneira geral a descrição das atividades. No Capítulo 6 aplicamos o artefato, instanciando o modelo proposto por meio de atividades concretas, com seleção de atividades, ferramentas, etc. Neste apêndice, complementamos o detalhamento do processo, ao pormenorizar cada atividade do processo, suas possibilidades e justificativas, de modo a se melhor compreender qual o racional empreendido para a escolha das atividades.

\section{A.1 Especificação}

O primeiro passo, comum explicitamente à maioria das metodologias levantadas, consiste em conhecer os dados e seu domínio em profundidade. Este entendimento da estrutura dos dados e de sua semântica é crucial para as fases seguintes. Como as iniciativas de dados abertos governamentais são derivadas de políticas públicas de acesso à informação, é necessário também conhecer quais são as leis e diretrizes estabelecidas sobre esse aspecto e que podem influenciar em todos os passos do processo, tais como o uso de URIs oficiais, vocabulários adotados, metadados obrigatórios e opcionais, licenças adotadas e o contexto de outras bases de dados complementares. Como pré-requisitos dessa fase é importante que o responsável pelo processo de abertura de dados no âmbito da entidade governamental conheça o esquema de 5 estrelas de Berners-Lee, os 4 princípios dos dados conectados e a nuvem de DAC, para identificar possíveis conexões à Web de dados existente (JOVANOVIK; TRAJANOV, 2017).

\section{A.1.1 Identificar necessidades de dados}

Ao planejar abrir um conjunto de dados ao público, é boa prática mapear o mais cedo possível atores da comunidade de dados que possam fazer uso futuro dos dados. Para isso, é necessário descobrir potenciais usuários que possam ajudar a validar as informações contidas nos dados, em termos de utilidade e relevância. Este levantamento pode facilitar a especificação do 
conteúdo e estrutura dos dados a serem abertos por determinação do plano de dados da instituição (transparência ativa) ou pelos pedidos de acesso à informação vindos da sociedade (transparência passiva). Essa comunicação pode ser o feedback de dados já publicados - dando ideia ao 'ciclo de vida'. Muitas vezes, os dados não chegarão aos usuários finais diretamente, mas sim por meio dos "infomediários" - entidades que recuperam e transformam os dados para serem apresentados a outros grupos de pessoas (JOHNSON; GREENE, 2017; JANSSEN; ZUIDERWIJK, 2014), que também devem ser mapeados. Uma tarefa desejável é a criação de cenários de uso para os dados ou mesmo a definição de questões de competência - modelo de validação de expressividade dos dados representados, comumente utilizadas para avaliação de ontologias. Essa ação pode ajudar a mitigar o risco de despender grandes esforços para coletar, limpar e publicar dados que não sejam de interesse da comunidade ou que não estejam em formatos que sejam úteis para sua reutilização.

- Papéis: gerente de comunidade, especialista de domínio, publicador de dados

- Tarefas: mapear demandas de potenciais usuários dos dados,

- Entrada: conjunto de dados a ser aberto

- Saída: plano simplificado de comunicação para levantamento de necessidades; conjunto de cenários de uso e/ou questões de competência;

- V\&V: plano de comunicação com membros da comunidade e infomediários; cenários de uso, contendo que questões podem ser respondidas com esses dados.

- Ferramentas: hackathons ou comunidades on-line para coletar feedbacks junto à comunidade de dados; para os cenários de uso, pode-se adotar modelos de casos de uso ou questões de competência.

\section{A.1.2 Selecionar/identificar dados a serem abertos}

O passo inicial de abertura dos dados exige o levantamento, a seleção e a priorização dos dados a serem abertos, que podem vir por meio de requisições de pedidos de informação (transparência passiva) ou pela relevância julgada pela própria instituição, alinhada a seu objetivo final (transparência ativa). Para o caso de republicação de dados existentes, os mapeamentos feitos na etapa anterior são utilizados. Após identificar e selecionar as fontes de dados, é necessário i) buscar e compilar todos os dados e documentações disponíveis, como propósito, componentes, modelo de dados e detalhes de implementação; ii) identificar e especificar o esquema de dados e seus relacionamentos (VILLAZON-TERRAZAS et al., 2011). Uma característica desejável deste passo é a disponibilização de dados em tempo real - aqui definido como o mais atualizado possível, mesmo que, em alguns casos seja de granularidade anual ou maior, como os censos populacionais. 
- Papéis: publicador dos dados, especialistas de domínio, alta gestão;

- Tarefas: organizar inventário de dados da instituição, priorizar quais dados serão abertos, definir estratégias de abertura, definir cronogramas e marcos, definir o responsável por cada conjunto de dados a ser aberto;

- Entrada: plano de dados abertos da instituição, caso já tenha sido elaborado; datasets mapeados;

- Saída: plano de ação contendo cronograma de execução da liberação dos dados;

- V\&V: plano de ação com metas para a liberação dos dados;

- Ferramentas: editores ou planilhas de texto, para listar os dados a serem abertos

\section{A.1.3 Especificar conexões externas entre fontes de dados}

Outro passo importante é especificar quais outras fontes de dados podem ser usadas para estender o conjunto original de dados e oferecer informações contextuais para futuras análises. Essas bases de dados podem pertencer à mesma organização - mas que por diversos motivos, são publicados em um dataset diferente - ou a outras organizações, mesmo em outras línguas, disponíveis na Web. Por exemplo, ao analisar os dados de uma escola, pode ser desejável usar a informação de localização da escola para analisar o contexto em que os municípios em que as escolas estão contidas, podendo usar fontes de dados com mais informações sobre as escolas, geográficas ou de conhecimento geral (PENTEADO, 2016).

- Papéis: especialista de domínio, publicador de dados

- Tarefas: especificar que outras bases de dados podem ser reutilizadas para compor soluções para os cenários de uso levantados

- Entrada: cenários de uso, conjunto de dados em questão

- Saída: lista de bases de dados externas que deverão ser usadas para responder às questões dos cenários de uso

- V\&V: lista de bases de dados, com suas respectivas URIs e pontos de ligação com o conjunto de dados em questão

- Ferramentas: editores ou planilhas de texto, para mapear quais os pontos de ligação entre diferentes fontes de dados 


\section{A.1.4 Especificar diretrizes}

Este passo é geralmente negligenciado na literatura. No entanto, acreditamos que seja imprescindível. Neste passo devem ser levantados todas as diretrizes, práticas, ou legislações específicas que possam influenciar a produção, processamento ou publicação dos dados. Especificações institucionais brasileiras, como as definidas pelo e-PING, pela INDA ou pelo e-VoG, em nível federal no Brasil, definem ou restringem decisões técnicas em torno dos artefatos tecnológicos adotados, metadados obrigatórios e opcionais, padrões de URI, padrões de formato de arquivos, dentre outras recomendações que impactam todo o processo. Por exemplo, de acordo com o e-PING, os dados devem ser disponibilizados em formatos XML, JSON, CSV (nível 3) e o e-VoG fornece um vocabulário controlado para categorizar os diferentes tipos de datasets conforme seu tema (ex.: educação, cultura, agricultura, saúde, previdência social, transportes, etc.). Tais diretrizes também frequentemente determinam a necessidade de trazer os dados dos contatos. (HYLAND; WOOD, 2011) apresenta este passo como um 'ingrediente' do processo, porém especificando apenas padrões da W3C, desconsiderando os institucionais.

- Papéis: especialista de domínio, alta gestão, publicador de dados

- Tarefas: levantar toda a documentação que norteia a publicação de dados pela instituição em termos institucionais (padrões internos da organização), legais (por ex.: privacidade e anonimidade de dados pessoais) ou tecnológicos (tecnologias recomendadas ou obrigatórias a serem adotadas).

- Entrada:conjunto de documentos que influenciam o processo de publicação dos dados;

- Saída: listagem de documentos e seções específicas que influenciam o processo de publicação dos dados;

- V\&V: mapeamento de todas diretrizes que impactam a produção

- Ferramentas: editores e planilhas de texto, listando e apontando para as diretrizes cabíveis ao contexto

\section{A.1.5 Especificar metadados}

Os metadados são atributos sobre um recurso informacional que facilitam a descoberta e o reuso dos dados publicados (W3C, 2017), e são críticos para auxiliar que pessoas possam entender e validar os dados, encorajando seu reuso (LAESSIG; JACOB; ABOUZAHR, 2019). Ele deve documentar o contexto dos segmentos de informação presentes no arquivo de dados, desde cada campo, tipo de dados aceitos, descrições, códigos, abreviações, possíveis restrições de valores (metadados estruturais) até mesmo descrever características do arquivo de dados em si, com informações como título, palavras-chave, cobertura espacial, granularidade temporal, data de modificação, categoria dos dados, metodologia de coleta (metadados descritivos). Devem 
ser definidos os metadados do: i) catálogo como um todo, de ii) cada conjunto de dados e de suas iii) distribuições. Em organizações governamentais existem diretrizes de conjuntos de metadados obrigatórios e desejáveis.

- Papéis: engenheiro de ontologias, publicador de dados, especialista de domínio, cientista da informação

- Tarefas: levantar metadados obrigatórios e opcionais para cada dataset; preencher os metadados com os valores correspondentes;

- Entrada: documentos de diretrizes; dados

- Saída: conjunto de metadados preenchidos

- V\&V: metadados em conformidade com diretrizes institucionais e com vocabulários validados por sua sintaxe e sua validade de domínio

- Ferramentas: editores ou planilhas de texto. No caso brasileiro, existe a Cartilha Técnica para publicação de dados abertos no Brasil que contém essa lista.

\section{A.1.6 Especificar, aplicar e validar licenças}

A publicação dos termos da licença de uso dos dados junto aos dados em si é essencial. É por meio da licença de uso dos dados que são estabelecidas as restrições de reuso adotadas pelo publicador dos dados (W3C, 2017). A ausência ou a seleção de uma licença restritiva são barreiras que impedem o desenvolvimento do potencial dos dados abertos - o que pode acontecer pela crença de que não atribuir licença significa que seu uso é aberto, quando, na verdade, o oposto é verdadeiro (LAESSIG; JACOB; ABOUZAHR, 2019). Para os dados abertos conectados, a licença pode estar especificada dentro do datasets ou em URI separada, conectada ao dataset por meio de termos de vocabulário como dcterms:license, dcterms:rights ou schema:license tendo como objeto uma URI resolvível para uma licença de uso. Deve-se verificar também a existência de descrição legível para humanos, criando uma tripla que tenho por objeto a distribuição, por predicado um termo de descrição (wv:waiver) e como objeto o texto da licença, mesmo que em sua forma sumarizada. Essa informação pode adquirir um nível mais complexo onde exista o cruzamento de dados de diferentes fontes, com cada uma possuindo um conjunto diferente de restrições, que por vezes, pode impedir seu enriquecimento com os dados.

- Papéis: consultor jurídico, publicador de dados

- Tarefas: catalogar as licenças existentes ou criar uma nova licença para os dados disponíveis para publicação; associar uma licença a uma versão do dataset; caso reutilize dados de outras fontes, analisar licença de uso dos dados originais, de modo a garantir que nenhum direito de uso é violado; criar metadados que especifiquem o texto da licença e aponte para URI da licença adotada; 
- Entrada: dataset e suas distribuições;

- Saída: licença especificada e atribuída ao dataset;

- V\&V: a licença está atribuída nos metadados, ela é resolvível, associada ao dataset em formato legível por máquina (dcterms:license); verificar se existe a versão legível por humanos (rdfs: comment);

- Ferramentas: para buscar modelos de licenças de uso existentes: Creative Commons Choose ou na página da Open Definition, seção de Licenses. Caso o dataset já exista em formato não conectado, deve-se utilizar a mesma licença. Para aplicar, o CKAN disponibiliza como possível metadado, mas não com representação semântica. Assim, é necessário criar manualmente as triplas.

\section{A.1.7 Projetar padrão de URIs}

As URIs são ferramentas indispensáveis para a publicação de dados conectados. Dada a natureza distribuída da Web, é necessário um mecanismo que permita identificar, encontrar e usar os recursos. Elas permitem identificar inequivocamente um recurso disponível na Web, seja ela um documento ou conceitos do mundo real (pessoas, organizações, tópicos, coisas) de modo que seja possível para um programa de computador processá-lo adequadamente (W3C, 2008a). Este mesma guia da W3C oferece duas maneiras de modelar: por meio de URIs hash (ex.: http://www.example.com/about\#bob) ou por redirecionamento (ex.: http://www.example.com/id/bob, que redireciona para o formato de representação desejado, mediante negociação de conteúdo). Uma boa prática pode ser o uso de PURL (Permanent URL), que consiste na adoção de identificadores persistentes para a gestão de recursos na Web e que age como identificadores permanentes face à infraestrutura dinâmica e em constante mudança da Web. Este tipo de funcionalidade fornece um nível de indireção que permite que os recursos da Web mudem ao longo do tempo sem afetar negativamente os sistemas que dependem deles, fornecendo continuidade de referências para recursos de dados que podem migrar para outros endereços, por motivos técnicos, sociais ou de negócios (ex.: DOI - Digital Object Identifier). Uma boa prática é evitar que o comprimento total da URI seja maior que 80 caracteres (THÉREAUX, 2003), pois impacta no tamanho total do arquivo de dados resultante do processo. Outra boa prática é o uso de URIs mnemônicas, ou seja, que são facilmente interpretadas por humanos para saberem do que se trata, sem ser necessário acessá-las. Além disso, a declaração explícita de como é o padrão de string das URIs, expresso por meio de expressão regular, facilita a compreensão de acesso aos recursos para agentes de software (ZAVERI et al., 2016).

- Papéis: administrador de sistemas, alta gestão

- Tarefas: definir o padrão de como serão representadas as URIs dos dados, levando em conta as diretrizes e organização de domínios da instituição 
- Entrada: diretriz institucional sobre o formato das URIs

- Saída: formato das URIs a serem adotadas para a publicação dos recursos de dados e metadados selecionados; metadados contém expressão regular que define como interpretar as URIs do dataset; configurar serviço de PURL;

- V\&V: verificar a boa prática de tamanho máximo de caracteres na URI (80); verificar a interpretação sobre o significado das URIs; existência de expressão regular que expressa as URIs do dataset; caso adotado, verificar resolução de URIs permanentes que apontem para os dados publicados;

- Ferramentas: Cool URIs, Style Guidelines for Ontologies (modelo do Reino Unido para URIs), e-PING (governo federal brasileiro) para dar suporte às boas práticas de modelagem de URIs.

\section{A.1.8 Criar e manter portal de dados (conectados)}

A tarefa de publicar dados se dá, oficialmente, por meio de um portal de dados criado e mantido pela instituição responsável, sendo este a interface entre a organização e a comunidade de dados. Para isso, é necessário planejar e destinar toda a infraestrutura tecnológica de software, hardware, largura de banda e outros serviços necessários para que esta demanda seja adequadamente atendida junto à comunidade -além de outros serviços necessários para a gestão de usuários e do catálogo de dados (JANEV et al., 2012). Aqui, o portal de dados pode ser entendido tanto como um portal de catálogo de dados (por ex.: CKAN), que também pode disponibilizar API de consulta aos dados, quanto por um endpoint SPARQL, que contempla ferramentas de extração, transformação e carregamento (ETL) para o armazenamento em uma triplestore, bem como da disponibilização de acesso na Web, via protocolo SPARQL de consulta a dados semânticos. No caso ideal, os dados estão publicados em ambos, tirando vantagens de cada portal. Em muitos casos, os portais já existem e o publicador deve seguir suas diretrizes de acesso para realizar a publicação. A W3C compilou uma coleção de estudos e dados de benchmarkings que podem ser usados para escolher a melhor escolha de repositórios de dados conectados: https://www.w3.org/wiki/RdfStoreBenchmarking.

- Papéis: administrador de portal, alta gestão

- Tarefas: cadastrar usuários; criar grupos; definir permissões; catalogar datasets e distribuições; organizar busca no portal; garantir funcionamento das APIs de dados ou de endpoints SPARQL; gerir disponibilização de vocabulários, metadados e licenças; sincronizar diferentes portais, quando existir serviço federado (por ex.: https://data.europa.eu); configurar identidade visual; definir configuração de caracteres, especialmente em ambientes multilíngues; observar regras de acessibilidade aos dados; aplicar diretrizes de segurança aos serviços; atender SLA; 
- Entrada: URL para o portal de dados

- Saída: portal configurado para o contexto da comunidade-alvo; preferencialmente, existe catálogo de dados e triplestore, com referências entre si e representados nos metadados (void:dataDump e void:sparqlEndpoint);

- V\&V: portal operacional, com usuários, grupos e acesso aos datasets e distribuições definidos e operacionais, de acordo com as regras de permissão definidas; acesso operacional às APIs e endpoints SPARQL; presença dos metadados de pontos acesso (void:dataDump e void:sparqlEndpoint);

\section{- Ferramentas:}

- CKAN, Socrata, OpenDataSoft para portais de catálogos de dados;

- Virtuoso, Fuseki, Linked Media Framework, Jena TDB, Sesame, 4Store para armazenamento de triplas RDF com endpoint SPARQL;

- Hydra, para APIs;

\section{A.2 Modelagem}

Nesta fase, o publicador dos dados foca-se na preparação, na modelagem e alinhamento com outros datasets e com a especificação semântica precisa de cada dado fornecida no esquema dos dados abertos. Para isto, são indispensáveis os conhecimentos de especialistas de domínio, engenheiros de ontologia e/ou de profissionais da Ciência da Informação, que detenham o conhecimento de reconhecer, selecionar ou criar quando necessário vocabulários, ontologias ou taxonomias que descrevam os dados. Como regra geral desta fase, deve-se reutilizar o máximo possível de vocabulários existentes, poupando tempo e esforços de desenvolvimento (Bizer et al., 2007).

\section{A.2.1 Pré-processar dados}

A coleta dos dados tem frequentemente como resultado a criação de arquivos de dados nos mais variados tipos de esquemas, granularidade de dados, representações, dentre outras características. Além disso, pode conter erros de formatação, codificação de caracteres, campos faltando, dentre outros problemas. Uma tarefa necessária, e que consome muito tempo (de acordo com (PRESS, 2016) até 60\% do tempo de profissionais analistas de dados) do publicador de dados é limpar (também chamado de higienizar) esses dados, de modo de deixá-los num formato mais estruturado possível. Nesta fase, o responsável deve verificar se todos os campos de dados estão todos presentes, com valores e tipos de dados esperados, além de possíveis transformações de formatação dos valores (como por exemplo, a troca do valor de caractere decimal, o uso de strings complexas de caracteres ou a junção de vários campos em um único). 
- Papéis: especialista de domínio, publicador de dados

- Tarefas: checar a consistência dos dados, transformar para seu formato estruturado, tipos de arquivos correspondentes aos esperados, estrutura esperada;

- Entrada: arquivos com os dados brutos, geralmente vindo de áreas especializadas dentro da organização e centralizadas na equipe de publicação, podendo ser comumente frutos de exportações de sistemas legados (geração automática) ou compiladas manualmente, em planilhas de dados (geração manual);

- Saída: dados em formato estruturado, em nível de granularidade, codificação e formatação desejados;

- V\&V: especialista de domínio valida conteúdo do arquivo estruturado em função de corretude dos dados, correspondência entre cabeçalho e conteúdo, correspondência entre tipos de dados esperados, número de campos esperados em cada registro de dados;

- Ferramentas: OpenRefine, DataWrangler, DataCleaner, editores de planilhas

\section{A.2.2 Normalizar dados}

A natureza descentralizada da Web torna difícil a previsão de como se será dará o reuso dos dados. Caso um dado esteja formatado para uma aplicação específica, seu potencial reaproveitamento fica restrito a aplicações similares, a menos que o consumidor tenha recursos para fazer transformações sobre os dados. Dados como datas, moedas e números podem parecer similares, mas terem diferentes significados em diferentes contextos culturais (W3C, 2017). Uma tarefa que aumenta o potencial de reuso é a normalização desses dados, no sentido de usar representações neutras dos dados, quebrando-o em unidades menores para facilitar seu processamento. Uma boa prática é de separar campos que tragam a informação da unidade junto com o valor no mesmo campo. Por exemplo, uma análise de dados pode usar os dados de orçamento de dois países com diferentes moedas. Uma implementação comum é apenas representar os valores, sem especificar a moeda, deixando implícito o conhecimento para a transformação. Uma implementação normalizada quebra essa informação em dois campos: um com o valor e outro com a especificação da moeda, facilitando o processamento automático por agentes de software.

- Papéis: engenheiro de ontologias, publicador de dados

- Tarefas: mapear campos de dados e metadados que utilizam padrão específico de formatação, com por exemplo datas (ex.: 03-07-2019 significa 03 de julho de 2019 ou 07 de março de 2019), moedas (ex.: R,US) e números (ex.: 1.053 significa mil e cinquenta e três ou um ponto zero cinquenta e três?), formatando-os para algum padrão estabelecido para o domínio. 
- Entrada: conjunto de dados e metadados para ser analisado

- Saída: lista de transformações para cada campo que seja detectado ser feita a normalização

- $\mathbf{V} \& \mathbf{V}$ : cada campo listado deve ser mapeado para seu valor normalizado

- Ferramentas: OpenRefine, DataWrangler, DataCleaner, editores de planilhas

\section{A.2.3 Criar dados}

Por vezes, é desejável criar novos dados sobre os dados originais do dataset, por diversos motivos. Por exemplo, certos algoritmos de análise de dados exigem que não existam dados faltantes na base dados, o que nem sempre acontece em bases de dados reais. Uma prática possível é imputar dados faltantes inferidos a partir dos dados existente, para habilitar o uso desses algoritmos. Em outros casos, pode-se criar um novo campo calculado sobre os dados, que aplique alguma fórmula de indicador por exemplo, de modo a facilitar para o consumidor dos dados. Em outros casos, é possível que o publicador dos dados disponha em mãos tipos de dados não estruturados (como textos). Assim, o publicador pode derivar campos estruturados a partir da informação não estruturada. A adição desses novos dados aumenta o potencial valor dos datasets (W3C, 2017).

- Papéis: publicador de dados, especialista de domínio, gestor da comunidade

- Tarefas: especificar novos campos de dados que devem ser inseridos no dataset original; criar os novos campos calculados; registrar processo de criação (memória de cálculo);

- Entrada: conjunto de dados em questão;

- Saída: conjunto de dados, acrescido de novos campos calculados;

- V\&V: verificar integridade dos campos criados (valores dentro das faixas permitidas e formato válido); verificar se dados faltantes estão preenchidos conforme esperado (caso especificado);

- Ferramentas: OpenRefine, DataWrangler, DataCleaner, editores de planilhas

\section{A.2.4 Pesquisar e reutilizar vocabulários}

Uma grande barreira para a implantação de dados conectados é a dificuldade que publicadores de dados têm de determinar quais vocabulários usar para descrever seus dados (VANDENBUSSCHE et al., 2017). Vocabulários definem os conceitos e relacionamentos usados para descrever uma área de interesse, usados para classificar termos, relações ou restrições que podem ser utilizados em aplicações (W3C, 2017). Diversos vocabulários já foram criados e representam consensos dentro da comunidade dos dados de domínio ao passo que outros 
vocabulários representam dados mais genéricos, usados para representar conceitos e relações válidas para qualquer ambiente como pessoas, lugares. O uso desses vocabulários compartilhados auxilia o processamento automático e a comparação de dados e metadados descritos por eles, evitando ambiguidades entre elementos ou valores similares. Existem serviços Web como LOV no qual é possível pesquisar e verificar se atendem aos requisitos de reusabilidade dos dados em questão. Vandenbussche et al. (2017) trazem um comparativo sobre diferentes serviços de busca de vocabulários. Neste passo, devem ser buscados os vocabulários gerais e específicos do domínio que possam ser usados para descrever os dados. Para cada arquivo de dados é necessário analisar cada campo, julgando se o mesmo será mapeado ou não (existem muitos casos de redundância nos dados, que não precisariam ser remapeados).

- Papéis: engenheiro de ontologias, especialista de domínio, publicador de dados

- Tarefas: buscar, para cada campo dos dados e dos metadados, se já existe sua representação semântica definida em algum vocabulário conhecido

- Entrada: dados e metadados do conjunto a ser anotado

- Saída: mapeamento de cada valor para seu respectivo valor semântico, assinalando quais campos não foram atendidos e que precisam ser criados em novos vocabulários

- V\&V: Todos os campos dos dados e dos metadados devem ter um valor especificado (quando for encontrado um termo correspondente) ou marcado como 'a ser desenvolvido'.

- Ferramentas: LOV, Vocab.cc, Swoogle para a busca de vocabulários de diferentes domínios; BioPortal para vocabulários nas ciências da vida; vocabulários genéricos: FOAF, Dublin Core, SKOS, Schema.org, Creative Commons. Comuns: WSG84 (para localização de latitude e longitude), Time Ontology (modelagem de conceitos relacionados a tempo), RDF Data Cube (informações estatísticas), Dublin Core (informações sobre obras publicadas: páginas web, livros, etc.), FOAF (descrever dados de pessoas e seus relacionamentos), SKOS (categorias e relacionamentos), BIBO (citações bibliográficas), Creative Commons (licenciamentos de recursos informacionais), DOAP (descrição de projetos de software), SIOC (comunidades virtuais), XSD (tipos de dados básicos), DQV (métricas e dimensões de qualidade de dados), DUV (coleta de feedback de consumidores dos dados). Mais genéricos ainda, como DBpedia e Schema.org.

\section{A.2.5 Criar vocabulários}

Conforme explicado anteriormente, os vocabulários servem para descrever os dados, resolvendo problemas de ambiguidade, granularidade e de validação com os dados. No entanto, são poucas as áreas que dispõem de vocabulários de domínio que especificam os conceitos básicos de seu campo de conhecimento (VANDENBUSSCHE et al., 2017). E quanto maior o refinamento 
dos cenários de uso dos dados abertos, é cada vez menor o número de vocabulários específicos, sendo necessária a criação de novos vocabulários ou mesmo a extensão de vocabulários existentes. A literatura fornece diretrizes e metodologias para a criação de novas vocabulários e ontologias (NOY; MCGUINNESS, 2001; SUÁREZ-FIGUEROA, 2010; FERNÁNDEZ-LÓPEZ; GOMEZPEREZ; JURISTO, 1997), que podem ser utilizadas para estender ou criar novos vocabulários = que devem, por sua vez, também estarem publicados na Web. Além disso, é necessário definir um formato para a disponibilização dos vocabulários criados. A W3C oferece um conjunto de boas práticas para nomear e desreferenciar as URIs dos recursos. Um passo de validação importante é garantir que as novas classes criadas usem a declaração owl:disjoint With quando for cabível, de modo a garantir que um indivíduo que seja membro de uma classe não seja membro de outra classe disjunta (SMITH; WELTY; MCGUINNESS, 2004).

- Papéis: engenheiro de ontologia, publicador de dados, especialista de domínio

- Tarefas: criar ou estender vocabulários para anotar os campos marcados em passo anterior como não cobertos por vocabulários existentes;

- Entrada: lista de campos de dados e metadados ainda não mapeados a algum vocabulário;

- Saída: lista de campos de dados e metadados mapeados para os novos termos de vocabulários criados e a publicação dos novos vocabulários na Web

- V\&V: verificar que todos os campos da lista inicial tenham sido mapeados para algum novo termo e/ou vocabulário; os novos vocabulários devem estar publicados na Web;

- Ferramentas: Protégé, NeOn Toolkit, TopBraid Composer, Altova, Neologism

\section{A.2.6 Mapear semanticamente os dados}

Neste passo, os dados devem ser explicitamente anotados em seu formato semântico que, posteriormente serão usados para sua conversão de fato em estruturas de dados RDF (recursos, literais ou nós em branco). Existem diferentes formas de mapeamento (BURANARACH et $a l ., 2017):$ i) mapeamento direto, em que são definidos mapeamentos entre os campos de uma base de dados e sua representação RDF, com mínimo de intervenção humana ii) mapeamento com alinhamento estrutural, que estende o modo anterior ao alinhar um esquema de dados a ontologias existentes, de modo semiautomático e iii) mapeamento com alinhamento de células, em que o valor campos em um registro são mapeados para outros recursos informacionais, transformando-os em URIs conectados a recursos externos. Um comparativo entre diferentes métodos está disponível em (NGOMO et al., 2014). Quanto às validações, alguns cuidados podem ser tomados. Citamos aqui i) não usar blank nodes na modelagem, pois não podem ser referenciados externamente, conflitando com os princípios dos dados conectados (HEATH; BIZER, 2011); ii) evitar usar estruturas RDF como contêineres, coleções e reificação, devido à sua 
complexidade sintática e semântica, particularmente para consultas (HOGAN et al., 2012); iii) verificar se todas as instâncias apresentam propriedades de tipo de dados (owl:DatatypeProperty), em sua forma léxica, o tipo de dados daquele literal (ex: "10"^^xsd:integer), para que seu processamento seja mais eficiente (BEEK et al., 2018); iv) verificar uso de objetos de tipo corretos para os domínios e escopo das propriedades v) algumas ferramentas, como a OpenRefine, permitem pré-visualizar o resultado da conversão para RDF com os mapeamentos feitos - neste momento é possível checar o tamanho médio esperado para as URIs geradas e fazer o refinamento para que tenham um tamanho razoável (80 caracteres, como argumentado no passo 1.4).

- Papéis: engenheiro de ontologias, especialista de domínio

- Tarefas: criar scripts de mapeamento de cada campo para sua representação semântica, definida anteriormente

- Entrada: mapeamento de dados e metadados à sua representação semântica

- Saída: script ou modelo contendo o mapeamento e que será usado por ferramenta de conversão

- V\&V: o script ou modelo de conversão existe, sua sintaxe está correta e cobre todos os campos de dados e metadados especificados no dataset; não são utilizados blank nodes ou containers na modelagem; respeitar especificações de domain e range nas propriedades; objetos literais devem trazer seu tipo de dados; verificar comprimento total das URIs modeladas;

- Ferramentas: OpenRefine, D2RQ stack, Ontop, UnBGOLD, Semantic Media Wiki, OntoWiki, WebDAV, Sponger, StdTrip, XLWrap, RDF123, NOR2O, UltraWrap, GRDDL, TopBraid Composer, ReDeFer, any23, Stats2RDF

\section{A.2.7 Anotar metadados dos datasets}

Os metadados são informações complementares sobre os dados a serem publicados, contextualizando-os para facilitar sua interpretação por potenciais consumidores (W3C, 2017). Neste passo, deve-se registrar os metadados relevantes relacionados ao catálogo, seus datasets e distribuições, conforme metadados especificados na etapa 1.5. Alguns motores de busca, como o Google dataset Search, utilizam metadados dos datasets para indexá-los e facilitar sua descoberta (NOY, 2018). Mais comumente, são especificados os dados descritivos do conjunto, tais como seu criador, data de criação, palavras-chave associadas, assunto, período de coleta dos dados, contatos, etc. Para aumentar seu potencial de reuso, é desejável que os metadados contenham informações sobre a estrutura dos dados, ou seja, o significado de cada campo, seu tipo de dado, restrições de valores.

- Papéis: publicador de dados, especialista de domínio 
- Tarefas: executar programas de conversão de formatos, usando os dados selecionados na Fase 1 e mapeados para vocabulários na Fase 2;

- Entrada: conjunto de dados e scripts/modelos de mapeamento;

- Saída: arquivo contendo todos os metadados preenchidos, em formato RDF;

- V\&V: o arquivo de saída deve conter todos os metadados mapeados registrados; além disso, deve-se verificar, ao menos, sua validade sintática;

- Ferramentas: vocabulários VoID (metadados sobre os datasets, seus meios de acesso e relacionamentos), Dublin Core (sobre a produção do dataset, como título, criador, palavraschave), DCAT (interoperabilidade de catálogos publicados na Web), OPV (entidades, pessoas e atividades envolvidas na sua criação), PAV (versionamento) para os datasets e suas distribuições.

\section{A.3 Conversão}

Nesta fase, os dados em seus formatos originais são transformados para o formato RDF - que é o modelo padrão de acordo com os princípios de dados conectados (BERNERS-LEE, 2006). Assim, em posse dos dados selecionados na Fase 1 e modelados na Fase 2, podemos transformá-los neste formato semântico. É importante lembrar que os metadados também devem ser convertidos para RDF e adicionados junto ao arquivo de dados. Além disso, um dos princípios fundamentais dos dados conectados diz respeito a incluir conexões a outras bases de dados, de modo a se descobrir novos dados (BERNERS-LEE, 2006), o que é feito por meio da conexão entre diferentes fontes.

\section{A.3.1 Conectar dados a outras fontes}

Conectar diferentes datasets (também chamado como reconciliação) faz a Web de dados deixar de ser uma coleção de conjuntos de silos informacionais isolados para uma Web de dados global (BIZER; CYGANIAK, 2009). Uma vez que se tenha definidas quais bases de dados podem ser reaproveitadas para enriquecer os dados em questão, é necessário estabelecer as respectivas conexões. Um desafio que se apresenta nesta tarefa é o de encontrar pontos comuns entre as diferentes bases, para que possa ser feito o cruzamento, conforme mapeado na etapa 1.3. Em casos em que as entidades representadas nos dados possuem identificadores compartilhados entre diferentes bases é relativamente simples, mesmo que se apresentem em diferentes formatos de arquivos. No entanto, o mais comum é que não hajam identificadores comuns entre instâncias de diferentes bases de dados. Para resolver este problema, existem métodos em que o publicador dos dados cria heurísticas para que exista o ponto de conexão - ideal para casos em que existem muitos milhares ou mesmo milhões de instâncias nas bases de dados, tornando infactível a 
conexão manual. Por exemplo, como ligar o campo que especifica a cidade de São Carlos (SP) à Dbpedia, uma vez que essas duas fontes de dados não compartilham um identificador único (ex.: código do município) entre si? O mapeamento apenas por nome leva à página de desambiguação, pois também existe uma cidade chamada São Carlos no estado do Rio de Janeiro. Para isso, são criados os dados de ligação, chamados de linkset, que fazem o mapeamento de instâncias entre dois conjuntos de dados, indicando que se tratam da mesma entidade e, portanto, compartilham os dados.

- Papéis: engenheiro de ontologias, especialista de domínio, publicador de dados

- Tarefas: para cada conexão entre diferentes pares de fontes, estabelecer: i) os identificadores comuns entre elas, de modo a permitir sua junção ou ii) estabelecer heurísticas que façam com que essa junção seja estimada automaticamente via software (esta opção deve ser validada pelo especialista de domínio, de modo a se medir - e que podem variar a depender dos algoritmos de matching de instâncias empregados).

- Entrada: lista de bases de dados a serem conectadas (Fase 1)

- Saída: para cada base de dados listada, criar mapeamento para os casos: i) o identificador compartilhado entre as bases ou ii) conjunto de heurísticas para a determinação automática da junção das instâncias;

- V\&V: testagem dos mapeamentos, buscando encontrar instâncias que não foram pareadas, seja por erro nos dados, má especificação de identificador ou heurísticas fracas de conexão; estimar valores de precisão e revocação das heurísticas adotadas automaticamente, buscando melhorá-las; checar se os relacionamentos descobertos automaticamente são válidos no domínio dos dados; verificar se as URIs das triplas que apontam para recursos externos são desreferenciáveis;

- Ferramentas: OpenRefine, SILK, LIMES, RKBEplorer, GNAT, RDF-AI, Pundit; sameAs Link Validator para validação das conexões descobertas

\section{A.3.2 Enriquecer a base de dados original}

A visão da Web de dados requer que todas as fontes de dados estejam disponíveis, operacionais e com formato semântico ao longo do tempo. Porém, dada a dinamicidade e descentralização da Web, isso raramente é possível. Uma possibilidade de fornecer mais contexto aos dados originais é recuperar os dados mapeados e conectados anteriormente e inseri-los como parte do dataset original, facilitando para o consumidor dos dados e evitando problemas com indisponibilidade futura dos dados. Como exemplo, temos análises de dados estatísticos de políticas públicas, onde existe a fusão (merging) entre diferentes indicadores, ou a comparação ou a fusão de diferentes bases para a preparação das análises (JANEV et al., 2012; PENTEADO, 2016). 
- Papéis: publicador de dados, especialista de domínio

- Tarefas: estender o conjunto de dados inicial com novas informações extraídas das bases externas, fazendo com que ambos sejam parte do mesmo arquivo (observando as restrições de licença de uso dos novos dados);

- Entrada: conjunto de dados em questão e mapeamento de informações que devem ser acrescentadas;

- Saída: conjunto de dados inicial enriquecido com novos campos, vindos das fontes externas de dados, em formato adequado (tipo de dado, faixa de valores, estrutura do campo);

- V\&V: o conjunto de dados apresenta novos campos, mantendo válidas suas propriedades estruturais e sintáticas;

- Ferramentas: LODRefine, MOMIS, Fusepool P3, csv2rdf4lod, DL-Learner, Protégé reasoners, plugins do OntoWiki

\section{A.3.3 Transformar dados e metadados para RDF}

Este é talvez o passo mais importante de todo o processo, uma vez que materializa a transformação dos dados brutos em dados enriquecidos semanticamente (níveis 4 e 5 no esquema de 5 estrelas), em formatos de triplas RDF. Aqui é possível escolher dentre diferentes formas de representação dos dados RDF, como XML, Turtle, N-Triples, JSON-LD. Características dos arquivos de dados - como seu formato, tamanho, tipo de mapeamento, entre outros - influencia a escolha da ferramenta mais apropriada para a tarefa.

- Papéis: publicador de dados

- Tarefas: executar programas de conversão de formatos, usando os dados selecionados na Fase 1 e mapeados para vocabulários na Fase 2;

- Entrada: conjunto de dados brutos e scripts/modelos de mapeamento;

- Saída: arquivo contendo todos os dados em formato RDF;

- V\&V: o arquivo de saída deve conter todos os dados mapeados, empregando os mapeamentos realizados; para os casos de conversão on-line (via mapeamento direto em bases de dados operacionais), deve-se verificar se é possível consultar esses dados; além disso, deve-se verificar, ao menos, sua validade sintática, por meio de ferramentas apropriadas;

- Ferramentas: OpenRefine, D2RQ, Jena, Kettle, StdTrip, csv2rdf4lod, OpenCalais, Alchemy, FOX, Sparqlify, entre outros. Para validar sintaticamente os dados, pode-se utilizar a ferramenta de validação de RDF da W3C: https://www.w3.org/RDF/Validator/. 


\section{A.3.4 Verificar e limpar RDF}

A transformação dos dados, como fase final dos processos de coleta e mapeamento pode introduzir outros tipos de problemas com os dados comuns, como ruídos na estrutura ou o erro na aplicação de termos semânticos, uso de URIs quebrados ou tipos de dados incompatíveis (HOGAN et al., 2012). Esse passo, que verifica os dados e metadados, faz com que seu resultado apresente um maior nível de qualidade, em termos de corretude das informações e resolução dos recursos na Web. A W3C uma recomenda uma linguagem para validação de dados em grafos RDF, a Shapes Constraints Language (SHACL), que consiste em uma linguagem para definir critérios e condições a serem verificados sobre as triplas - o que pode ser útil para modelar validações específicas de contexto ou mesmo conhecimentos gerais (por ex.: data de nascimento anterior à data de morte). Além disso, Debattista, Lange e Auer (2018) trazem alguns dos erros mais comuns, a serem verificados durante esta atividade: i) verificar se todas as classes e propriedades usadas nos dados estão definidas, tomando cuidado com erros de digitação (DEBATTISTA et al., 2015); ii) usar dados de proveniência nos metadados, de modo que os consumidores dos dados possam entender de onde o dado vem e quem produziu (W3C, 2017); iii) verificar que todas as classes, propriedades e atores descritos tem comentário legíveis por humanos, pois um dos objetivo é fazer com que os dados também sejam consumidos por humanos, que possam ler e interpretar o significado dos dado (HEATH; BIZER, 2011); iv) indicar quais vocabulários foram usados na distribuição (por meio do termo void:vocabulary, com escopo para a URI desreferenciável do vocabulário), de modo a auxiliar que humanos possam interpretar melhor o contexto da modelagem (ZAVERI et al., 2016); v) verificar, onde aplicável, que propriedades estejam no predicado e definição de classes no objeto das triplas, com exceção de poucos casos (W3C, 2014b); vi) Mau uso de propriedades, ao construir triplas que definem o escopo de uma propriedade como objeto (owl:ObjectProperty), mas usá-la como propriedade de dados (owl:DatatypeProperty) e vice-versa; vii) verificar a existência de classes ou propriedades descontinuadas (anotadas em ontologia como owl:DeprecatedClass ou owl:DeprecatedProperty), pois estas não são mais recomendadas para uso.

- Papéis: publicador de dados, especialista de domínio

- Tarefas: checar integridade do arquivo e das triplas contidas nele, em diferentes níveis; tomar as ações corretivas necessárias para sanar os problemas identificados, seja para aperfeiçoar um dos passos anteriores ou para adaptar o serviço que disponibiliza os dados;

- Entrada: arquivo de dados RDF;

- Saída: arquivo de dados com correções feitas e registradas; arquivo com validações em formato SHACL;

- V\&V: o arquivo RDF de saída passa em todos os critérios de testes estabelecidos (por ex. Hogan et al. (2012), Villazon-Terrazas et al. (2011): resolução das URIs não retornarem 
códigos 400 ou 500; erros de grafia no mapeamento semântico, termo inexistente no vocabulário reutilizado); verificar erros comuns descritos; o script SHACL não aponta violações dos critérios; metadados corretos;

- Ferramentas: IDLab Turtle Validator, W3C RDF Validator, Vapour (verificações sintáticas); Jena Eyeball, RDF Alerts, VRP (Validating RDF Parser) (verificações sintáticas e semânticas); sameAs Link Validator (verificação de ligações de instâncias); OWL Validator, Oops! (verificação de ontologias); RDFUnit; Luzzu (critérios personalizados); LOD Washing Machine

\section{A.4 Publicação}

Uma vez em posse dos dados transformados para seu formato semântico, é necessário que ele seja disponibilizado para acesso público na Web, usando diferentes formas de acesso (W3C, 2014a). Para isso, tanto os dados em si, quanto seus metadados e os mecanismos de auxílio à descoberta são considerados (VILLAZON-TERRAZAS et al., 2011). O anúncio da disponibilização do dataset à comunidade, tanto por meio dos metadados e sua indexação em mecanismos de busca, quanto ao registro de catálogos de dados oficiais ou extra-oficiais (ex.: Datahub), permitem uma maior visibilidade sobre o dataset. Além disso, é considerada uma boa prática divulgar a disponibilização de novos datasets ou distribuições tanto por meio de mídias tradicionais quanto por facilitar sua indexação a diferentes mecanismos de buscas. De modo a garantir a auditoria e sua rastreabilidade, é necessário versionar os arquivos de dados, por meio do gerenciamento de sua configuração. É necessário também selecionar e aplicar um modelo de licenciamento de uso dos dados. Sem essa licença não é possível estabelecer o grau de reuso desses dados por parte da comunidade.

\section{A.4.1 Versionar dados}

As informações disponíveis na Web mudam constantemente, seja por correções nos dados ou pelo processo natural de evolução e maturação dos dados junto à comunidade. Mesmo pequenas alterações, como a adição de um registro ou a modificação de um valor devem ser registradas para permitir a auditoria de possíveis modificações sobre os dados, tornando-os mais confiáveis. Como resultado, é possível determinar que uma aplicação use uma versão específica dos dados, evitando que defeitos surjam como decorrência dessa alteração. Ferramentas originalmente projetadas para controle de versão de código-fonte em projetos de desenvolvimento de software podem ser usados também para este fim, conforme apontado em um blog da Open Knowledge Foundation, já que traz essa funcionalidade como componente essencial de seu funcionamento. Uma abordagem comum é a de utilizar a data (e também a hora, para casos de temporalidade mais granular que um dia; ou mesmo o uso de timestamps para dados em tempo real) da publicação como parte da URI. Outra abordagem desejável é o uso do protocolo Memento 
(SOMPEL; NELSON; SANDERSON, 2013) que, por meio de negociação em requisições HTTP, é possível acessar a versões de um mesmo recurso em uma determinada data.

- Papéis: publicador de dados

- Tarefas: atribuir um identificador de versão ao conjunto de dado a cada modificação feita sobre ele (a organização deve estabelecer um padrão para o formato do versionamento e um racional de como incrementá-lo, de acordo com a relevância da alteração); atribuir uma nova URI para a nova versão dos dados;

- Entrada: conjunto de dados com versão inicial (por ex.: 1.0, com URI http://exemplo.gov/dados/1.0)

- Saída: conjunto de dados com as modificações necessárias e com acréscimo no valor da versão (por ex.: 1.1 para pequenas modificações com URI http://exemplo.gov/dados/1.1; ou 2.0 para uma grande modificação, com URI http://exemplo.gov/dados/2.0), contendo os comentários sobre o quê foi alterado (rdfs:comment) e com link para versão anterior em seus metadados (pav:previousVersion);

- V\&V: o conjunto de dados inicial foi modificado; o versionamento foi incrementado conforme as regras (data ou numeração); foi atribuída uma nova URI para a nova versão; a nova versão contém comentários e aponta para versão anterior;

- Ferramentas: Semantic Versioning, que fornece um racional para a escolha no incremento da versão; repositórios de código como GIT e Mercurial; TimeGate para implementação de protocolo Memento.

\section{A.4.2 Publicar dados e metadados no portal}

Este passo consiste em efetivamente tornar disponível o acesso ao produto da fase anterior, em que os dados já foram convertidos ao padrão RDF. Para isso, o conteúdo do arquivo contendo todas as informações do dataset deve ser tornado público por meio de uma URI resolvível pela Web, via protocolo HTTP. Esta URI pode apontar para diferentes representações dos dados, sendo as mais comuns, em grau crescente de flexibilidade: i) uma URI para o dump do arquivo RDF, ii) uma URI para uma API em que seja possível consultar os dados segundo determinados parâmetros de busca ou iii) uma URI que aponte para um endpoint SPARQL, ou seja, um triplestore que armazene todas as triplas geradas pelos dados e, por meio da qual, seja possível criar consultas abertas na própria base permitindo junções com dados em outros endpoints (cf. Penteado (2016) para um exemplo de consulta federada). Para atender os requisitos de ecossistema da Web, os dados devem ser processáveis tanto por humanos quanto por agentes de software (W3C, 2017). Atualmente, o mais comum é haver conjuntos de dados formatados e disponibilizados maximizando a compreensão humana em detrimento da processabilidade 
automática (PENTEADO; BITTENCOURT; ISOTANI, 2019a). Este acesso automático pode ser, inclusive, habilitado por meio de negociação de conteúdo, em que o agente de software define em tempo de execução - qual tipo de arquivo deseja recuperar como resposta à consulta sobre os dados. Para uma maior chance de reaproveitamento dos dados é necessário que os metadados estejam acessíveis tanto para humanos quanto para processamento automático por agentes de software - e isso inclui a adição dos acessos aos dados nos metadados dos datasets (usando o termos void:endpoint Sparql <URL $>$ e void:dataDump <URL $>$ ).

- Papéis: administrador de portal e publicador de dados;

- Tarefas: carregar os dados convertidos em RDF para um repositório com acesso via Web, fornecendo acesso total e/ou parcial aos dados, via parâmetros de busca;

- Entrada: arquivo(s) gerado(s) durante o processo de publicação, contendo os dados em si, suas definições de esquema e seus metadados estruturais e descritivos, contendo informações auxiliares (licença, qualidade, etc.).

- Saída: conjuntos de dados disponíveis para acesso ao público, por meio de URIs resolvíveis (representada por API, endpoint SPARQL ou RDF dump);

- V\&V: URIs de acesso aos dados devem estar resolvíveis (resposta HTTP 200 ou 303), trazendo os dados solicitados conforme os parâmetros, para cada uma das formas de acesso (dump, API, endpoint) especificadas nos metadados;

- Ferramentas: importação em plataforma específica, como

- CKAN, Socrata, OpenDataSoft para portais de catálogos de dados (arquivos dump);

- Virtuoso, Apache Jena Fuseki, Linked Media Framework, Sesame, 4Store para armazenamento de triplas RDF com endpoint SPARQL;

- Elda, Puelia (Linked Data API), para gerar APIs semânticas;

- JaCKAN para integração entre OpenRefine e CKAN;

\section{A.4.3 Divulgar os dados publicados}

Uma vez que os dados tenham sido produzidos e disponibilizados ao público é necessário fazer sua divulgação, tanto para humanos (os atores da comunidade) quanto para que máquinas (mecanismos de busca que possam indexá-los em suas consultas). Um pré-requisito para que os consumidores possam acessar os dados produzidos é registrar os dados e metadados no portal de dados, de modo que usuários potenciais possam encontrar o que precisam, diminuindo assim o custo de encontrar os dados corretos (VEENSTRA; BROEK, 2015), feito no passo anterior. Três opções não excludentes podem ser adotadas: 
- Criar mapa de site para mecanismos de busca: implementar o protocolo sitemap para informar web crawlers sobre o novo recurso de dados disponibilizado. Ele foi desenvolvido para auxiliar mecanismos de busca a encontrar o recursos de dados ao anexar um arquivo XML no diretório raiz no servidor Web do portal, contendo informações sobre o recurso dos dados, como: sua URI, sua data de modificação, sua frequência de modificações, e seu grau de importância (FLEINER, 2018).

- Criar declarações nos metadados dos datasets e do catálogo de dados: vocabulários como o voID e o Service Description especificam termos que podem ser usados para que agentes de software possa encontrar mais informações sobre os dados.

- Registrar o portal e os datasets em catálogos. Um passo desejável para conjuntos de dados conectados é registrá-los na $L O D$ Cloud, de modo que ele seja visível a outros conjuntos semânticos já disponíveis na Web (VILLAZON-TERRAZAS et al., 2011). Para isso, são postos diversos critérios, disponíveis no site, como: i) ser resolvível por meio de protocolo HTTP, ii) resolver para conteúdo RDF, com ou sem mecanismo de negociação de conteúdo, iii) conter ao menos mil triplas, iv) estar conectado a datasets já contidos na nuvem, no mínimo com 50 relacionamentos e v) acesso a todo o conjunto de dados via endpoint SPARQL, dump do RDF ou crawling RDF. No entanto, registrar os dados em mecanismos de busca ou catálogos pode não ser suficiente para garantir seu reuso. Um passo complementar é o de anunciar a disponibilização dos novos dados junto a usuários potenciais da comunidade de dados, comunicando sobre seu conteúdo e sua licença de uso. Assim, para atender esta atividade, é necessário que ao menos uma dessas ações seja executada.

- O portal < datahub.io>, descrito em diversos trabalhos na literatura, é limitado para publicações de grande volume, como é o caso de dados governamentais. Além disso, para publicar o dataset é necessário ter uma conta Github ou do Google para ser usada na autenticação de usuário. No caso publicar os arquivos dump para download no CKAN, uma boa prática é de registrar o novo portal de dados em CKAN.org (https://ckan.org/census/), de modo a deixá-lo para demonstração para usuários desta plataforma. O portal Data Catalogs (http://datacatalogs.org) também é um ponto de divulgação que pode ser explorado.

- Papéis: administrador portal, gestor da comunidade

- Tarefas: gerar arquivo sitemap e indexá-lo em mecanismos de buscas, integrar o dataset à LOD Cloud, comunicar junto à comunidade os dados disponibilizados;

- Entrada: URIs de acesso aos dados; 
- Saída: ao menos uma das ações: plano de comunicação com a comunidade; protocolo sitemap implementado; registro no LOD Cloud ou outro catálogo; metadados voID nos datasets.

- V\&V: arquivo sitemap registrado; registro em catálogos (CKAN ou LOD Cloud); registro comunicação feita com stakeholders da comunidade de dados; metadados criados para os datasets (void:dataset e void:sparqlEndpoint) e para a descrição dos serviços Sparql (sd:endpoint).

- Ferramentas: sitemap4rdf para gerar o arquivo XML; cadastro em mecanismo de buscas como Google dataset Search; aqui também é possível encontrar diretrizes para conectar à LOD Cloud especificamente para usuários da plataforma CKAN;

\section{A.5 Exploração}

O universo de dados abertos governamentais contém uma quantidade muito grande de informações e, por vezes, fica difícil para que o consumidor (ou mesmo o produtor) consiga ter consciência (awareness) de tudo o que foi disponibilizado. Uma forma eficiente de tratar este problema é fornecer apresentações complementares dos dados, de modo que o usuário possa navegar pelos dados, descobrindo sua natureza, distribuição, relacionamentos - sem ter que baixá-los, já que, por vezes, se tratam de arquivos muito grandes. Outra forma é disponibilizar softwares com demonstrações de aplicações em cima de certos conjuntos de dados, de modo a demonstrar a reusabilidade dos dados e possíveis mashups. Portais nacionais de dados geralmente catalogam aplicações desenvolvidas sobre seus dados. Por exemplo, o site dados.gov.br traz uma página com algumas aplicações desenvolvidas.

\section{A.5.1 Implantar interface de dados conectados}

Aplicações genéricas de dados conectados, como navegadores, mecanismos de busca semântica ou de aplicações, podem ser muito úteis para que os membros da comunidade possam descobrir os mapeamentos dos dados e suas conexões. As triplas armazenadas em triplestores e endpoints SPARQL geralmente só podem ser acessados via aplicações cliente que usam o protocolo SPARQL e não por outros clientes, como navegadores HTML ou navegadores semânticos. As chamadas interfaces de dados conectados (LDI - Linked Data Interfaces), ou navegadores RDF, fornecem um meio para acessar os recursos de dados. Em RDF, os recursos são identificados com URIs; no entanto essas URIs geralmente não são desreferenciáveis, ou seja, não podem ser acessadas em navegadores semânticos. Os LDI, ao se conectarem a um endpoint SPARQL, melhoram a experiência do usuário ao fornecer acesso a representações HTML dos recursos RDF. Este tipo de apresentação complementar permite que membros da comunidade tenham insights sobre os dados, ao apresentá-los de maneiras que sejam fáceis de entender (W3C, 2017). Além disso, os LDI fornecem acesso aos recursos por meio de negociação de conteúdo, 
em que o cliente passa em sua requisição HTTP qual o formato desejado para o retorno de sua requisição.

- Papéis: administrador do portal, publicador de dados

- Tarefas: implementar ferramenta de interface de dados conectados que fornece acesso às triplas de um endpoint SPARQL em diferentes representações (HTML, CSV, JSON, etc.);

- Entrada: endpoint SPARQL funcional, com as triplas já armazenadas;

- Saída: interface de dados conectados funcional;

- V\&V: conseguir acessar os recursos pelo browser (desreferenciação das URIs por acesso direto) - por ex.: http://dbpedia.org/resource/Curitiba, se acessado pelo navegador redireciona para representação em HTML do recurso; conseguir navegar pelas conexões feitas entre os dados (desreferenciação das URIs pelo valor da propriedade das instâncias);

- Ferramentas: LODView, Pubby, Virtuoso Facets Web Service, Elda, djubby, D2R Server (no caso de mapeamento direto à bases de dados) para navegadores dos dados conectados.

\section{A.5.2 Construir exemplos de uso sobre os dados}

Apenas disponibilizar os dados ao público não é suficiente, especialmente no domínio governamental em que a quantidade e a riqueza de dados é muito alta, onde podemos encontrar datasets com centenas de campos, tornando mais difícil para que os consumidores dos dados possam interpretá-los (W3C, 2017). Particularmente, o público-alvo é composto por desenvolvedores de aplicações ou especialistas de domínio que necessitem buscar, conhecer, analisar e integrar informações presentes em diferentes datasets (KASCHESKY; SELMI, 2013). Possivelmente, as aplicações mais interessantes neste contexto são os de visualização dos dados brutos ou os mashups (CIFUENTES-SILVA; SIFAQUI; LABRA-GAYO, 2011). Fleiner (2018) argumenta que aplicações específicas do domínio fornecem maior awareness sobre possíveis funcionalidades específicas do domínio.

- Papéis: administrador do portal, publicador de dados

- Tarefas: especificar e implementar ferramentas que facilitam aos usuários dos dados sua compreensão;

- Entrada: conjunto de dados em questão, já convertidos;

- Saída: aplicações criadas sobre os dados ou consultas SPARQL que respondam às questões de competência ou casos de uso levantados na fase 1;

- $\mathbf{V} \& \mathbf{V}$ : conseguir implementar e responder (ou ao menos tratar) as questões de competência ou casos de uso postos na fase 1 ; 
- Ferramentas: plugins dos catálogos de dados; página de aplicativos no portal brasileiro de dados abertos.

\section{A.6 Manutenção}

Com os dados conectados já publicados, seu ciclo de vida ainda não acabou. Os dados precisam ser mantidos em serviços estáveis, que resolvam as URIs dos dados usados por aplicações consumidoras ou que contenham informações sobre sua indisponibilidade (seja redirecionando para outro local ou comunicando que os dados não estão mais disponíveis). Simplesmente apagar os dados é considerada uma má prática (W3C, 2017), fazendo com que ocorra links quebrados. Este costuma ser uma fonte de erros e impacta a reutilização dos dados conectados, afetando a percepção de qualidade das fontes de dados. Além disso, é necessário criar um canal de comunicação com a comunidade que utiliza esses dados, de modo a garantir sua evolução e depuração ao longo do tempo.

\section{A.6.1 Definir e implementar requisitos não funcionais}

A implementação da publicação de dados conectados exige a definição e implementação de requisitos não-funcionais que garantam suas vantagens em ambiente de produção (CIFUENTES-SILVA; SIFAQUI; LABRA-GAYO, 2011). De forma mais ampla, frameworks de qualidade podem ser implementados, como os requisitos da ISO 25010 (ISO, 2011), referentes a produtos de software. Como por exemplo: segurança, privacidade, usabilidade, tolerância a falhas, tempo de resposta, estabilidade, adaptabilidade, dentre outros requisitos. Outros frameworks podem ser aplicados, como por exemplo o ITIL (AXELOS, 2019), para o gerenciamento de serviços de TI, que especifica práticas de gerenciamento de níveis de serviço, disponibilidade, capacidade e desempenho, incidentes, solicitações de serviço, configurações de serviço, ativos, dentre outras. Requisitos de qualidade, em dimensões representacionais, contextuais ou intrínsecas e verificados previamente nos datasets, também podem ser adicionados como triplas. Vandenbussche et al. (2017) e Buil-Aranda et al. (2013) listam quatro dimensões gerais que podem ser adotadas como requisitos mínimos para esta atividade: disponibilidade (endpoint SPARQL responde a consultas simples), descoberta dos dados (endpoint fornece descrições sobre os datasets), desempenho (tempo para responder consultas) e interoperabilidade (compatibilidade com protocolo SPARQL 1.1). Outra medida importante é de criar nos metadados os registros de qualidade já medidos no dataset, usando o termo dqv:hasQualityMeasurement, para métricas obtidas nos passo de limpeza do RDF (exemplos no site da Data on the Web Best Practices) e por meio de ferramentas como Luzzu e RDF Unit.

- Papéis: administrador de portal, publicador de dados 
- Tarefas: definir conjunto de requisitos não-funcionais mensuráveis; implementar mecanismos que garantam o atendimento desses requisitos; implementar requisitos mínimos de requisitos; outras verificações podem ser estabelecidas conforme as diretrizes da organização. Por exemplo: uptime do serviço Web, comunicação via HTTPS, práticas de acessibilidade e usabilidade em serviços de governo, dentre outras

- Entrada: conjunto de dados já publicado (endpoint SPARQL disponível via sua URI);

- Saída: mecanismos de mensuração e atendimento dos requisitos especificados; metadados anotados;

- V\&V: verificar requisitos mínimos; verificar se os outros requisitos levantados são atendidos.

- Ferramentas: variável, conforme os requisitos especificados. SPARQLES para verificação dos requisitos mínimos.

\section{A.6.2 Definir e implementar tarefas de preservação dos dados}

Dada a dinamicidade intrínseca do conteúdo da Web, é possível que em determinados momentos as URIs não apontem mais para os recursos de dados, por diversos motivos (mudança de domínio, mudança de organização, mudança nos dados, extinção dos dados ou da organização, etc). No entanto, é uma boa prática preservar os identificadores, indicando como proceder para acessar os dados ou mesmo descobrir que eles foram de fato removidos da Web (W3C, 2017). Vale lembrar que a remoção de dados da Web pode fazer com que aplicações que as utilizem deixem de funcionar sem mesmo se dar conta do que pode ter ocorrido, o que pode prejudicar a percepção de qualidade dos dados ou mesmo da organização que os publica (HYLAND; WOOD, 2011). Manutenções planejadas devem ser comunicadas à comunidade com antecedência. $O$ uso de localizadores de recursos uniformes persistentes (PURL) ou os permalinks são usados para redirecionar ao local apropriado para o recurso requisitado, usando códigos HTTP para o redirecionamento. Com isso, se a URI do recurso de dados muda de local, seu localizador permanente pode ser atualizado. Os usuários dos localizadores permanentes usam sempre o mesmo URI (o permanente), mesmo que o recurso possa ter mudado. (REGINO et al., 2019) identificaram, baseados em revisão da literatura, 7 abordagens para o tratamento do problema de manutenção de links: notificações, hipermídia, controle de mudanças, representação por metadados, modificações de alto nível, mecanismos de gerenciamento de links e baseados em ontologias. Ferramentas foram desenvolvidas para detectar a existência de links quebrados (ou seja, que não são desreferenciados), como a DS-Notify, para garantir a integridade dos links criados.

- Papéis: administrador de portal, administrador de sistema, gestor de comunidade, publicador de dados 
- Tarefas: caso o conjunto de dados não esteja mais disponível no URI solicitado, é necessário indicar como chegar a ele (códigos HTTP 410, 303 ou 503); adotar ao menos uma abordagem de manutenção de links.

- Entrada: conjuntos de dados a serem monitorados;

- Saída: indicação automática de quais dados não estão mais disponíveis e qual a razão;

- V\&V: para conjuntos de dados não resolvidos pela URI, checar códigos HTTP 410 (caso os dados tenham sido deliberadamente removidos da Web), código HTTP 303, (caso ele tenha se mudado para outra URI e seja possível fazer o redirecionamento) ou código HTTP 503 (caso o serviço que oferece os dados esteja indisponível; mostrar mensagem descritiva sobre a mudança dos dados);

- Ferramentas: PURL.org, que faz os redirecionamentos necessários sem quebrar e que configura qual tipo de retorno; para manutenção de links: DS-Notify para envio de notificações de detecção de links quebrados, SILK, que mantém o mapeamento entre datasets e avalia os links mapeados.

\section{A.6.3 Engajar com a comunidade de dados}

A comunidade de dados se refere a um grupo de indivíduos e organizações com diferentes competências (grandes empresas, ONGs, agências governamentais, pesquisadores, especialistas e cidadãos), que compartilha interesses econômicos, sociais ou profissionais ao longo de toda a cadeia de valor - desde a produção, gestão, disseminação, arquivamento e exploração (NAÇÕES UNIDAS, 2000a). Ela colabora criando valor ao: i) fornecer feedback sobre quais dados publicar; ii) contribuir para a depuração da qualidade dos dados e iii) colaborar com outros membros para o desenvolvimento de soluções a partir dos dados (LAESSIG; JACOB; ABOUZAHR, 2019). Feedbacks estabelecem um canal de comunicação entre publicadores e consumidores de dados. $\mathrm{O}$ publicador dos dados deve criar mecanismos para que isso funcione apropriadamente, nomeando um responsável pelo dataset que se engaje com a comunidade para tirar suas dúvidas, buscar proativamente o feedback e capturar estórias de usuários para validar os cenários de uso dos dados (LAESSIG; JACOB; ABOUZAHR, 2019). Diferentes ferramentas podem ser usadas, como formulários de contato, atribuição de nota para a qualidade dos dados e caixas de comentários e, preferencialmente, disponibilizada publicamente para outros membros da comunidade (W3C, 2017). Além de anunciar a disponibilização dos dados, o gestor da comunidade pode colaborar ativamente com membros da comunidade que podem querer usar os dados, especialmente em fases iniciais do processo de abertura, facilitando seu reuso (VEENSTRA; BROEK, 2015).

- Papéis: administrador de portal, publicador de dados, gestor de comunidade;

- Tarefas: fornecer mecanismos que registrem feedbacks dos membros da comunidade de dados; citar a fonte dos dados reutilizados de outras fontes; é desejável vincular os 
comentários feitos sobre os datasets por meio do vocabulário Web Annotation; (W3C (2017); usando os termos oa:hasBody para o conteúdo dos comentários e oa:hasTarget para apontar para a URI do dataset comentado).

- Entrada: conjunto de dados publicados em portal de dados;

- Saída: mecanismo de feedback operacional; dados enriquecidos são mapeados e documentados; metadados contém apontamento para página de comentários;

- V\&V: comentários de qualquer membro da comunidade são direcionados a um ponto focal (dcat:contactPoint); os comentários são registrados e disponibilizados para exame de outros membros; os dados reutilizados de outras fontes são mapeados, quando o publicador não for a fonte primária do conjunto de dados (prov:wasDerivedFrom); metadados do dataset deve apontar para os comentários (ou minimamente, a página de comentários) destinada para ofeedback (oa:hasBody e oa:hasTarget).

- Ferramentas: catálogos de dados geralmente já incluem - nativamente ou via extensões a opção de coleta de feedback; sistema de abertura ao público como o e-SIC para viabilizar a transparência passiva; . 

APÊNDICE

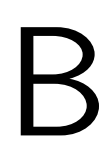

B

\section{MODELO DE METADADOS}

Código-fonte 1 - Template de metadados para a infraestrutura proposta.

1:

2: Oprefix foaf: <http://xmlns.com/foaf/0.1/>.

3: @prefix dbo: <http://dbpedia.org/ontology/>.

4: @prefix owl: <http://www.w3.org/2002/07/owl\#>.

5: @prefix : <@@_URI_BASE_@@ >

6: @prefix time: <http://www.w3.org/2006/time\#> .

7: @prefix xsd: <http://www.w3.org/2001/XMLSchema\#> .

8: Qprefix dcterms: <http://purl.org/dc/terms/>.

9: @prefix rdfs: <http://www.w3.org/2000/01/rdf-schema\#> .

10: Oprefix sd: <http://www.w3.org/ns/sparql-service-description\#>

11: @prefix dcat: <http://www.w3.org/ns/dcat\#>.

12: Oprefix dctype: <http://purl.org/dc/dcmitype/> .

13: @prefix prov: <http://www.w3.org/ns/prov\#> .

14: Qprefix void: <http://rdfs.org/ns/void\#>.

15: Oprefix schema: <https://schema.org/>.

16: @prefix cc: <http://creativecommons.org/ns\#>.

17: @prefix rdf: <http://www.w3.org/1999/02/22-rdf-syntax-ns\#>.

18: @prefix adms: <http://www.w3.org/ns/adms\#> .

19: Oprefix pav: <http://purl.org/pav/>.

20: @prefix dqv: <http://www.w3.org/ns/dqv\#>.

21: @prefix skos: <http://www.w3.org/2004/02/skos/core\#>.

22: Qprefix ent: <http://www.w3.org/ns/entailment/> .

23: Oprefix dbp: <http://pt.dbpedia.org/property/>.

24: @prefix vcard: <http://www.w3.org/2006/vcard/ns\#>.

25: @prefix dce: <http://purl.org/dc/elements/1.1/>. 
26: @prefix dctype: <http://purl.org/dc/dcmitype/> .

27: @prefix format: <http://www.w3.org/ns/formats/> .

28:

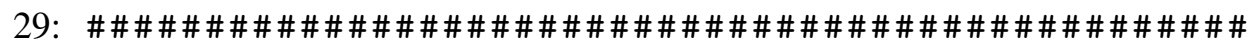

30: <@Q_URI_BASE_@@> a dcat:Catalog ;

31: dc:license <@@_URL_LICENÇA_@@> ;

32: dc:description "Dados do experimento USP" ;

33: dc:creator :criador1;

34: dc:subject "government"@en, "education"@en.

35: 〈@@_URL_LICENÇA_@@> a dcterms:LicenseDocument ;

36: rdfs: comment " " @@_ TEXTO_DA_LICENÇA_@@" " " .

37:

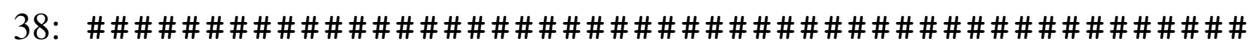

39: \# para cada servidor SPARQL ou CKAN

40: : sparqlServer rdf:type sd:Service, dcat:DataService.

41: : sparqlServer dcat: endpointURL <@Q_URL_SPARQL_@Q > .

42: : sparqlServer sd: endpoint <@@_URL_SPARQL_@@ > .

43: : sparqlServer sd:defaultEntailmentRegime ent:RDFS .

44: : sparqlServer rdfs:comment "Representa um servidor SPARQL" .

45: \# para cada tipo de dado que for dipsonbilizado pelo endpoint

adicionar aqui. para consulta: https://www.w3.org/ns/

formats /

46: : sparqlServer sd:resultFormat formats:Turtle.

47: : sparqlServer sd:resultFormat formats:RDF_XML .

48: : sparqliserver sd:resultFormat formats: JSON-LD.

49: : sparqlServer sd:resultFormat formats:SPARQL_Results_CSV .

50: : sparqlServer sd:resultFormat formats:SPARQL_Results_JSON .

51: :sparqlServer sd:supportedLanguage :SPARQL11Update .

52: : SPARQL11Update a sd:Language ;

53: rdfs:label "SPARQL 1.1 Update"@pt ;

54: rdfs:comment "sd:SPARQLUpdate is an sd:Language representing

the SPARQL 1.1 Update language."@en.

55: \#sd:Service owl:disjointWith dcat:DataService .

56 :

57: ent:RDFS a sd:EntailmentRegime.

$58:$

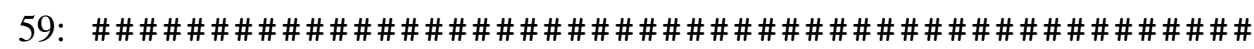

60: \# Catálogo (ou grafo nomeado) no servidor

61: : catalogo rdf:type dcat:Catalog.

62: : catalogo dcterms:title "Experimento USP"@pt .

63: : catalogo dcterms:description "@@_DESCRICAO_CATALOGO_@@"@pt .

64: : catalogo rdfs:label "@@_TITULO_CATALOGO_@@"@pt . 
65: : catalogo foaf:homepage <@@_HOMEPAGE_CATALOGO_@@ > .

66: :catalogo dcterms:publisher :publicador.

67: : catalogo dcterms:creator :criador1.

68: : catalogo dce:language "pt-br" - xsd:language .

69: : catalogo dcat:keyword " "@pt, " "@pt, " "@pt .

70: :catalogo dcterms:spatial :local1.

$71:$

72: <@@_HOMEPAGE_CATALOGO_@@ > a foaf: Document.

73:

74: \# para cada dataset dentro do catálogo

75: : catalogo dcat:dataset : dataset1.

76: : catalogo dcat:dataset : dataset2.

$77:$

$78:$

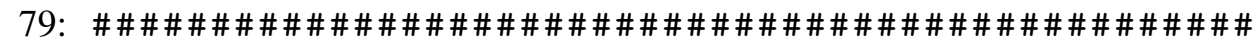

80: \# DATASETS

81:

82: :versaoInicial a dcat: Dataset ;

83: dct:title "Não existe versão anterior" ;

84: dct:creator : criador 1 .

85:

86: \# Dataset1: Estados

87: :dataset1 rdf:type dcat:Dataset, void:Dataset, dctype:

Collection, prov:Entity .

88: :dataset1 dcterms:title "@@_TITULO_DATASET_@@"@pt .

89: : dataset1 rdfs:label "@@_TITULO_DATASET_@@"@pt .

90: : dataset1 dcterms:description "@@_DESCRICAO_DATASET_@@"@pt .

91: :dataset1 dcat:keyword " "@pt, " "@pt, " "@pt .

92: :dataset1 foaf:homepage <@@_HOMEPAGE_DATASET_@@> .

93: : catalogo void:uriRegexPattern "@@_REGEX_URI_@@" .

94: : dataset1 dcterms: source <@@_URL_DADOS_ORIGINAIS_@Q > .

95: : dataset1 dcterms:publisher : publicador.

96: : dataset1 dcterms:creator : criador1.

97: : dataset1 dcat: theme <@@_URL_TEM_EVOG_@@ $>$.

98: : dataset1 dce:language "pt-br"^xsd:language .

99: : dataset1 owl:versionInfo "@@_VERSAO_DATASET_@@" .

100: : dataset1 adms:versionNotes "@@_COMENTARIOS_DA_VERSAO_@@"@pt .

101: : dataset1 pav:previousVersion :versaoInicial.

102: : dataset1 dcterms:license <@Q_URL_LICENÇA_@@ > .

103: : dataset1 dcat:contactPoint [ a vcard:Organization; rdf:value < @Q_URL_FORMULARIO_CONTATO_@Q > ] ; 
104: : dataset1 void:dataDump <@@_URL_DUMP_DATASET_@@ > \# endereço

direto para download do arquivo de dados

105: : dataset1 void:sparqlEndpoint <@@_URL_SPARQL_ENDPOINT_@@ > .

106: : dataset1 void:uriSpace "@@_URI_BASE_@@" .

107: : dataset1 void:feature formats:Turtle.

108: : dataset1 void:feature formats:RDF_XML .

109: : dataset1 void:feature formats:N-Triples.

110: : dataset1 schema:datePublished "

QQ_DATA_PUBLICACAO_YYYY_MM_DD_Q@" .

111: :dataset1 schema: dateModified "

QQ__DATA_MODIFICACAO_YYYY_MM_DD_@@" .

112: : dataset1 schema:measurementTechnique "@@_InSTRUMENTO_@@" . \# que instrumento foi usado para medir

113: \# :dataset1 void:urilookupEndpoint

114: : dataset1 dcterms:temporal <@@_ANO_DO_DATASET_@@> . \# ex: <http ://reference.data.gov.uk/id/year/2015>

115: :dataset1 dcterms:spatial :local1 . \# Granularidade geográfica

(qual a unidade física representada nos dados? país, estado , escola?)

116: :dataset1 dcterms:accrualPeriodicity <http://purlorg/cld/freq/

biennial> \# Granularidade temporal: conferir possiveis

valores em: <http://purl.org/cld/freq/>

117: :dataset1 dcterms:coverage :esfera1.

118: : dataset1 dcterms: coverage : poder1.

119: : dataset1 prov:wasGeneratedBy :atividade 1 .

120: : dataset1 prov:wasAttributedTo : criador 1 .

121: : dataset1 owl:versionInfo "@@_VERSAO_DISTRIBUICAO_@@" .

122:

123:

124: :atividade1 rdf:type prov:Activity .

125: : atividade1 prov: wasAssociatedWith :criador1.

126: : atividade1 prov:startedAtTime "@@_HORARIO_INICIO_EXECUCAO_YYYY -MM-DD_@@" - xsd:dateTime.

127: :atividade1 prov:endedAtTime "@@_HORARIO_FIM_EXECUCAO_YYYY -MMDD_@Q"

128: : atividade1 rdfs: label "Criação do dataset"@pt.

129:

130:

131: \# para cada vocabulário usado, preencher aqui

132: : dataset1 void:vocabulary <@@_URL_VOCABULARIOS_USADOS_@@> . \# exemplo: void:vocabulary <http://xmlns.com/foaf/0.1/>. 
134: \# para cada diretriz atendida, preencher aqui

135: : dataset1 dcterms: conformsto <

@@_URL_PARA_PADRAO_EM_CONFORMIDADE_@@ >

136: <@@_URL_PARA_PADRAO_EM_CONFORMIDADE_@@> a dcterms:Standard .

137:

138: \# para cada distruição, adicionar um registro aqui

139: : dataset1 dcat:distribution : dist1.

140:

141: <@@_URL_TEM_EVOG_@@> rdf:type skos:Concept.

142: <@@_URL_TEM_EVOG_@@> dcterms:title "< @Q_TITULO_CATEGORIA_EVOG_@@ $>$ _ \# procurar em http://vocab.e .gov.br/

143:

144: <@@_URL_DADOS_REUTILIZADOS_@@> rdf:type prov:Entity .

145:

146:

147: : publicador rdf:type foaf:Agent.

148: : publicador rdfs:label "@@_NOME_ENTIDADE_PUBLICADORA_@@"@pt .

149: : publicador foaf: name "@@_NOME_ENTIDADE_PUBLICADORA_@@"@pt .

150: : publicador schema: url <@@_URL_PUBLICADOR_@@ > .

151:

152: : criador1 a foaf:Person, dcterms:Agent, prov:Agent.

153: : criador1 foaf:name "@@_SEU_NOME_AQUI_@@"@pt .

154: : criador1 foaf:mbox <mailto:@@_SEU_EMAIL_AQUI_@@ > .

155: : criador1 prov:actedOnBehalfof : publicador.

156:

157: : local1 rdf:type dcterms:Location .

158: : local1 rdfs:label "Brasil"@pt .

159:

160: : esfera1 rdf:type dcterms: Jurisdiction .

161: : esfera1 rdfs:label "Federal "@pt.

162:

163: : poder1 rdf:type dcterms: Jurisdiction.

164: : poder1 rdfs:label "Executivo"@pt.

165:

166: \# Dataset2: Ideb

167: :dataset2 rdf:type dcat:Dataset, void:Dataset, dctype:

Collection, prov:Entity .

168: : dataset2 dcterms:title "@@_TITULO_DATASET_@@"@pt .

169: :dataset2 rdfs:label "@@_TITULO_DATASET_@@"@pt .

170: : dataset2 dcterms:description "@@_DESCRICAO_DATASET_@@"@pt .

171: :dataset2 dcat:keyword ""@pt, " "@pt, " "@pt. 
172: : dataset2 foaf:homepage <@@_HOMEPAGE_DATASET_@@> .

173: : catalogo void:uriRegexPattern "@@_REGEX_URI_@@" .

174: : dataset2 dcterms: source <@@_URL_DADOS_ORIGINAIS_@@ > .

175: : dataset2 dcterms:publisher : publicador.

176: : dataset2 dcterms:creator : criador1.

177: : dataset2 dce:language "pt-br" - xsd:language.

178: : dataset2 owl:versionInfo "@@_VERSAO_DATASET_@@" .

179: : dataset2 adms:versionNotes "@@_COMENTARIOS_DA_VERSAO_@@"@pt .

180: :dataset2 pav:previousVersion :versaolnicial.

181: : dataset2 dcterms:license <@@_URL_LICENÇA_@@> .

182: : dataset2 dcat:contactPoint <@Q_URL_FORMULARIO_CONTATO_@Q > .

183: : dataset2 schema:datePublished " @@_DATA_PUBLICACAO_YYYY_MM_DD_@Q" .

184: : dataset2 schema:dateModified " QQ_DATA_MODIFICACAO_YYYY_MM_DD_Q@" .

185: : dataset2 void:dataDump <@@_URL_DUMP_DATASET_@@> . \# endereço

direto para download do arquivo de dados

186: : dataset2 void:sparqlEndpoint <@@_URL_SPARQL_ENDPOINT_@@ > .

187: :dataset2 dcterms:temporal [ a dcterms:PeriodofTime; rdf:value

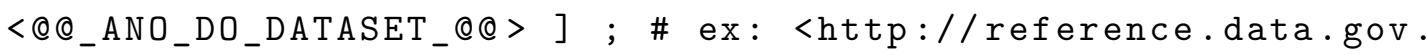
uk/id/year/2015>

188: :dataset2 dcterms:spatial :local1. \# Granularidade geográfica (qual a unidade física representada nos dados? país, estado , escola?)

189: :dataset2 dcterms:accrualPeriodicity <http://purl.org/cld/freq/ biennial> . \# Granularidade temporal: conferir possiveis valores em: <http://purl.org/cld/freq/>

190: : dataset2 schema:measurementTechnique "@@_InSTRUMENTO_@@ " . \# que instrumento foi usado para medir

191: :dataset2 dcterms:coverage :esfera1.

192: : dataset2 dcterms: coverage : poder1.

193: : dataset2 void:uriSpace <@Q_URI_BASE_Q@ > .

194: : dataset2 dcat: theme <@Q _URL_TEM_EVOG_@@ . \# dcat:theme é

subproperty de dcterms:subject, admite apenas rdfs:Resources

195: : dataset2 prov:wasGeneratedBy :atividade 1 .

196: : dataset2 prov:wasAttributedTo : criador 1.

197: : dataset2 void:feature formats:Turtle.

198: : dataset2 void:feature formats:RDF_XML .

199: :dataset2 void:feature formats:N-Triples.

200:

201:

202: <@@_HOMEPAGE_DATASET_@@> a prov:Entity, foaf:Document ; 
203: rdfs:label "IDEB por estado" ;

204: prov: wasttributedTo :criador ;

205: prov: wasGeneratedBy :atividade1.

206:

207: <@Q_URL_LICENÇA_@@> a dcterms:LicenseDocument ;

208: $\quad$ rdfs: comment " " "@@_TEXTO_DA_LICENÇA_@@ " " " .

209:

210: \# para cada vocabulário usado, preencher aqui

211: :dataset2 void:vocabulary <@@_URL_VOCABULARIOS_USADOS_@@> . \# ex: void:vocabulary <http://xmlns.com/foaf/0.1/>.

212:

213: <http://purl.org/cld/freq/biennial> a dct:Frequency ;

214: $\quad$ rdfs:label "Bienal"@pt.

215:

216: \# para cada diretriz atendida, preencher aqui

217: : dataset2 dcterms: conformsTo <

$$
\text { @@_URL_PARA_PADRAO_EM_CONFORMIDADE_@@ }>\text {. }
$$

218:

219: \# para cada dataset reaproveitado, preencer aqui

220: : dataset 2 prov:wasDerivedFrom : dataset 1 .

221:

222: \# para cada distruição, adicionar um registro aqui

223: : dataset2 dcat:distribution : dist2 .

224: :dataset 2 dcat:distribution : dist 3 .

225:

226: <@@_URL_TEM_EVOG_@@> rdf:type skos:Concept.

227: <@@_URL_TEM_EVOG_@@> dcterms:title "< QC_TITULO_CATEGORIA_EVOG_@Q $>"$. \# procurar em http://vocab.e .gov.br/

228:

229: <@@_URL_DADOS_REUTILIZADOS_@@> rdf:type prov:Entity .

230:

231:

232:

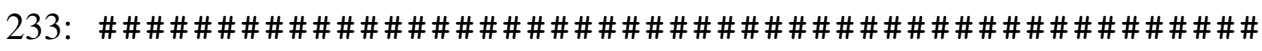

234: \# Distribuição 1: Estados

235: : dist1 rdf:type dcat:Distribution.

236: : dist1 dcterms:title "@@_TITULO_DISTRIBUICAO_@@"@pt .

237: : dist1 rdfs:comment "@@_TITULO_DISTRIBUICAO_@@"@pt .

238: : dist1 dcterms:description "@@_DESCRICAO_DISTRIBUICAO_@@"@pt .

239: : dist1 dcterms:license <@Q_URL_LICENÇA_@Q > .

240: : dist1 dcat:downloadURL <@@_URL_DOWNLOAD_@@ > . 
241: : dist1 owl:versionInfo "@Q_VERSAO_DISTRIBUICAO_@Q" .

242: : dist1 dcat:accessURL <Q@_URL_SPARQL_@Q > ;

243:

244: \# Distribuição 2: Ideb 2015

245: : dist2 rdf:type dcat:Distribution .

246: : dist2 dcterms:title "@@_TITULO_DISTRIBUICAO_@@"@pt .

247: : dist2 rdfs:comment "@@_TITULO_DISTRIBUICAO_@@"@pt .

248: : dist2 dcterms:description "@@_DESCRICAO_DISTRIBUICAO_@@"@pt .

249: : dist2 dcterms:license <@Q_URL_LICENÇA_@@ >

250: : dist2 dcat: downloadURL <@@_URL_DOWNLOAD_@Q > .

251: : dist2 owl:versionInfo "@Q_VERSAO_DISTRIBUICAO_QQ " .

252: : dist2 dcat:accessURL <@@_URL_SPARQL_@@ > ;

253:

254:

255: \# Distribuição 3: Ideb 2017

256: : dist3 rdf:type dcat:Distribution .

257: : dist3 dcterms:title "@@_tITULO_DISTRIBUICAO_@@"@pt .

258: : dist3 rdfs:comment "@@_TITULO_DISTRIBUICAO_@@"@pt .

259: : dist3 dcterms:description "@@_DESCRICAO_DISTRIBUICAO_@@ "@pt .

260: : dist3 dcterms:license <@Q_URL_LICENÇA_@@ > .

261: : dist3 dcat: downloadURL <Q@_URL_DOWNLOAD_@Q > .

262: : dist3 owl:versionInfo "@@_VERSAO_DISTRIBUICAO_@@" .

263: : dist13 dcat:accessURL <@@_URL_SPARQL_@@> ;

264:

265:

266: <@@_URL_LICENÇA_@@> a dcterms:LicenseDocument.

267:

268: \# para cada medida de qualidade aferida, preencher aqui

269: : dist1 dqv:hasQualityMeasurement :medida1, :medida2.

270: : dist2 dqv:hasqualityMeasurement :medida1, :medida2.

271: : dist3 dqv:hasqualityMeasurement :medida1, :medida2.

272:

273: :medida1 rdf:type dqv:QualityMeasurement .

274: : medida1 dqv: isMeasurement0f : p1.

275: :medida1 rdfs: comment "Medida de qualidade P1" .

276: :medida1 dqv:value "@@_VALOR_METRICA_QUALIDADE_P1_@@" .

277:

278: :medida2 rdf:type dqv:QualityMeasurement .

279: :medida2 dqv:isMeasurement0f : 11 .

280: : medida2 rdfs: comment "Medida de qualidade L1" .

281: : medida2 dqv:value "@@_VALOR_METRICA_QUALIDADE_L1_@@" .

282: 


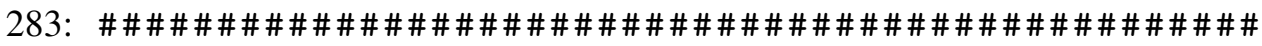

284: \# Definições de qualidade - servem para todos os níveis - NÃO ALTERAR

285:

286: \# Nível de categorias de qualidade

287: :accessibility rdf:type dqv:Category .

288: : accessibility skos:preflabel "Acessibilidade"@pt .

289: :intrinsic rdf:type dqv:Category .

290: : intrinsic skos:preflabel "Intrínsecos"@pt .

291: : contextual rdf:type dqv:Category .

292: : contextual skos:preflabel "Contextual "@pt .

293: :representational rdf:type dqv:Category .

294: :representational skos:preflabel "Representacional"@pt .

295:

296: \#Nível de dimensões de qualidade

297: : concisaoRepresentacional rdf:type dqv:Dimension .

298: : concisaoRepresentacional skos:prefLabel "Concisão representacional"@pt.

299: : concisaoRepresentacional dqv:inCategory :representational .

300: : interoperabilidade rdf:type dqv:Dimension .

301: : interoperabilidade skos:prefLabel "Interoperabilidade"@pt .

302: : interoperabilidade dqv:inCategory :representational .

303: : interpretabilidade rdf:type dqv:Dimension .

304: : interpretabilidade skos:prefLabel "Interpretabilidade"@pt .

305: : interpretabilidade dqv: inCategory :representational .

306: :versatilidade rdf:type dqv:Dimension .

307: : versatilidade skos:prefLabel "Versatilidade"@pt .

308: :versatilidade dqv:inCategory :representational .

309: : proveniencia rdf:type dqv:Dimension .

310: : proveniencia skos:prefLabel "Proveniência"@pt .

311: : proveniencia dqv:inCategory : contextual .

312: : compreensibilidade rdf:type dqv:Dimension .

313: : compreensibilidade skos:prefLabel "Compreensibilidade"@pt .

314: : compreensibilidade dqv: inCategory : contextual .

315: : concisao rdf:type dqv:Dimension .

316: : concisao skos:preflabel "Concisão"@pt .

317: : concisao dqv:inCategory :intrinsic .

318: : consistencia rdf:type dqv:Dimension .

319: : consistencia skos:prefLabel "Consistência"@pt .

320: : consistencia dqv:inCategory : intrinsic .

321: :validadeSintatica rdf:type dqv:Dimension .

322: : validadeSintatica skos: preflabel "Validade sintática"@pt . 
323: :validadeSintatica dqv: inCategory :intrinsic .

324: : disponibilidade rdf:type dqv:Dimension.

325: : disponibilidade skos:preflabel "Disponibilidade"@pt .

326: : disponibilidade dqv:inCategory :accessibility .

327: :licenciamento rdf:type dqv:Dimension.

328: :licenciamento skos:prefLabel "Licenciamento"@pt .

329: :licenciamento dqv:inCategory :accessibility .

330: :interligacao rdf:type dqv:Dimension .

331: : interligacao skos:prefLabel "Interligação"@pt .

332: : interligacao dqv: inCategory :accessibility .

333: : desempenho rdf:type dqv:Dimension .

334: : desempenho skos:preflabel "Desempenho"@pt .

335: : desempenho dqv:inCategory :accessibility .

336:

337: :rc1 rdf:type dqv:Metric.

338: :rc1 skos:definition "IN3 - Uso de classes e propriedades indefinidas" @pt.

339: :rc1 rdfs:comment "IN3 - Uso de classes e propriedades indefinidas" @pt.

340: :rc1 dqv:inDimension :interpretabilidade .

341:

342: : p1 rdf:type dqv:Metric.

343: :p1 skos:definition "P1: Informações básicas de proveniencia" Qpt .

344: :p1 rdfs:comment "P1: Informações básicas de proveniencia"@pt

345: : p1 dqv:inDimension : proveniencia.

346:

347: : 11 rdf:type dqv:Metric.

348: : 11 skos:definition "L1 - Licença legível por máquina"@pt.

349: : 11 rdfs:comment "L1 - Licença legível por máquina"@pt .

350: :l1 dqv:inDimension :licenciamento.

351:

352:

353: format:Turtle a void:Technicalfeature; a format:Format ;

354: rdfs:label "Unique identifier for the RDF Serialization in Turtle".

355: format:RDF_XML a void:TechnicalFeature; a format:Format ;

356: rdfs:label "Unique identifier for the RDF/XML Serialization in Turtle".

357: format:N-Triples a void:TechnicalFeature; a format:Format ; 
358: rdfs:label "Unique identifier for the N-Triples Serialization in Turtle".

359: format:JSON-LD a void:TechnicalFeature; a format:Format ;

360: rdfs:label "Unique identifier for the JSON-LD Serialization in Turtle".

361: format:SPARQL_Results_CSV a void:TechnicalFeature; a format: Format ;

362: rdfs:label "Unique identifier for the SPARQL Results in CSV file format.".

363: format:SPARQL_Results_JSON a void:Technicalfeature; a format: Format ;

364: rdfs:label "Unique identifier for the SPARQL Results in JSON file format.". 

APÊNDICE

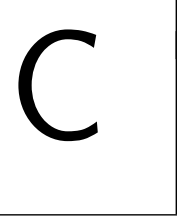

\section{TERMO DE CONSENTIMENTO}

A seguir é mostrado o documento usado com os participantes após sua participação no experimento, para coletar suas percepções em torno do que foi trabalhado.

\section{C.1 Termo de consentimento livre e esclarecido}

Esta é uma pesquisa sobre "Modelo de infraestrutura para publicação de dados abertos governamentais conectados de qualidade" que faz parte do projeto de doutorado em Ciência da Computação do aluno Bruno Elias Penteado, sob orientação do professor Seiji Isotani, ambos do Instituto de Ciências Matemáticas e da Computação da Universidade de São Paulo (ICMC/USP), campus São Carlos.

Todas as respostas serão anônimas e todos os resultados obtidos serão utilizados somente para fins acadêmicos.

Ao aceitar participar desta pesquisa, você está ciente e concorda com os itens a seguir:

1. Você está sendo convidado a participar da avaliação de uma metodologia de produção de dados conectados em âmbito governamental;

2. Você foi selecionado para ser voluntário e sua participação não é obrigatória;

3. A qualquer momento você pode desistir de participar e retirar seu consentimento;

4. Sua recusa não trará nenhum prejuízo em sua relação com os pesquisadores e instituições envolvidas;

5. Essa pesquisa tem por objetivo principal a obtenção de dados relativos ao processo de produção de dados abertos conectados em um contexto de dados governamentais;

6. Sua participação nesta pesquisa consistirá em realizar as atividades propostas no processo proposto na metodologia e responder aos questionários; 
7. As informações obtidas por meio desta pesquisa serão confidenciais e asseguramos o sigilo sobre sua participação;

8. Os dados não serão divulgados de forma a possibilitar sua identificação;

9. Esta é uma cópia do termo onde constam os dados do responsável pela pesquisa, com a qual você pode dirimir dúvidas sobre o projeto e sua participação a qualquer momento.

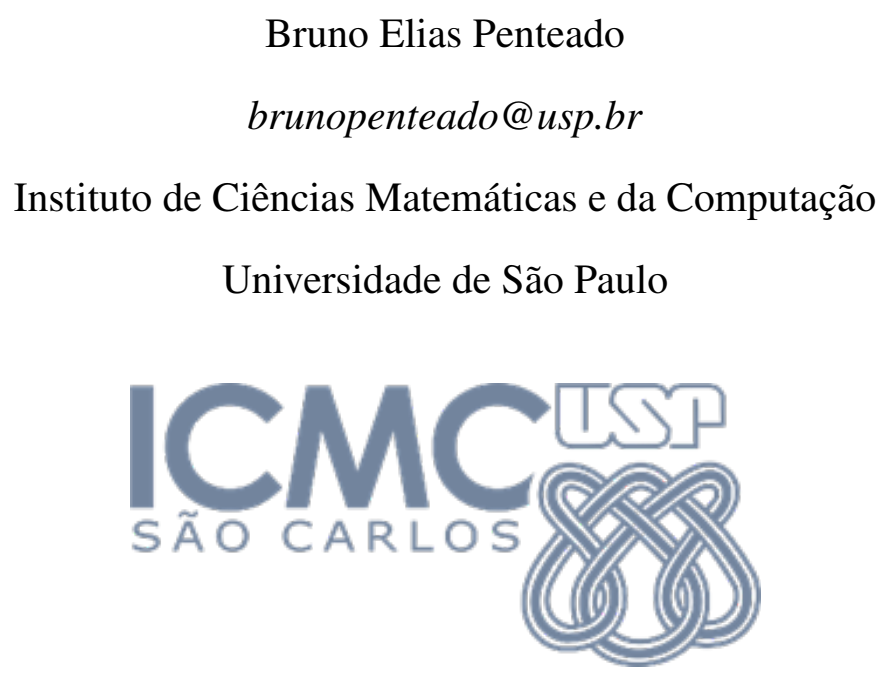

Fonte: Elaborada pelo autor. 
APÊNDICE

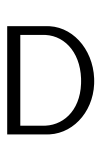

ROTEIRO DE EXPERIMENTO

\section{D.1 Roteiro do experimento}

A seguir é mostrado o documento usado com os participantes para a condução do experimento. 


\section{Roteiro do experimento}

\section{Objetivo}

Este estudo visa explorar os passos, tecnologias e outros recursos necessários para publicar dados abertos governamentais conectados (DAGC) que atendam a critérios de qualidade específicos para dados conectados. O estudo é parte do escopo da tese de doutorado intitulada "Modelo de ciclo de vida para publicação de dados abertos governamentais conectados de qualidade".

A Figura 1 demonstra uma visão geral do modelo de ciclo de vida proposto, composto por 5 fases. Primeiramente, é feita a especificação dos materiais necessários para a publicação dos dados, com os dados, especificações técnicas e diretrizes institucionais a serem adotados. Em seguida, os dados são pré-processados e modelados para seu formato semântico, usando vocabulários existentes na Web ou criados para o contexto em questão. Após mapeados, os dados são convertidos em triplas RDF e conectados a fontes externas, para aumentar o contexto dos dados originais. Em seguida, na publicação, os dados são divulgados ao público por meio de catálogos de dados e triplestores de RDF. Para uma melhor conscientização sobre os dados disponíveis, são oferecidas formas de exploração dos dados, por meio de interfaces de navegação nos dados e de exemplos de uso. Por fim, são necessárias práticas para a manutenção e preservação desses dados, garantindo a continuidade em aplicações que os consuma. 


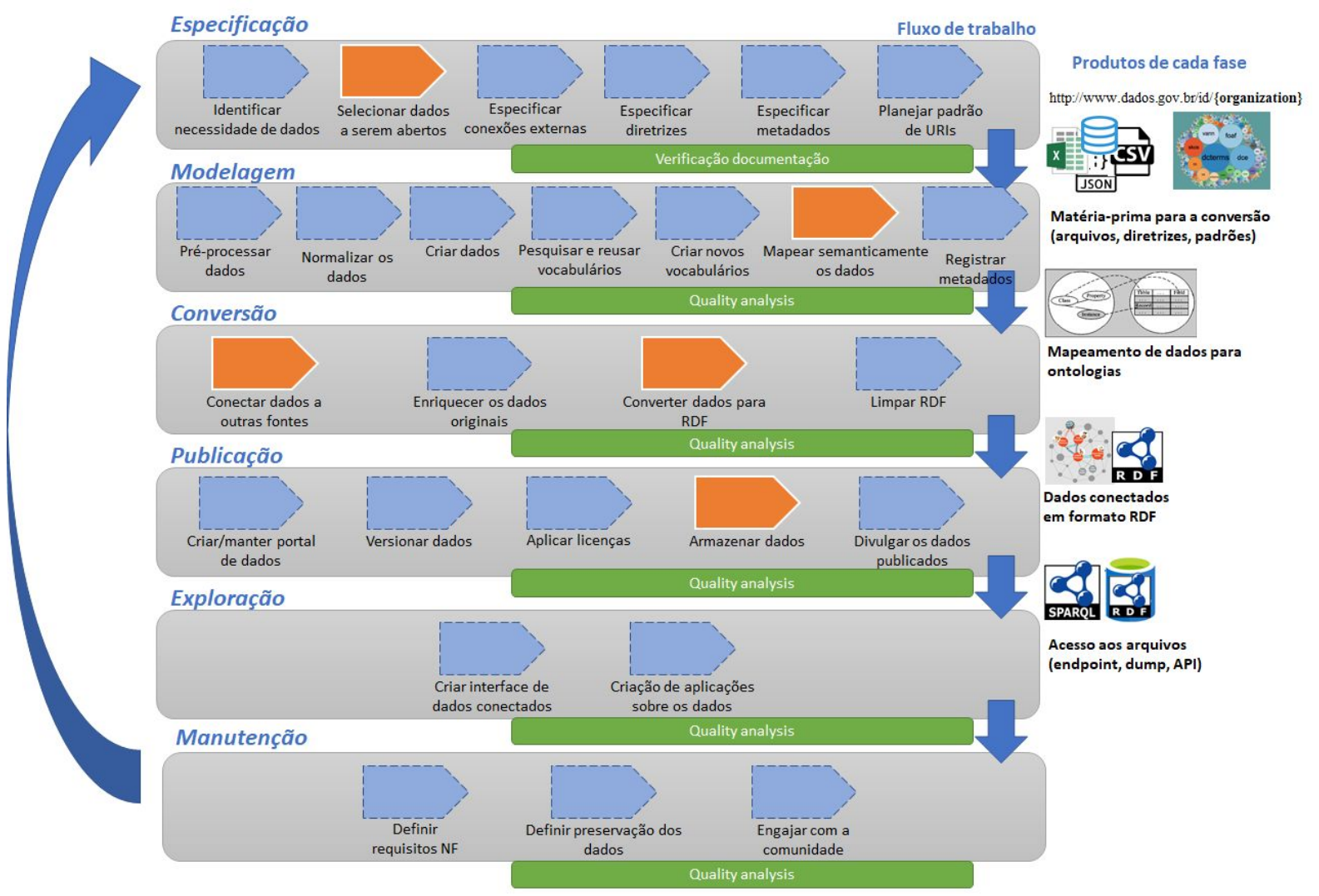

Figura 1. Fases e atividades do modelo de ciclo de vida de publicação de DAGC.

A Figura 2 demonstra a arquitetura geral, com os componentes básicos para que os passos sejam atendidos e implantados em um ambiente Web funcional. Os dados especificados, em um contexto governamental, vêm por meio de pedidos de transparência ativa (quando o governo determina os dados) ou passiva (quando as requisições vêm da sociedade), seguindo um Plano de Dados Abertos com o cronograma para essas publicações. Junto a isso, são adotadas práticas e diretrizes de uso de tecnologias dentro do órgão publicador, que impactam como os dados devem ser publicado, em termos de formato, metadados, padrão de URIs, ontologias, dentre outras características técnicas. No modelo de ciclo de vida descrito anteriormente, esses dados são pré-processados, formatados, versionados, licenciados e disponibilizados em um catálogo de dados (ex: software CKAN, usado pelo portal http://dados.gov.br), que reúne todos os dados da instituição e que oferece ferramentas alternativas de acesso aos dados como APIs e também de mecanismos de interação com a sociedade, de modo que ela possa fornecer feedback sobre a acurácia ou utilidade dos dados publicados. Ainda de acordo com o modelo de ciclo de vida, esses dados são conectados a fontes externas, preferencialmente conectadas à nuvem de LOD (contém a ligação de diferentes bases de dados de diferentes domínios), e convertidas para seu formato semântico. Os termos semânticos usados para anotar os dados são publicados na Web em ontologias, seja por exemplos 
conhecidos na Web (por exemplo: FOAF, Schema.org, Dublin Core, etc.) ou desenvolvidos para atender ao contexto dos dados. Esses dados convertidos são, por sua vez, publicados em um servidor de triplas, com acesso por meio de um endpoint SPARQL, no qual é possível executar consultas sobre os dados usando o protocolo HTTP. Para tornar as triplas desreferenciáveis (ou seja, resolvidas quando acessadas por meio de requisição HTTP), é necessário um software de interface para dados conectados, que permite que os consumidores de dados possam navegar e acessar esses recursos mais facilmente. Por fim, são necessários mecanismos que atuem para preservar as URIs em relação à sua evolução ao longo do tempo, durante o ciclo de vida dos dados.

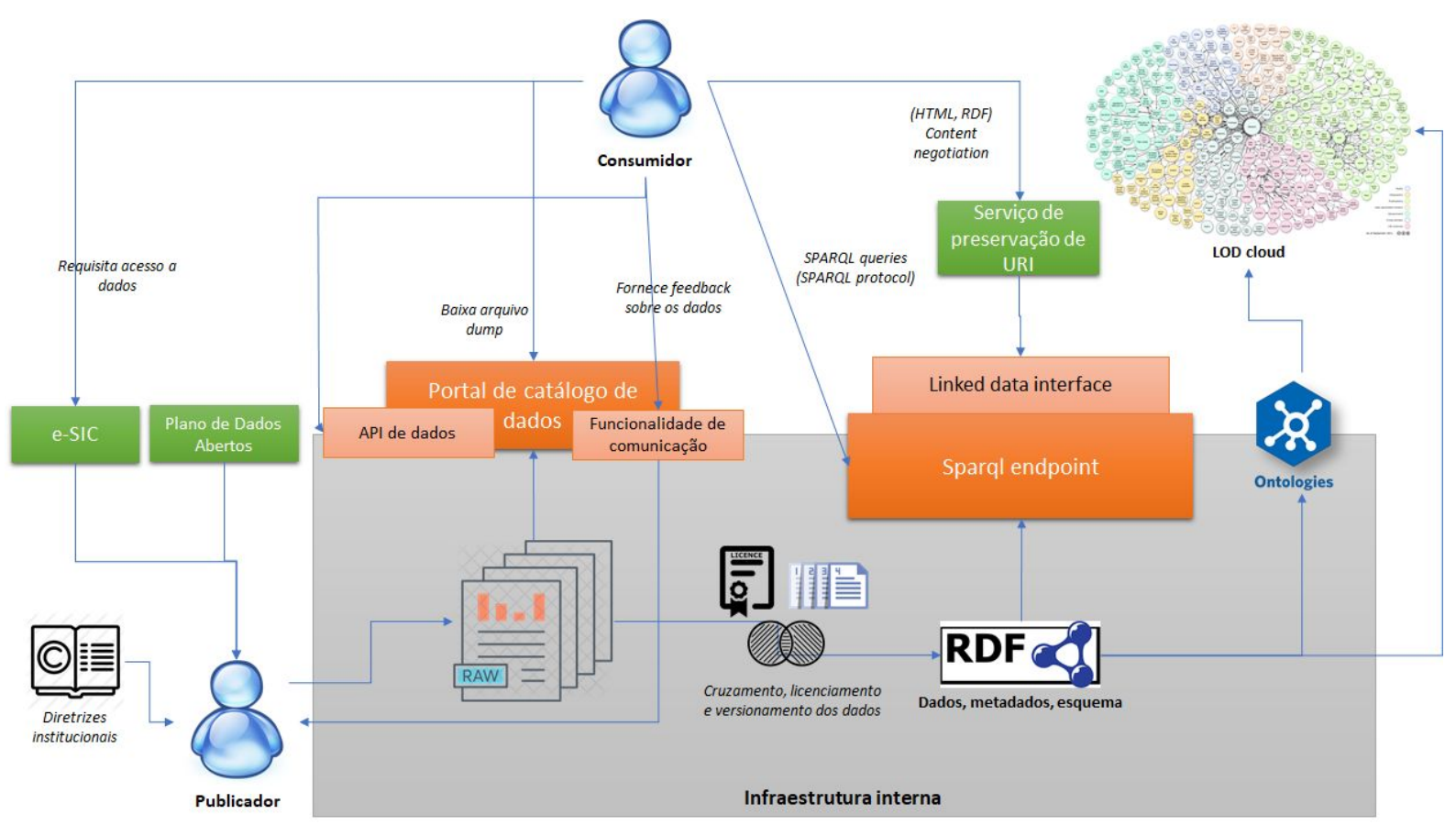

Figura 2. Arquitetura contendo os componentes básicos da infraestrutura para publicação de DAGC.

Neste roteiro é proposto um cenário simplificado que explora dados reais da educação brasileira e será pedido para que você execute tarefas relacionadas às fases propostas no modelo (exceto a fase de Manutenção) e usando os componentes básicos da arquitetura demonstrada, para simular a publicação de dados governamentais em formato conectado. Ao final de cada fase, será pedido para que você registre suas impressões sobre as atividades e possíveis melhorias ao processo proposto. 


\section{Cenário}

Os datasets do IDEB estão entre os mais procurados e acessados no domínio educacional no Brasil, sendo adotado desde e funcionando como o principal indicador do desempenho acadêmico para a criação de políticas públicas. Ele é medido a cada dois anos, por meio da aplicação de avaliações de larga escala a todas as escolas públicas (municipais, estaduais ou federais) do Brasil, ao final de cada ciclo da educação básica (nos $5^{\circ}$ ano e $9^{\circ}$ anos do ensino fundamental e no $3^{\circ}$ ano do ensino médio). Em seu nível mais básico, a nota do IDEB é calculada por unidade escolar, mas frequentemente é agregada em níveis maiores, como o município, o estado ou o país como um todo.

Neste experimento, adotaremos um cenário simplificado para a representação de dados, em nível estadual, conforme a figura a seguir:

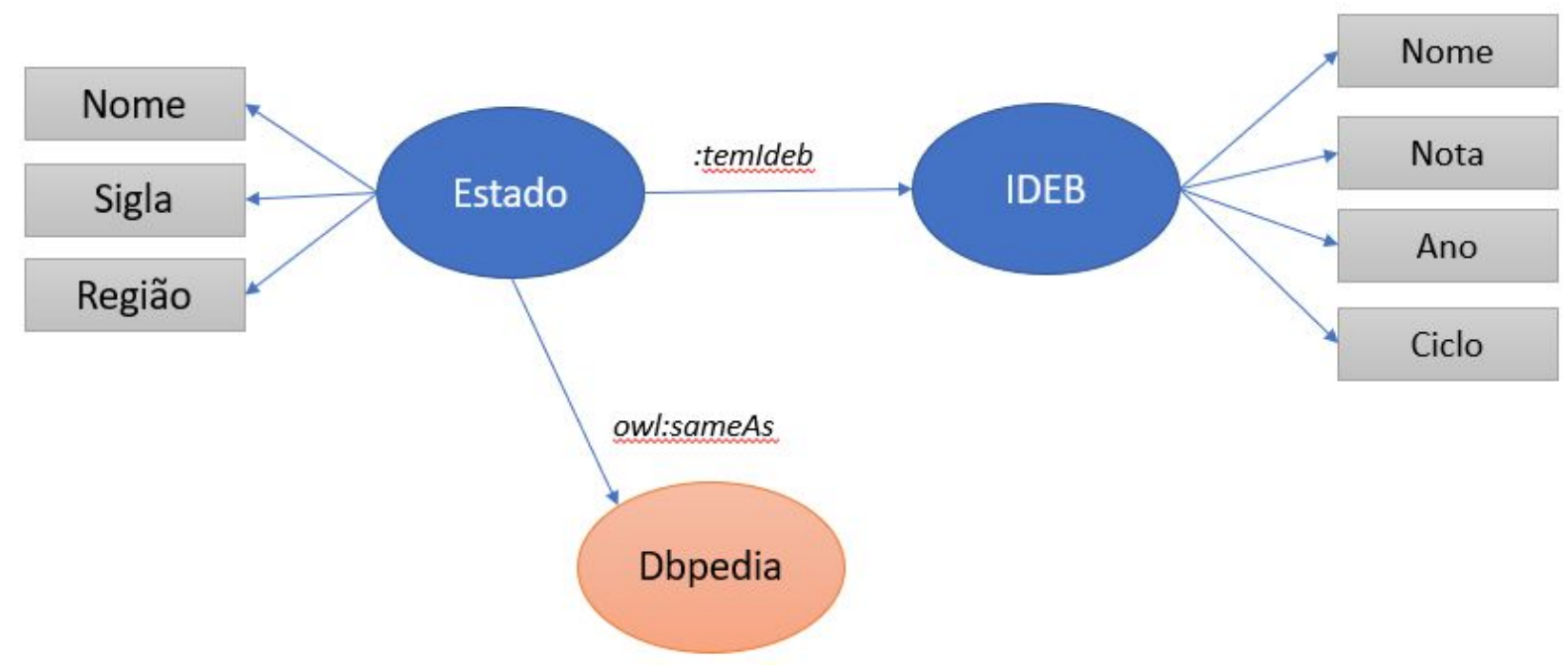

\section{Datasets}

Serão utilizados 2 datasets (Estados e Ideb) e 3 distribuições ${ }^{1}$ (Estados 2020, Ideb 2015 e Ideb 2017) neste experimento simplificado: um contendo os estados brasileiros, com seus nomes, siglas e região do país e o outro o IDEB. O IDEB destes estados é representado por dois arquivos, um com as notas da edição de 2017 e outro com as notas da edição de 2015. Além do nome do estado e sua nota, duas outras informações estão implícitas: o ano (2015 ou 2017) e o ciclo (Anos finais do ensino fundamental) do qual as notas foram aferidas. A seguir são descritos os campos dos arquivos de dados. Esta lista deve ser usadas durante o script para descrever os dados.

Estado

1 Dataset aqui se refere ao conceito que os dados representam. Já a Distribuição representa uma versão específica do dataset, seja por ser de um período diferente de coleta dos dados ou por diferentes formatos de arquivo. 
- Nome: Nome do estado. String.

- Sigla: Sigla do estado. String.

- Região: Região política ao qual o estado pertence. String.

Ideb

- Estado: Estado brasileiro. String.

- Sigla: Sigla do estado. String.

- Aprendizado: Nota no SAEB. Double.

- Fluxo: \% de alunos aprovados no ano. Double.

Os arquivos estão em formato XLS (Ideb 2015 e Ideb 2017) e CSV (Estados) e suas fontes originais, conforme descrito a seguir.

- Estados 2020: https://drive.google.com/file/d/1MkPYfbQgTpus6ElBBnn90dfAUtyc0wgl/view?usp=sharing Fonte: https://cidades.ibge.gov.br/brasil/ (IBGE).

- Ideb 2017: https://drive.google.com/file/d/1KjmEdZwW6yuevHZuor6zGd6do1sezaJm/view?usp=sharing . Fonte: http://dados.gov.br/dataset/ideb-por-estados (INEP).

- Ideb 2015: https://drive.google.com/file/d/16FYxOfsBbBMRaayygKzPLJCbRv0oKnnh/view?usp=sharing . Fonte: http://dados.gov. br/dataset/ideb-por-estados (INEP).

São postas as seguintes questões a serem respondidas, na última fase, a partir dos dados disponibilizados sobre este cenário:

- Qual estado evoluiu mais sua nota Ideb entre 2015 e 2017 ?

- Qual região do país teve maior evolução?

O público-alvo principal deste cenário são: pesquisadores acadêmicos e sociedade civil.

\section{Vocabulários}

Os seguintes vocabulários podem ser utilizados para modelar os dados deste estudo:

- RDF, prefixo rdf: http://www.w3.org/1999/02/22-rdf-syntax-ns\#

- RDFS, prefixo $r d f s$ : http://www.w3.org/2000/01/rdf-schema\#

- Dbpedia ontology, prefixo dbo: http://dbpedia.org/ontology/

- Dbpedia properties, prefixo $d b p$ : $\underline{\text { http://dbpedia.org/property/ }}$

- OWL, prefixo owl: http://www.w3.org/2002/07/owl\#

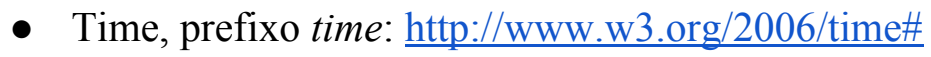


Além deste vocabulários nos dados dos arquivos, os seguintes vocabulários são usados nos metadados:

- Service Description, prefixo $s d$ : http://www.w3.org/ns/sparql-service-description\#

- DCAT, prefixo dcat: http://www.w3.org/ns/dcat2\#

- Dublin Core, prefixo dcterms: http://purl.org/dc/terms/

- Friend of a Friend, prefixo foaf: http://xmlns.com/foaf/0.1/

- Provenance Ontology, prefixo prov: $<$ http://www.w3.org/ns/prov\#

- XSD, prefixo $x s d$, http://www.w3.org/2001/XMLSchema\#

- VoID, prefixo void, http://rdfs.org/ns/void\#

- Schema.org, prefixo schema: http://schema.org/

- Creative Commons, prefixo $c c$ : http://creativecommons.org/ns\#

- Data Quality Vocabulary, prefixo $d q v$ : http://www.w3.org/ns/dqv\#

- Asset Description Metadata Schema, prefixo adms: https://www.w3.org/ns/adms\#

Nem todos os campos dos arquivos podem ser mapeados a estes vocabulários. Para atender a esses campos adicionais, será necessário criar um novo vocabulário, conforme requisitado nos passos seguintes.

\section{Planilhas de acompanhamento}

Ao decorrer deste experimento, pedimos para que você registre seus passos, de modo a se ter uma rastreabilidade das escolhas feitas ao longo do caminho.

Para isso, faça o download das planilhas de acompanhamento disponibilizadas no link: https://drive.google.com/open?id=1FnLqhRW7vmBnYltWWSaIqThKh6M9Psm1.

\section{Softwares necessários}

Para executar todos os passos deste processo é necessário baixar e executar um conjunto de softwares, disponibilizados abaixo:

- LODRefine

(LODRefine):

https://drive.google.com/file/d/1vAKK9Orw3eWXIT8tZrPNQ8vTawteefkL

○ Para outras plataformas, faça download de:https://sourceforge.net/projects/lodrefine/files/

- Protégé Desktop: https://protege.stanford.edu/products.php\#desktop-protege

- Jena Fuseki: https://drive.google.com/file/d/1GjHpwQFcWQegZEmbzVpvScG8z2q6ZCk0 
- LODView:

https://drive.google.com/file/d/11 O6TiuTKe-KJRvO2L1WG6rAoxVdD9un/view?usp=sha ring

- Tomcat (https://tomcat.apache.org/download-80.cgi)
○ Para
Windows
existe
o
instalador:

http://mirror.nbtelecom.com.br/apache/tomcat/tomcat-8/v8.5.50/bin/apache-tomcat-8 $.5 .50 . \mathrm{exe}$

\section{Pré-requisitos}

- JRE instalado em sua máquina

- Conta no Github 


\section{Fase Especificação}

Nesta fase são especificados os materiais, propósito, padrões e diretrizes a serem utilizadas ao longo de todo o processo.

1. Abra a planilha "1-Especificação.xlsx".

2. Preencha o horário de início desta fase (aba 1.1, célula B2)

3. Preencha os dados da aba 1.1 com os dados fornecidos na seção 'Cenário'. Insira a data de hoje no campo 'Data para publicação'.

4. Leia a aba 1.2 ("Diretrizes") para saber quais são as diretrizes gerais relacionadas à publicação de dados e de formatos conectados no governo federal brasileiro. Caso conheça mais alguma, por favor, adicione outros registros.

5. Leia a aba 1.3 ('Metadados') para saber quais são os metadados obrigatórios recomendados pelo governo brasileiro.

6. Na aba 1.4, defina a URI-base a ser usada pelos recursos de dados durante sua modelagem e publicação. Coloque o valor "http://localhost:8080/educacao-basical". Esta será a URI base a ser usada pelos dados a serem produzidos.

7. Na aba 1.5, inserir as questões de competência definidas no início deste documento, na seção 'Cenário'

8. $\mathrm{Na}$ aba 1.6, mapear quais serão os relacionamento feitos entre as bases de dados, ou seja, quais são os campos em comum entre os arquivos, para que possa ser feita seu cruzamento. Por ora, a direção do relacionamento não é importante.

a. Para a relação com a Dbpedia, usar como origem Estado e nome e destino Dbpedia e rdfs:label no preenchimento.

9. Baixe o arquivo de modelo de metadados. Ele contém os metadados necessários para descrever semanticamente quais dados estão sendo publicados e sob quais condições. Ele contém diversos marcadores com o formato@@_VARIAVEL_@@, que deverão ser substituídos pelos valores usados ao longo do roteiro. Para editá-lo, use um editor de textos, como o Notepad++ ou Sublime.

10. Substitua os marcadores no arquivo conforme a seção Metadados abaixo.

11. Por favor, anote o horário de finalização desta fase, na aba 1.6, célula B18.

12. Preencha também quais foram suas impressões sobre este passo (em termos de dificuldade, clareza e importância dos passos) e possíveis sugestões de melhorias. 
Metadados:

- @@_TITULO_CATALOGO_@@: portal onde serão hospedados os dados conectados. Colocar "Experimento USP".

-@@@DESCRICAO_CATALOGO_@@: inserir o valor "Portal de dados conectados"

-@@@HOMEPAGE_CATALOGO_@@: inserir o valor "http://localhost:8080/"

-@@@_REGEX_URI_@@pela expressão regular definida na aba 1.4 da planilha (célula $\mathrm{B} 15)$.

-@@@URI_BASE_@@: use a URI base definida na aba 1.4, célula B3.

-@@@_URL_PARA_PADRAO_EM_CONFORMIDADE_@@: replique esta declaração (linha toda) para cada padrão levantado na aba 1.2. Caso exista duplicação de padrões, devido a referências a diferentes seções, crie uma nova linha para cada URL única (coluna URL da diretriz).

-@@@_NOME_ENTIDADE_PUBLICADORA_@@: inserir o nome e a sigla da instituição onde você trabalha.

-@@@_URL_PUBLICADOR_@@: URL com a homepage da instituição definida acima.

-@@@SEU_NOME_AQUI_@@: substituir por seu código.

- @@_SEU_EMAIL_AQUI_@@: substituir por um endereço de e-mail qualquer.

-@@@_HORARIO_INICIO_EXECUCAO_YYYY-MM-DD_@@: data e hora do momento, no formato YYYY-MM-DD T HH:MM:SS (por exemplo: 2020-02-10T10:04:00).

Verificações:

- Verificar que existam cenários de uso e questões de competência mapeados;

- Verificar que estejam mapeados quem é o público-alvo dos dados;

- Verificar existência de cronograma de publicação dos datasets;

- Verificar a existência e a validade dos mapeamentos entre as bases de dados;

- Verificar o mapeamento das diretrizes cabíveis ao contexto;

- Verificar o mapeamento dos metadados obrigatórios;

- Verificar tamanho da URI-base seja menor que 40 caracteres;

- Verificar que as URI a serem geradas são interpretáveis por humanos (por ex: ao ler a URI, sabe-se qual domínio e tema do dado)

- Verificar existência e validade da expressão regular que represente as URI; 


\section{Fase Modelagem}

Nesta fase, você deverá pré-processar os dados originais, preparando-os para as próximas fases. Serão reutilizados os vocabulários especificados na fase anterior e deverá ser criado um novo, com dados específicos do cenário. Esse vocabulário deverá ser publicado na Web, para que possa ser referenciado e consultado por outras pessoas. Para garantir que o vocabulário tenha uma URI estável, deverá ser criada uma URL permanente, que permitirá a flexibilização para eventuais mudanças no domínio dos dados. Ao final, deverá existir um mapeamento de todos os dados de entrada do cenário para respectivos termos semânticos.

1. Instale o software LODRefine. É necessário apenas descompactá-lo.

2. Abra a planilha "2-Modelagem.xlsx" e insira o horário atual.

3. Abra o LODRefine, clicando no arquivo lodrefine.exe.

4. Acesse o menu 'Create project' e importe os dados do arquivo Estados.csv, dando o nome "Estados do Brasil" para o projeto. Em seguida, importe os outros dois arquivos, dando os nomes "IDEB 2015 - Anos Finais" e "IDEB 2017 - Anos Finais". Cada arquivo deve gerar um projeto no LODRefine.

a. Verifique que foram criados 27 registros em cada projeto, um para cada estado.

5. Para cada projeto:

a. Verifique que os dados estão estruturados em linhas e colunas, com os dados esperados em cada uma delas.

b. Verifique que os valores numéricos estão de fato representado por números e não como texto. No LODRefine, os números aparecem em fonte de cor verde.

c. Caso seja necessária alguma transformação nos dados, use as funcionalidades disponíveis no LODRefine.

d. Na planilha "2-Modelagem", aba 2.1, mapeie quais foram as transformações feitas para pré-processar os dados. Se não houver, colocar observação "Este passo não foi necessário." na linha 15.

e. Verifique se existem dados que precisem ser normalizados, ou seja, quando um mesmo campo contém mais de uma informação ao mesmo tempo (exemplos: moedas com o formato $R \$ x x x x$,yy, devem ser desmembrados em duas colunas, uma com especificação da moeda e a outra com o valor em si). 
f. Na planilha "2-Modelagem", aba 2.2, mapeie quais foram as transformações necessárias. Se não houver, colocar a observação "Este passo não foi necessário." na linha

6. Em ambos projetos de IDEB, crie uma nova coluna calculada:

a. Nome da coluna: Nota IDEB

b. Expressão: Aprendizado * Fluxo

c. Para isso, clique na seta ao lado do campo 'Fluxo' e acesse o menu 'Edit column' > 'Add column based on this column...'. Insira o nome 'nota' e no campo 'Expression', coloque o seguinte:

cells ['Fluxo'].value * cells ['Aprendizado'].value

7. Acesse o projeto "IDEB 2017 - Anos Finais" e cria mais uma coluna:

a. Nome da coluna: Evolução

b. Expressão: Nota IDEB 2017 - Nota IDEB 2015

i. Cria uma nova coluna, como no passo anterior, usando a expressão abaixo e clique em OK. cells['Nota IDEB'].value - cells['Sigla'].cross("IDEB 2015 - Anos Finais", "Sigla")[0].cells['Nota IDEB'].value

ii. Selecione a coluna criada e clique em 'Edit cells $>$ Transform'. Use a seguinte expressão para arredondar para duas casas decimais. Selecione a linguagem Jython, no canto direito superior:

return round(value, 2 )

8. Na aba 2.3, preencher a planilha com os dados criados. Insira as fórmulas usadas nos passos anteriores no campo 'Transformação'.

9. Na aba 2.4, listar todos os vocabulários especificados na seção 'Cenário', tanto para os dados quanto para os metadados.

10. Abra a ferramenta Protégé, clicando no ícone Protege.exe.

11. Na aba 'Active ontology', clique no botão de adicionar, na seção 'Annotations':

a. Selecione owl:versionInfo e, na aba 'Literal' (à direita), adicione um valor para esta versão da ontologia e clique em 'OK'; 
b. Adicione nova anotação (seção 'Annotations', clique no botão 'mais'), selecione 'rdfs:comment' (à esquerda) e adicione o seguinte texto (em 'Literal', à direita): “Ontologia para descrição do IDEB por estados brasileiros.” e clique em 'OK';

c. Vá em 'Ontology prefixes' e clique em 'Add prefix mapping', colocando o valor $d c t$ em 'Prefix' (duplo clique na célula) e http://purl.org/dc/terms/ em 'Value';

d. Adicione uma nova anotação (seção 'Annotations', clique no botão 'mais'), selecione 'add sibling property' (canto esquerdo superior) e digite dct:license e clique em ' $\mathrm{OK}$ '.

e. Selecione dcterms:license e insira o valor em 'IRI Editor': http://creativecommons.org/licenses/by/3.0/ e clique em OK.

12. Cada um dos dois datasets será mapeado para uma classe; os respectivos campos serão mapeados como propriedades dessas classes. Acesse a aba 'Entities' (ao lado de 'Active Ontology') e crie as classes (aba 'Classes') e propriedades ('Object properties' ou 'Data Properties'), baseado nos dois arquivos:

a. Para criar a classe, selecione owl:Thing e clicar em 'Add subclass'.

b. Preencher para cada classe:

i. Nomes das classes: Estado e Ideb

ii. Outras propriedades da classe (lado direito):

1. Em Annotations, inserir comentário da classe (rdfs:comment): em Literal, fornecer uma descrição sucinta;

2. Em Annotations, inserir rótulo da classe (rdfs:label): o próprio nome da classe;

c. Após criar as duas classes:

i. Declarar todas as classes como disjuntas entre si

1. Para isso, selecione uma classe e vá até 'Disjoint With' e adicione as outras classes, uma por vez, e clique $\mathrm{OK}$;

ii. Verificar que as classes estão no mesmo nível e são filhas diretas de owl:Thing.

d. Tratar cada campo como uma propriedade, inclusive a que relaciona o Estado ao Ideb (temIdeb).

e. Criar as seguintes propriedades: 
1. DatatypeProperty: neste cenário, use este tipo para todos os campos não mapeados a outros vocabulários (ciclo, fluxo, aprendizado, nota e evolucao, tendo domain: Ideb e range conforme a tabela 1)

2. ObjectProperty: neste cenário, crie a propriedade temIdeb, com domain Estado e range a classe Ideb.

ii. Selecionar a aba apropriada ('Object properties' ou 'Data properties'), selecionar e clicar em 'Add subproperty'.

iii. Nome da propriedade (não usar acentos ou caracteres especiais; conferir a Tabela 1).

iv. Outras propriedades (lado direito):

1. Em 'Annotations', inserir comentário da propriedade (rdfs:comment): descrição sucinta da propriedade

2. Em 'Annotations', inserir rótulo da propriedade (rdfs:label): o próprio nome da propriedade

3. Em Domains, clique em adicionar e selecione a classe (arquivo) à qual a propriedade pertence

4. Em Ranges, clique em adicionar e selecione o tipo de valor que a propriedade aceita

f. Após criar as propriedades:

i. Declarar todas as propriedades como disjuntas entre si

1. Para isso, vá até 'Disjoint With' (abaixo de 'Ranges'), clique em adicionar e adicione, uma por vez as outras propriedades.

ii. Verificar que todas as propriedades contêm Domain, Range, DisjointWith e Comment preenchidos.

13. Exporte a ontologia criada ('File' > 'Save As...'), selecione a sintaxe RDF/XML e salve em seu computador.

14. Abra o arquivo em algum editor de texto de sua escolha. Copie o conteúdo do arquivo.

15. Acesse a ferramenta OOPS no endereço Web: http://oops.linkeddata.es/.

16. Insira o conteúdo do arquivo no campo 'Scanner by direct input:' e clique no botão 'Scanner by $R D F^{\prime}$ (este serviço aceita somente no formato RDF/XML).

17. Verifique os erros gerados. Corrija o arquivo de ontologia em sua máquina, com o que for exibido como 'Critical' ou 'Important'. Volte até o passo 14 até que não existam mais erros 'Critical' ou 'Important'. 
18. Publique on-line, em sua conta no Github ou outro serviço que forneça acesso direto ao arquivo com sua URL original (não se aplica ao Google Drive ou DropBox). Assegure que se trata de um repositório público.

19. Acesso o site PURL.org, crie uma conta ('Sign up'). Crie um domínio com o formato /caed \{seu codigo\} (em letras minúsculas).

20. Em seguida, vá até 'Add a new PURL to this domain' e insira os seguintes dados:

a. name: /caed \{seu codigo\}/ontology

b. type: 303

c. target url: usar a URL para o formato raw do arquivo no Github (que começa com https://raw.githubusercontent.com/\{usuario\}/\{projeto $\}$ )

i. Para pegar essa URL, acesso o arquivo no Github, clique no botão 'Raw' e copie a URL para onde o navegador foi direcionado;

d. Verifique que a URL passada em target url é transferida para o arquivo criado no Github.

21. Volte à planilha, na aba 2.5 e adicione seu novo vocabulário, usando no campo URL a URL permanente (por ex: http://purl.org/caedBruno/ontology\#) e 'ex' como prefixo.

22. Abra novamente a ferramenta Protégé, acesse a aba Active Ontology e modifique o valor da propriedade 'Ontology IRI' para o endereço permanente criado no passo anterior.

a. Publique novamente a versão modificada no Github.

23. Acesse a aba 2.6 e liste todos os campos dos arquivos e os respectivos vocabulários e termos usados para mapeá-los. Faça o mesmo para as classes criadas na ontologia e sua relação com os arquivos.

24. Abra a ferramenta LODRefine, abra um projeto e acesse o menu $R D F>$ 'Edit $R D F$ skeleton...'.

a. Caso o menu não carregue, execute os passos de 2 a 5 da fase de Conversão (fase 3) e então retorne para este passo (bug da ferramenta).

25. Adicione, para cada projeto, os prefixos dos vocabulários mapeados, clicando em 'add prefix'.

a. Adicionar todos os vocabulários mapeados nas abas 2.4 e 2.5 da planilha, uma por vez. Em 'prefix' coloque os respectivos prefixos (coluna B da planilha) e em 'URI', coloque (coluna C da planilha). Marcar a opção 'Force input', para não dar erro.

26. Modifique a URI base (Base URI> edit) para a definida na fase de Especificação (aba 1.4). 
a. Nos projeto de IDEB, adicione ao final o ano (por ex: http://localhost:8080/educacao-basica/Ideb/2015/ http://localhost:8080/educacao-basica/Ideb/2017/);

b. No projeto de estados, sua a Base URI: http://localhost:8080/educacao-basica/;

27. No nó raiz, adicione a classe do arquivo ('add rdf:type'), conforme mapeado na tabela de classes na aba 2.6 e selecione o campo Estado (que contém o nome do Estado).

28. Para cada propriedade, adicionar o mapeamento feito na aba 2.5 e exemplificado na Tabela 1.

Tabela 1. Classes e propriedades a serem mapeados neste cenário.

\begin{tabular}{|c|c|c|}
\hline Classe/propriedade & Termo e vocabulário & Tipo do dado \\
\hline Estado & rdf:type & ex:Estado \\
\hline Nome & foaf:name & String \\
\hline Sigla & dbp:sigla & String \\
\hline Região & dbo:region & String \\
\hline & A ser criado (ex:temIdeb) & URI para $<$ Ideb $>$ \\
\hline & owl:sameAs & URI para $<$ Dbpedia $>$ \\
\hline Ideb & rdf:type & ex:Ideb \\
\hline Sigla & dbp:sigla & String \\
\hline Ano & time:year & Integer \\
\hline Ciclo & A ser criado (ex:ciclo) & String \\
\hline Fluxo & A ser criado (ex:fluxo) & Double \\
\hline Aprendizado & A ser criado (ex:aprendizado) & Double \\
\hline Nota & A ser criado (ex:nota) & Double \\
\hline Evolução & A ser criado (ex:evolucao) & Double \\
\hline
\end{tabular}

a. Os alinhamentos devem ficar semelhantes aos das Figuras abaixo, para Estados e Ideb, respectivamente (somente a versão 2017 é mostrada; a versão 2015 é semelhante, alterando apenas a URI base para 2015, além dos dados em si): 


\section{RDF Schema Alignment}

The RDF schema alignment skeleton below specifies how the RDF data that will get generated from your grid-shaped data. The cells in each record of your data will get placed into nodes within the skeleton. Configure the skeleton by specifying which column to substitute into which node.

Base URI: http://localhost:8080/educacao-basica/ edit

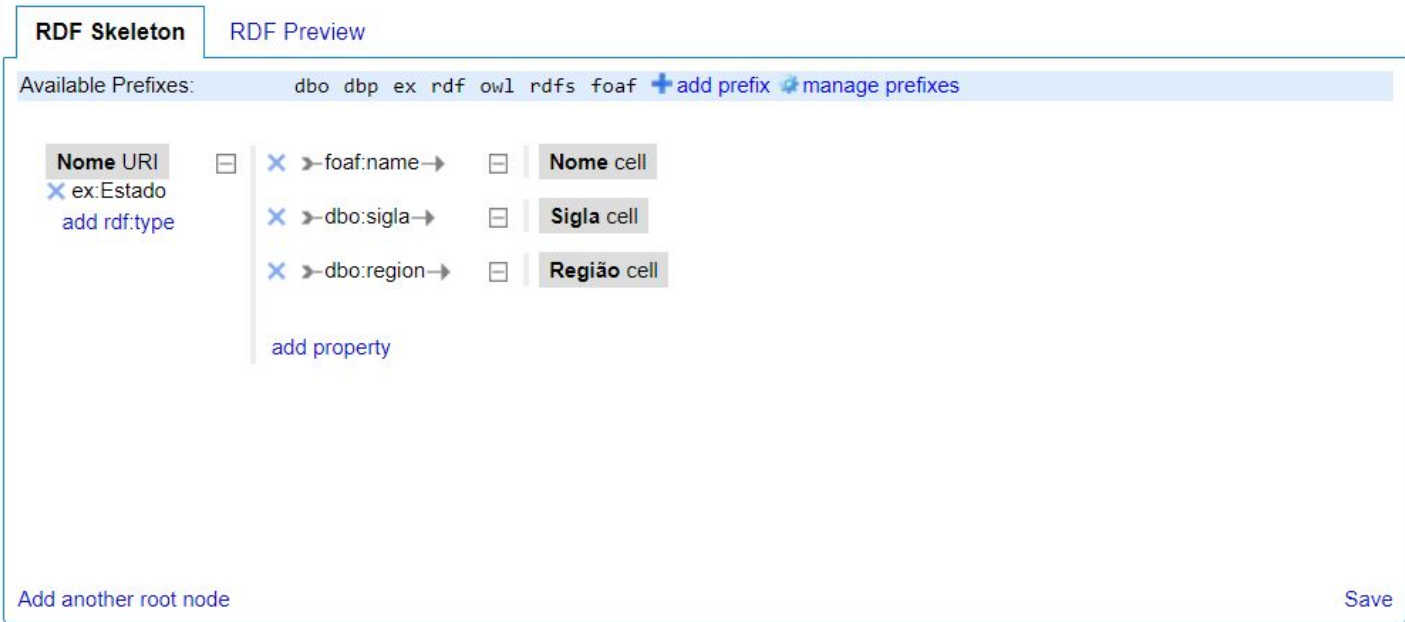

\section{RDF Schema Alignment}

The RDF schema alignment skeleton below specifies how the RDF data that will get generated from your grid-shaped data. The cells in each record of your data will get placed into nodes within the skeleton. Configure the skeleton by specifying which column to substitute into which node

Base URI: http://localhost:8080/educacao-basica/ldeb/2017/ edit

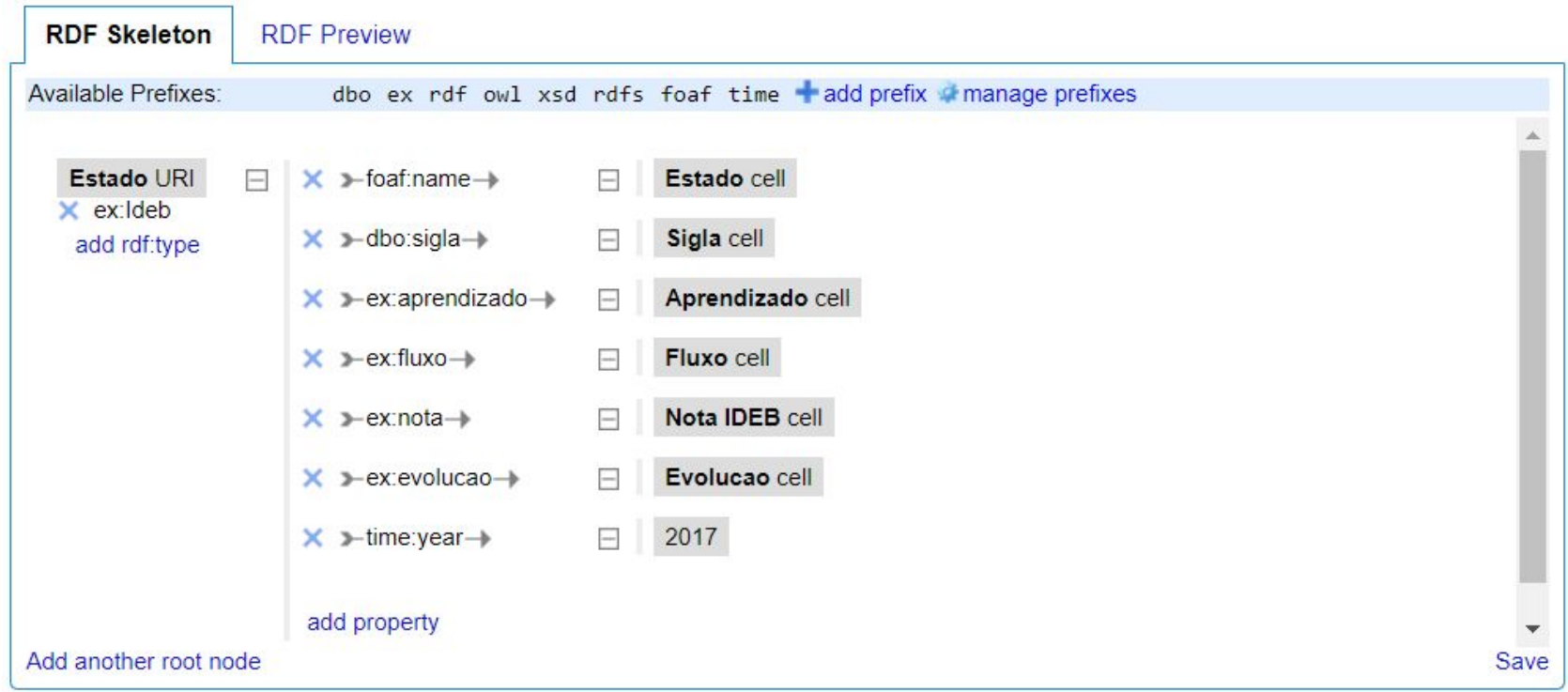

29. Visualize o resultado, acessando a opção 'RDF Preview'.

a. Para o mapeamento dos Estados: 
Base URI: http://localhost:8080/educacao-basica/ edit

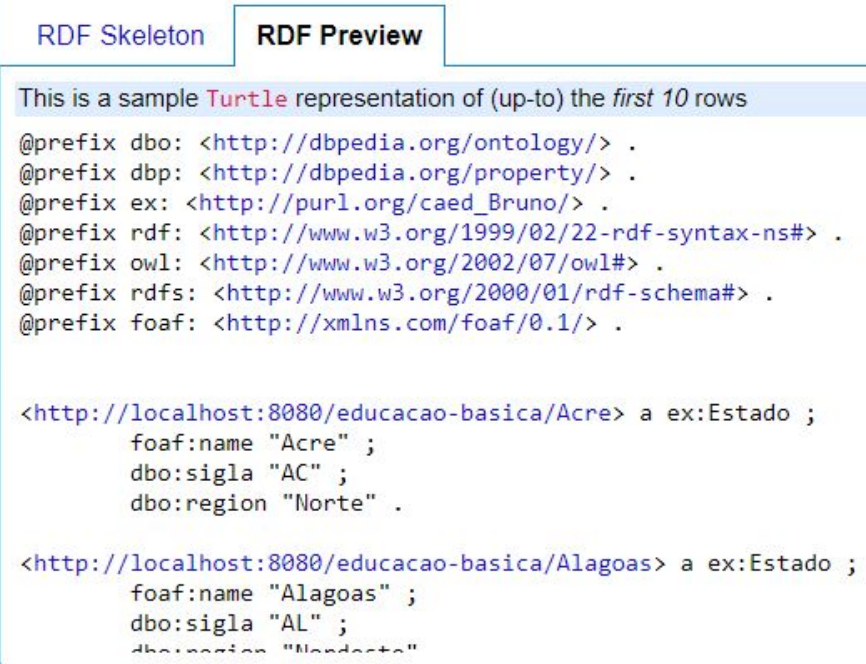

\section{b. Para o mapeamento do Ideb:}

Base URI: http://localhost:8080/educacao-basica/ldeb/2017/ edit

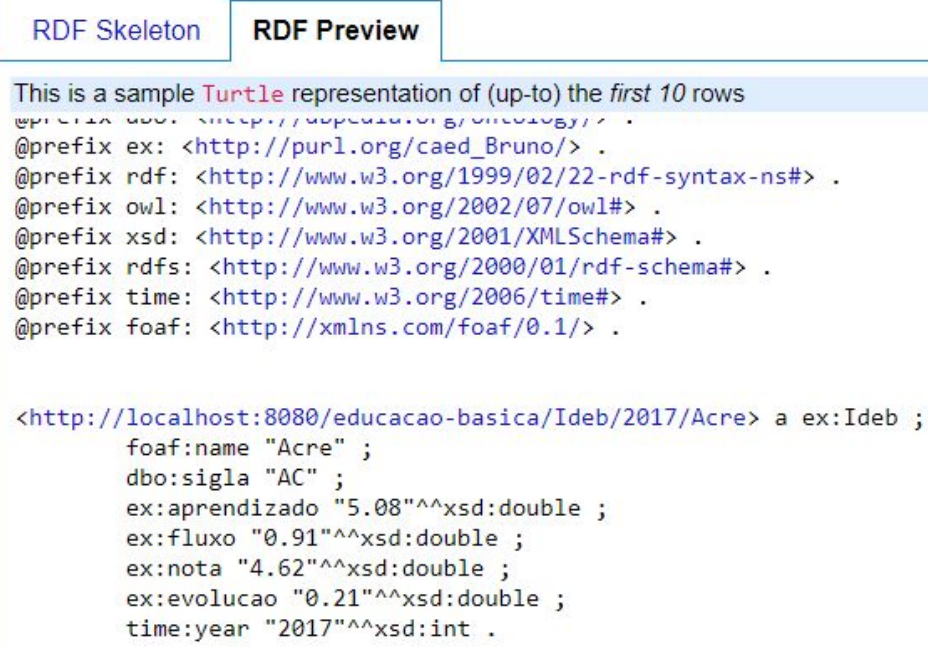

30. Volte ao passo 24 até que todos os arquivos de dados tenham sido mapeados.

31. Crie os metadados conforme especificado abaixo.

32. Faça as verificações conforme especificadas abaixo.

33. Adicione o horário atual na aba 2.6.

34. Preencha também quais foram suas impressões sobre este passo (em termos de dificuldade, clareza e importância dos passos) e possíveis sugestões de melhorias. 
Metadados:

- No arquivo de metadados existe a representação de dois datasets (:dataset1 e :dataset2; Estado e Ideb, respectivamente). Para cada dataset, preencha os seguintes campos:

○@@@TITULO_DATASET_@@: título do dataset.

○@@@DESCRICAO_DATASET_@@: breve descrição do que se tratam os dados.

○@@_HOMEPAGE_DATASET_@@: página (ver fonte na seção ‘Cenário’).

○@@_PALAVRAS_CHAVE_@@: palavras-chave associadas ao dataset.

○@@_URL_DADOS_ORIGINAIS_@@: ver fonte na seção ‘Cenário'.

○@@_ANO_DO_DATASET_@@: pelo ano em que os dados foram coletados (não é 2020!), no seguinte formato de exemplo para 2015: <http://reference.data.gov.uk/id/year/2015>

○@@_INSTRUMENTO_@@: como foram coletados os dados. Use “avaliação educacional” para o dataset do IDEB e "divisão política" para o dataset de Estados.

○@@_URL_VOCABULARIOS_USADOS_@@: replique uma linha dessa para cada vocabulário listado na seção 'Vocabulários’ no Cenário (pág. 2). Substitua o marcador pela URI do vocabulário.

○@@_URL_TEM_EVOG_@@: em cada dataset, procurar em http://vocab.e.gov.br/id/governo\#esquema qual seu assunto específico e usar este valor

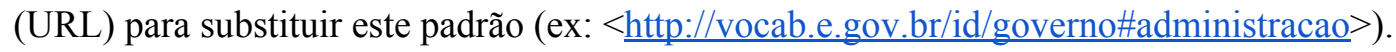

o@@@TITULO_CATEGORIA_EVOG_@@: na mesma página, procurar pelo texto em 'Termo Autorizado (TA)' e usá-lo para substituir este marcador.

○@@_VERSAO_DATASET_@@: fornecer uma versão para o dataset (ex: “1.0”)

○@@_COMENTARIOS_DA_VERSAO_@@: fornecer uma breve descrição do que foi feito nesta versão.

○@@@VERSAO_ANTERIOR_DATASET_@@: fornecer o código para um versão anterior. Deixar em branco, caso não exista.

○@@@URL_LICENÇA_@@: procurar qual a licença usada pelo dataset original do IDEB, em http://dados.gov.br/dataset/ideb-por-estados (seção Licença, à esquerda). Usar a mesma para os Estados.

○@@@TEXTO_DA_LICENÇA_@@: clique no link da licença encontrada acima e copie seu sumário, usando-o para substituir este marcador. Por se tratar de um texto multilinhas, usar aspas triplas ao início e ao fim do texto. (Por ex: “"”’Texto da licenças “"”’)

○@@@DATA_PUBLICACAO_YYYY_MM_DD_@@: coloque o dia de hoje neste formato (por ex: 2020-01-31)

o@@@DATA_MODIFICACAO_YYYY_MM_DD_@@: coloque o dia de hoje, como acima. 
- Para as distribuições (:dist1, :dist2, :dist3 - Estados, Ideb2015 e Ideb2017, respectivamente), preencha:

○@@@TITULO_DISTRIBUICAO_@@: forneça o nome contextualizado (Por ex: Ideb 2015 Anos Finais; Estados brasileiros)

○@@_DESCRICAO_DISTRIBUICAO_@@: forneça descrição sucinta dos dados.

○@@@URL_LICENÇA_@@: use a mesma licença do dataset.

○@@@URL_DOWNLOAD_@@: use a URL de onde os arquivos foram baixados (seção 'Cenário').

○@@@_VERSAO_DISTRIBUICAO_@@: forneça uma versão para a versão atual. usar o ano da distribuição como indicador da versão.

\section{Verificações:}

- Verifique que a ferramenta OOPS não gera avisos nas categorias 'Critical' e 'Important' em relação à ontologia criada por você.

- Verifique se a URL permanente (endereço purl.org) resolve para a ontologia criada por você.

- Verifique que cada classe tenha um tipo definido e que cada campo seja representado por uma propriedade semântica especificada.

- Verifique se as classes estão definidas como disjuntas. Verifique se as propriedades também estão declaradas como disjuntas entre si.

- Verifique que os tipos de dados estejam corretos (URI, text, integer number, non-integer number).

- Verifique se, para cada arquivo, existe uma classe com seu tipo especificado com as classes criadas na ontologia.

- Copie o conteúdo do arquivo de metadados e verifique sua sintaxe no seguinte site: http://ttl.summerofcode.be/ 


\section{Fase Conversão}

Nesta fase, você irá mapear os dados modelados na fase anterior para dados externos (os arquivos entre si e com uma fonte de dados na Web). Depois de mapeados para as fontes de dados externas, será necessário triplificar os dados originais - ou seja, convertê-los em formato de triplas RDF (sujeito-predicado-objeto).

1. Abra a planilha "3-Conversão.xlsx", aba 3, e insira o horário atual.

2. Abra novamente a ferramenta LODRefine, e acesse o projeto 'Estados'

3. Acesse o menu " $R D F>$ Add reconciliation service $>$ Based on SPARQL endpoint...". Em 'Name', coloque 'dbpedia-pt', em 'Endpoint URL', coloque 'http://pt.dbpedia.org/sparql' e em 'Type' selecione 'Virtuoso'. Clique em OK.

4. Faça a reconciliação da coluna 'Nome' no projeto Estado com a DBpedia. Clique na seta ao lado da coluna "Nome" e selecione o menu "Reconcile $>$ Start reconciling..." e selecione o serviço recém-criado (dbpedia-pt).

a. Use a propriedade dbo:Settlement ou dbo:AdministrativeRegion.

b. Clique em 'Start reconciling' e aguarde.

c. No final, alguns candidatos foram selecionados para cada nome. Clique novamente na seta ao lado da coluna "Nome" e selecione o menu "Reconcile $>$ Actions $>$ Match each cell to its best candidate".

5. Verifique que todos os estados foram ligados aos recursos corretos, clicando sobre o nome do estado. Caso não esteja correto ou não tenha sido encontrado, faça manualmente.

a. Para verificar se foi ligado ao conceito correto, clique e veja a nova página carregada. Ela deve conter uma seção $r d f$ s:comment com detalhes sobre o estado (URL: http://pt.dbpedia.org/resources/\{nome_do_estado\}).

b. Caso não tenha encontrado o correto (ou mesmo nenhum), clique em 'Choose new match', abaixo do nome do estado. Deverá ser carregada uma lista de possíveis correspondências. Escolha a mais apropriada.

6. Crie uma nova coluna a partir desta reconciliação. Para isso, clique na seta ao lado da coluna "Nome" e selecione o menu "Edit column > Add column based on this column...". Insira para o novo nome da coluna "URI Dbpedia" e utilize a seguinte expressão e clique em OK.

cell.recon.match.id 
7. No esqueleto RDF (menu ' $R D F>$ Edit $R D F$ Skeleton...'), adicione a propriedade owl:sameAs e mapeie a coluna 'URI Dbpedia', com o formato de URI.

8. É necessário vincular o Estado às suas medidas de Ideb 2015 e 2017. Para isso, acesse novamente o projeto Estado e edite seu mapeamento (menu " $R D F>$ Edit RDF Skeleton...").

a. Clique em 'add property'. Em 'property?' coloque a propriedade de objeto criada na ontologia (ex:temIdeb). Clique em 'Configure?', selecione 'Nome” e 'as URI' e clique em 'preview/edit'. Na caixa expression digite a seguinte expressão.

"Ideb/2015/" + escape(cells["Nome"].value, "url")

b. Verifique e assegure que esta nova propriedade deverá apontar exatamente para as URIs geradas no arquivos de IDEB.

c. Repita este passo para a outra versão (Ideb 2017), alterando a URI com o número do ano.

d. O resultado do mapeamento no LODRefine deve ser semelhante às figuras abaixo:

\section{RDF Schema Alignment}

The RDF schema alignment skeleton below specifies how the RDF data that will get generated from your grid-shaped data. The cells in each record of your data will get placed into nodes within the skeleton. Configure the skeleton by specifying which column to substitute into which node.

Base URI: http://localhost:8080/educacao-basica/ edit

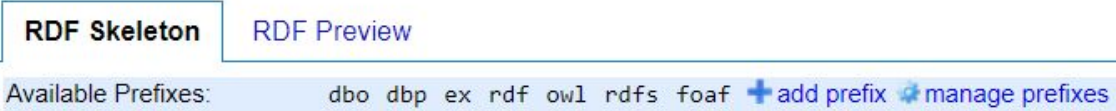


Base URI: http://localhost:8080/educacao-basica/ edit

This is a sample Turtle representation of (up-to) the first 10 rows

@prefix dbo: 〈http://dbpedia.org/ontology/> .

@prefix dbp: 〈http://dbpedia.org/property/>.

@prefix ex: 〈http://purl.org/caed_Bruno/>

@prefix rdf: 〈http://wWw.w3.org/1999/02/22-rdf-syntax-ns\#〉.

@prefix owl: 〈http://wWw.w3.org/2002/07/owl\#>

@prefix rdfs: 〈http://Www.w3.org/2000/01/rdf-schema\#〉.

@prefix foaf: 〈http://xmlns.com/foaf/0.1/>.

〈http://localhost:8080/educacao-basica/Acre> a ex:Estado ;

foaf: name "Acre"

dbo:sigla "AC" ;

dbo:region "Norte" ;

owl: sameAs 〈http://pt.dbpedia.org/resource/Acre>;

ex:temIdeb 〈http://localhost:8080/educacao-basica/Ideb/2015/Acre〉, 〈http://localhost:8080/educacao-basica,

9. Para cada projeto no LODRefine, exporte seu RDF para o formato Turtle, salvando o arquivo com o mesmo nome que o Projeto do LODRefine, com a extensão $t t l$. Para isso, acesse o menu "Export $>$ RDF as Turtle" e salve-os em seu computador.

10. Acesse a ferramenta IDLab Turtle Validator (http://ttl.summerofcode.be/) e teste cada arquivo de dados gerado, verificando sua sintaxe.

11. Crie os metadados para os datasets convertidos, usando os passos abaixo (seção 'Metadados').

12. Baixe o arquivo Estados-shacl.ttl e acesse o site: https://shacl.org/playground/.

13. Copie o conteúdo do arquivo Estados-shacl.ttl e cole na seção 'Shapes Graph' (à esquerda) e selecione o formato 'Turtle'.

a. Verifique se o objeto da propriedades sh:targetClass apontam para as classes criadas e as propriedades sh:path apontam para as propriedades de sua ontologia;

b. Copie e cole o conteúdo de cada arquivo de dados na seção 'Data Graph' (à direita), selecione o formato 'Turtle' e clique em 'Update' (logo abaixo).

c. Verifique se existe erros nos dados, checando a seção 'Validation Report'

d. Conserte os erros e repita o passo 12 até que nenhum erro seja mostrado.

14. Acesse a planilha '3-Conversão' e vá para a aba 3.

15. Preencha as ferramentas usadas nesta fase. Se para alguma dessas tarefas não foi usada uma ferramenta, preencha 'Não se aplicou' na respectiva tabela.

a. Transformação de dados: ferramenta usada para triplificar os dados;

b. Transformação de metadados: ferramenta usada para tratar os metadados; 
c. Conexão entre os dados: ferramenta usada para conectar a fontes externas;

d. Enriquecimento dos dados: campos incorporados aos datasets;

e. Verificação de RDF: ferramenta usada para verificar a sintaxe do RDF.

16. Anote o horário de fim desta fase (célula B45, aba 3).

17. Preencha também quais foram suas impressões sobre este passo (em termos de dificuldade, clareza e importância dos passos) e possíveis sugestões de melhorias.

Metadados:

- Não há metadados a serem preenchidos nesta fase.

Verificações:

- Verificar que os estados estão mapeados para as URIs corretas da Dbpedia.

- Verificar que todos os campos mapeados foram gerados.

- Verificar que não existam erros sintáticos nos dados gerados.

- Verificar que não existam erros semânticos nos dados gerados.

- Verifique que todos os marcadores de métricas foram substituídos no arquivo de metadados 


\section{Fase Publicação}

Nesta fase, você usará os dados disponibilizados para publicá-los em locais que possa ser acessados por outras pessoas. Os dados originais e seus metadados deverão ser publicados em local amigável para que humanos busquem e utilizem-os. As triplas RDF e seus metadados deverão ser publicados em um servidor de triplas, que respondam ao padrão SPARQL para consultas via protocolo HTTP. Por fim, será criado um arquivo de sitemap, para que possa ser indexado por máquinas de busca na Web, como o Google Dataset Search.

1. Abra a planilha "3-Conversão.xlsx", aba 4, e insira o horário atual.

2. Crie um pacote de dados, acessando o site: $\mathrm{http}: / /$ create.frictionlessdata.io/

3. Clique em 'Load' (menu direito superior) e selecione o arquivo de Estados.csv. Insira o nome 'estados' no campo 'Name'.

a. Clique em 'Add all inferred fields' e adicione uma descrição em cada coluna gerada (campo de texto 'Description').

b. Do lado esquerdo, preencha os seguintes metadados:

i. Name: "estados"

ii. Title: "Estados brasileiros"

iii. Description: "Lista de estados brasileiros."

iv. Version: ano do dataset

v. Author: seu código

vi. Keywords: "educação" "desempenho"

vii. License: a respectiva licença

c. Clique em 'Download'. Será gerado um arquivo datapackage.json.

4. Atualize a página e repita o passo 2, selecionando os arquivos Excel do IDEB.

a. Em 'Name', insira 'ideb2015'.

b. Clique em 'Load' e selecione 'IDEB 2015 por estado.xlsx'. A ferramenta não reconhece automaticamente as colunas de dados.

c. Clique em 'Add field' quatro vezes (uma para cada coluna de dados do arquivo: Estado, Sigla, Aprendizado, Fluxo)

d. Preencha os dados conforme cada um dos campos

i. Nome, Title, Description e Data type (string ou number)

e. Clique em 'Add resource' (final da página, ao centro). 
f. Insira 'ideb2017' em 'Name'

g. Clique em 'Load' e selecione 'IDEB 2017 por estado.xlsx'.

h. Adicione novamente os campos e preencha os dados campos, como no arquivo anterior.

i. Preencha os metadados do pacote, como no passo 2 .

j. Valide e faça o download do arquivo (datapackage.json)

5. Acesse o site de demonstração do $C K A N$ : https://demo.ckan.org/ e entre com as seguintes credenciais:

a. username: user_usp

b. senha: user_usp

6. Procure pela organização 'ExperimentoUSP' (menu 'Organizations').

7. Crie 2 datasets

a. Para o nome do dataset de estados, coloque: Estados_<seu código $>$

i. Faça o upload do arquivo Estados.csv, preenchendo seus metadados. Clique em 'Save \& add another';

ii. Faça upload do arquivo datapackage.json relativo aos estados. Clique em 'Finish';

b. Para o nome do dataset de IDEBs, coloque: Ideb_<seu código>

i. Faça o upload de ambos os arquivos .xlsx, preenchendo seus metadados e clicando em 'Save \& add another';

ii. Faça upload do arquivo datapackage.json relativo aos arquivos do Ideb. Clique em 'Finish';

8. Baixe e instale o software Apache Jena Fuseki, e clique em fuseki-server.bat para iniciá-lo. Será aberta uma tela no prompt de comando e o servidor poderá ser acessado pelo navegador.

9. Acesse a URI: http://localhost:3030, clique em 'manage datasets > add new dataset', insira o nome 'educacao-basica' e selecione a opção 'Persistent (TDB2)'.

10. Na tela seguinte, clique em 'upload data', na mesma linha do dataset 'educacao-basica'.

a. Clique em 'select files...' e selecione o arquivo de ontologia (.owl), o arquivo de estados (.ttl) e ambos os arquivos do ideb (.ttl) e clique em 'upload all'

b. Verifique se foram cadastrados corretamente. Acesse o menu 'query' e, no espaço reservado para consultas SPARQL, insira a seguinte consulta e verifique que a consulta retorna os registros esperados (54 registros): 
PREFIX ex: <http://purl.org/caed \{seu código\}/ontology\#>

SELECT *

WHERE $\{$ ?s a ex:Ideb $\}$

11. Gere o arquivo sitemap, usando a ferramenta sitemap4rdf.

a. Abra um console de linha de comando

b. Vá até o diretório onde foi feito o download do arquivo (cd 'c:lusers...').

c. Use o seguinte comando:

java -jar sitemap4rdf.jar \{URL do endpoint $\}$ UURI base $\}$

Sendo:

\{URL do endpoint $\}$ : endereço do dataset no endpoint SPARQL

(http://localhost:3030/educacao-basica/sparql)

$\{$ URI base $\}$ : definido no passo 1.6

d. Verifique se foi criado um arquivo 'sitemap.xml' no mesmo diretório e se ele contém as URIs do dataset.

12. Preencha os metadados abaixo (seção Metadados).

13. Acesse a ferramenta IDLab Turtle Validator (http://ttl.summerofcode.be/) e teste o arquivo de metadados, verificando sua sintaxe.

14. Acesse novamente o site: https://shacl.org/playground/ e valide o conteúdo do arquivo de metadados, inserindo-o em 'Data Graph' e o conteúdo do arquivo Estados-shacl.ttl em 'Shapes Graph'.

a. Corrija eventuais erros.

15. Acesse o servidor Fuseki (http://localhost:3030) e selecione a opção 'add data' do dataset 'educacao-basica'

a. Na caixa de texto 'Destination graph name' deixe vazio

b. Selecione o arquivo ('select files...') que contém os metadados preenchidos até aqui e clique em 'upload now...'

16. Faça as verificações requisitadas como abaixo.

17. Abra a planilha 3 , aba 4 e preencha:

a. A URL do CKAN, no nível de organização;

b. A URL de acesso SPARQL ao Fuseki;

c. Descreva a versão atribuída a cada distribuição;

d. Descreve a licença de dados aplicada a cada distribuição;

e. Marque um X para cada opção de descoberta de dados usada (sitemap e metadados); 
18. Anote o horário na planilha 3, aba 4, célula B40.

19. Preencha também quais foram suas impressões sobre este passo (em termos de dificuldade, clareza e importância dos passos) e possíveis sugestões de melhorias.

Metadados:

- @@_URL_SPARQL_ENDPOINT_@@: http://localhost:3030/ (endereço do Fuseki)

-@@@URL_SPARQL_@@: http://localhost:3030/ (endereço do Fuseki)

- Para cada distribuição, preencha@@@URL_DOWNLOAD_@@: coloque o endereço gerado no CKAN para fazer download do arquivo (acesse o dataset, selecione um dos arquivos e copie o caminho que aparece em URL).

- @@_URL_DUMP_DATASET_@@: para cada dataset, usar um dos URIs acima, conforme correspondência

- @@_URL_FORMULARIO_CONTATO_@@: para cada dataset nos metadados, inserir o endereço URL para a página do CKAN em que os datasets originais foram publicados e que existe o plugin de comentários.

- @@_HORARIO_FIM_EXECUCAO_YYYY-MM-DD_@@: data e hora atuais, no formato YYYY-MM-DD T HH:MM:SS (por exemplo: 2020-02-10T10:04:00).

- Para cada distribuição, substitua os marcadores pelos valores na coluna 'Valor a ser preenchido', caso a consulta SPARQL retorne os valores conforme presente na coluna 'Valor Esperado' (execute as consultas no Fuseki - http://localhost:3030/, no menu 'Query'):

$$
\begin{aligned}
& \text { 0@@_VALOR_METRICA_QUALIDADE_P1_@@ } \\
& \text { ○@@_VALOR_METRICA_QUALIDADE_L1_@@ }
\end{aligned}
$$

\begin{tabular}{|c|c|c|c|c|}
\hline Categorias & Métrica & Consulta SPARQL & $\begin{array}{c}\text { Valor } \\
\text { esperado }\end{array}$ & $\begin{array}{l}\text { Valor a ser } \\
\text { preenchido }\end{array}$ \\
\hline Contextual & $\begin{array}{l}\text { P1 - Provisão } \\
\text { de informações } \\
\text { básicas de } \\
\text { proveniência }\end{array}$ & $\begin{array}{l}\text { PREFIX dcat: }<\text { http://www.w3.org/ns/dcat\#> } \\
\text { PREFIX dcterms: }<\text { http://purl.org/dc/terms/> } \\
\text { Select (count }\left(^{*}\right) \text { AS ?criadoresDatasets) } \\
\text { where \{ } \\
\text { ?ds a dcat:Dataset . } \\
\text { ?ds dcterms:creator ?criador. } \\
\text { \} }\end{array}$ & 2 & 1 \\
\hline Acessibilidade & $\begin{array}{lr}\text { L1 } & \text { - } \\
\text { legívencel } & \text { pora } \\
\text { máquina } & \end{array}$ & $\begin{array}{l}\text { PREFIX dcat: }<\text { http://www.w3.org/ns/dcat\#> } \\
\text { PREFIX dcterms: }<\text { http://purl.org/dc/terms/> } \\
\text { Select (COUNT(?licenca) AS ?numLicencas) } \\
\text { where \{ } \\
\text { ?dataset a dcat:Distribution. } \\
\text { ?dataset dcterms:license ?licenca } \\
\text { \} }\end{array}$ & 3 & True \\
\hline
\end{tabular}

Verificações:

- Verifique que o link para download dos arquivos originais estão funcionando no CKAN 
- Verifique que existe uma visualização criada para cada arquivo no CKAN (“Data Explorer”)

- Verifique que a API de acesso aos dados está funcionando

- Verifique que é possível fazer comentários nos datasets

- Verifique que os metadados estão registrados no Fuseki.

- Verificar que o sitemap foi criado e contém as URIs geradas em seu conteúdo. 


\section{Fase Exploração}

Nesta fase, você criará mecanismos para facilitar que potenciais usuários desses dados possam ganhar consciência sobre o que foi publicado. Para isso, será necessário aplicar uma interface de dados conectados que permita desreferenciar, via negociação de conteúdo, o acesso aos recursos de dados. Além disso, deverá ser implementados exemplos de uso desses dados, por meio das respostas às questões de competência postas no cenário deste estudo.

1. Abra a planilha "3-Conversão.xlsx", aba 5, e insira o horário atual.

2. Baixe o servidor Tomcat conforme seu sistema operacional, instale-o e inicie-o (https://tomcat.apache.org/download-80.cgi)

a. Para o sistema operacional Windows, existe o instalador: http://ttp.unicamp.br/pub/apache/tomcat/tomcat-8/v8.5.50/bin/apache-tomcat-8.5.50. $\underline{\text { exe }}$

b. Verifique que o servidor está sendo executado, acesso a URL: http://localhost:8080

3. Baixe o software LodView (arquivo lodview.war) e insira o arquivo na pasta 'webapps/' dentro da pasta onde foi instalado o Tomcat.

a. No Windows, por padrão: C:IProgram Files\Apache Software Foundation\Tomcat 8.5.

b. Verifique que o serviço está executando, acessando a URL: http://localhost:8080/lodview/.

4. Configure o software LodView para apontar para o servidor Fuseki instalado na fase anterior.

a. Assegure-se que o servidor Fuseki está sendo executado (http://localhost:3030).

b. Abra o arquivo 'webapps/lodview/WEB-INF/conf.ttl' com um editor de texto.

c. Modifique a declaração conf:endpoint para apontar para seu endpoint SPARQL configurado na fase anterior ( $<$ http://localhost:3030/educacao-basica $>$ - nome do dataset criado no Fuseki).

d. Modifique também a declaração conf:IRInamespace para conter a URI base usada na modelagem ( $<$ http://localhost:8080/educacao-basica/ $>$ ).

e. Reinicie o serviço do Tomcat. 
i. No Windows, deve haver um ícone 'Apache Tomcat' na bandeja do sistema. Clique com o botão direito e selecione 'Stop service' e, sem seguida, clique novamente com o botão direito e selecione 'Start service'.

ii. Caso contrário, dê duplo clique sobre o arquivo startup.bat.

5. Verifique que o LodView está desreferenciando corretamente as URIs criadas na fase anterior.

a. Teste o acesso à: http://localhost:8080/lodview/Acre.

b. Verifique que o servidor Fuseki esteja sendo executado, pois esses dados serão consultados a partir dele.

6. Acesse o Fuseki e execute uma consulta que retorne os estados do país e sua evolução do Ideb entre os anos 2015 e 2017, conforme a questão de competência 1.

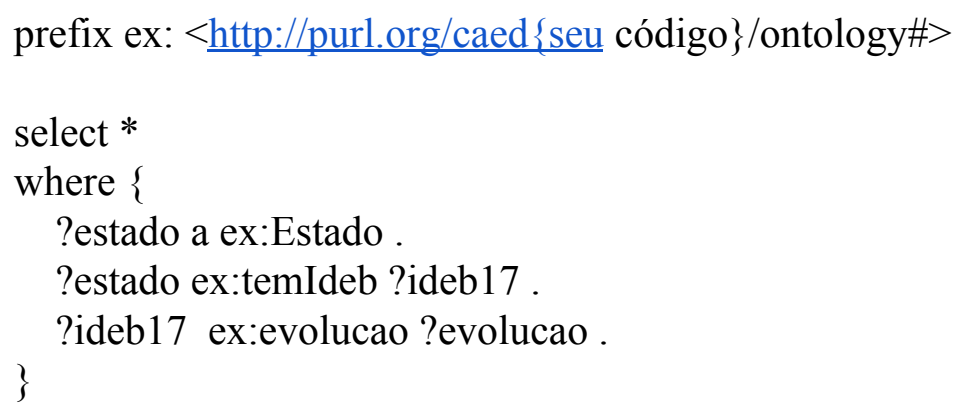

7. Acesse a planilha 3, aba '5 - Exploração', preencha a linha 15 com a pergunta, a consulta e coloque na célula $\mathrm{C} 15$ a resposta da consulta acima.

8. Salve esta consulta em um arquivo com extensão '.rq' e faça upload no CKAN, junto ao dataset do IDEB.

9. Execute outra consulta que retorne os dados agregados por região, conforme a questão de competência 2. Exporte o resultado para CSV.

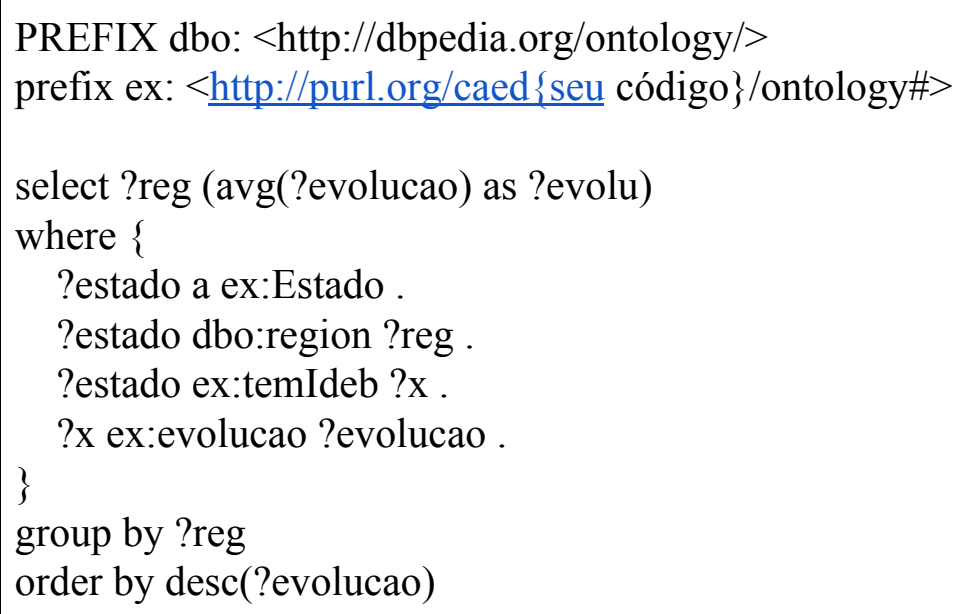


10. Acesse a planilha 3, aba '5 - Exploração', preencha a linha 16 com a pergunta, a consulta e coloque na célula $\mathrm{C} 16$ a resposta da consulta acima.

11. Salve esta consulta em um arquivo com extensão '.rq' e faça upload no CKAN, junto ao dataset do IDEB.

a. Para isso, acesse a página do dataset, clique em 'Manage', depois em 'Resources' e na página seguinte em 'Add new resource';

12. Acesse a planilha '3-Conversão' e vá até a aba 5. Indique quais foram as ferramentas usadas e quais as consultas realizadas.

13. Anote na planilha 3 o horário atual, na célula B20, aba 5.

14. Preencha também quais foram suas impressões sobre este passo (em termos de dificuldade, clareza e importância dos passos) e possíveis sugestões de melhorias.

Verificações:

- Acesse a definição de uma classe pela ferramenta LodView (por ex.: http://localhost:8080/educacao-basica/ontology/Ideb) e verifique se os dados são retornados.

- Acesse um recurso de dados cadastro no Fuseki, pela ferramenta LodView (por ex.: http://localhost:8080/educacao-basica/Acre) e verifique se ele é desreferenciado, ou seja, dados são retornados.

- Verifique se as respostas das questões de competência 1 e 2, definidas na seção 'Cenário' são respondidas pelas consultas aplicadas no servidor SPARQL.

- Verifique que as consultas SPARQL estão disponíveis junto aos datasets.

- Verifique, no CKAN, que existem visualizações complementares para os dados de cada distribuição. Entre no link de cada distribuição e veja se o Data Explorer exibe o conteúdo do mesmo. 


\section{Finalização}

1. Crie um arquivo de dados com o conteúdo do catálogo 'educacao-basica' do servidor Fuseki. Para isso, acesse a URL: http://localhost:3030/educacao-basica/data e salve o conteúdo retornado em um arquivo local com a extensão '\{seu código\}.ttl' .

2. Compacte-o junto com as planilhas, tendo por nome o seu código, e faça upload do arquivo no site http://wetransfer.com. 
APÊNDICE

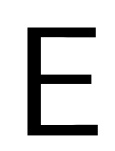

QUESTIONÁRIO PÓS-ESTUDO

\section{E.1 Questionário pós-experimento}

A seguir é mostrado o documento usado com os participantes após sua participação no experimento, para coletar suas percepções em torno do que foi trabalhado. 


\section{Questionário de feedback}

Obrigado por ter participado do experimento do projeto "Modelo de ciclo de vida para publicação de dados abertos conectados governamentais".

Este questionário tem por objetivo complementar os dados gerados durante a execução do processo.

A seguir, pediremos sua impressão sobre os artefatos produzidos por você durante o roteiro do experimento.

*Obrigatório

Caracterização

1. Forneça seu código no experimento: *

2. Forneça sua idade: *

3. Há quantos anos trabalha com tecnologia? *

4. Qual sua experiência com Dados Conectados? *

Marcar apenas uma oval.

Nunca havia trabalhado com Dados Conectados

Já trabalhei com Dados Conectados em algum curso

Já trabalhei com Dados Conectados em algum projeto

Trabalho com Dados Conectados diariamente 
5. Qual sua experiência com Dados Abertos Governamentais? *

Marcar apenas uma oval.

Nunca havia trabalhado com Dados Abertos Governamentais

Já trabalhei com Dados Abertos Governamentais em algum curso

Já trabalhei com Dados Abertos Governamentais em algum projeto

Trabalho com Dados Abertos Governamentais diariamente

Percepções sobre os

Nesta seção será pedido para que você forneça suas impressões artefatos

6. Sobre o PROCESSO, você considera que as atividades foram adequadas para transformar e publicar os dados? *

Marcar apenas uma oval.

$\begin{array}{lllll}1 & 2 & 3 & 4 & 5\end{array}$

Totalmente adequadas

Totalmente inadequadas

7. Sobre o PROCESSO, você considera que a ordem das atividades foram adequadas? *

Marcar apenas uma oval.

$\begin{array}{lllll}1 & 2 & 3 & 4 & 5\end{array}$

Totalmente adequada $\square \square \bigcirc$ Totalmente inadequada

8. Sobre o PROCESSO, você considera que a divisão das fases foi adequada? * Marcar apenas uma oval.

$\begin{array}{lllll}1 & 2 & 3 & 4 & 5\end{array}$

Totalmente adequada $\square \square \bigcirc$ Totalmente inadequada 
9. Que sugestões você daria para melhorar as atividades do PROCESSO?

10. Qual foi a fase mais difícil do processo? Por quê?

11. Sobre a ARQUITETURA (os componentes instalados e utilizados para o cenário: PURL, CKAN, Fuseki, LodView, ferramentas de validação), você considera que foi fácil de configurar e utilizar? *

Marcar apenas uma oval.

$\begin{array}{lllll}1 & 2 & 3 & 4 & 5\end{array}$

Extremament fácil $\square \longrightarrow \square$ Extremamente difícil

12. Que sugestões você daria para melhorar a ARQUITETURA? 
13. Sobre os METADADOS (do arquivo específico de metadados), você considera que foi fácil de configurar? *

Marcar apenas uma oval.

$\begin{array}{lllll}1 & 2 & 3 & 4 & 5\end{array}$

Extremamente fácil

Extremamente difícil

14. Que sugestões você daria para melhorar a configuração dos METADADOS?

15. Sobre as FERRAMENTAS utilizadas no experimento, você considera que foram fáceis de aprender e utilizar? *

Marcar apenas uma oval.

$\begin{array}{lllll}1 & 2 & 3 & 4 & 5\end{array}$

Extremamente fácil $\square \square$ Extremamente difícil

16. Sobre as FERRAMENTAS, você considera que elas foram adequadas para realizar o experimento? *

Marcar apenas uma oval.

$\begin{array}{lllll}1 & 2 & 3 & 4 & 5\end{array}$

Totalmente adequadas

Totalmente inadequadas 
17. Que sugestões você daria para melhorar o uso das ferramentas?

Fim

Este conteúdo não foi criado nem aprovado pelo Google.

Google Formulários 


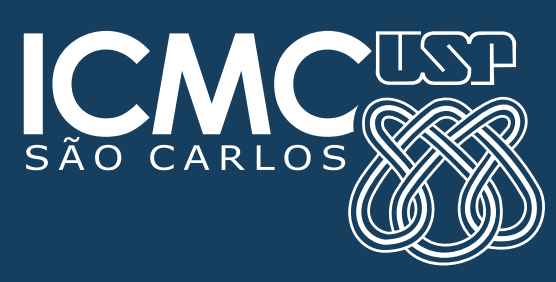

